\title{
Genome-wide identification of novel small RNAs in Pseudomonas aeruginosa
}

\section{Gómez Lozano, María}

Publication date:

2013

Document Version

Publisher's PDF, also known as Version of record

Link back to DTU Orbit

Citation (APA):

Gómez Lozano, M. (2013). Genome-wide identification of novel small RNAs in Pseudomonas aeruginosa. Novo Nordisk Foundation Center for Biosustainability.

\section{General rights}

Copyright and moral rights for the publications made accessible in the public portal are retained by the authors and/or other copyright owners and it is a condition of accessing publications that users recognise and abide by the legal requirements associated with these rights.

- Users may download and print one copy of any publication from the public portal for the purpose of private study or research.

- You may not further distribute the material or use it for any profit-making activity or commercial gain

- You may freely distribute the URL identifying the publication in the public portal

If you believe that this document breaches copyright please contact us providing details, and we will remove access to the work immediately and investigate your claim. 


\title{
Genome-wide identification of novel small RNAs in
}

\section{Pseudomonas aeruginosa}

\author{
PhD thesis by \\ María Gómez-Lozano
}

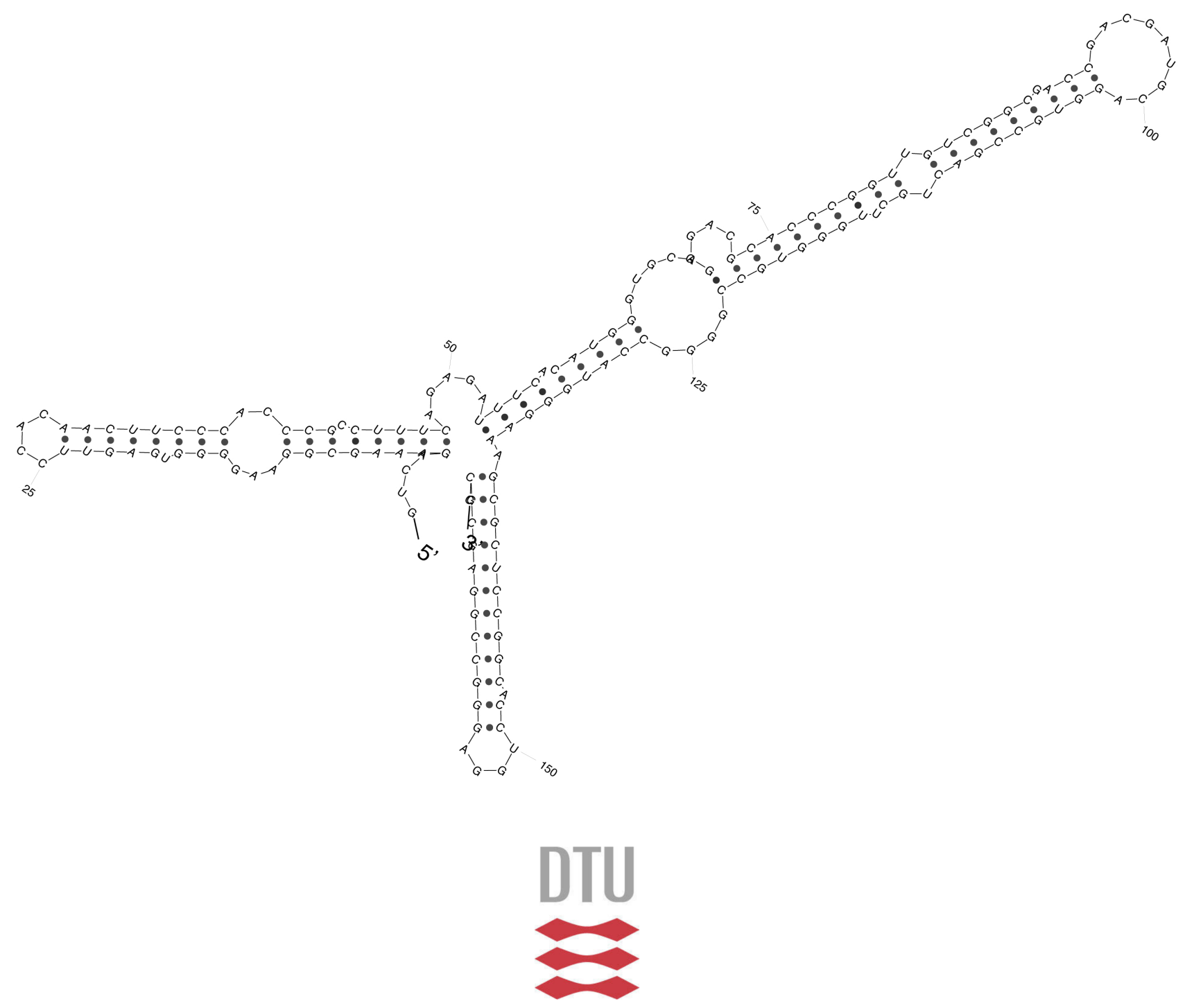


C María Gómez-Lozano 2013

Novo Nordisk Foundation Center for Biosustainability Technical University of Denmark

Kogle Alle $62970 \mathrm{Hørsholm}$

Denmark

ISBN 978-87-91494-62-8

Cover illustration: Secondary structure of the primary transcript of OsiS RNA from $P$. aeruginosa 
"A DNA sequence for the genome of bacteriophage $\varphi X 174$ of approximately 5,375 nucleotides has been determined using the rapid and simple 'plus and minus' method. The sequence identifies many of the features responsible for the production of the proteins of the nine known genes of the organism, including initiation and termination sites for the proteins and RNAs. Two pairs of genes are coded by the same region of DNA using different reading frames."

Frederick Sanger, 1978

[Co-author]

Sanger, F., Coulson, A. R., Friedmann, T., Air, G. M., Barrell, B. G., Brown, N. L., et al. (1978). The nucleotide sequence of bacteriophage $\varphi$ X174. Journal of Molecular Biology, 125(2), 225-246. doi:10.1016/0022-2836(78)90346-7 


\section{PREFACE}

This thesis is written as a partial fulfillment of the requirements to obtain a PhD degree at the Technical University of Denmark (DTU). The work presented in this thesis was carried out from October 2010 to September 2013. From October 2010 to December 2011 I worked at the Infection Microbiology Group (IMG), Department of Systems Biology at DTU, under the supervision of Professor Søren Molin and Katherine Long. From January 2012 to September 2013 I worked at the Novo Nordisk Foundation Center for Biosustainability (CFB) under the supervision of Professor Søren Molin. The work was financed by DTU, the Novo Nordisk Foundation and the Danish National Research Agency.

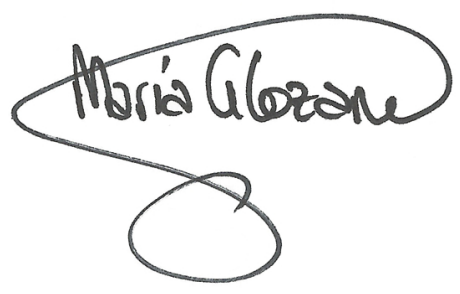

María Gómez-Lozano

Copenhagen, September 2013 


\section{ACKNOWLEDGEMENTS}

Being a PhD student has been a great adventure with many joys and challenges. I would like to express my gratitude to all the people that have helped me in so many ways during these fantastic 3 years.

First of all, I must thank my supervisor Professor Søren Molin for giving me the opportunity to join his lab as a naïve MSc student. It is really hard to put into words how grateful I am for your excellent support and guidance, both scientifically and personally. As a scientist, you have taught me how to be rigorous, open, selfconfident, creative, independent and passionate. Personally, you have always been tremendously encouraging and supportive. You are the kind of boss that listen to and respects other scientists, no matter whether they are renowned professors or undergraduate students. I am sure your guidance and personality will have a long lasting impact both on my career and on what kind of scientist I wish to become.

I would like to thank Katherine Long for her dedicated daily supervision during the first part of my PhD project. I will always be grateful for introducing me to the exciting topic of RNA regulation and for the time you spent helping me.

I would like to thank all the members of the Infection Microbiology Group (IMG), past and present: Lei Yang, Rasmus Marvig, Nicholas Jochumsen, Søren D Pedersen, Susse Hansen, Lars Jelsbak, Claus Sternberg, Anders Folkesson, Yang Liu, Liang Yang, Juliane C Thøgersen, Vinoth Wigneswaran, Martin W Nielsen, Lisse St. ClairNorton, Sussane Koefoed, Sofia Feliziani, Trine Markussen, Fátima Yousef, Rasmus Bojsen, Alexandra Burleigh, Cristina Hierro, Adela Luján, Mariló Maciá, Eva Andresen and so many more. It has been a pleasure to work with all of you in the same group. I need to specially thank Lei Yang and Rasmus Marvig. Both have shown great enthusiasm and patience, Lei as my daily supervisor during my MSc thesis, and Rasmus as he taught me about bioinformatic analysis of sequencing data. I also need to thank Laurent Gautier and Khoa Do from the DmAc facility at DTU for their help and for allowing me the use of their labs during the first year of my PhD studies. During these three years, I also had the opportunity to supervise MSc 
students Christian Bager and Monica Tulstrup. Thank you for your work and for teaching me how to be a teacher.

During my stay at the Novo Nordisk Foundation Center for Biosustainability (CFB) I have being very lucky to work with Martin H Rau, Carlotta Ronda, Anna Koza, José M Seoane, Mette Munk, Paula Tribelli, Alex T Nielsen, Christian B Jendresen, Helle K Johansen, Hemanshu Mundhada, Holger Døssing, Jerome Maury, Jiangfeng Zhu, Julia Hinderberger, Lasse H Lauridsen, Lone Riisberg, Markus Herrgard, Mikkel Lindegaard, Morten Nørholm, Morten Sommer, Morten T Nielsen, Neda F Parapari, Pernille Smith, Sailesh Malla, Sheila I Jensen, Simo A Jacobsen, Solvej Siedler, Susanna Seppala, Susanne R Pedersen, Ariane Zutz, Annika N Wallin, Isotta D'Arrigo, Jochen Förster, Margit Pedersen, Patricia Calero, Carlos Molina, Juan L Ramos, Estrella Duque, Margit Pedersen, and many many more. Mette Munk has been the perfect office mate, counselor and friend: funny, supportive, helpful, understanding, positive... You have always cared and been there for me, thanks! I need to thank Martin Holm Rau and Carlota Ronda for the fantastic scientific discussions and the funny times when going together to conferences. Anna Koza and José $M$ Seoane, thanks for your friendship, for fantastic scientific discussions and great coffee breaks. I thank Morten Sommer, Alex T Nielsen and Markus Herrgard for his great suggestions about my work. Thanks also to Paula Tribelli for introducing me to $P$. extremaaustralis and for her help in the lab. Juan L Ramos and Estrella Duque are thanked for their help and great advice during their stay in our labs.

Last but not least, I want to thank my family and friends for their love and support: Mamá, Papá, Yayay, Tate, Patricia, Pati, Marta, Laura, Anneke, Achille, Stefano, Francesca, Raúl, Alberto, Juan, Alessandro, Eduardo, Tamara, Marcello, Jacopo. I need to thank my parents for supporting and loving me since... ever. Finally, I need to thank my husband, Rolando, for endless love, support and for making my life so colorful in so many ways. 


\section{ABSTRACT}

Bacterial small regulatory RNAs (sRNAs) are known to have regulatory functions in a variety of processes including metabolic reactions, stress responses and pathogenesis in response to environmental signals. Recent genome-wide studies to identify sRNAs have been largely based on tiling arrays and RNA sequencing (RNAseq) technologies. The latter approach, in particular, has revolutionized sRNA discovery by enabling interrogation of the transcriptome at unprecedented depths. The size and complexity of the $P$. aeruginosa genome suggests that it encodes many hitherto undetected sRNAs. In this study, RNA-seq is used to identify sRNAs in $P$. aeruginosa using a combination of three different sequencing libraries. Over 750 novel sRNAs (including intergenic and cis-encoded sRNAs) have been identified with this approach in this study. The results also reflect that although the use of three libraries increased the number of novel transcripts identified, there were significant differences in the subset of transcripts detected in each library, underscoring the importance of library preparation strategy and relative sRNA abundance for successful sRNA detection. These data will be useful for the study of regulatory sRNAs in $P$. aeruginosa and the approach described here may be applied to identify sRNAs in any bacterium under different growth and stress conditions.

In addition the role of SRNA OsiS was investigated. OsiS was identified in our genome-wide search of sRNAs in $P$. aeruginosa. OsiS is highly transcribed during oxidative stress conditions. We show that by inducing the expression of OsiS the levels of the sRNA PhrS are greatly reduced. PhrS activates the translation of the pqs $R$ gene under low oxygen concentrations, which in turn activates the synthesis of the Pseudomonas quinolone signal (PQS). Thus, OsiS links the oxygen levels to the production of quorum sensing (QS) molecules. It is hypothesized that the interaction is by direct base-pairing between the two SRNAs, with a predicted recognition site of OsiS at the highly conserved-region of PhrS. However, more experiments are required to know the exact nature of the interaction between these two sRNAs. Notably, OsiS is, to the best of our knowledge, the first sRNA whose main function seems to be regulating the cellular levels of another sRNA. 


\section{RESUMÉ}

Bakterielle små regulatoriske RNA (sRNA) molekyler er involveret i regulering i en række forskellige processer, heriblandt metaboliske, stress relaterede samt patogene som svar på eksterne signaler. Nylige teknologier anvendt til global genomidentificering af sRNA molekyler har overvejende været baseret på tiling arrays og RNA sekventering (RNA-seq). Specielt sidstnævnte teknologi har revolutioneret opdagelsen af sRNA molekyler ved at efterforske transkriptomet med et hidtil uhørt tilbundsgående detektionsniveau. Størrelsen og kompleksiteten af $P$. aeruginosas genom antyder at det kan kode for hidtil uopdagede sRNA molekyler. I dette studie har vi anvendt RNA-seq til at identificere sRNA molekyler i $P$. aeruginosa via en kombination af tre forskellige sekventeringsbiblioteker. Over 750 nye sRNA molekyler (inklusive intergeniske og cis-kodede sRNA molekyler) er blevet identificeret med denne metode. Studiet viser desuden at selvom brugen af tre forskellige biblioteker forøgede detektionen af antallet af nye transkripter, så var der betydelige forskelle i detekterede transkripter bibliotekerne imellem. Dette understreger at strategien for valg af bibliotek samt den relative mængde af sRNA molekyler har stor betydning for en succesfuld detektion af sRNA molekyler. Vi forventer at de præsenterede data vil være brugbare i studiet af regulatoriske sRNA molekyler i $P$. aeruginosa og at den beskrevne metode kan anvendes til identifikationen af sRNA molekyler i enhver given bakterie under forskellige vækst og stress forhold.

Et specifikt sRNA molekyle, OsiS, som blev identificeret $\mathrm{i}$ vores globale genomundersøgelse af sRNA molekyler i $P$. aeruginosa, blev yderligere karakteriseret. Det viser sig at transkriptionen af OsiS er betydelig under oxidative stress forhold og vi viser at induktion af OsiS ekspression fører til stærkt reduceret ekspression af et andet sRNA molekyle, PhrS. PhrS aktiverer translationen af PqsR under lave ilt koncentrationer, hvilket aktiverer syntesen af Pseudomonas quinolone signal (PQS). OsiS repræsenterer derfor et link mellem oxygen niveauet og produktionen af quorum sensing (QS) molekyler. Det er vores hypotese at interaktionen mellem de to sRNA molekyler foregår via direkte base parring og OsiS har da også et forudsagt bindings-site i den meget konserverede del af PhrS. Yderligere eksperimenter er til gengæld nødvendige for at kunne bevise den eksakte interaktion mellem de to sRNA 
molekyler. OsiS er desuden, ud fra vores viden, det første sRNA molekyle hvis overordnede funktion er at regulere det cellulære niveau af et andet sRNA molekyle. 


\section{PUBLICATIONS}

Gómez-Lozano, M., Marvig, R. L., Molin, S., \& Long, K. S. (2012). Genome-wide identification of novel small RNAs in Pseudomonas aeruginosa. Environmental Microbiology, 14(8), 2006-2016. doi:10.1111/j.1462-2920.2012.02759.x

Gómez-Lozano, M., Marvig, R. L., Molin, S., \& Long, K. S. (2013). Identification of bacterial small RNAs by RNA sequencing. Methods in Pseudomonas aeruginosa. Accepted for publication.

Gómez-Lozano, M., Marvig, R. L., Tulstrup, M. V. L., Tribelli, P., \& Molin, S. (2013). Antisense small RNAs respond to osmotic, oxidative and antibiotic stress in Pseudomonas aeruginosa. Manuscript in preparation.

Gómez-Lozano, M. \& Molin, S. (2013). Small RNA OsiS links oxidative stress to quorum sensing control in Pseudomonas aeruginosa. Manuscript in preparation. 


\section{CONTENTS}

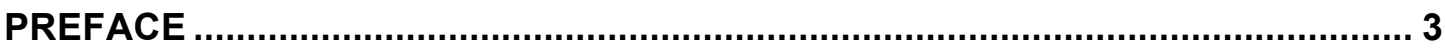

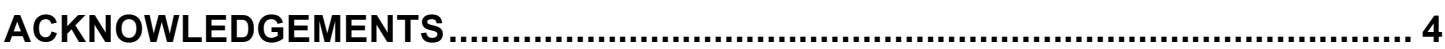

ABSTRACT

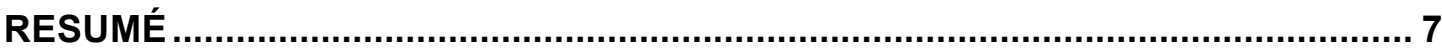

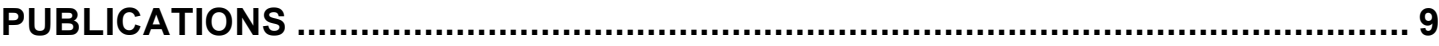

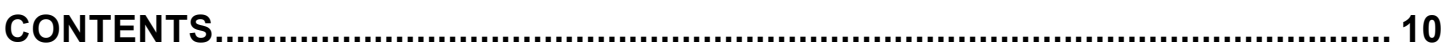

1. INTRODUCTION \& OUTLINE .......................................................................... 11

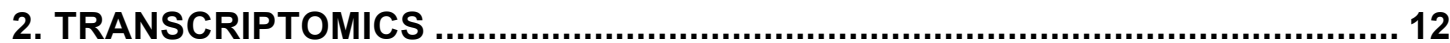

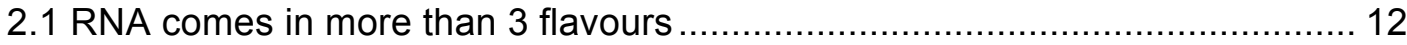

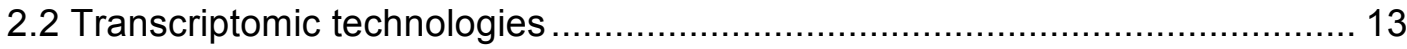

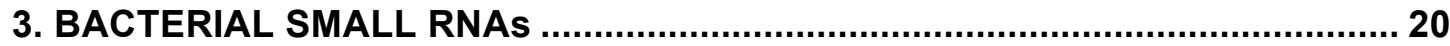

3.1 Mechanisms of action of bacterial small RNAs …....................................... 21

3.1.1 Trans-encoded sRNAs .................................................................. 22

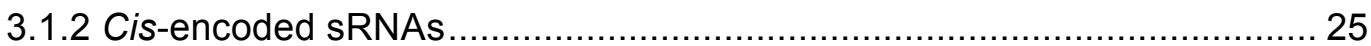

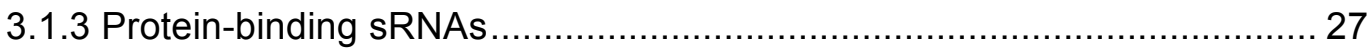

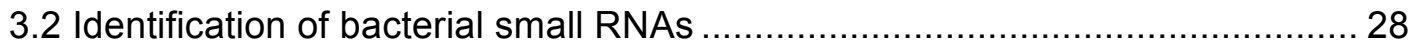

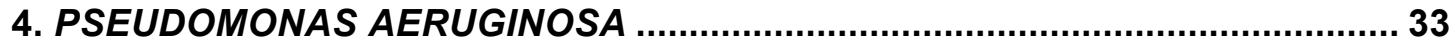

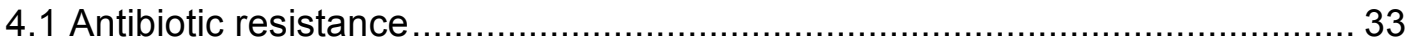

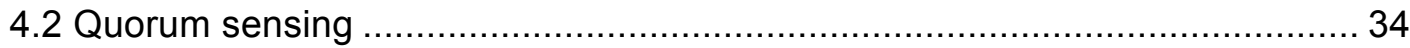

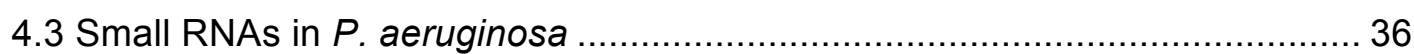

5. CONCLUSION AND PERSPECTIVES.......................................................... 40

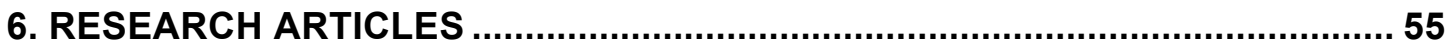




\section{INTRODUCTION \& OUTLINE}

Historically, research on regulation of bacterial transcription focused on proteinbased systems, and RNA was believed to be a relatively inactive information carrier. However, that has changed in the last decade due to the discovery of regulatory RNA activity. The regulatory role of certain bacterial RNA molecules has been known since the early 70 s. However, until 2001, only about a dozen regulatory small RNAs (sRNAs) were identified in bacteria, representing biochemically abundant species and anecdotal discoveries. Technological advances such as DNA microarrays and RNA sequencing (RNA-seq) have recently allowed researchers to discover hundreds of sRNAs in all organisms studied so far. Bacterial sRNAs, which typically range from 70 to $500 \mathrm{nt}$ in length, have been mainly found to function in post-transcriptional control of gene expression and control a variety of processes including metabolic reactions, stress responses and pathogenesis in response to environmental signals (reviewed in (1)). The main focus of this thesis was to identify novel transcripts in Pseudomonas aeruginosa and, in order to do so, the existing RNA-seq protocols have been optimized to increase the sensitivity of the method. As a result more than 700 novel sRNAs have been discovered in this clinically-relevant opportunistic pathogen. The optimized RNA-seq method can be used to study the transcriptome any bacterium in any growth condition.

This thesis is divided in six sections. Section 2 (RNA sequencing and technology) introduces some general theory on transcriptomics and specifically on RNA-seq. The section serves as a fundamental theoretical background for the experimental investigations presented in the following chapters. Section 3 (Bacterial small RNAs) provides basic information about the classification and the mechanisms of action of sRNAs in bacteria, and describes the traditional methods used to identify bacterial sRNAs and the current considerations when using RNA-seq to detect sRNAs. Section 4 (Pseudomonas aeruginosa) focuses on the bacterium used for the investigations presented in this work, with an emphasis on antibiotic resistance, quorum sensing and known sRNAs. Section 5 (Conclusions and perspectives) summarizes the main conclusions obtained from the research articles presented. Finally, section 6 (Research articles) consists of the full-length research articles that were prepared as part of this $\mathrm{PhD}$ project. 


\section{TRANSCRIPTOMICS}

\subsection{RNA comes in more than 3 flavours}

The "central dogma" of molecular biology was first enunciated by Francis Crick in 1958 (2), but was first sketched already in 1952 by James Watson (3) (Figure 1). The "central dogma" at that time postulated that the DNA information can be copied into RNA, and proteins can be synthesized using the information in the RNA in the cytoplasm. It was clear that although DNA was located in the eukaryotic nucleus, proteins were synthesized in the cytoplasm where there was no DNA, but there was lots of RNA (4). Most of the cytoplasmatic RNA could be found as discrete particles, which were later shown to be the ribosomes (5).

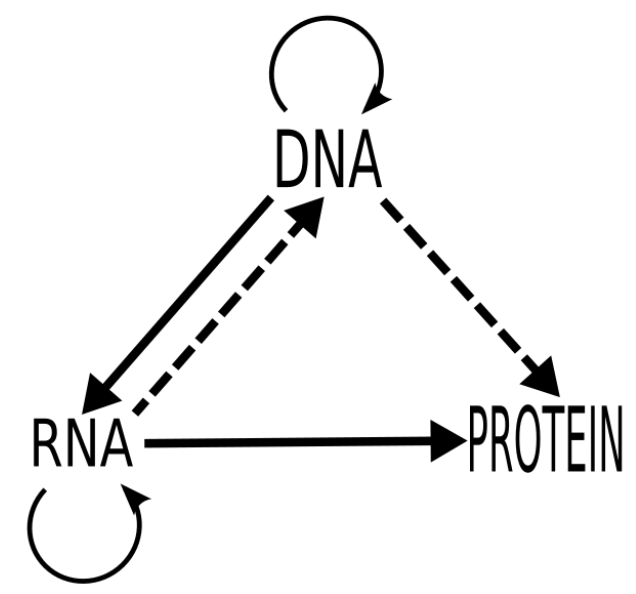

Figure 1. A diagram of the central dogma of molecular biology in 1958 (2). Solid arrows represent probable transfers, dotted arrows possible transfers.

Francis Crick predicted the existence of a second class of functional RNA, a molecule that acts as an adaptor between the triplet genetic code and the encoded amino acid (5). Interestingly, Crick hypothesized that the adaptor might be an RNA, because base pairing made RNA exceptionally fit for a role as a small, specific RNA recognition molecule (5). This hypothesis could be proven by Hoagland and colleagues, and Crick's adaptors are now known as transfer RNAs (tRNAs) (6).

A few years later ribosomes were found to be composed largely of stable ribosomal RNAs (rRNAs), and to have no variety compared to the great variety found in genes 
(7). It was shown that ribosomes were general-purpose RNA/protein machines, and that they were able to synthesize proteins when in contact with diverse unstable messenger RNAs (mRNA), which are only a small fraction of the total RNA population (7).

Therefore, in only a few years, RNA changed from coming in just one flavor (the messenger intermediate in the "central dogma") to having three flavors, all exclusively involved in protein synthesis: rRNA, tRNA, and everything else, which was thought to be mRNA. The non-ribosomal and non-transfer RNA fraction is complex, non-abundant and very unstable, and for decades there has been no interest in or no skills for investigating if it contained more than mRNA. Today, it is widely accepted that not all RNAs in the cell are involved in the synthesis of proteins as there are abundant small non-messenger RNAs (sRNAs), different from rRNA and tRNA, that regulate translation initiation, transcription termination, mRNA stability, or can sequester and modify proteins.

\subsection{Transcriptomic technologies}

Altering the levels of gene expression is one of the main mechanisms of cell regulation as it leads to all kinds of changes in the cellular machinery. The entire pool of transcribed sequences in a specific condition (termed transcriptome), provides enormous information about the physiological state of the cells. The first studies investigating transcription in cells used cDNA synthesis of specific mRNA transcripts, combined with cloning and Sanger sequencing (8). The transcriptomic field experienced a huge revolution when DNA microarrays were developed, providing a powerful tool to quantify expression of all annotated genes (9). DNA microarrays consist of immobilized gene-specific DNA probes that hybridize to their corresponding cDNA, producing a change in fluorescence. The measurement of fluorescence produced after hybridization correlates to the relative abundance of the transcript (Figure 2). The first cDNA microarrays had probes that hybridize to known or predicted mRNAs, and provided no information about transcription in intergenic regions or about transcription from the complementary strand of known mRNAs.

Several years later, the development of high-density tiled probes (tiling arrays) overcame this limitation. Tiling arrays contain probes that cover the entire genome of 
an organism, so they are able to detect novel genes and sRNA species in intergenic regions in all organisms for which there was a tiling array available. Microarray-based studies provided the first global transcriptomic analyses in pathogens such as Escherichia coli (10), Vibrio cholera (11), Borrelia burgdorferi (12), Chlamydia trachomatis (13), Chlamydia pneumoniae (14), Listeria monocytogenes (15) and Salmonella enterica (16). In addition, transcriptomic studies using tiling arrays were able to provide accurate strand-specific information from 2006 thanks to the use of actinomycin $\mathrm{D}$ in the reverse transcription reaction to inhibit DNA polymerase activity (17).

While microarrays have been instrumental for the study of transcription, there are some major limitations to this approach. In microarray analysis, as with any other a probe-dependent method, the relative abundance of a given labeled transcript is inferred from the fluorescent signal produced following hybridization to immobilized probes. Transcript quantification is limited because the fluorescent intensity has both a lower (sensitivity) and upper (saturation) threshold. On the contrary, when using RNA-seq, which is a digital and probe-independent method, direct counting of sequencing reads for a given transcript has a much higher dynamic range. In addition, microarrays are usually designed to include sequences from a single strain, which will not be optimal for other strains of the same species as mismatches can significantly affect hybridization efficiency. There are microarrays that contain probes for multiple strains, but this may lead to a high background noise due to non-specific or cross-hybridization. Another limitation is the high cost of tiling arrays. Until recently, our interest was limited to mRNAs, tRNAs and rRNAs, and these RNAs could easily be probed with arrays at a reasonable cost. However, now it is known that mRNAs, tRNAs and rRNAs represent only part of the functional transcriptome. The study of the complete transcriptome at high resolution, including intergenic regions, requires microarrays with a very high density of probes (in the order of hundreds of millions), which currently exceeds the cost of RNA-seq experiments. Furthermore, the problem of cross-hybridization is increased in tiling arrays. Background noise due to cross-hybridization limits even more the dynamic range of microarrays (18). Also probe-based methods cannot discriminate between different mRNA isoforms or define transcript borders and splice junctions with high resolution. 


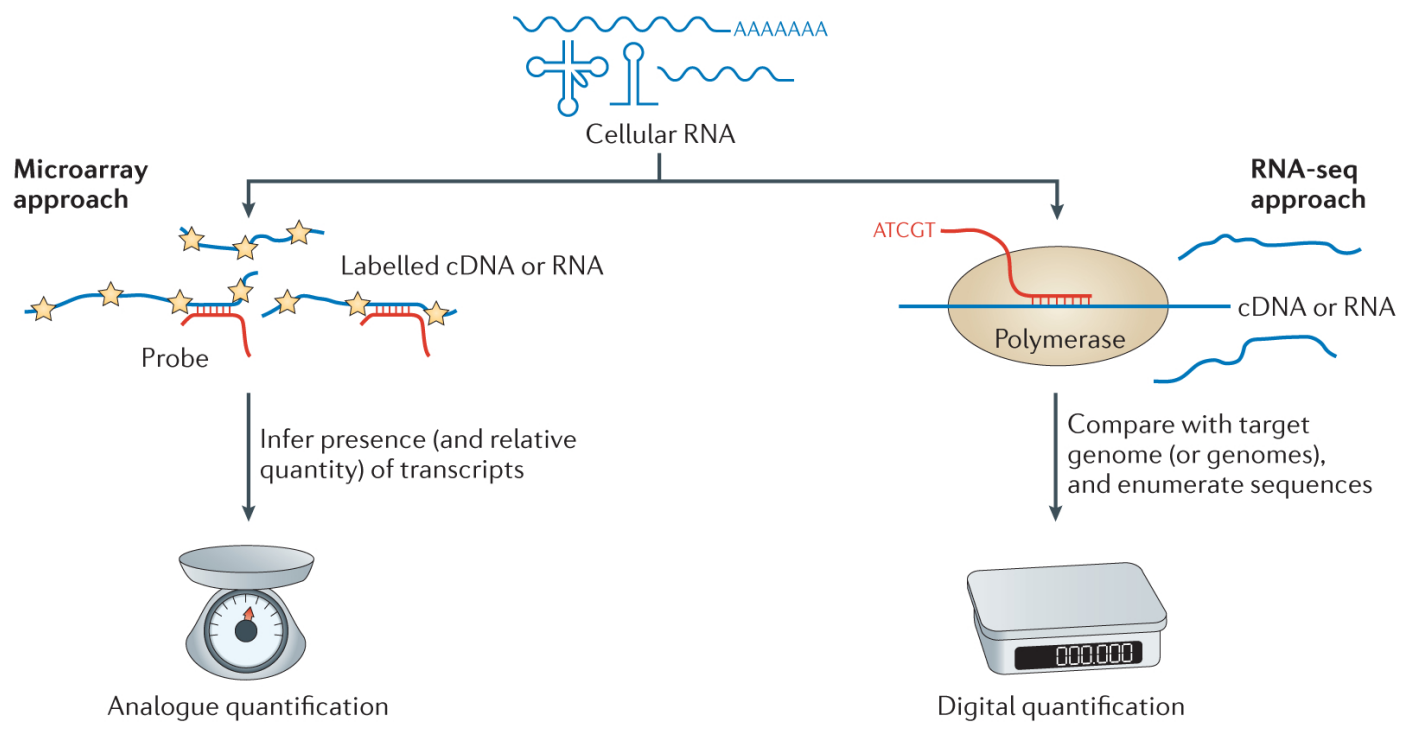

Figure 2. Fundamental differences between microarray and RNA-Seq technologies. Figure adapted from (19).

RNA-seq was introduced in 2008, and has already become the method of choice for studying transcriptomes as it overcomes many of the limitations of tiling arrays. It provides high resolution of the coordinates of transcripts, a higher dynamic range, lower cost, it does not have background noise due to cross-hybridization, and it is not a strain-specific method (reviewed in (20)). In addition to providing full-genome coverage, RNA-seq is very sensitive and has a high resolution. RNA-seq can identify novel transcripts and allows gene structure to be refined through accurate determination of transcript borders.

RNA-seq involves deep sequencing of cDNA generated from RNA preparations (reviewed in (21)). The design of library preparation methods is crucial when performing a high-quality RNA-seq experiment, as the data generated will depend greatly on the way libraries are prepared. The accuracy and precision of gene expression quantification and transcript identification are greatly influenced by cDNA library construction methods. The steps of a typical library preparation for RNA-seq are shown in figure 3. 
(1) mRNA or total RNA

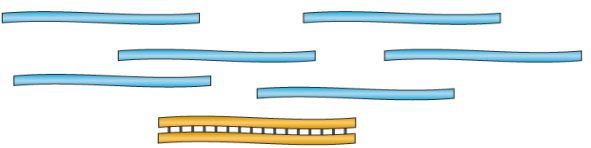

(2) Remove contaminant DNA

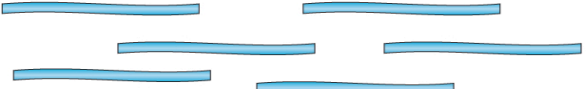

(3) Fragment RNA

Remove rRNA?

Select mRNA?

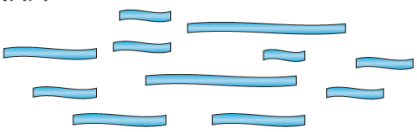

(4) Reverse transcribe into cDNA

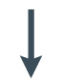

$$
\text { ग्य }
$$

(5) Ligate sequence adaptors

Strand-specific RNA-seq?

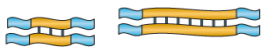

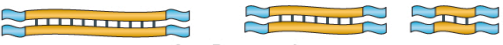

व्मात्त्र

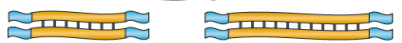

(6) Select a range of sizes

PCR amplification?

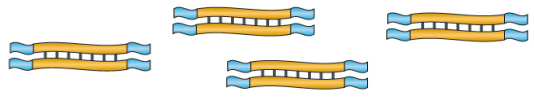

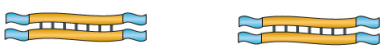

(7) Sequence cDNA ends

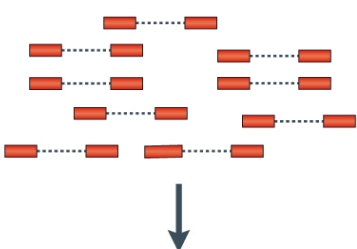

(8) Align reads to transcripts

to quantify expression

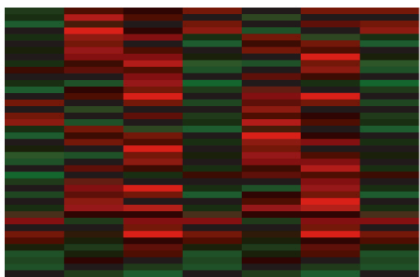

Figure 3. The data generation and analysis steps of a typical RNA-seq experiment. Figure adapted from (21). 
Typically, total RNA is treated with DNase in order to remove any possible DNA contamination. In order to increase the genome coverage and the sensitivity of the experiment, rRNAs are usually removed during at this step of library preparation. Poly-A selection is very effective at enriching mRNAs in eukaryotes, but this approach does not retain sRNAs and mRNAs that lack a poly-A tail, and it is not suitable for prokaryotes. Instead rRNA can be removed by subtractive hybridization (Section 3.2 and Article 2 provide more details about successful rRNA-depletion in prokaryotes). If quantification of rRNAs is a goal of the study, then the sequencing of non-depleted libraries will be required. Following rRNA depletion, the RNA mixture is fragmented and converted into a library of cDNAs containing sequencing adaptors. Generally, the cDNA molecules are amplified before deep sequencing using primer complementary to the ligated adaptors. The cDNA library is then sequenced by highthroughput sequencers to produce millions of short reads from one end or both ends of the cDNA fragments. If both ends of the cDNAs are sequenced, then paired-end reads are generated. Paired-end reads are useful as they greatly reduce the complexity of transcriptome assembly. After the sequencing reaction has taken place, the obtained sequence reads are filtered by removing low-quality reads and artifacts, such as adaptor sequences and PCR duplicates. The filtered reads are then mapped onto a reference genome and assembled into transcripts. The expression level of each transcript is then estimated by counting the number of reads that align to each transcript. Section 3.2 provide information about optimal library preparation specific for sRNA identification, and Article 2 presented in this thesis describes in detail how to construct libraries specific for sRNA identification as well as how to analyze the data generated with them. 


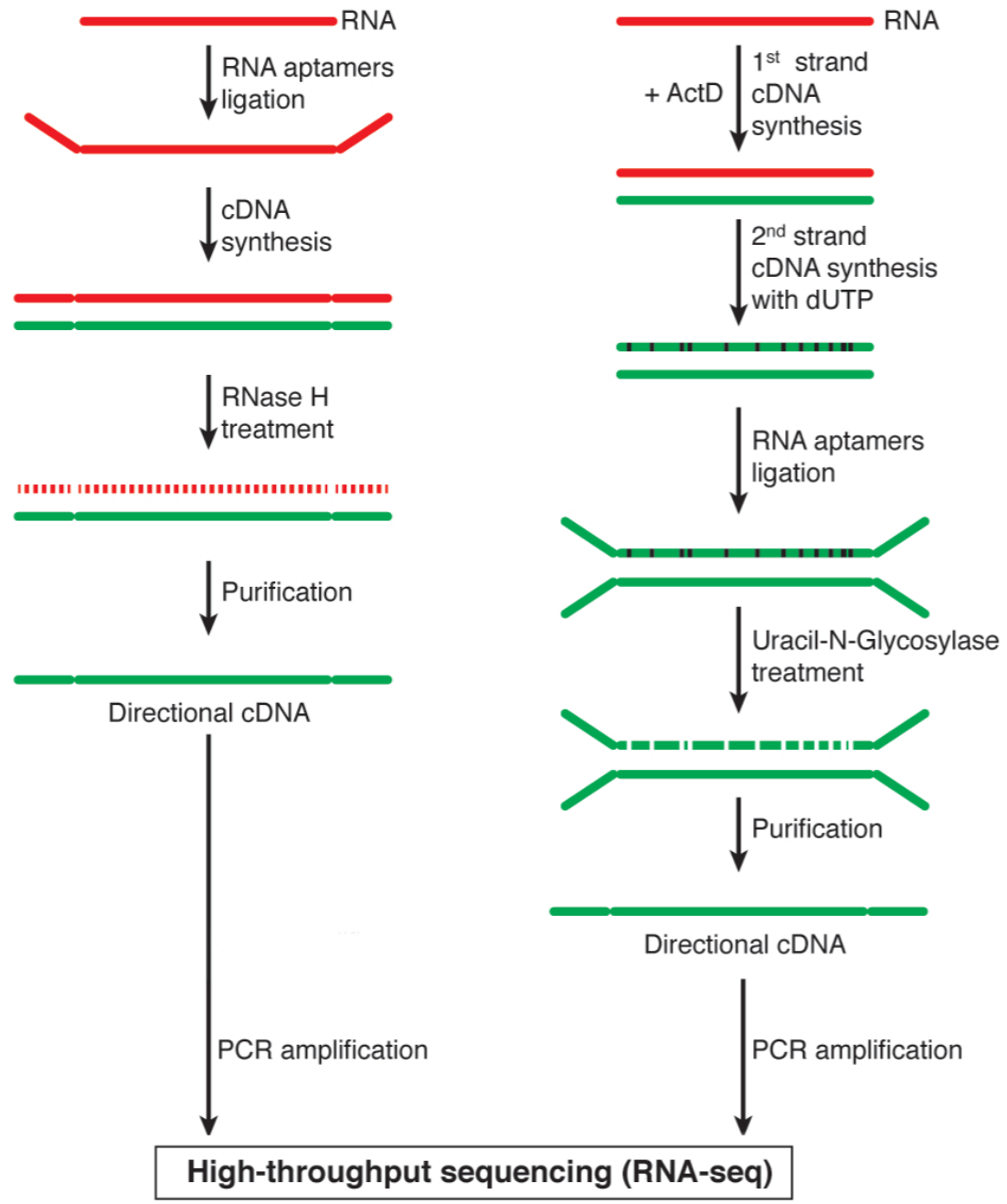

Figure 4. Flowchart illustrating technical improvements used to preserve the polarity of RNA molecules for transcriptome analysis. Figure adapted from (22).

An important step in the study of transcriptomes was the development of strandspecific RNA-seq protocols, which preserves information about the directionality of a transcript. Retaining strand-specificity is essential for studying for antisense transcription. In fact, by 2007, only about 30 antisense sRNAs (asRNAs) were known in bacteria (reviewed in (23)). After the introduction of strand-specific RNA-seq protocols the number of asRNAs detected has increased exponentially, with tens to hundreds of asRNAs detected in every bacterium studied $(15,24-30)$. Strandspecificity is retained if the cDNA library is prepared using a directional protocol (Figure 4). During first-strand cDNA synthesis from RNA molecules by reverse transcription, unintended second-strand cDNA synthesis could occur using the first- 
strand cDNA as a template. To avoid this, directional libraries can be prepared with the two following protocols: (i) first strand cDNA synthesis can be performed in the presence of actinomycin $D$, which specifically inhibits the DNA-dependent DNA polymerase activity of the reverse transcriptase enzyme (17). Then second strand cDNA synthesis is carried out in the presence of dUTP, which allows the selective removal of the strand with UNG (uracil-N-glycosylase) after ligation of $5^{\prime}$ and $3^{\prime}$ adaptors, leaving the first cDNA strand intact (31). Random oligonucleotides are used for the synthesis of first and second cDNA strands. (ii) Direct labeling of the RNA molecules with different adapters at the $5^{\prime}$ and 3 ' ends before cDNA synthesis, which preserves the strand orientation of each RNA molecule $(29,32)$. The transcripts are ligated to different RNA adapters in the 5' and the 3' ends using T4 RNA ligase. In this approach oligonucleotides complementary to the 5' and 3' adaptors are used for the synthesis of cDNA, considerably reducing the bias introduced by use of random primers to synthesize the cDNA. 


\section{BACTERIAL SMALL RNAS}

The regulatory role of RNAs was first reported around 40 years ago in E. coli, when the plasmid- and transposon-encoded antisense sRNAs RNAI and CopA were found to negatively regulate plasmid copy number $(33,34)$. However, there has not been much interest on this kind of regulation until the beginning of this century. Nowadays it is known that RNA-mediated regulation is found in all kingdoms of life, maybe in all species. In eukaryotes, microRNAs (miRNAs) are a large class of very short (21-25 nt) non-coding RNAs that affect translation and degradation of target mRNAs by antisense base pairing. The first miRNA was discovered in C. elegans in 1993 (35), but it was not until the early 2000s that miRNAs were recognized as a conserved class of biological regulators. Today miRNAs are known to be pivotal regulators of processes such as development and disease in eukaryotes $(36,37)$.

In contrast to the eukaryotic miRNAs, bacterial sRNAs range in size approximately from 70 to 500 nucleotides (nt), though some sRNAs are shorter or longer than that. Bacterial sRNAs can modulate gene expression and most of them function through base-pairing interactions with mRNA targets that can affect translation initiation, transcription termination or mRNA stability (reviewed in $(1,38)$ ). There are examples of sRNAs involved in transcription reprogramming, carbon metabolism, iron homeostasis, cell envelope homeostasis and coordination of virulence (reviewed in (39)). At present, sRNAs have been found in all bacterial species investigated, and in some cases regulatory sRNAs may exceed protein regulators in number as well as diversity. Other RNA regulatory elements found in bacteria include riboswitches encoded in untranslated regions (UTRs) of mRNAs and CRISPR elements, and the reader is directed to fantastic existing reviews $(40,41)$. 


\subsection{Mechanisms of action of bacterial small}

\section{RNAs}

Numerous bacterial sRNAs and all eukaryotic miRNAs regulate expression of mRNAs that are transcribed from a different genomic location, and are therefore named trans-encoded regulatory RNAs. There are also examples of cis-encoded sRNAs. They are transcribed from the reverse complementary strand of their target RNAs, thus generating fully complementary RNAs. Both trans- and cis-encoded sRNAs regulate the activity of a different RNA molecule, thus they are trans-acting regulators. There are also cis-encoded and cis-acting RNA elements, for example riboswitches encoded in UTRs of mRNAs.

A strand of DNA that is transcribed into an mRNA is called sense. Transcription from the opposite DNA strand (the antisense strand) of an mRNA-coding locus generates a cis-encoded antisense RNA that is fully complementary to the mRNA. However, trans-encoded antisense sRNAs also base pair to sense RNAs with limited complementarity. Thus, antisense sRNAs can be either trans- or cis-encoded.

In an effort to make the classification of SRNAs easier, trans-encoded and transacting sRNAs with limited complementarity with their targets are sometimes referred to as intergenic sRNAs, due to the fact that most of these sRNAs are encoded in intergenic regions. Cis-encoded and trans-acting sRNAs are normally referred to as antisense $s R N A s$, to emphasize that they are encoded from the antisense strand of the target RNA. These types of nomenclature, though not scrupulous, are easier and more widely used than the exact ones. In this thesis I sometimes refer to transencoded and trans-acting sRNAs as intergenic sRNAs, and to cis-encoded and trans-acting sRNAs as antisense sRNAs (asRNAs). I prefer not to use the term noncoding RNAs to refer to regulatory RNAs as some trans- and cis-encoded sRNAs also encode small peptides and are therefore dual-function sRNAs (reviewed in (42)). 

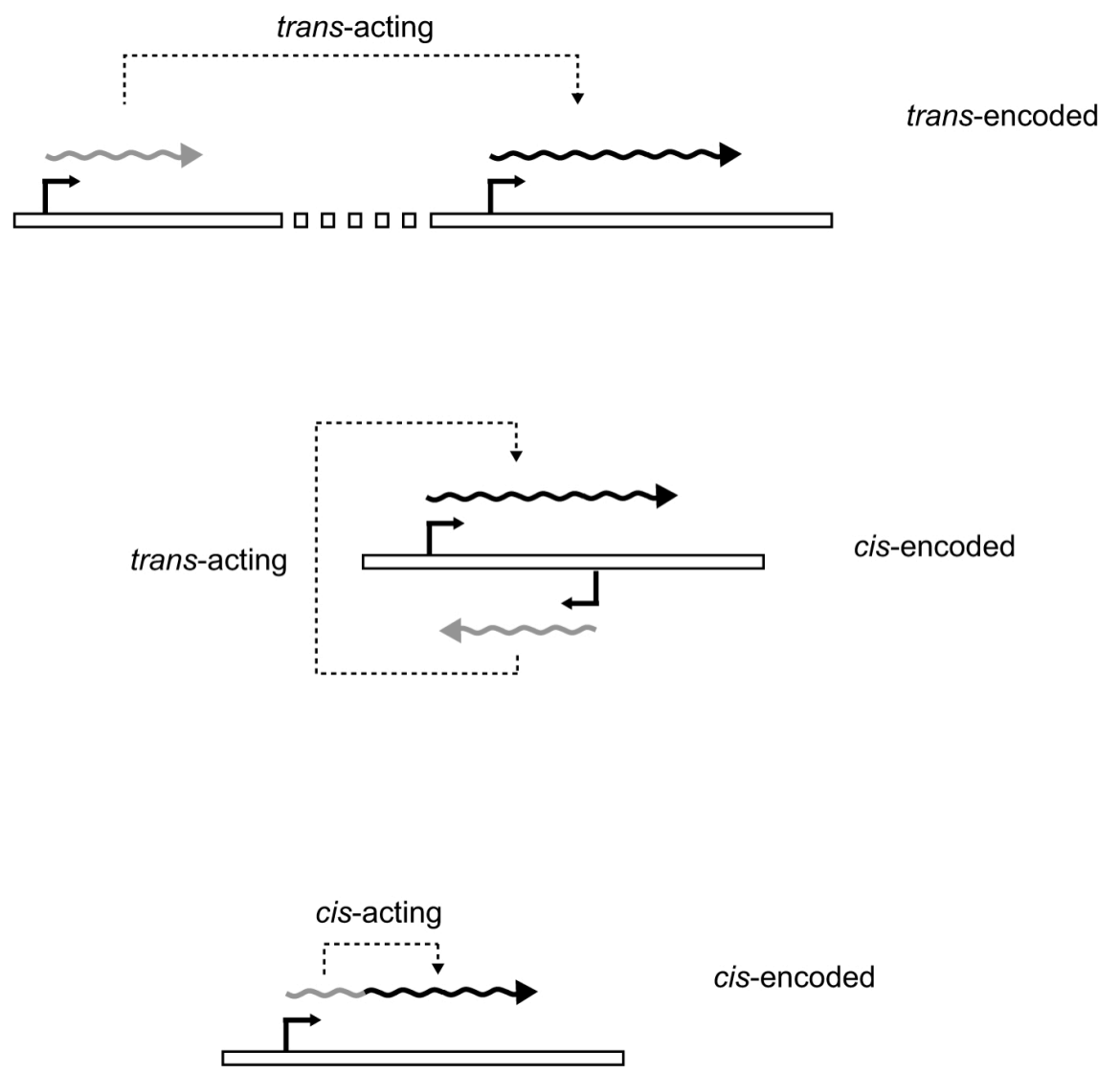

Figure 5. Regulatory RNAs can act on other RNA molecules (trans-acting) or on themselves (cis-acting), and can be expressed from a separate locus (trans-encoded) or from the same locus as the target RNA (cis-encoded). Regulatory RNA, mRNA, and DNA are shown in grey arrows, black arrows, and white boxes, respectively. Figure adapted from (43).

\subsubsection{Trans-encoded sRNAs}

After the discovery in the 1970s that the life cycle or copy number of bacterial transposons and plasmids is regulated by asRNAs, a similar regulatory RNA, MicF, was found to be encoded in the chromosome of $E$. coli (44). Unlike the asRNAs of transposons and plasmids, MicF was not transcribed from the DNA strand opposite its target gene ompF, which encodes the outer membrane protein $F$, but it was encoded in an intergenic region. Furthermore, MicF had incomplete and imperfect sequence complementarity to its target, but its base pairing strongly inhibited the translation of the ompF mRNA. Nowadays, most of the identified bacterial sRNAs are known to be encoded in different genomic loci (usually intergenic regions) than their target mRNAs and share only limited complementarity with their targets, like MicF.

Base pairing between the sRNA and its target mRNA can promote or inhibit 
translation, and can decrease or increase mRNA stability. Most of the intergenic sRNAs characterized to date, bind to the 5' UTR of mRNAs most often inhibiting translation by base pairing with the ribosome-binding site (RBS) or upstream of the AUG codon of the mRNA $(45,46)$. Trans-encoded sRNAs can also activate translation of their target mRNAs when base pairing of the sRNA disrupts an inhibitory secondary structure that sequesters the RBS (47-49). sRNA-mRNA duplexes are often degraded by RNase $E$ or RNase III, the two major endoribonucleases in bacteria. The first, RNase III, specifically degrades doublestranded RNA complexes, which makes it an ideal candidate for processing asRNAs base paired with their targets. The asRNA-directed cleavage can generate two target RNA halves that are both less stable, both more stable, or differentially stabilized relative to each other. RNase $E$, which cleaves single-stranded RNA, is the other endonuclease involved in asRNA-directed processing. RNase $E$ is a component of the degradosome, a multiprotein complex that affects mRNA stability and interacts with $\mathrm{Hfq}$ (reviewed in (50)). However it is not exactly clear how RNase E activity is stimulated by double-stranded RNA regions, though it is presumed that the 5 ' end of an base-pairing sRNA could provide a monophosphate, which has been shown to stimulate RNase E activity (51). Trans-encoded sRNAs can also increase the stability of mRNAs, by inducing cleavage by endonucleases that generates a mRNA with a different 5 ' structure that increases stability (52), or by protecting the 5' end of mRNAs from nucleases (53). For example, base pairing between the sRNA and its target mRNA might be able to block an RNase $E$ recognition site, leading to increased stability of the target RNA. Theoretically, base pairing between a transencoded SRNA and its target could also promote transcription termination or antitermination, as has been found for some cis-encoded sRNAs.

There is little correlation between the genomic location of trans-encoded SRNAs and their target mRNA genes. In fact, several trans-encoded sRNAs are known to base pair with multiple mRNAs. This results from the fact that trans-encoded sRNAs have limited complementarity with their target mRNAs, usually in discontinuous patches, rather than extended regions of perfect complementarity, as for cis-encoded sRNAs. The region of base pairing between trans-encoded sRNAs and target mRNAs is typically 10-25 nt, but only some of the nucleotides seem to be critical for regulation. For example, although the SgrS sRNA can form 23 base pairs with the ptsG mRNA, only changes in 4 of these nucleotides in SgrS affects downregulation of ptsG (54). 


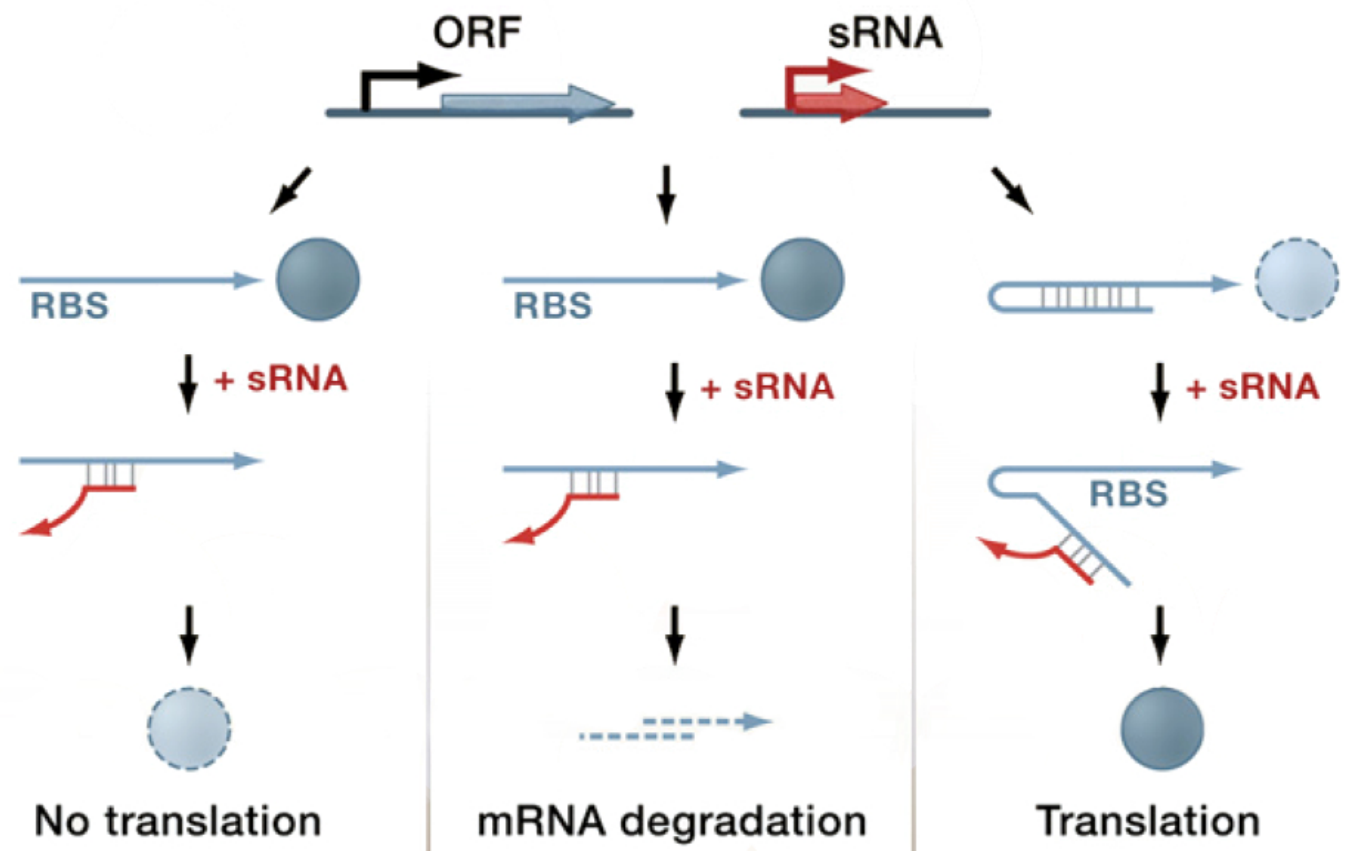

Figure 6. Mechanisms of action of trans-encoded sRNAs. Genes encoding trans-encoded sRNAs (red) are located separately from the genes encoding their target RNAs (blue) and only have limited complementarity. Trans-encoded sRNA can act negatively by base pairing with the 5'UTR and blocking ribosome binding (left panel) and/or targeting the sRNA-mRNA duplex for degradation by RNases (middle panel). Trans-encoded sRNA can also act positively by preventing the formation of an inhibitory structure, which sequesters the ribosome-binding site (RBS) (right panel). Figure adapted from (1).

In Gram-negative bacteria, the RNA binding protein $\mathrm{Hfq}$ is very frequently required for the function and stability of trans-encoded sRNAs (reviewed in (55)). However the detailed mechanisms by which Hfq promotes base pairing of sRNAs and their targets are still not well characterized. Hfq has been shown to facilitate base pairing by increasing annealing rates $(56,57)$, by stabilizing sRNA-mRNA duplexes $(58)$, and by promoting changes in secondary structure of one of the RNAs (59). Many transencoded SRNAs have been identified in studies that precipitate $\mathrm{Hfq}$ along with its bound RNAs (60-63). It is possible that there is a significant number of sRNAs that do not require $\mathrm{Hfq}$ to regulate mRNAs, but the most studied sRNAs so far are the ones that bind $\mathrm{Hfq}$. Studies of $\mathrm{Hfq}$ in a range of organisms other than E. coli are necessary to uncover its full role as RNA chaperone. The E. coli ProQ protein has also been suggested to be an RNA chaperone, as it has a C-terminal domain with similar to $\mathrm{Hfq}$ (64). The YbeY protein, which is ubiquitous in bacteria, impacts gene expression similarly to $\mathrm{Hfq}$ in Sinorhizobium meliloti (65). Other proteins also may act as RNA chaperones bacterial species where there is no Hfq homolog. 


\subsubsection{Cis-encoded sRNAs}

A significant number of protein-coding genes are also transcribed from the reverse complementary strand in a wide range of bacterial species (15,24-30). In general, overlapping transcription results in the generation of a cis-encoded asRNA whose size usually varies between various tens to hundreds of nucleotides (nt). By 2007, only about 30 bacterial asRNAs had been identified (reviewed in (23)). Antisense transcription detected in initial tiling array experiments was suspected to be an experimental artifact generated during cDNA synthesis. This problem was overcome by the development of strand- specific cDNA synthesis protocols (17). The number of reported asRNAs has lately exploded due to the use of RNA-seq. However characterization of the physiological function of individual asRNAs is growing at a much slower speed.

AsRNAs are known to affect the expression of the target gene by different mechanisms (Figure 7) (reviewed in (66)). (i) One is transcription interference, in which transcription from one promoter is suppressed by a second promoter located in the opposite strand. Transcription interference does not involve base-pairing and does not occur when the asRNA is provided in trans. This effect was first detected in two convergent bacteriophage promoters that produce transcripts which have an overlap of $62 \mathrm{bp}$ at their 5 ' ends (67). It was observed that the stronger promoter significantly reduced the activity of the weaker promoter. When the promoters were oriented divergently, the transcription from both promoters was not affected despite the transcripts still maintained their regions of complementarity. Moreover, the introduction of a terminator before the convergent weak promoter resulted in reduced interference. These results led to the conclusion that the convergent orientation of the promoters was the source of the interference rather than base pairing. (ii) Antisense RNAs also can alter induce mRNA transcription attenuation, in which base pairing of the asRNA to the target mRNA causes premature transcription termination. In some cases base pairing of the asRNA to the mRNA has been shown to induce the formation of a terminator structure in the target mRNA. One example of this type of regulation is the asRNA RNA $\beta$, encoded opposite to the fatDCBA-angRT iron transport-biosynthesis operon in the fish pathogen Vibrio anguillarum (99). Premature transcription termination results in increased levels of the fatDCBA fraction of the mRNA compared to the down-stream angRT, providing a mechanism for discoordinate expression within an operon. (iii) AsRNAs can also promote 
changes in the target RNA stability by the same mechanism as intergenic sRNAs, where the asRNA either promotes or blocks degradation or cleavage of the mRNA by ribonucleases. As example, RNase III is known to be responsible for the of the plasmid-encoded copT-copA and hok-sok asRNA pairs $(68,69)$. The AmgR RNA of Salmonella enterica induces degradation of the mgtC mRNA in a manner that requires RNase E but not RNase III (70). (iv) Just as trans-encoded sRNAs, asRNAs whose complementarity extends into the $5^{\prime}$ UTR of their target RNA can impact on ribosome binding to the target mRNA (either positively or negatively) by affecting the target RNA structure.

In addition, regulating the expression of the opposite gene is not the only function of certain asRNAs. As intergenic sRNAs, some asRNAs encode small proteins (71), and some have the potential to act on multiple targets in trans (72-76). The number of existing asRNAs is far from complete, and other mechanisms of action will probably be found. Some possibilities are that antisense transcription serves to stabilize certain regions of the chromosome or as a defense against plasmids containing complementary regions.

a Transcription interference

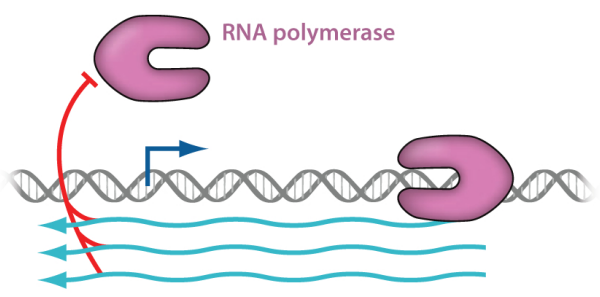

C Substrate for endonuclease altered

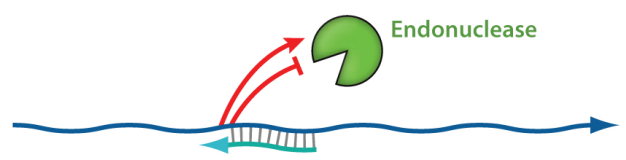

e Translation blocked directly

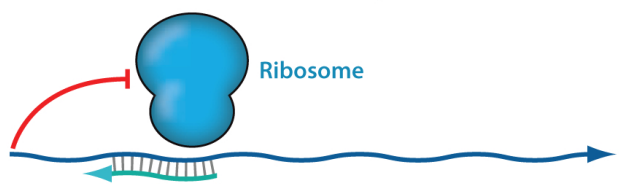

b Transcription attenuation

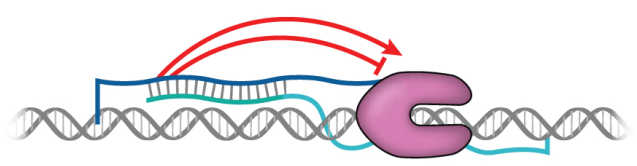

d Substrate for exonuclease altered

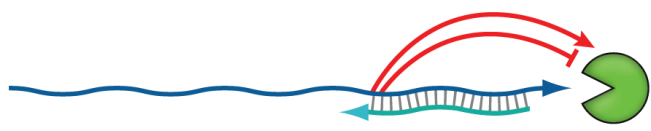

Exonuclease

f Translation blocked indirectly

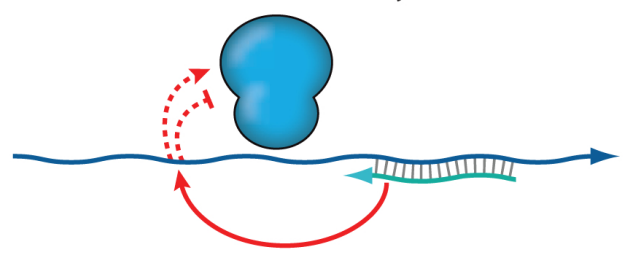

$\longrightarrow$ Sense RNA $\longrightarrow$ Antisense RNA $\longrightarrow$ Positive regulation $\longrightarrow$ Negative regulation

Figure 7. Mechanisms of action of antisense RNAs. Sense RNAs are depicted in dark blue while asRNA in light blue. Figure adapted from (66). 


\subsubsection{Protein-binding sRNAs}

The number of sRNAs that directly regulate the activity of proteins is much lower than the number of intergenic sRNAs and asRNAs. However, their regulatory roles are by no means less powerful. sRNAs can regulate RNA binding proteins by containing the protein recognition sequence (molecular mimicry), often in multiple copies. This is the case of $E$. coli CsrB RNA, which has 18 binding sites for the RNA binding protein CsrA, which regulates mRNA translation and stability (reviewed in (77)). The $P$. aeruginosa CrcZ RNA is another example of this kind of regulation. CrcZ contains 5 CA-rich motifs which can bind up to 5 copies of the translation repressor protein $\mathrm{Crc}(78)$. Other sRNAs bind enzymes, and can inhibit, activate or modify protein activity. The most studied example is 6S RNA, which binds to the house-keeping form of RNA polymerase $\left(\sigma^{70}\right.$-RNAP) by mimicking the secondary structure of DNA during transcription initiation (reviewed in (79)). The changes on transcription after binding 6S RNA are very complex, which indicates that $\sigma^{70}$-RNAP activity is modified rather than simply inhibited (80). It is expected that the number of sRNAs that bind to proteins will increase, and that more modes of regulation will be discovered. For example, it is proposed that sRNA binding to proteins might also modulate proteins by allosteric regulation or by tethering proteins close to each other (Figure 8).

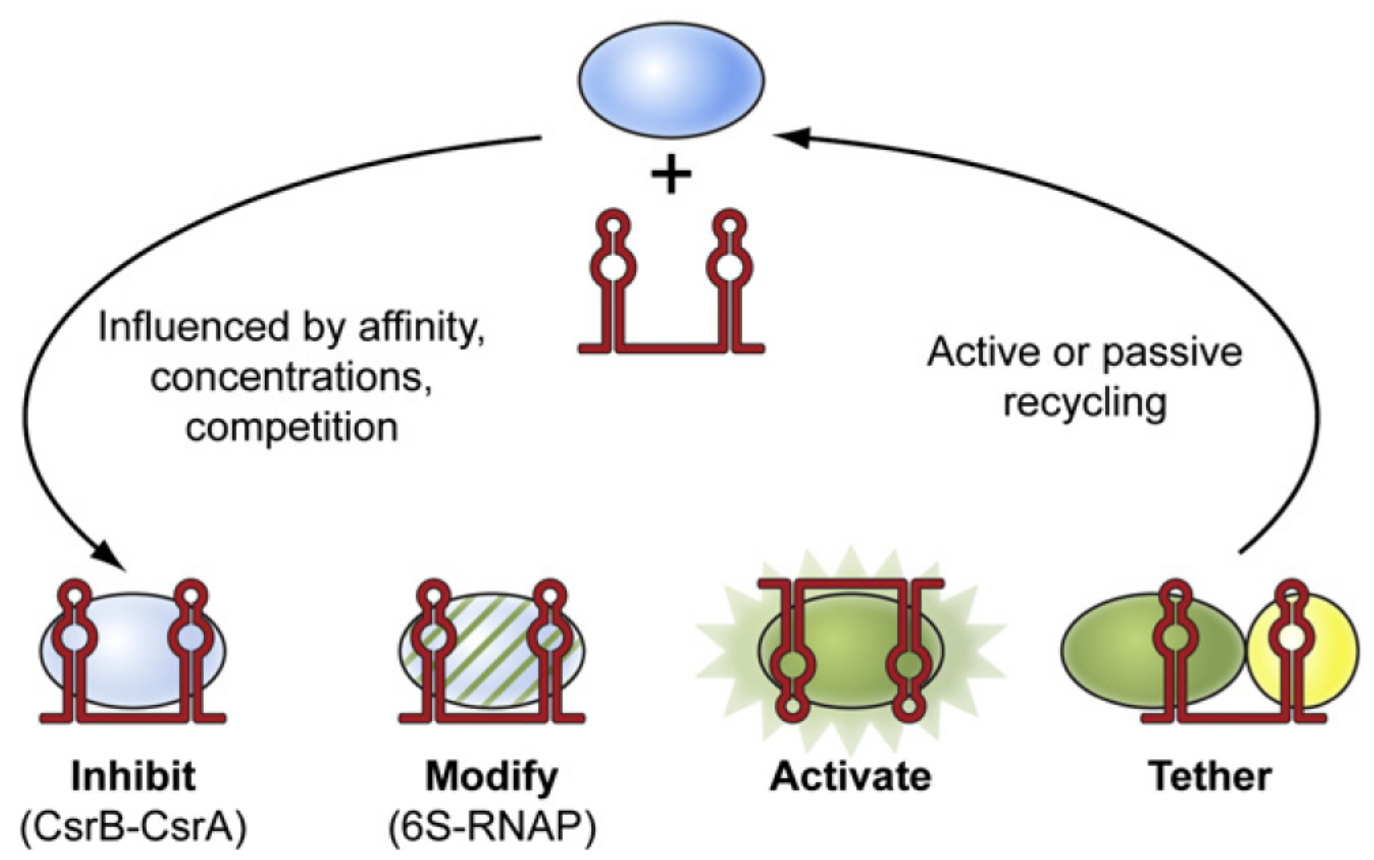

Figure 8. Mechanisms of action of sRNAs that modulate protein activity. Figure adapted from (81). 


\subsection{Identification of bacterial small RNAs}

Until very recently, bacterial SRNAs have been overlooked mainly because there was no systematic technical skills to detect them. Despite the fact that the first bacterial sRNAs have been known for four decades, earlier studies to identify sRNAs have often depended on serendipity, direct detection due to high abundance, protein copurification, and computational predictions based on sequence conservation (reviewed in (82)). Computational predictions of sRNAs often search exclusively within intergenic regions and only detect sRNAs that fall into a certain definition, based on a combination of sequence conservation, specific promoters and Rhoindependent terminators (83-86). Although various sRNAs have been identified in bioinformatics predictions, sRNAs that are transcribed within or antisense to already annotated loci are missed. In addition, sRNAs whose 3' ends are formed by Rhodependent terminators or processed by RNases are missed by computational methods that search for Rho-independent terminators. Similarly, studies that rely on chaperone-binding to find sRNAs will miss chaperone-independent sRNAs.

Until 2001 only a dozen of sRNAs were known in bacteria, 10 of them identified in $E$. coli (reviewed in (87)). Most of these sRNAs were identified serendipitously while analyzing flanking protein-coding genes. In 2001, the first genome-wide systematic searches for sRNAs were performed in $E$. coli by three independent groups, and more than 50 sRNAs were identified $(62,88,89)$. These studies predicted the existence of sRNAs based on sequence conservation between $E$. coli intergenic regions and those of the closely related bacteria Salmonella typhimurium and Yersinia pestis, for which complete genome sequences had been published at the time. By 2007 , only 140 bacterial sRNAs had been discovered (reviewed in (90)).

The first transcriptomic studies investigating sRNAs used cDNA synthesis from RNA samples, combined with cloning and Sanger sequencing $(60,91)$. Recent genomewide studies to identify sRNAs have been based on tiling arrays and, since 2008, primarily on RNA-seq. As mentioned in section 2.2, RNA-seq has many advantages over tiling arrays, and has enabled the study of the transcriptome at unprecedented depths and in a strand-specific manner. RNA-seq has revealed several hundreds of previously undetected transcripts in diverse bacteria including Bacillus subtilis (92), Chlamydia trachomatis (28), Helicobacter pylori (24), Legionella pneumophila (93), Listeria monocytogenes (94,95), Salmonella enterica (96-98), Streptomyces 
coelicolor (99), Synechocystis (100), Vibrio cholerae (91,101), Yersinia pseudotuberculosis (102), Escherichia coli $(103,104)$, Mycobacterium tuberculosis (105), Staphylococcus aureus (29), and Agrobacterium tumefaciens (106).

Special attention must be paid to the way RNA-seq experiments are designed, as different protocols will yield a very different number of detected sRNAs. Many of the RNA-seq studies published so far are not optimal for the identification of sRNAs, even if some are identified. One of the first considerations when designing an RNAseq experiment to study sRNAs is the method used to extract total RNA. Historically RNA extraction methods have been optimized to exclude sRNAs under the assumption that they were products of degradation of no interest or importance. Many commercially available kits for RNA isolation do not quantitatively retain the short RNAs. This is the case for most of the kits that use spin columns. Spin-column kits provide very quick and efficient methods for extracting high-quality RNA, but are not suitable to study sRNAs since their size exclusion limit is too large. Transcriptomic studies that use this kind of RNA extraction cannot detect most of the sRNAs transcribed by both prokaryotic and eukaryotic cells. There are commercially available spin-column kits specially designed for the study of eukaryotic miRNAs (20$22 \mathrm{nt})$. These kits are not suitable for the study of prokaryotic sRNAs, as these typically range in size from 70 to 500 nt. Methods as the hot-phenol protocol or the guanidinium thiocyanate-phenol-chloroform extraction allow retention of all RNA species (see Article 2 presented in this thesis for details). Another important consideration is that strand-specific library preparations are necessary for the accurate determination of the direction of the transcripts, as well as the identification of antisense transcription events, as mentioned in section 2.

Other consideration when designing RNA-seq experiments is whether or not it is desirable to include highly abundant rRNAs in the library preparation. The relative abundance of mRNAs in bacterial total RNA can be as low as $5 \%$, being the rest rRNAs and tRNAs (107). This results in a major technical challenge for RNA-seq. Unlike eukaryotic mRNAs, which can be selectively synthesized into cDNA by virtue of their poly-A tails (108), bacterial and archaeal cDNA synthesis results predominantly in rRNA sequences (109). To improve mRNA and sRNA detection sensitivity, prokaryotic rRNAs are often removed before preparing RNA-seq libraries $(32,91,97,110,111)$. Successful reduction of the rRNA fraction can result in a ten-fold enrichment of the mRNA and sRNA output, and that ensures sufficient transcript coverage. Although mRNA enrichment is not absolutely necessary, it can 
substantially increase transcript coverage and therefore increase the sensitivity of the experiment. The downside of enrichment might be unanticipated biases in the sequenced transcriptome. Other possibility would be to compensate the lower coverage in non-enriched samples by sequencing more cDNA, but this will significantly increase the cost of the experiment. Different methods have been used to eliminate prokaryotic rRNA, including subtractive hybridization with rRNA-specific probes, digestion with exonuclease that acts on processed transcripts, and gel electrophoresis size separation and extraction of non-rRNA fractions, which has the drawback of excluding also transcripts similar in size to rRNAs. A study compared the effectiveness and fidelity of the two most commonly used approaches, subtractive hybridization and exonuclease digestion (Figure 9), on two different synthetic metatranscriptomes and found that only subtractive hybridization adequately preserved relative transcript abundance for quantitative analyses, whereas the exonuclease treatment greatly compromised mRNA abundance fidelity (112). This is not surprising since many non-ribosomal transcripts (including sRNAs) are processed, and treatment with exonuclease results in the loss of these. Article 2 presented in this thesis describes how to use subtractive hybridization to efficiently deplete 23S, 16S and 5S rRNAs from total RNA samples.
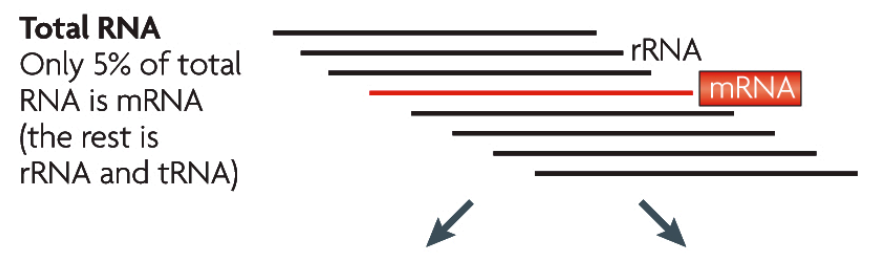

a rRNA capture

Magnetic beads with probes that are specifically directed to bind rRNA

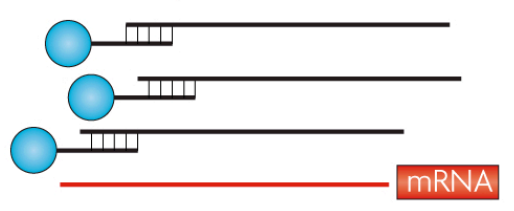

b Degradation of processed RNA

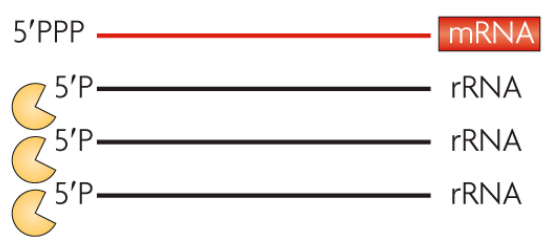

Exonuclease that specifically degrades 5'P RNAs

Figure 9. Methods for non-rRNA enrichment in prokaryotes (113).

Size is a key factor when detecting novel sRNAs using RNA-seq. RNA size fractionation prior to library preparation allows a greater coverage of small size RNAs and of transcripts expressed at low levels, increasing the number of novel RNAs 
detected $(29,32,91)$. As mentioned further, our study of the transcriptome of $P$. aeruginosa involved the use of three different types of sequencing libraries, with different degrees of RNA size selection (32). The libraries that contained the fraction of shorter RNAs were clearly superior in detecting sRNAs compared to a library that contained the full transcriptome, which highlights the importance of adequate library preparation to detect SRNAs (see Article 1 presented in this thesis for details). Thus, RNA-seq libraries that contain all the transcriptome will detect only a fraction of highly expressed sRNAs, unless using an enormous sequencing depth, which normally results in increased economic costs. RNA-size fractionation should be performed prior to rRNA-depletion, as the larger rRNA molecules will be excluded during size selection. The smaller rRNAs, like 5S rRNA, can be excluded after the size selection (see Article 2 presented in this thesis for details).

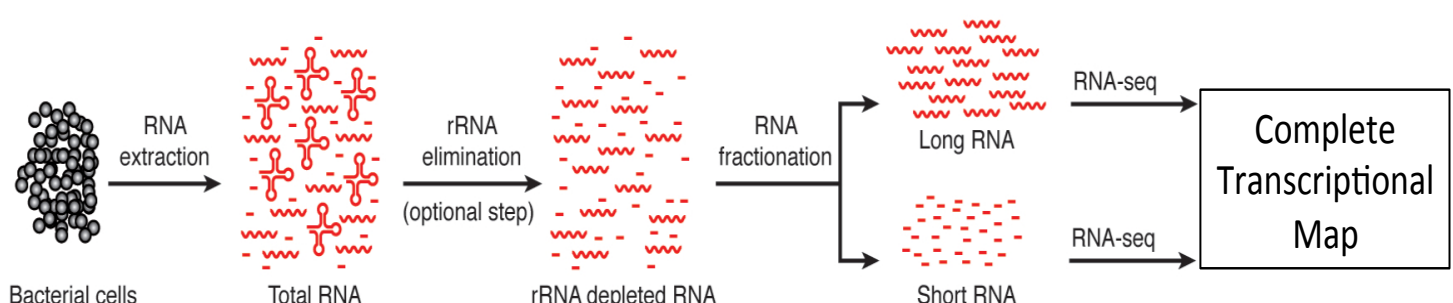

Figure 10. Summary flowchart suggesting an experimental design to define a complete transcriptional map. Figure adapted from (22).

To summarize, the sensitivity of RNA-seq for detecting sRNAs greatly depends on the design of the experiment. The most important factors when designing such experiments are:

(i) The choice of a method for RNA extraction that does retain all sRNA species. Methods as the hot-phenol protocol or the guanidinium thiocyanate-phenol-chloroform extraction allow retention of all RNA species.

(ii) Removal of abundant rRNAs increases the relative abundance of mRNA and SRNA species and ensures sufficient transcript coverage. Subtractive hybridization depletion methods are preferred over the use of exonuclease, as exonuclease digestion results in the loss of many nonribosomal transcripts (including sRNAs) that are processed.

(iii) RNA size fractionation prior to library preparation also allows a greater coverage of small size RNAs and of transcripts expressed at low levels, and thus the sensitivity of the experiment increases. 
(iv) The use of a strand-specific method for library preparation retains the directionality of RNA molecules, making possible to detect antisense transcription. Direct labeling of the RNA molecules with different adapters at the $5^{\prime}$ and $3^{\prime}$ ends is preferred over other methods as oligonucleotides complementary to the 5' and 3' adaptors are used for the synthesis of cDNA, considerably reducing the bias introduced by use of random primers to synthesize the cDNA. 


\section{PSEUDOMONAS AERUGINOSA}

This Gram-negative bacillus can be found in a wide variety of environmental sources, from water to soil. It grows on a wide range of media over a wide range of temperature. It is an important opportunistic pathogen in humans, causing urinary tract infections, respiratory system infections, systemic infections in burn patients as well as being the major cause of morbidity and mortality in cystic fibrosis patients (114).

The increasing clinical relevance of $P$. aeruginosa as an opportunistic human pathogen is based in several reasons: its adaptability, its innate resistance to many antibiotics and disinfectants, its armoury of virulence factors, an increasing number of patients compromised by age, disease or immunosuppressive therapy, and its ability to persist and multiply in a great variety of moist environments and equipment in hospital wards, bathrooms and kitchens, which is of particular importance in crossinfection control. The genome of $P$. aeruginosa is one of the largest among bacteria: it contains approximately 6.2 million base pairs and 5,570 genes, including a high proportion of regulatory genes which most likely reflect its adaptability (115). The choice of $P$. aeruginosa in this study was mainly motivated by the fact that it possesses vast and complex regulatory networks, whose mechanisms are not entirely understood, and by the low number of regulatory sRNAs identified in this bacterium prior to our study (reviewed in (116)). We hypothesized that $P$. aeruginosa must have many unknown sRNAs encoded in its large genome, and that has been shown to be true.

\subsection{Antibiotic resistance}

$P$. aeruginosa is intrinsically resistant to many antimicrobial agents and acquired resistance is frequently developed during antibiotic therapy (117). The mechanisms of resistance consist of chromosomally encoded $\beta$-lactamases, multidrug efflux systems, low outer membrane permeability and lipopolysaccharide (LPS) modification. Antibiotics such as piperacillin, aztreonam, ceftazidime, meropenem, 
ciprofloxacin, colistin, azithromycin or tobramycin are usually active against $P$. aeruginosa, but resistance often develops in the case of chronic infected CF patients (118-122). P. aeruginosa has more than 10 resistance-nodulation-division (RND) family transporters, of which 9 transport multiple antibiotics. These pumps export antibiotics but also biocides, dyes, detergents, metabolic inhibitors, organic solvents and molecules involved in bacterial cell-to-cell communication. Despite drug efflux not being the natural function of RND pumps, these pumps enable many pathogens to resist antimicrobial drugs and thus compromise treatment of infectious diseases (123). P. aeruginosa also produces a chromosomally encoded cephalosporinase designated AmpC. The expression of AmpC is highly inducible by certain $\beta$-lactams, such as cefoxitin, imipenem or ampicillin. The antipseudomonal penicillins (such as piperacillin) and cephalosporins (such as ceftazidime) are very weak AmpC inducers, despite the fact that this enzyme hydrolyzes them. However, during treatment with these weak inducers, mutants showing high expression of AmpC (AmpCderepressed mutants) are frequently selected, leading to the failure of antimicrobial therapy (124). In addition $P$. aeruginosa is able to modify its outer-membrane lipopolysaccharides (LPS) leading to increased tolerance towards cationic antimicrobial peptides, like colistin, and increased inflammatory responses (125).

\subsection{Quorum sensing}

Quorum sensing (QS) has been defined as the chemical-mediated cell-to-cell communication systems to coordinate gene expression and group activities within bacterial communities (126). $P$. aeruginosa produces at least three small molecules that function as cell-to-cell communication signals. The acyl homoserine lactone signals $3-0 x 0-\mathrm{C}_{12}-\mathrm{HSL}$ and $\mathrm{C}_{4}-\mathrm{HSL}$ have been well studied and function in combination with the LasR and RhIR proteins, respectively (127-131). Together, these two HSLs control up to $11 \%$ of the $P$. aeruginosa genes (132-134). The third $P$. aeruginosa cell-to-cell signal, named the Pseudomonas quinolone signal (PQS), is a quinolone compound that was identified as 2-heptyl-3-hydroxy-4-quinolone (135). PQS is synthesized from anthranilate by the products of the pqs operon pqsABCDEH. The precursor of the PQS molecule is 4-hydroxy-2-heptyl-quinoline $(\mathrm{HHQ})$, which is released from and taken up by bacterial cells (136). The expression of $p q s A B C D E$ is regulated by the transcriptional regulator PqsR (also designated as MvfR) (137). By contrast, pqsH, which is necessary for the conversion of $H H Q$ to 
PQS, is positively regulated by LasR (138). PQS controls numerous virulence factors and it serves as a regulatory link between the las and $r h l$ QS systems $(139,140)$. PQS is produced in the lungs of CF patients infected with $P$. aeruginosa (141), it is required for virulence in nematodes, plants, and mice $(137,138,142-144)$, and it also induces apoptosis and decreases viability in eukaryotic cells (145).

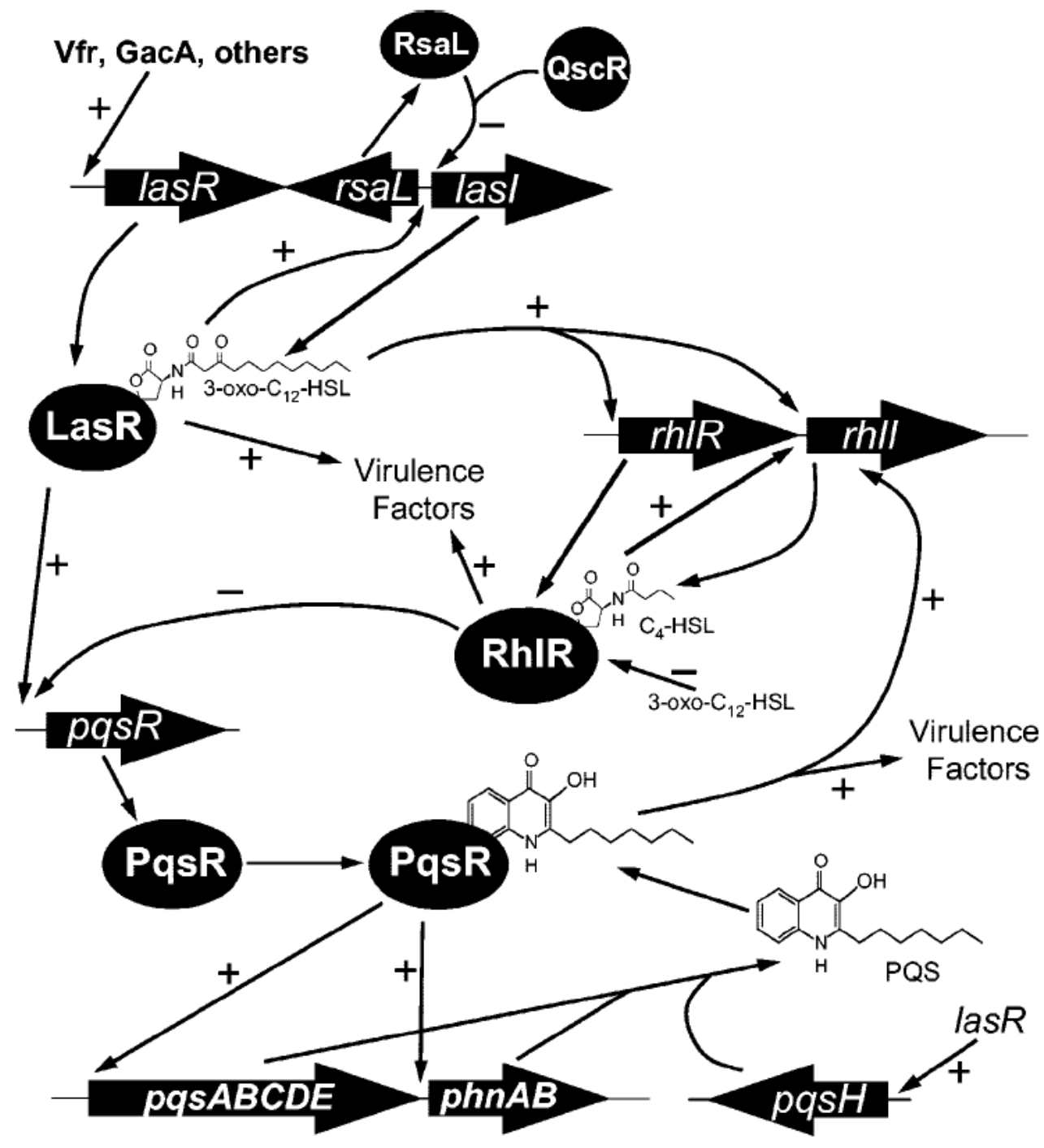

Figure 11. Model of the $P$. aeruginosa QS signaling hierarchy. Plus and minus symbols indicate positive and negative effects, respectively. The QS system consists of two HSL regulatory circuits (las and rhl) linked to a 2-alkyl-4-quinolone (PQS) system. In complex interactions with additional regulators, including Vfr, GacA, RsaL, and RpoS, the QS systems regulate the expression of several of virulence factors. Figure adapted from (146). 


\subsection{Small RNAs in P. aeruginosa}

Only 44 sRNAs were identified in $P$. aeruginosa up to 2012. A variety of approaches were used to identify these 44 sRNAs in $P$. aeruginosa (reviewed in (116)) including those based on direct detection due to high abundance (147), similarity with a known sRNA of E. coli (148), computational predictions (149), and co-purification with a protein (60). Three systematic searches for sRNAs were undertaken in $P$.aeruginosa, where all focused on intergenic regions. In two studies sRNAs were predicted on the basis of sequence conservation, as well as the presence of rho-independent terminators, putative promoters and conserved secondary structure $(85,86)$. A third study used a combined bioinformatics and RNomics approach, where total RNA was size-fractionated, co-immunoprecipitated with $\mathrm{Hfq}$, cloned and sequenced (60).

Of the 44 sRNAs known in $P$. aeruginosa, only the role of 12 sRNAs is characterized, where 4 are classical sRNAs (6S, 4.5S, RNase P and tmRNA) (reviewed in (116)). In $P$. aeruginosa, sRNAs are known to be involved in the regulation of virulence genes (RsmY/Z), carbon catabolite repression (CrcZ), iron metabolism (PrrF1, PrrF2, PrrH), nitrogen assimilation (NrsZ), and QS regulation (PhrS) $(47,78,149-152)$. PhrS is a 213-nt long sRNA, predicted by biocomputation $(85,86)$ and isolated by an RNomics approach (60). PhrS is highly transcribed under low oxygen conditions, and its expression requires the oxygen-responsive regulator ANR (47) (Figure 12). PhrS activates the translation of the pqs $R$ gene by base-pairing with a short untranslated open reading frame (uof) to which the pqsR gene is translationally coupled (47). PqsR is one of the key QS regulators in $P$. aeruginosa and its synthesis induces the PQS synthetic operon pqsABCDE $(138,153)$. Beside its function in inter-bacterial signaling, $P Q S$ is required for full synthesis of the $P$. aeruginosa virulence factor pyocianin, which can react with molecular oxygen to generate oxidative stress (154). In addition to its function as a regulatory RNA, PhrS encodes a highly conserved 37 amino-acid peptide (60). The peptide contains a predicted transmembrane segment and sub-cellular fractionation revealed that the peptide is indeed located in the cytoplasmic membrane (CM). In Article 4 presented in this thesis we investigated the role of sRNA OsiS, which was first identified in the genome-wide search presented in Article 1. OsiS is highly transcribed during oxidative stress conditions, including treatment with sublethal concentration of hydrogen peroxide and lethal concentrations of ciprofloxacin. We show that by inducing the expression of OsiS the levels of the sRNA PhrS are greatly reduced. We predict that the interaction is by 
direct base-pairing between the two sRNAs, with a recognition site of OsiS at the highly conserved-region of PhrS (155). However, more experiments are required to know the exact mechanism of interaction between these two sRNAs. OsiS is, to the best of our knowledge, the first SRNA whose main function seems to be regulating the cellular levels of another sRNA.

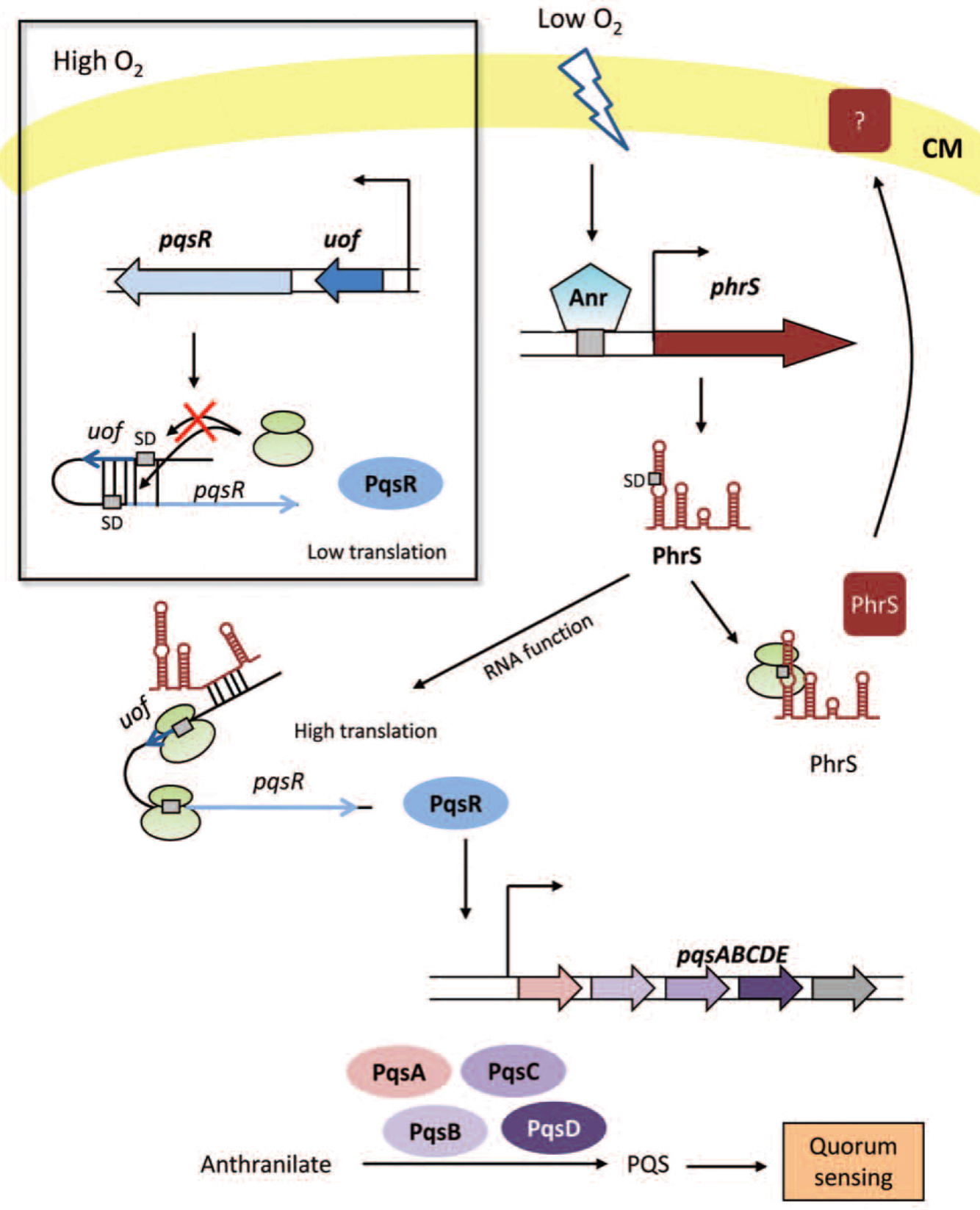

Figure 12. Quorum sensing regulation by PhrS. Figure adapted from (156). 
The size and complexity of the $P$. aeruginosa genome suggested that there were many undetected sRNAs in this bacterium. In 2012, we published the first genomewide search of sRNAs using RNA-seq in $P$. aeruginosa (32). RNA isolated from exponential and early-stationary phase cells was used to prepare three different types of libraries for sequencing. The sequencing libraries were named $L I B>100$, $\mathrm{LIB}<500$ and $\mathrm{LIB}<200$ to denote the transcript sizes in nucleotides that are included in each preparation. Library LIB $>100$ contained all mRNAs transcribed. Libraries $L I B<500$ and $L I B<200$ were each prepared with size selection steps and contain transcripts shorter than 500 and 200 nt respectively. We found over 500 novel intergenic sRNAs in the three libraries, where a different number of transcripts were detected in each library. The two libraries that do not include larger transcripts $(\mathrm{LIB}<500$ and $\mathrm{LIB}<200)$ were clearly superior in detecting sRNAs. Our data suggests that the set of identified RNAs obtained depends strongly on the specific library preparation strategy used, and that RNA fractionation increases the sequencing depth favoring identification of trasncripts expressed at low copies (see Article 1 in Chapter 2 for details). In addition we identified 249 antisense sRNAs (asRNAs) in $P$. aeruginosa PAO1 grown in 13 different conditions, including osmotic and oxidative stress, early and stationary phases, and a variety of antibiotics clinically used (see Article 3 in Chapter 2 for details). In this study only one library type was used, which contained transcripts shorter than $500 \mathrm{nt}$ (library LIB<500).

Later in 2012, two independent studies that used RNA-seq in $P$. aeruginosa were published. One of the studies investigated strains PAO1 and PA14 at early stationary phase using a similar preparation than that of library LIB $<500$. The authors found 163 novel sRNAs, of which 60 were antisense sRNAs (asRNAs) (157). Interestingly, the authors found that a number of these sRNAs were strain-specific or showed strainspecific expression (157). The other study sequenced $P$. aeruginosa PA14 grown at $28^{\circ} \mathrm{C}$ and at $37^{\circ} \mathrm{C}$ using a strategy similar to library LIB $>100$. This study identified 165 intergenic sRNAs and 384 antisense transcriptional start sites (TSS) (158). The strategy used to prepare the libraries only detected the strand specificity of TSS, thus the authors could only identify antisense TSS, but not the full length of asRNAs. The strategy used by Wurtzel et al (2012) enabled the identification of TSSs thanks to the differential treatment of RNA with tobacco acid pyrophosphatase (TAP). TSSs can be detected by selecting for primary RNA transcripts that have a 5'-triphosphate (processed RNAs have a 5'-monophosphate) (24). In conclusion, our sequencing approach was the most sensitive, identifying novel sRNAs, both intergenic sRNAs and full-length asRNAs, compared to the other two genome-wide studies in $P$. 
aeruginosa. However our library preparations could be further improved by sequencing differential cDNA library pairs (one fraction treated with TAP or with terminator exonuclease, and the other fraction left untreated) to discriminate primary from processed 5' ends. It would be interesting to make a comparison between the three studies to assess the level of overlap between them, as well as for creating a single database with all the sRNAs detected so far in $P$. aeruginosa strains and their patterns of expression in the conditions studied. 


\section{CONCLUSION AND PERSPECTIVES}

Identifying the full set of transcripts, including large and small RNAs, is crucial for a comprehensive study of the transcriptome. Until recently, our knowledge of the transcriptome was largely derived from gene predictions based on sequence conservation and limited evidence, and has thus been partial. During the last decade, RNA-seq has revealed the complex landscape and dynamics of the transcriptome of all organisms studied at an unprecedented level of sensitivity and accuracy. Compared with traditional low-throughput Sanger sequencing technology, which only detects the more abundant transcripts, the enormous sequencing depth of a typical RNA-seq experiment can offer an almost complete snapshot of a transcriptome, if using appropriate library preparations. As mentioned earlier, the main focus of this thesis has been to investigate the number and characteristics of sRNAs in the highly adaptable pathogen $P$. aeruginosa. RNA-seq protocols have been optimized in order to increase their sensitivity and detect as many sRNAs as possible. The research articles written as part of this work are enclosed in the next section. Article 1 describes how a combination of three different RNA-seq libraries is used to identify novel transcripts encoded in intergenic regions. Almost all known sRNAs and over 500 novel intergenic sRNAs were identified with this approach. The use of three libraries in combination increased the number of novel transcripts identified. However there were significant differences in the subset of transcripts detected in each library, underscoring the importance of library preparation strategy and relative SRNA abundance for successful sRNA detection. Article $\mathbf{2}$ is a book chapter that provides detailed experimental procedures for preparing the three different sequencing libraries used in Article 1, as well as a computational pipeline to analyze the data generated and find both intergenic and asRNAs. One of the libraries ( $L I B>100)$ is prepared using a standard RNA-seq protocol for full transcriptomes and contains information on all mRNAs transcribed by the bacteria. The other two libraries $(L I B<500$ and $L I B<200)$ are prepared from size-selected RNA containing transcripts shorter than 500 and $200 \mathrm{nt}$, respectively. The different libraries can either be used alone or in combination to increase the number of identified sRNAs. In Article 3249 asRNAs are identified using the library type LIB<500. $P$. aeruginosa PAO1 was grown in 13 different conditions to ensure a comprehensive characterization of the $P$. aeruginosa asRNA-ome. The conditions studied include exponential and earlystationary phase, osmotic, oxidative and antibiotic stress. A considerable number of 
asRNAs were transcribed opposite to genes encoding membrane proteins and genes involved in the transport of small molecules, cell wall, lipopolysaccharide (LPS), and capsule biosynthesis. A substantial number of asRNAs significantly changed their expression under osmotic, oxidative and antibiotic stress, suggesting that asRNAs play a regulatory role during these conditions. Finally, Article 4 investigates the role of sRNA OsiS that was first identified in the genome-wide search presented in Article 1. OsiS is highly transcribed during oxidative stress conditions. We show that by inducing the expression of OsiS the levels of the sRNA PhrS are greatly reduced. PhrS activates the translation of PqsR under low oxygen concentrations, which in turn activates the synthesis of PQS. Thus, OsiS links the oxygen levels to the production of QS molecules. OsiS is another example of a sRNA that responds to oxygen levels in bacteria, such as PhrS in $P$. aeruginosa (47), RgsA in $P$. fluorescens (86), OxyS, FnrS and MicF in E. coli (159-162), and RliB in L. monocytogenes (15). OsiS is, to the best of our knowledge, the first SRNA whose main function seems to be regulating the cellular levels of another SRNA.

The study presented in Article 1 is the first to use RNA-seq to discover novel sRNAs in $P$. aeruginosa and utilized three types of sequencing libraries to maximize the number of detected sRNAs. Over 500 novel sRNA transcripts were identified, increasing the number of known sRNAs in $P$. aeruginosa by a factor of 12 and revealing a large set of potential regulatory molecules in an already highly regulated species. Two libraries that do not include larger transcripts $(L I B<500$ and $L I B<200)$ were clearly superior in detecting sRNAs. Although the use of three libraries increased the number of novel transcripts identified, there were significant differences in the subset of transcripts detected in each library, underscoring the importance of library preparation strategy and relative sRNA abundance for successful sRNA detection. The limited extent of sRNA sequence conservation observed among pseudomonads highlights the challenges of SRNA bioinformatic prediction and emphasizes the importance of sRNAs at the species level in monitoring changes in environmental conditions. The approach described can be applied to identify sRNAs in any bacterium under different growth and stress conditions.

The multitude of sRNAs found in Articles 1 and 3 suggests the involvement of sRNAs in probably all the regulatory networks in $P$. aeruginosa, and characterizing their role will be highly important for our understanding of an organism with such a versatile life style that can successfully move from the environment into the human body as a 
pathogen. There are many questions that remain to be answered regarding the physiological roles of bacterial sRNAs. Even with the recent advances in transcriptomics, the hundreds of sRNAs now being reported in all bacteria studied need to be further validated and functionally characterized before we can really grasp the importance/role of bacterial sRNAs.

Interestingly, few of the known bacterial sRNAs genes have been identified by mutational screens. This might be due to the fact that most of the sRNA genes do not code for proteins and are thus immune to frameshift or nonsense mutations. In addition, sRNAs are often very small (few hundred nucleotides) and sometimes multicopy, which makes them difficult (even impossible) targets for mutational screens. This could also be a consequence of the regulatory rather than essential nature of many sRNAs. Marvig et al (2013) studied the transmissible $P$. aeruginosa DK2 clone isolated from Danish CF patients, and analyzed the genomes of 55 bacterial isolates collected from 21 infected individuals over 38 years (163). Subsequent to transmission, sub-lineages of DK2 evolved independently for years in separate patients, enabling the study of parallel evolution and identification of genes targeted by mutations to increase pathogen fitness in the CF airway. The authors found that the genes targeted by mutations were related to antibiotic resistance, cell envelope, or regulatory functions, and that the prevalence of adaptive mutations correlated with the evolutionary success of the sub-lineages. We looked for conserved adaptive mutations in all the intergenic sRNAs in $P$. aeruginosa, the known sRNAs prior to our genome-wide study plus the 513 novel sRNAs detected by it. We could not find any conserved adaptive mutation in any of the sRNA genes, suggesting that though sRNAs play important roles in regulatory networks, they are not the primary targets of bacterial evolution. In agreement with this, a long-term evolution experiment with $E$. coli, still ongoing, has not yet revealed any relevant changes in SRNA genes (164). However, a short-term evolution experiment reported a spontaneous mutation in Myxococcus xanthus that eliminated the regulatory function of the Pxr RNA, affecting multicellular fruiting body development (165). It will be interesting to perform more evolution experiments in other species to assess the role of SRNA regulation in the long-term adaptation of bacteria. 
From our work with OsiS, we infer that $P$. aeruginosa most likely needs a tight and fine-tuned regulation of the mechanisms that allow adapting to shifts in oxygen tension, and that the sRNA OsiS is involved in this kind of regulation by responding to high oxygen tension and regulating the levels of sRNA PhrS. PhrS is assumed to counteract the low levels of PQS under hypoxic conditions, when PQS production is limited (47). The sRNA OsiS role seems to "counteract the counteracting effect" of sRNA PhrS at high oxygen tension. So both sRNAs OsiS and PhrS respond to oxygen levels and allow the fine-tuning of PQS synthesis. In laboratory conditions, the growth rate of mutants deficient in PhrS production is the same as the wild-type strain, though the deletion mutant produced less pyocianin. We could not produce a strain lacking the OsiS gene, however over-expression of OsiS does not affect any apparent phenotype. Does that mean that sRNAs PhrS and OsiS have a minor regulatory role? And what is the biological implication of oxygen-dependent finetuning of PQS? During infection, $P$. aeruginosa is subject to constant shifts in oxygen tension due to the human airway structure, biofilm formation, antibiotic treatment and the host immune response. Thus, fine-tuning regulators as PhrS and OsiS make no extraordinary difference in controlled and steady laboratory conditions, however we hypothesized that they might be pivotal for a fast and fine-tuned regulation of the mechanisms necessary to survive during adaptation to an environment with such fluctuating levels of oxygen tension as the one inside the host.

As the number of sRNAs detected increases day by day, it would be interesting to understand why RNA-based regulation is sometimes preferred over protein-based regulation. It has been suggested previously that SRNA regulation has benefits over using protein regulators. These benefits might include reduced metabolic cost, additional levels of regulation, faster regulation and unique regulatory properties (reviewed in (166)). The coupled degradation of both the regulatory sRNA and the target mRNAs allows to achieve responses that are different than those obtained with transcriptional factors (167). However, it seems that in many cases a combination of both types regulation seems to be the way in which bacteria regulate the cellular levels of certain proteins and RNAs. For example, PhrS RNA regulates the expression of the pqsR gene (47), which is also regulated by other transcriptional factors, such as LasR and RhIR (146). In this case the regulation by transcriptional factors and PhrS is counteractive, as PhrS promotes the expression of pqsR in conditions when the transcriptional regulators limit its expression. Similarly, PhrS is regulated by both the oxygen-responsive regulator ANR and by OsiS RNA (Article 4). In this case the regulation of both protein and SRNA act in a complementary way, 
ANR activating the expression of PhrS under low oxygen conditions, and OsiS reducing the levels of PhrS under high oxygen conditions. Thus, regulating a target at two levels, with both a transcription regulator and base-pairing SRNA, allows modifying the dynamics of target gene expression (as the regulation of pqs $R$ by transcriptional factors and PhrS RNA) as well as reducing leakiness (as the regulation of PhrS by ANR and OsiS RNA).

As we start to solve some of the traditional challenges for studying sRNAs, such as the lack of technical skills to detect them, new challenges arise. One of them is the handling of RNA-seq data. Comparing these extremely large data sets between different studies is difficult, as library preparation protocols, sequencing platforms, and thresholds for detecting transcripts differ from study to study. It is necessary to address considerations like what is an appropriate threshold of reads for transcript detection, or how reproducibility should be reported. Ironically, we now have such an enormous volume of data that it is hard to use them. Universally available platforms are already and will be needed for sharing, analyzing, and storing transcriptomic data. An even greater challenge than sharing and comparing RNA-seq data, will be the validation and characterization of the hundreds of novel sRNAs reported by every new study. While Northern blot analysis has been the golden standard for validating RNAs, its sensitivity is significantly lower than that achieved by RNA-seq. Techniques such as 5' and 3' RACE experiments might be a good alternative for validating sRNAs. Just as Northern blots, RACE experiments provide information about the size and processing of a transcript. However, contrary to Northern analysis, RACE experiments provide single-base resolution of the coordinates of the transcripts. Without higher throughput techniques than the now available, it will take years, probably decades, to characterize the hundreds of sRNAs now being reported. The studies that characterize the function of sRNAs are mostly based in deletion strains and sRNA overexpression (168-170). Unfortunately, the phenotypes associated with decreased or increased expression of sRNAs are often subtle and might only be detected under specific conditions, as is the case of strains overexpressing PhrS and OsiS RNAs. The understanding of the molecular mechanisms of action of individual novel RNAs will most likely be one of the biggest challenges of current RNA research. 


\section{REFERENCES}

1. Waters LS, Storz G. Regulatory RNAs in bacteria. Cell. 2009 Feb 20;136(4):615-28.

2. Crick F. Central dogma of molecular biology. Nature. 1970 Aug 8;227(5258):561-3.

3. Gesteland RF, Cech TR, Atkins JF. The RNA World. CSHL Press. 2006.

4. Brachet $\mathrm{J}$, Chantrenne $\mathrm{H}$. The function of the nucleus in the synthesis of cytoplasmic proteins. Cold Spring Harbor symposia on quantitative biology. 1956;21:329-37.

5. Crick FH. On protein synthesis. Symposia of the Society for Experimental Biology. 1958.

6. Hoagland MB, Stephenson ML, Scott JF, et al. A soluble ribonucleic acid intermediate in protein synthesis. J Biol Chem. 1958 Mar;231(1):241-57.

7. Brenner S, Jacob F, Meselson M. An unstable intermediate carrying information from genes to ribosomes for protein synthesis. Nature. 1961 May 13;190:576-81.

8. Faust PLP, Kornfeld SS, Chirgwin JMJ. Cloning and sequence analysis of cDNA for human cathepsin D. Proceedings of the National Academy of Sciences. $1985 \mathrm{Jul}$ 31;82(15):4910-4.

9. Schena MM, Shalon DD, Davis RWR, Brown POP. Quantitative monitoring of gene expression patterns with a complementary DNA microarray. Science. 1995 Oct 19;270(5235):467-70.

10. Selinger DWD, Cheung KJK, Mei RR, Johansson EME, Richmond CSC, Blattner FRF, et al. RNA expression analysis using a 30 base pair resolution Escherichia coli genome array. Nat Biotechnol. 2000 Nov 30;18(12):1262-8.

11. Merrell DS, Butler SM, Qadri F, Dolganov NA, Alam A, Cohen MB, et al. Hostinduced epidemic spread of the cholera bacterium. Nature. 2002 Jun $5 ; 417(6889): 642-5$.

12. Revel ATA, Talaat AMA, Norgard MVM. DNA microarray analysis of differential gene expression in Borrelia burgdorferi, the Lyme disease spirochete. Proceedings of the National Academy of Sciences. 2002 Feb 4;99(3):1562-7.

13. Belland RJR, Zhong GG, Crane DDD, Hogan DD, Sturdevant DD, Sharma JJ, et al. Genomic transcriptional profiling of the developmental cycle of Chlamydia trachomatis. Proceedings of the National Academy of Sciences. $2003 \mathrm{Jul}$ 7;100(14):8478-83.

14. Mäurer APA, Mehlitz AA, Mollenkopf HJH, Meyer TFT. Gene expression profiles of Chlamydophila pneumoniae during the developmental cycle and iron depletionmediated persistence. PLoS Pathog. 2007 May 31;3(6):e83-3.

15. Toledo-Arana A, Dussurget O, Nikitas G, Sesto N, Guet-Revillet H, Balestrino D, et al. The Listeria transcriptional landscape from saprophytism to virulence. Nature. 2009;459(7249):950-6.

16. Eriksson S, Lucchini S, Thompson A, Rhen M, Hinton JCD. Unravelling the biology 
of macrophage infection by gene expression profiling of intracellular Salmonella enterica. Molecular Microbiology. 2002 Dec 31;47(1):103-18.

17. Perocchi $F, X u Z$, Clauder-Münster S, Steinmetz LM. Antisense artifacts in transcriptome microarray experiments are resolved by actinomycin D. Nucleic Acids Research. 2006 Dec 31;35(19):e128-8.

18. Canales RDR, Luo YY, Willey JCJ, Austermiller BB, Barbacioru CCC, Boysen CC, et al. Evaluation of DNA microarray results with quantitative gene expression platforms. Nat Biotechnol. 2006 Aug 31;24(9):1115-22.

19. Westermann AJ, Gorski SA, Vogel J. Dual RNA-seq of pathogen and host. Nat Rev Micro. 2012 Sep;10(9):618-30.

20. Wang Z, Gerstein M, Snyder M. RNA-Seq: a revolutionary tool for transcriptomics. Nat Rev Genet. 2009;10(1):57-63.

21. Martin JAJ, Wang ZZ. Next-generation transcriptome assembly. Nat Rev Genet. 2011 Sep 30;12(10):671-82.

22. Lasa I, Toledo-Arana A, Gingeras TR. An effort to make sense of antisense transcription in bacteria. RNA Biol. 2012 Aug;9(8):1039-44.

23. Brantl S. Regulatory mechanisms employed by cis-encoded antisense RNAs. Current Opinion in Microbiology. 2007 Apr;10(2):102-9.

24. Sharma CM, Hoffmann S, Darfeuille F, Reignier J, Findeiss S, Sittka A, et al. The primary transcriptome of the major human pathogen Helicobacter pylori. Nature. 2010 Mar 11;464(7286):250-5.

25. Filiatrault MJ, Stodghill PV, Bronstein PA, Moll S, Lindeberg M, Grills G, et al. Transcriptome Analysis of Pseudomonas syringae Identifies New Genes, Noncoding RNAs, and Antisense Activity. Journal of Bacteriology. 2010 May 1;192(9):2359-72.

26. Guell M, Van Noort V, Yus E, Chen W-H, Leigh-Bell J, Michalodimitrakis K, et al. Transcriptome Complexity in a Genome-Reduced Bacterium. Science. 2009 Nov 27;326(5957):1268-71.

27. Dornenburg JE, DeVita AM, Palumbo MJ, Wade JT. Widespread antisense transcription in Escherichia coli. mBio. 2010 Apr;1(1).

28. Albrecht M, Sharma CM, Reinhardt R, Vogel J, Rudel T. Deep sequencing-based discovery of the Chlamydia trachomatis transcriptome. Nucleic Acids Research. 2010 Jan;38(3):868-77.

29. Lasa I, Toledo-Arana A, Dobin A, Villanueva M, de los Mozos IR, Vergara-Irigaray $\mathrm{M}$, et al. Genome-wide antisense transcription drives mRNA processing in bacteria. Proc Natl Acad Sci USA. 2011 Dec 13;108(50):20172-7.

30. Rasmussen $\mathrm{S}$, Nielsen HB, Jarmer $\mathrm{H}$. The transcriptionally active regions in the genome of Bacillus subtilis. Molecular Microbiology. Wiley Online Library; 2009;73(6):1043-57.

31. Parkhomchuk DD, Borodina TT, Amstislavskiy VV, Banaru MM, Hallen LL, Krobitsch SS, et al. Transcriptome analysis by strand-specific sequencing of complementary DNA. Nucleic Acids Research. 2009 Sep 30;37(18):e123-3.

32. Gómez-Lozano M, Marvig RL, Molin S, Long KS. Genome-wide identification of novel small RNAs in Pseudomonas aeruginosa. Environmental Microbiology. 2012 Aug;14(8):2006-16. 
33. Stougaard $\mathrm{P}$, Molin S, Nordström K. RNAs involved in copy-number control and incompatibility of plasmid R1. Proceedings of the National Academy of Sciences. 1981 Oct;78(10):6008-12.

34. Tomizawa J, Itoh T, Selzer G, Som T. Inhibition of ColE1 RNA primer formation by a plasmid-specified small RNA. Proceedings of the National Academy of Sciences. 1981 Mar;78(3):1421-5.

35. Lee RC, Feinbaum RL, Ambros V. The C. elegans heterochronic gene lin-4 encodes small RNAs with antisense complementarity to lin-14. Cell. 1993 Dec 3;75(5):84354.

36. Ambros V. MicroRNAs and developmental timing. Current opinion in genetics \& development. 2011 Aug;21(4):511-7.

37. Ambros V. The functions of animal microRNAs. Nature. Nature Publishing Group; 2004 Sep 16;431(7006):350-5.

38. Gottesman S, Storz G. Bacterial small RNA regulators: versatile roles and rapidly evolving variations. Cold Spring Harb Perspect Biol. 2011 Dec;3(12):a00379.

39. Repoila F, Darfeuille F. Small regulatory non-coding RNAs in bacteria: physiology and mechanistic aspects. Biology of the Cell. 2009;101:117-31.

40. Breaker RR. Prospects for riboswitch discovery and analysis. Molecular Cell. 2011 Sep 16;43(6):867-79.

41. Karginov FV, Hannon GJ. The CRISPR System: Small RNA-Guided Defense in Bacteria and Archaea. Molecular Cell. Elsevier Ltd; 2010 Jan 15;37(1):7-19.

42. Vanderpool CK, Balasubramanian D, Lloyd CR. Dual-function RNA regulators in bacteria. Biochimie. 2011 Nov;93(11):1943-9.

43. Holmqvist E. Macromolecular Matchmaking: Mechanisms and Biology of Bacterial Small RNAs. Digital Comprehensive Summaries of Uppsala Dissertations from the Faculty of Science and technology. 2012 Apr 3;:916.

44. Mizuno T, Chou MY, Inouye M. A unique mechanism regulating gene expression: translational inhibition by a complementary RNA transcript (micRNA). Proceedings of the National Academy of Sciences. 1984 Apr;81(7):1966-70.

45. Sharma CM, Darfeuille F, Plantinga TH, Vogel J. A small RNA regulates multiple $A B C$ transporter mRNAs by targeting C/A-rich elements inside and upstream of ribosome-binding sites. Genes \& development. 2007 Nov 1;21(21):2804-17.

46. Večerek B, Moll I, Bläsi U. Control of Fur synthesis by the non-coding RNA RyhB and iron-responsive decoding. EMBO J. 2007 Feb 1;26(4):965-75.

47. Sonnleitner E, Gonzalez N, Sorger-Domenigg T, Heeb S, Richter AS, Backofen R, et al. The small RNA PhrS stimulates synthesis of the Pseudomonas aeruginosa quinolone signal. Molecular Microbiology. 2011 May;80(4):868-85.

48. Urban JH, Vogel J. Two seemingly homologous noncoding RNAs act hierarchically to activate glmS mRNA translation. PLoS Biol. 2008 Mar 18;6(3):e64.

49. Hammer BK, Bassler BL. Regulatory small RNAs circumvent the conventional quorum sensing pathway in pandemic Vibrio cholerae. Proceedings of the National Academy of Sciences. 2007 Jul 3;104(27):11145-9. 
50. Carpousis AJ, Luisi BF, McDowall KJ. Endonucleolytic Initiation of mRNA Decay in Escherichia coli. Progress in Molecular Biology and Translational Science. Progress in Molecular Biology and Translational Science; 2009. pp. 91-135.

51. Celesnik H, Deana A, Belasco JG. Initiation of RNA Decay in Escherichia coli by $5^{\prime}$ Pyrophosphate Removal. Molecular Cell. Elsevier; 2007;27(1):79-90.

52. Obana N, Shirahama Y, Abe K, Nakamura K. Stabilization of Clostridium perfringens collagenase mRNA by VR-RNA-dependent cleavage in $5^{\prime}$ leader sequence. Molecular Microbiology. 2010 Sep;77(6):1416-28.

53. Ramirez-Peña E, Treviño J, Liu Z, Perez N, Sumby P. The group A Streptococcus small regulatory RNA FasX enhances streptokinase activity by increasing the stability of the ska mRNA transcript. Molecular Microbiology. 2010 Dec;78(6):133247.

54. Kawamoto $\mathrm{H}$, Koide $\mathrm{Y}$, Morita $\mathrm{T}$, Aiba $\mathrm{H}$. Base-pairing requirement for RNA silencing by a bacterial small RNA and acceleration of duplex formation by Hfq. Molecular Microbiology. 2006 Aug;61(4):1013-22.

55. Vogel J, Ben F Luisi. Hfq and its constellation of RNA. Nat Rev Micro. Nature Publishing Group; 2011 Aug 1;9(8):578-89.

56. Hopkins JF, Panja S, Woodson SA. Rapid binding and release of Hfq from ternary complexes during RNA annealing. Nucleic Acids Research. 2011 Jul;39(12):5193202.

57. Hwang W, Arluison V, Hohng S. Dynamic competition of DsrA and rpoS fragments for the proximal binding site of $\mathrm{Hfq}$ as a means for efficient annealing. Nucleic Acids Research. 2011 Jul;39(12):5131-9.

58. Soper T, Mandin P, Majdalani N, Gottesman S, Woodson SA. Positive regulation by small RNAs and the role of Hfq. Proc Natl Acad Sci USA. 2010 May 25;107(21):9602-7.

59. Maki K, Morita T, Otaka H, Aiba H. A minimal base-pairing region of a bacterial small RNA SgrS required for translational repression of ptsG mRNA. Molecular Microbiology. 2010 May;76(3):782-92.

60. Sonnleitner E, Sorger-Domenigg T, Madej MJ, Findeiss S, Hackermüller J, Hüttenhofer A, et al. Detection of small RNAs in Pseudomonas aeruginosa by RNomics and structure-based bioinformatic tools. Microbiology (Reading, Engl). 2008 Oct;154(Pt 10):3175-87.

61. Christiansen JK, Nielsen JS, Ebersbach T, Valentin-Hansen P, Sogaard-Andersen $\mathrm{L}$, Kallipolitis $\mathrm{BH}$. Identification of small Hfq-binding RNAs in Listeria monocytogenes. RNA. 2006 Jul;12(7):1383-96.

62. Wassarman KM, Repoila F, Rosenow C, Storz G, Gottesman S. Identification of novel small RNAs using comparative genomics and microarrays. Genes \& development. 2001 Jul 1;15(13):1637-51.

63. Zhang A, Wassarman KM, Rosenow C, Tjaden BC, Storz G, Gottesman S. Global analysis of small RNA and mRNA targets of Hfq. Molecular Microbiology. 2003 Nov;50(4):1111-24.

64. Chaulk SG, Smith Frieday MN, Arthur DC, Culham DE, Edwards RA, Soo P, et al. ProQ is an RNA chaperone that controls ProP levels in Escherichia coli. Biochemistry. 2011 Apr 19;50(15):3095-106. 
65. Pandey SP, Minesinger BK, Kumar J, Walker GC. A highly conserved protein of unknown function in Sinorhizobium meliloti affects sRNA regulation similar to Hfq. Nucleic Acids Research. 2011 Jun;39(11):4691-708.

66. Thomason MK, Storz G. Bacterial Antisense RNAs: How Many Are There, and What Are They Doing? *. Annu Rev Genet. 2010 Dec;44(1):167-88.

67. Callen BP, Shearwin KE, Egan JB. Transcriptional Interference between Convergent Promoters Caused by Elongation over the Promoter. Molecular Cell. 2004 Jun 3;14(5):10-0.

68. Blomberg PP, Wagner EGE, Nordström KK. Control of replication of plasmid R1: the duplex between the antisense RNA, CopA, and its target, CopT, is processed specifically in vivo and in vitro by RNase III. EMBO J. 1990 Jun 30;9(7):2331-40.

69. Gerdes KK, Nielsen AA, Thorsted PP, Wagner EGE. Mechanism of killer gene activation. Antisense RNA-dependent RNase III cleavage ensures rapid turn-over of the stable hok, srnB and pndA effector messenger RNAs. Journal of Molecular Biology. 1992 Aug 4;226(3):637-49.

70. Lee E-J, Groisman EA. An antisense RNA that governs the expression kinetics of a multifunctional virulence gene. Molecular Microbiology. 2010 May;76(4):1020-33.

71. Silby MW, Levy SB. Overlapping protein-encoding genes in Pseudomonas fluorescens Pf0-1. PLoS Genet. 2008 Jun;4(6):e1000094.

72. Sayed N, Jousselin A, Felden B. A cis-antisense RNA acts in trans in Staphylococcus aureus to control translation of a human cytolytic peptide. Nat Struct Mol Biol. 2012 Jan;19(1):105-12.

73. Arnvig KB, Young DB. Identification of small RNAs in Mycobacterium tuberculosis. Molecular Microbiology. 2009 Aug;73(3):397-408.

74. Mandin $\mathrm{P}$, Gottesman S. Integrating anaerobic/aerobic sensing and the general stress response through the ArcZ small RNA. EMBO J. 2010 Sep 15;29(18):3094107.

75. Papenfort K, Said N, Welsink T, Lucchini S, Hinton JCD, Vogel J. Specific and pleiotropic patterns of mRNA regulation by ArcZ, a conserved, Hfq-dependent small RNA. Molecular Microbiology. 2009 Oct;74(1):139-58.

76. Mandin P, Repoila F, Vergassola M, Geissmann T, Cossart P. Identification of new noncoding RNAs in Listeria monocytogenes and prediction of mRNA targets. Nucleic Acids Research. 2007;35(3):962-74.

77. Babitzke P, Romeo T. CsrB sRNA family: sequestration of RNA-binding regulatory proteins. Current Opinion in Microbiology. 2007 Apr;10(2):156-63.

78. Sonnleitner E, Abdou L, Haas D. Small RNA as global regulator of carbon catabolite repression in Pseudomonas aeruginosa. Proc Natl Acad Sci USA. 2009 Dec 22;106(51):21866-71.

79. Wassarman KM. 6S RNA: a regulator of transcription. Molecular Microbiology. 2007 Sep;65(6):1425-31.

80. Neusser T, Polen T, Geissen R, Wagner R. Depletion of the non-coding regulatory 6S RNA in E. coli causes a surprising reduction in the expression of the translation machinery. BMC Genomics. 2010;11:165.

81. Storz G, Vogel J, Wassarman KM. Regulation by small RNAs in bacteria: expanding 
frontiers. Molecular Cell. 2011 Sep 16;43(6):880-91.

82. Vogel J, Sharma CM. How to find small non-coding RNAs in bacteria. Biol Chem. 2005 Dec;386(12):1219-38.

83. Pánek J, Bobek J, Mikulík K, Basler M, Vohradský J. Biocomputational prediction of small non-coding RNAs in Streptomyces. BMC Genomics. 2008;9:217.

84. Xiao B, Li W, Guo G, Li B, Liu Z, Jia K, et al. Identification of small noncoding RNAs in Helicobacter pylori by a bioinformatics-based approach. Current microbiology. 2009 Mar;58(3):258-63.

85. Livny J, Brencic A, Lory S, Waldor M. Identification of 17 Pseudomonas aeruginosa sRNAs and prediction of SRNA-encoding genes in 10 diverse pathogens using the bioinformatic tool sRNAPredict2. Nucleic Acids Research. 2006;34(12):3484.

86. Gonzalez N, Heeb S, Valverde C, Kay E, Reimmann C, Junier T, et al. Genomewide search reveals a novel GacA-regulated small RNA in Pseudomonas species. BMC Genomics. 2008;9:167.

87. Wassarman KM, Zhang A, Storz G. Small RNAs in Escherichia coli. Trends in Microbiology. 1999 Jan;7(1):37-45.

88. Argaman L, Hershberg R, Vogel J, Bejerano G, Wagner E, Margalit H, et al. Novel small RNA-encoding genes in the intergenic regions of Escherichia coli. Current Biology. 2001;11(12):941-50.

89. Rivas E, Klein RJ, Jones TA, Eddy SR. Computational identification of noncoding RNAs in E. coli by comparative genomics. Curr Biol. 2001 Sep 4;11(17):1369-73.

90. Altuvia S. Identification of bacterial small non-coding RNAs: experimental approaches. Current Opinion in Microbiology. 2007;10(3):257-61.

91. Liu JM, Livny J, Lawrence MS, Kimball MD, Waldor MK, Camilli A. Experimental discovery of sRNAs in Vibrio cholerae by direct cloning, 5S/tRNA depletion and parallel sequencing. Nucleic Acids Research. 2009 Apr 1;37(6):e46.

92. Irnov I, Sharma CM, Vogel J, Winkler WC. Identification of regulatory RNAs in Bacillus subtilis. Nucleic Acids Research. 2010 Oct;38(19):6637-51.

93. Weissenmayer BA, Prendergast JGD, Lohan AJ, Loftus BJ. Sequencing Illustrates the Transcriptional Response of Legionella pneumophila during Infection and Identifies Seventy Novel Small Non-Coding RNAs. PLoS ONE. 2011 Mar 3;6(3):e17570.

94. Oliver HF, Orsi RH, Ponnala L, Keich U, Wang W, Sun Q, et al. Deep RNA sequencing of $\mathrm{L}$. monocytogenes reveals overlapping and extensive stationary phase and sigma B-dependent transcriptomes, including multiple highly transcribed noncoding RNAs. BMC Genomics. 2009;10:641.

95. Mraheil MA, Billion A, Mohamed W, Mukherjee K, Kuenne C, Pischimarov J, et al. The intracellular sRNA transcriptome of Listeria monocytogenes during growth in macrophages. Nucleic Acids Research. 2011 May;39(10):4235-48.

96. Sittka A, Lucchini S, Papenfort K, Sharma CM, Rolle K, Binnewies TT, et al. Deep Sequencing Analysis of Small Noncoding RNA and mRNA Targets of the Global Post-Transcriptional Regulator, Hfq. PLoS Genet. 2008 Aug 22;4(8):e1000163.

97. Perkins TT, Kingsley RA, Fookes MC, Gardner PP, James KD, Yu L, et al. A StrandSpecific RNA-Seq Analysis of the Transcriptome of the Typhoid Bacillus Salmonella 
Typhi. PLoS Genet. 2009 Jul 17;5(7):e1000569.

98. Kröger C, Dillon SC, Cameron ADS, Papenfort K, Sivasankaran SK, Hokamp K, et al. The transcriptional landscape and small RNAs of Salmonella enterica serovar Typhimurium. Proc Natl Acad Sci USA. 2012 May 15;109(20):E1277-86.

99. Vockenhuber M-P, Sharma CM, Statt MG, Schmidt D, Xu Z, Dietrich S, et al. Deep sequencing-based identification of small non-coding RNAs in Streptomyces coelicolor. RNA Biol. 2011 May 1;8(3).

100. Mitschke J, Georg J, Scholz I, Sharma CM, Dienst D, Bantscheff J, et al. An experimentally anchored map of transcriptional start sites in the model cyanobacterium Synechocystis sp. PCC6803. Proc Natl Acad Sci USA. 2011 Feb 1;108(5):2124-9.

101. Bradley ES, Bodi K, Ismail AM, Camilli A. A Genome-Wide Approach to Discovery of Small RNAs Involved in Regulation of Virulence in Vibrio cholerae. PLoS Pathog. 2011 Jul 14;7(7):e1002126.

102. Koo JT, Alleyne TM, Schiano CA, Jafari N, Lathem WW. Global discovery of small RNAs in Yersinia pseudotuberculosis identifies Yersinia-specific small, noncoding RNAs required for virulence. Proc Natl Acad Sci USA. 2011 Aug 29.

103. Raghavan R, Groisman EA, Ochman H. Genome-wide detection of novel regulatory RNAs in E. coli. Genome Research. 2011 Sep;21(9):1487-97.

104. Shinhara A, Matsui M, Hiraoka K, Nomura W, Hirano R, Nakahigashi K, et al. Deep sequencing reveals as-yet-undiscovered small RNAs in Escherichia coli. BMC Genomics. 2011 Aug 24;12(1):428.

105. Arnvig KB, Comas I, Thomson NR, Houghton J, Boshoff HI, Croucher NJ, et al. Sequence-based analysis uncovers an abundance of non-coding RNA in the total transcriptome of Mycobacterium tuberculosis. PLoS Pathog. 2011 Nov;7(11):e1002342.

106. Wilms I, Overlöper A, Nowrousian M, Sharma CM, Narberhaus F. Deep sequencing uncovers numerous small RNAs on all four replicons of the plant pathogen Agrobacterium tumefaciens. RNA Biol. 2012 Apr;9(4):446-57.

107. Karpinets TV, Greenwood DJ, Sams CE, Ammons JT. RNA:protein ratio of the unicellular organism as a characteristic of phosphorous and nitrogen stoichiometry and of the cellular requirement of ribosomes for protein synthesis. BMC Biol. 2006;4:30.

108. Zhao J, Hyman L, Moore C. Formation of mRNA 3' ends in eukaryotes: mechanism, regulation, and interrelationships with other steps in mRNA synthesis. Microbiology and Molecular Biology Reviews. 1999 Jun;63(2):405-45.

109. Urich T, Lanzén A, Qi J, Huson DH, Schleper C, Schuster SC. Simultaneous assessment of soil microbial community structure and function through analysis of the meta-transcriptome. PLoS ONE. 2008;3(6):e2527.

110. Passalacqua KD, Varadarajan A, Ondov BD, Okou DT, Zwick ME, Bergman NH. Structure and complexity of a bacterial transcriptome. Journal of Bacteriology. 2009 May;191(10):3203-11.

111. Yoder-Himes DR, Chain PSG, Zhu Y, Wurtzel O, Rubin EM, Tiedje JM, et al. Mapping the Burkholderia cenocepacia niche response via high-throughput sequencing. Proc Natl Acad Sci USA. 2009 Mar 10;106(10):3976-81. 
112. He S, Wurtzel O, Singh K, Froula JL, Yilmaz S, Tringe SG, et al. Validation of two ribosomal RNA removal methods for microbial metatranscriptomics. Nat Meth. 2010 Oct:7(10):807-12.

113. Sorek R, Cossart P. Prokaryotic transcriptomics: a new view on regulation, physiology and pathogenicity. Nat Rev Genet. 2010;11(1):9-16.

114. Brennan AL, Geddes DM. Cystic fibrosis. Curr Opin Infect Dis. 2002 Apr;15(2):17582.

115. Stover CKC, Pham XQX, Erwin ALA, Mizoguchi SDS, Warrener PP, Hickey MJM, et al. Complete genome sequence of Pseudomonas aeruginosa PAO1, an opportunistic pathogen. Nature. 2000 Aug 30;406(6799):959-64.

116. Sonnleitner E, González N, Haas D. Small RNAs of Pseudomonas spp. Pseudomonas. 2010;:3-28.

117. Hancock REW, Speert DP. Antibiotic resistance in Pseudomonas aeruginosa: mechanisms and impact on treatment. Drug Resist Updat. 2000 Aug;3(4):247-55.

118. Saiman L, Marshall BC, Mayer-Hamblett N, Burns JL, Quittner AL, Cibene DA, et al. Azithromycin in patients with cystic fibrosis chronically infected with Pseudomonas aeruginosa: a randomized controlled trial. JAMA. 2003 Oct 1;290(13):1749-56.

119. Doring G, Conway SP, Heijerman HG, Hodson ME, Hoiby N, Smyth A, et al. Antibiotic therapy against Pseudomonas aeruginosa in cystic fibrosis: a European consensus. 2000. pp. 749-67.

120. Aronoff SC, Klinger JD. In vitro activities of aztreonam, piperacillin, and ticarcillin combined with amikacin against amikacin-resistant Pseudomonas aeruginosa and $P$. cepacia isolates from children with cystic fibrosis. Antimicrobial agents and chemotherapy. Am Soc Microbiol; 1984;25(2):279-80.

121. Szaff M, Hoiby N, Flensborg EW. Frequent antibiotic therapy improves survival of cystic fibrosis patients with chronic Pseudomonas aeruginosa infection. Acta Paediatr Scand. 1983 Sep;72(5):651-7.

122. Høiby N. Recent advances in the treatment of Pseudomonas aeruginosa infections in cystic fibrosis. BMC Medicine. BioMed Central Ltd; 2011 Apr 4;9(1):32.

123. Poole K. Bacterial multidrug efflux pumps serve other functions. Microbe-American Society For Microbiology. ASM PRESS; 2008;3(4):179.

124. Livermore D. Beta-lactamases in laboratory and clinical resistance. Clinical Microbiology Reviews. 1995;8(4):557.

125. Ernst R, Yi E, Guo L, Lim K, Burns J, Hackett M, et al. Specific lipopolysaccharide found in cystic fibrosis airway Pseudomonas aeruginosa. Science. 1999;286(5444):1561.

126. Fuqua WC, Winans SC, Greenberg EP. Quorum sensing in bacteria: the LuxR-LuxI family of cell density-responsive transcriptional regulators. Journal of Bacteriology. 1994 Jan;176(2):269-75.

127. Gambello MJ, Iglewski BH. Cloning and characterization of the Pseudomonas aeruginosa lasR gene, a transcriptional activator of elastase expression. Journal of Bacteriology. 1991 May;173(9):3000-9.

128. Ochsner UA, Koch AK, Fiechter A, Reiser J. Isolation and characterization of a regulatory gene affecting rhamnolipid biosurfactant synthesis in Pseudomonas 
aeruginosa. Journal of Bacteriology. 1994 Apr;176(7):2044-54.

129. Ochsner UA, Reiser J. Autoinducer-mediated regulation of rhamnolipid biosurfactant synthesis in Pseudomonas aeruginosa. Proceedings of the National Academy of Sciences. 1995 Jul 3;92(14):6424-8.

130. Pearson JP, Gray KM, Passador L, Tucker KD, Eberhard A, Iglewski BH, et al. Structure of the autoinducer required for expression of Pseudomonas aeruginosa virulence genes. Proceedings of the National Academy of Sciences. 1994 Jan 4;91(1):197-201.

131. Pearson JP, Passador L, Iglewski BH, Greenberg EP. A second N-acylhomoserine lactone signal produced by Pseudomonas aeruginosa. Proceedings of the National Academy of Sciences. 1995 Feb 28;92(5):1490-4.

132. Schuster M, Lostroh CP, Ogi T, Greenberg EP. Identification, timing, and signal specificity of Pseudomonas aeruginosa quorum-controlled genes: a transcriptome analysis. Journal of Bacteriology. 2003 Apr;185(7):2066-79.

133. Wagner VE, Bushnell D, Passador L, Brooks Al, Iglewski BH. Microarray analysis of Pseudomonas aeruginosa quorum-sensing regulons: effects of growth phase and environment. Journal of Bacteriology. 2003 Apr;185(7):2080-95.

134. Whiteley M, Lee KM, Greenberg EP. Identification of genes controlled by quorum sensing in Pseudomonas aeruginosa. Proceedings of the National Academy of Sciences. 1999 Nov 23;96(24):13904-9.

135. Pesci EC, Milbank JB, Pearson JP, McKnight S, Kende AS, Greenberg EP, et al. Quinolone signaling in the cell-to-cell communication system of Pseudomonas aeruginosa. Proceedings of the National Academy of Sciences. 1999 Sep 28;96(20):11229-34.

136. Déziel E, Lepine F, Milot S, He J, Mindrinos MN, Tompkins RG, et al. Analysis of Pseudomonas aeruginosa 4-hydroxy-2-alkylquinolines (HAQs) reveals a role for 4hydroxy-2-heptylquinoline in cell-to-cell communication. Proceedings of the National Academy of Sciences. 2004 Feb 3;101(5):1339-44.

137. Cao HH, Krishnan GG, Goumnerov BB, Tsongalis JJ, Tompkins RR, Rahme LGL. A quorum sensing-associated virulence gene of Pseudomonas aeruginosa encodes a LysR-like transcription regulator with a unique self-regulatory mechanism. Proceedings of the National Academy of Sciences. 2001 Dec 3;98(25):14613-8.

138. Gallagher LA, McKnight SL, Kuznetsova MS, Pesci EC, Manoil C. Functions required for extracellular quinolone signaling by Pseudomonas aeruginosa. Journal of Bacteriology. 2002 Dec;184(23):6472-80.

139. Diggle SP, Winzer K, Chhabra SR, Worrall KE, Cámara M, Williams P. The Pseudomonas aeruginosa quinolone signal molecule overcomes the cell densitydependency of the quorum sensing hierarchy, regulates rhl-dependent genes at the onset of stationary phase and can be produced in the absence of LasR. Molecular Microbiology. 2003 Aug 11;50(1):29-43.

140. McKnight SL, Iglewski BH, Pesci EC. The Pseudomonas quinolone signal regulates rhl quorum sensing in Pseudomonas aeruginosa. Journal of Bacteriology. 2000 May;182(10):2702-8.

141. Collier DN, Anderson L, McKnight SL, Noah TL, Knowles M, Boucher R, et al. A bacterial cell to cell signal in the lungs of cystic fibrosis patients. FEMS Microbiology Letters. 2002 Sep 24;215(1):41-6. 
142. Lau GW, Ran H, Kong F, Hassett DJ, Mavrodi D. Pseudomonas aeruginosa pyocyanin is critical for lung infection in mice. Infection and immunity. 2004 Jul;72(7):4275-8.

143. Mahajan-Miklos S, Tan MW, Rahme LG, Ausubel FM. Molecular mechanisms of bacterial virulence elucidated using a Pseudomonas aeruginosa-Caenorhabditis elegans pathogenesis model. Cell. 1999 Jan 8;96(1):47-56.

144. Rahme LG, Tan MW, Le L, Wong SM, Tompkins RG, Calderwood SB, et al. Use of model plant hosts to identify Pseudomonas aeruginosa virulence factors. Proceedings of the National Academy of Sciences. 1997 Nov 25;94(24):13245-50.

145. Calfee MW, Shelton JG, McCubrey JA, Pesci EC. Solubility and bioactivity of the Pseudomonas quinolone signal are increased by a Pseudomonas aeruginosaproduced surfactant. Infection and immunity. 2005 Feb;73(2):878-82.

146. Wade DS, Calfee MW, Rocha ER, Ling EA, Engstrom E, Coleman JP, et al. Regulation of Pseudomonas quinolone signal synthesis in Pseudomonas aeruginosa. Journal of Bacteriology. 2005 Jul;187(13):4372-80.

147. Vogel DW, Hartmann RK, Struck JCR, Ulbrich N, Erdmann VA. The sequence of the 6S RNA gene of Pseudomonas aeruginosa. Nucleic Acids Research. 1987;15(11):4583-91.

148. Toschka HY, Struck JC, Erdmann VA. The 4.5S RNA gene from Pseudomonas aeruginosa. Nucleic Acids Research. 1989 Jan 11;17(1):31-6.

149. Wilderman PJ, Sowa NA, FitzGerald DJ, FitzGerald PC, Gottesman S, Ochsner UA, et al. Identification of tandem duplicate regulatory small RNAs in Pseudomonas aeruginosa involved in iron homeostasis. Proc Natl Acad Sci USA. 2004 Jun 29;101(26):9792-7.

150. Brencic A, McFarland KA, McManus HR. The GacS/GacA signal transduction system of Pseudomonas aeruginosaacts exclusively through its control over the transcription of the RsmY and RsmZ regulatory small RNAs. Molecular Microbiology. 2009 Aug;73(3):434-45.

151. Oglesby-Sherrouse A, Vasil M. Characterization of a heme-regulated non-coding RNA encoded by the prrF locus of Pseudomonas aeruginosa. PLoS ONE. 2010;5(4):e9930.

152. Wenner N, Maes A, Cotado-Sampayo M, Lapouge K. NrsZ: a novel, processed, nitrogen-dependent small non-coding RNA that2 regulates Pseudomonas aeruginosa PAO1 virulence. Environmental Microbiology. 2013;:Availableonlineaheadofprint.

153. DArgenio DA, Calfee MW, Rainey PB, Pesci EC. Autolysis and autoaggregation in Pseudomonas aeruginosa colony morphology mutants. Journal of Bacteriology. 2002 Dec;184(23):6481-9.

154. Price-Whelan A, Dietrich LEP, Newman DK. Rethinking "secondary" metabolism: physiological roles for phenazine antibiotics. Nat Chem Biol. 2006 Feb;2(2):71-8.

155. Gómez-Lozano M, Molin S. Small RNA OsiS links oxidative stress to quorum sensing control in. Manuscript in preparation. 2013 Sep 6;:1-17.

156. Sonnleitner E, Romeo A, Bläsi U. Small regulatory RNAs in Pseudomonas aeruginosa. RNA Biol. 2012 Apr;9(4):364-71.

157. Ferrara S, Brugnoli M, De Bonis A, Righetti F, Delvillani F, Dehò G, et al. 
Comparative Profiling of Pseudomonas aeruginosa Strains Reveals Differential Expression of Novel Unique and Conserved Small RNAs. PLoS ONE. 2012;7(5):e36553.

158. Wurtzel O, Yoder-Himes DR, Han K, Dandekar AA, Edelheit S, Greenberg EP, et al. The single-nucleotide resolution transcriptome of Pseudomonas aeruginosa grown in body temperature. PLoS Pathog. 2012 Sep;8(9):e1002945.

159. Altuvia S, Weinstein-Fischer D, Zhang A, Postow L, Storz G. A small, stable RNA induced by oxidative stress: role as a pleiotropic regulator and antimutator. Cell. 1997 Jul 11;90(1):43-53.

160. Boysen A, Møller-Jensen J, Kallipolitis B, Valentin-Hansen P, Overgaard M. Translational regulation of gene expression by an anaerobically induced small noncoding RNA in Escherichia coli. J Biol Chem. 2010 Apr 2;285(14):10690-702.

161. Durand S, Storz G. Reprogramming of anaerobic metabolism by the FnrS small RNA. Molecular Microbiology. Wiley Online Library; 2010;75(5):1215-31.

162. Chou JH, Greenberg JT, Demple B. Posttranscriptional repression of Escherichia coli OmpF protein in response to redox stress: positive control of the micF antisense RNA by the soxRS locus. Journal of Bacteriology. 1993 Feb;175(4):1026-31.

163. Marvig RL, Johansen HK, Molin S, Jelsbak L. Genome Analysis of a Transmissible Lineage of Pseudomonas aeruginosa Reveals Pathoadaptive Mutations and Distinct Evolutionary Paths of Hypermutators. PLoS Genet. 2013 Sep;9(9):e1003741.

164. Barrick JE, Yu DS, Yoon SH, Jeong H, Oh TK, Schneider D, et al. Genome evolution and adaptation in a long-term experiment with Escherichia coli. Nature. 2009 Oct 28;461(7268):1243-7.

165. Yu Y-TN, Yuan X, Velicer GJ. Adaptive evolution of an sRNA that controls Myxococcus development. Science. 2010 May 21;328(5981):993.

166. Beisel CL, Storz G. Base pairing small RNAs and their roles in global regulatory networks. FEMS Microbiology Reviews. Wiley Online Library; 2010;34(5):866-82.

167. Levine EE, Zhang ZZ, Kuhlman TT, Hwa TT. Quantitative characteristics of gene regulation by small RNA. Audio, Transactions of the IRE Professional Group on. 2007 Aug 31;5(9):e229-9.

168. Hobbs ECE, Astarita JLJ, Storz GG. Small RNAs and small proteins involved in resistance to cell envelope stress and acid shock in Escherichia coli: analysis of a bar-coded mutant collection. Audio, Transactions of the IRE Professional Group on. 2009 Dec 31;192(1):59-67.

169. Massé E, Vanderpool CK, Gottesman S. Effect of RyhB small RNA on global iron use in Escherichia coli. Journal of Bacteriology. Am Soc Microbiol; 2005;187(20):6962-71.

170. Papenfort K, Pfeiffer V, Lucchini S, Sonawane A, Hinton JCD, Vogel J. Systematic deletion of Salmonella small RNA genes identifies CyaR, a conserved CRPdependent riboregulator of OmpX synthesis. Molecular Microbiology. $2008 \mathrm{Apr}$ 30;68(4):890-906. 


\section{RESEARCH ARTICLES}

This section consists of the full-length research articles that were prepared as part of this $\mathrm{PhD}$ project. The articles are enclosed in the following order:

\section{Article 1}

Genome-wide identification of novel small RNAs in Pseudomonas aeruginosa.

Gómez-Lozano, M., Marvig, R. L., Molin, S., \& Long, K. S. (2012). Environmental Microbiology, 14(8), 2006-2016. doi:10.1111/j.1462-2920.2012.02759.x

\section{Article 2}

Identification of bacterial small RNAs by RNA sequencing.

Gómez-Lozano, M., Marvig, R. L., Molin, S., \& Long, K. S. (2013). Methods in Pseudomonas aeruginosa. Accepted for publication.

\section{Article 3}

Antisense small RNAs respond to osmotic, oxidative and antibiotic stress in Pseudomonas aeruginosa.

Gómez-Lozano, M., Marvig, R. L., Tulstrup, M. V. L., Tribelli, P., \& Molin, S. (2013). Manuscript in preparation.

\section{Article 4}

Small RNA OsiS links oxidative stress to quorum sensing control in Pseudomonas aeruginosa.

Gómez-Lozano, M. \& Molin, S. (2013). Manuscript in preparation. 



\section{Article 1}

Genome-wide identification of novel small RNAs in Pseudomonas aeruginosa.

Gómez-Lozano, M., Marvig, R. L., Molin, S., \& Long, K. S.

Environmental Microbiology, 2012, 14(8), 2006-2016.

doi:10.1111/j.1462-2920.2012.02759.x 


\section{Genome-wide identification of novel small RNAs in Pseudomonas aeruginosa}

\author{
María Gómez-Lozano, ${ }^{1,2}$ Rasmus Lykke Marvig, ${ }^{1}$ \\ Søren Molin ${ }^{1,2}$ and Katherine S. Long ${ }^{1,2 *}$ \\ ${ }^{1}$ Department of Systems Biology, Technical University of \\ Denmark, Lyngby, Denmark. \\ ${ }^{2}$ Novo Nordisk Foundation Center for Biosustainability, \\ Technical University of Denmark, Hørsholm, Denmark.
}

\section{Summary}

Bacterial small regulatory RNAs (sRNAs) function in post-transcriptional control of gene expression and control a variety of processes including metabolic reactions, stress responses and pathogenesis in response to environmental signals. A variety of approaches have been used previously to identify 44 sRNAs in the opportunistic human pathogen Pseudomonas aeruginosa. In this work, RNA sequencing (RNA-seq) is used to identify novel transcripts in $P$. aeruginosa involving a combination of three different sequencing libraries. Almost all known sRNAs and over $\mathbf{5 0 0}$ novel intergenic sRNAs are identified with this approach. Although the use of three libraries increased the number of novel transcripts identified, there were significant differences in the subset of transcripts detected in each library, underscoring the importance of library preparation strategy and relative sRNA abundance for successful sRNA detection. Nearly $90 \%$ of the novel sRNAs have no orthologous bacterial sequences outside of $P$. aeruginosa, supporting a limited degree of sequence conservation and rapid evolution of SRNAs at the species level. We anticipate that the data will be useful for the study of regulatory SRNAs in bacteria and that the approach described here may be applied to identify sRNAs in any bacterium under different growth and stress conditions.

\section{Introduction}

Bacteria contain numerous small regulatory RNAs (sRNAs) ranging in size from 70 to 500 nucleotides (nt) that modulate gene expression (Waters and Storz, 2009; Gottesman and Storz, 2011). Most sRNAs function

Received 15 February, 2012; revised 27 March, 2012; accepted 30 March, 2012. *For correspondence. E-mail kalon@biosustain.dtu.dk; Tel. (+45) 452580 24; Fax (+45) 45258001 through base-pairing interactions with messenger RNA (mRNA) targets that can affect translation initiation, transcription termination or mRNA stability. Others function by binding to and altering the activity of proteins that regulate gene expression. Small RNAs are known to control diverse adaptation processes, where bacterial physiology is adjusted in response to environmental cues. There are examples of sRNAs that are involved in transcription reprogramming, carbon metabolism, iron homeostasis, cell envelope homeostasis and coordination of virulence (Repoila and Darfeuille, 2009). Although most current information on sRNA function is derived from Escherichia coli, progress is being made in the functional characterization of sRNAs in other bacteria (Papenfort and Vogel, 2010). In the important human pathogen Pseudomonas aeruginosa, there is knowledge on the roles of 12 out of the 44 sRNAs identified thus far, where four are classica sRNAs (6S, 4.5S, RNase P and tmRNAs) and the others function as regulators of primary and secondary metabolism (Sonnleitner and Haas, 2011).

A variety of approaches have been used to identify individual sRNAs in $P$. aeruginosa (reviewed in Sonnleitner et al., 2010) including those based on direct detection due to high abundance (Vogel et al., 1987), similarity with a known sRNA of E. coli (Toschka et al., 1989), computational predictions (Wilderman et al., 2004) and copurification with a protein (Sonnleitner et al., 2008). Three systematic searches for sRNAs have been undertaken in $P$. aeruginosa, where all have focused on intergenic regions. In two studies sRNAs were predicted on the basis of sequence conservation, as well as the presence of rho-independent terminators, putative promoters and conserved secondary structure. Although both studies used similar computational approaches followed by experimental verification by Northern blotting, two largely distinct sets of novel sRNAs were identified (Livny et al., 2006; González et al., 2008). A third study used a combined bioinformatics and RNomics approach, where total RNA was size-fractionated, co-immunoprecipitated with Hfq, cloned and sequenced (Sonnleitner et al., 2008).

Recent genome-wide studies to identify sRNAs have been largely based on tiling arrays and next-generation sequencing technologies. The latter approach, in particular, has revolutionized sRNA discovery by enabling interrogation of the transcriptome at unprecedented depths. Deep sequencing has revealed hundreds of previously 
undetected transcripts in diverse bacteria including Bacillus subtilis (Irnov et al., 2010), Chlamydia trachomatis (Albrecht et al., 2010), Helicobacter pylori (Sharma et al., 2010), Legionella pneumophila (Weissenmayer et al., 2011), Listeria monocytogenes (Oliver et al., 2009; Mraheil et al., 2011), Salmonella enterica (Sittka et al., 2008; Perkins et al., 2009), Streptomyces coelicolor (Vockenhuber et al., 2011), Synechocystis (Mitschke et al., 2011), Vibrio cholerae (Liu et al., 2009; Bradley et al., 2011) and Yersinia pseudotuberculosis (Koo et al., 2011). The detected transcripts derive from reads that map to both intergenic and coding regions, and in the sense and antisense directions relative to annotated genes. The many newly reported transcripts have uncovered new concepts on bacterial transcriptomes, including the presence of pervasive antisense transcription (Croucher and Thomson, 2010), but also raise issues of how to define sRNAs and the extent to which detected transcripts are functional (Storz et al., 2011).

The size and complexity of the $P$. aeruginosa genome suggests that it encodes many hitherto undetected sRNAs. In this study, we have used high-throughput cDNA sequencing (RNA-seq) to identify sRNAs in $P$. aeruginosa. RNA isolated from exponential and earlystationary phase cells was used to prepare three different types of libraries for sequencing. We find a total of over 500 novel intergenic sRNAs in the three libraries, where a different number of transcripts are detected in each library. As a significant number of unique sRNAs are detected in each library, the data suggest that the set of identified RNAs obtained depends strongly on the specific library preparation strategy used.

\section{Results and discussion}

\section{Experimental approach for global sRNA identification}

In order to optimize sRNA detection, three different types of sequencing libraries were generated using RNA isolated from $P$. aeruginosa grown to exponential and earlystationary phase in broth culture at $37^{\circ} \mathrm{C}$ (Fig. 1, Table 1). All steps including cell growth, RNA isolation and library preparation were performed in triplicate for each growth condition and sequenced using the Illumina HiSeq2000 platform. The sequencing libraries are named LIB $>100$, $\mathrm{LIB}<500$ and $\mathrm{LIB}<200$ to denote the transcript sizes in nucleotides that are not excluded from each, but do not imply that all transcripts in these size ranges are necessarily detected in the corresponding library. The LIB $>100$ library contains all mRNAs transcribed by the bacteria and was prepared using a standard RNA-seq protocol for full transcriptomes. This library does not contain sRNA transcripts shorter than $100 \mathrm{nt}$ because the corresponding cDNA fragments are not retained during the protocol. The $\mathrm{LIB}<500$ and $\mathrm{LIB}<200$ libraries were each prepared with size selection steps and contain transcripts shorter than 500 and $200 \mathrm{nt}$ respectively. These two libraries were prepared by ligating specific adapters to the $5^{\prime}$ and $3^{\prime}$ ends of the transcripts before cDNA synthesis, enabling retention of fragments corresponding to transcripts shorter than $100 \mathrm{nt}$. They are therefore strand-specific, where the information about the strand from which the sRNA is transcribed is retained. In addition, the RNA used to prepare the $L I B<500$ and $L I B<200$ libraries was treated with Tobacco Acid Pyrophosphatase to ensure the inclusion of primary transcripts containing a $5^{\prime}$-triphosphate. Although primary and processed transcripts are not distinguishable in these libraries, it is possible to modify the approach with additional libraries to obtain this information. The library preparation protocols also differ in terms of whether they include fragmentation steps. The protocols for preparation of the LIB $>100$ and $L I B<500$ libraries include fragmentation steps using divalent cations and RNase III respectively, whereas preparation of the LIB $<200$ library does not involve a fragmentation step due to the short lengths of the transcripts. Thus, library $\mathrm{LIB}<200$ does not have any biases associated with fragmentation.

On average, 16.7 million sequence reads were generated from each library, and of these 12.3 million were of sufficient quality to be mapped onto the $P$. aeruginosa PAO1 genome (Table S1). As ribosomal RNAs (rRNAs) account for the vast majority of total RNA in a bacterial cell (Karpinets et al., 2006), these RNAs were removed by subtractive hybridization to enrich samples for sRNAs. Although depletion of 165 and $23 \mathrm{~S}$ rRNAs using this approach is common (He et al., 2010), the 5S rRNA was also depleted in this work using a total of five oligonucleotides complementary to the $P$. aeruginosa rRNA sequences (Fig. S1, Table S2). The average percentage of read coverage corresponding to $23 \mathrm{~S}, 16 \mathrm{~S}$ and $5 \mathrm{~S}$ rRNAs was $7.1 \%, 3.8 \%$ and $0.15 \%$ (Table S1) respectively, indicating that the rRNA depletion procedure functioned satisfactorily in the case of $23 S$ and $16 S$ rRNAs and efficiently in the case of $5 S$ rRNA. A previous study used an oligonucleotide-directed RNase $\mathrm{H}$ digestion approach to deplete 5S rRNA and transfer RNAs (tRNAs), involving 4 and 25 oligonucleotides respectively (Liu et al., 2009). Although no attempt was made to deplete tRNAs in this work, the average percentage of read coverage corresponding to tRNAs was $2.7 \%$ (Table S1), indicating that these RNAs represent only a minor fraction of the total reads in non-depleted samples, and that their targeted removal is not necessary.

\section{Identification of previously annotated sRNAs}

Forty-four sRNAs have been identified previously in $P$. aeruginosa (reviewed in Sonnleitner and Haas, 2011) 
M. Gómez-Lozano, R. L. Marvig, S. Molin and K. S. Long

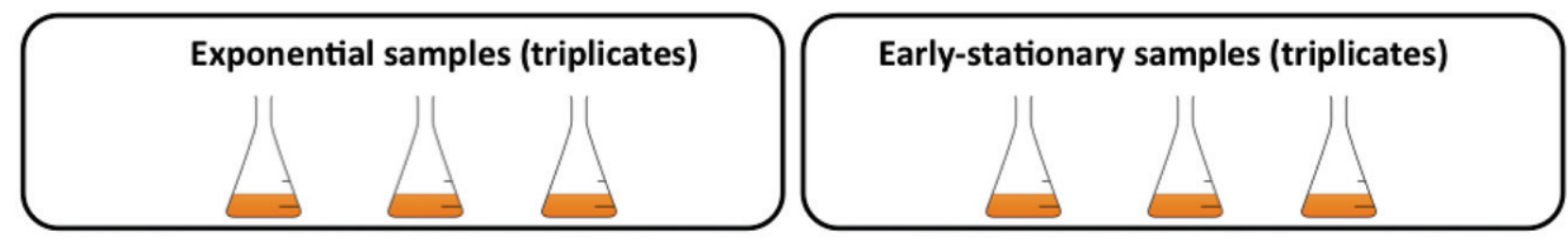

Total RNA Trizol extraction

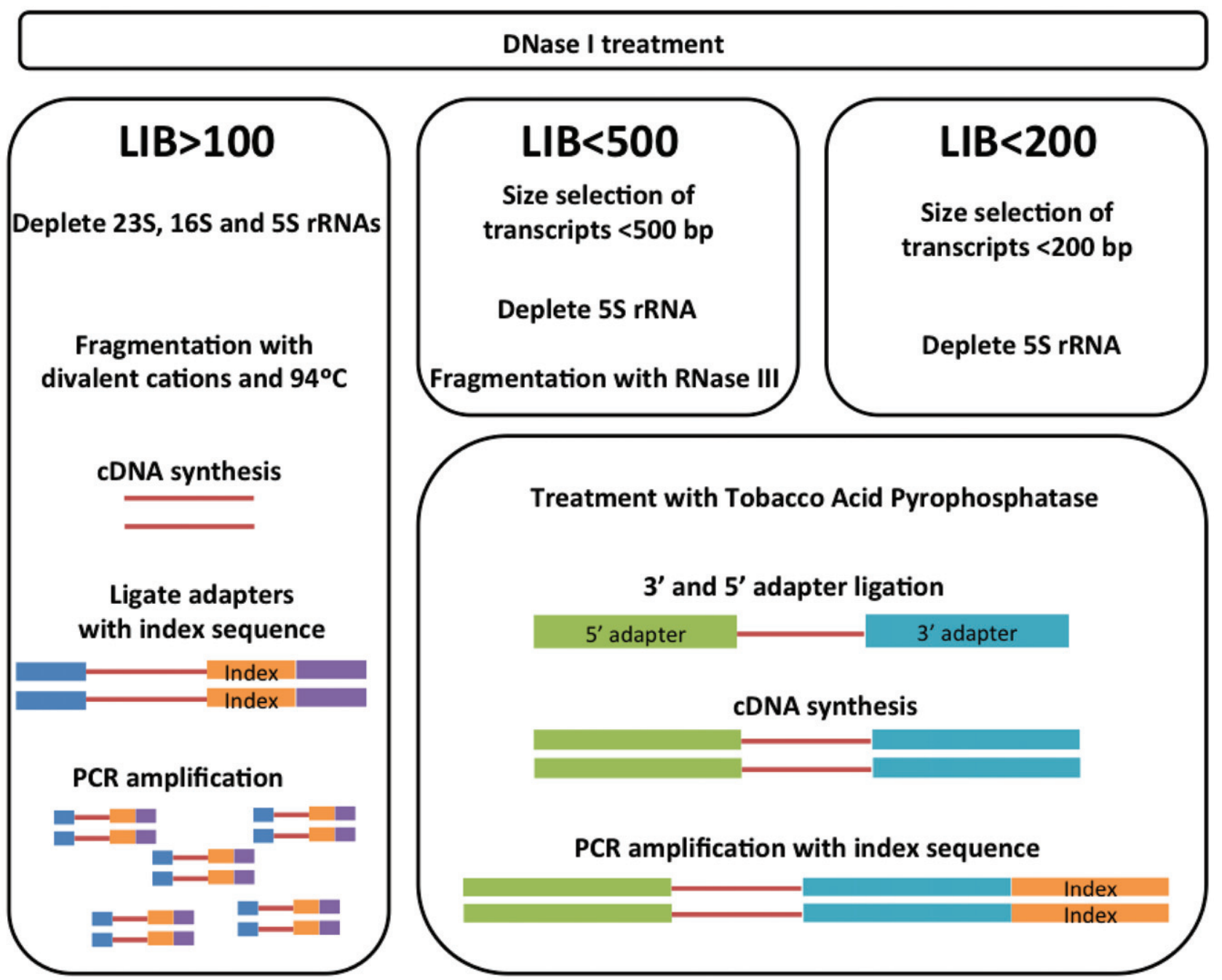

Multiplexed paired-end sequencing using Illumina's HiSeq2000
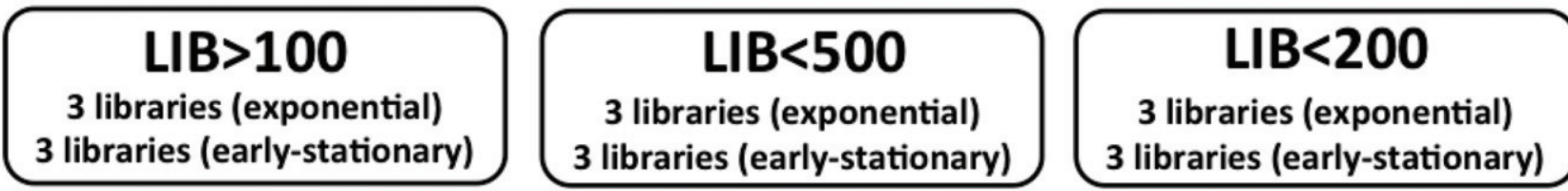

Fig. 1. Library preparation scheme. Three different sequencing libraries were generated ( $L I B>100$, $L I B<500$ and $L I B<200)$ using $R N A$ isolated from $P$. aeruginosa cells grown to exponential and early-stationary phase in broth culture at $37^{\circ} \mathrm{C}$. Each library was prepared using triplicates for each condition. 
Table 1. Library characteristics.

\begin{tabular}{|c|c|c|c|}
\hline & $\begin{array}{l}\text { Library } \\
\text { LIB }>100\end{array}$ & $\begin{array}{l}\text { Library } \\
\text { LIB }<500\end{array}$ & $\begin{array}{l}\text { Library } \\
\text { LIB }<200\end{array}$ \\
\hline $\begin{array}{l}\text { Length of transcripts sequenced } \\
\text { Fragmentation }\end{array}$ & $\begin{array}{l}>100 \mathrm{nt} \\
\text { Divalent } \\
\text { cations }\end{array}$ & $\begin{array}{l}<500 \mathrm{nt} \\
\text { RNase } \\
\quad \text { III }\end{array}$ & $\begin{array}{l}<200 \mathrm{nt} \\
\text { No }\end{array}$ \\
\hline Strand specificity retained & No & Yes & Yes \\
\hline
\end{tabular}

(Table S3). In order to test the accuracy and specificity of the sequencing approaches used here, the expression of the already identified sRNAs was inspected visually. All of the sRNAs except one could be visually identified in at least one of the three libraries. The sRNA that could not be identified, PA2744.1 (P13), was predicted and validated by Northern blotting in an earlier study, but the transcript length was unclear (Livny et al., 2006). The present data indicate that there is a $190 \mathrm{nt}$ sRNA encoded in the same intergenic region on the same strand as PA2744.1. This sRNA partially overlaps with PA2744.1, but the coordinates do not correspond to those predicted previously (Table S3). This suggests that the coordinates of PA2744.1 may be 3106752-3106942.

Visual inspection of RNA-Seq data is not convenient for a genome-wide search of novel transcripts, where a systematic and reproducible method must be used. We have developed a custom-made script designed to detect intergenic sRNAs (see Experimental procedures). We checked how many already known sRNAs our systematic script would detect. Of the 44 already reported sRNAs, four would not be identified by the script (P26, PA4451.1, P32, PA5316.1). The reason for this is that the peaks corresponding to these sRNAs do not start and/or terminate within an intergenic region and these are not detected by the script to prevent misclassification of untranslated regions (UTRs) as ncRNAs. The sRNAs detected in each library type using the script are shown in Fig. 2. A total of 20,34 and 36 sRNAs were detected in the $L I B>100, L I B<200$ and $L I B<500$ libraries respectively, where 18 were detected in all three libraries and 33 were detected in more than one library (Fig. 2). Thus, 39 out of 44 already annotated sRNAs could be detected in only two experimental conditions with the RNA-seq approach used here. The results, in particular those from the $\mathrm{LIB}<500$ and $\mathrm{LIB}<200$ libraries, are a validation of the sensitivity of RNA-seq at detecting sRNAs.

\section{Identification of novel intergenic sRNAs}

As the specific focus of this work was to identify novel intergenic sRNAs, a script was designed to analyse transcripts from all of the intergenic regions of $P$. aeruginosa PAO1 (see Experimental procedures). The script only detects transcripts that begin and end within an intergenic

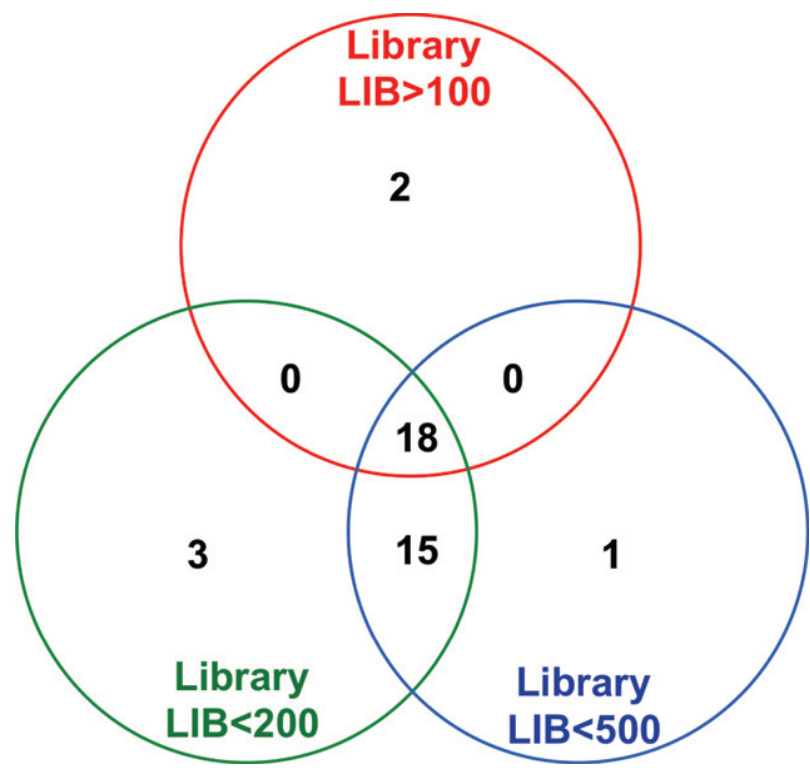

Fig. 2. Venn diagram summarizing the already annotated sRNAs detected in the three different libraries.

region in order to minimize misclassification of UTRs as sRNAs. A total of 513 novel sRNAs were identified by this approach and were named pant (for $P$. aeruginosa novel transcript) followed by an identification number (Table S4). The set of novel transcripts may include those corresponding to hitherto un-annotated genes and dualfunction sRNAs coding for small proteins. It is also possible that a subset of the RNAs identified here derive from 5' or 3' UTRs. However, this does not preclude that these RNAs are functionally important or could function as sRNAs, as there is precedence for cis-acting RNA elements functioning as trans-acting RNAs. This suggests that the regulatory function of a particular RNA sequence is context-dependent and the division between cis- and trans-acting RNAs is not always sharp. For instance, the fate of riboswitch RNAs that function by transcription termination is unknown, but evidence in the literature suggests that their stability and half-lives in the cell vary (reviewed in Bastet et al., 2011). A specific example is that of SAM riboswitches in L. monocytogenes that function as trans-acting sRNAs to regulate the expression of the virulence regulator PrfA (Loh et al., 2009).

The plethora of novel sRNAs identified in this work raises the issue of how many of these are functional and play regulatory roles in the cell. Determination of the fraction of functional transcripts requires the characterization and detailed analysis of each sRNA. Although functional assignment may be challenging and expression of some RNAs may only be induced under specific conditions, it is likely that the majority of novel transcripts represent functional SRNAs. New and unexpected functional roles for RNA are continuously being discovered. This includes 
RNAs that are relatively well understood, as recently in the case of mammalian tRNAs that, in addition to their well-known housekeeping roles in translation, can also function as regulators of gene expression (RudingerThirion et al., 2011).

Although many novel transcripts are identified, not all transcripts are detected in all three libraries and there are significant differences in the set of transcripts detected in each library. A total of 63,415 and 412 novel transcripts are detected in the $\mathrm{LIB}>100, \mathrm{LIB}<500$ and $\mathrm{LIB}<200$ libraries respectively, indicating that significantly more transcripts are detected in the latter two libraries compared with the first (Fig. 3A). This is consistent with the fact that the LIB $>100$ library contains the full transcriptome, and hence a lower relative percentage of sRNAs compared with the other libraries. The lengths of the detected sRNAs range from 70 to $1117 \mathrm{nt}$ with an average length of $188 \mathrm{nt}$. The length distribution of detected sRNAs in each library is shown in Fig. 3B. The lengths of the sRNAs detected in the $\mathrm{LIB}<500$ and $\mathrm{LIB}<200$ libraries are similar and for the most part shorter than $200 \mathrm{nt}$, whereas a significant fraction of those detected in the LIB>100 library are longer than $200 \mathrm{nt}$.

A significant overlap in sRNAs detected between the libraries is observed (Fig. 3A) with 326 novel sRNAs being identified in more than one library. A more surprising result is that $36 \%$ of the novel sRNAs were only detected in one library. Most of these novel sRNAs were detected either in the $\mathrm{LIB}<200$ or $\mathrm{LIB}<500$ libraries, but the length distributions of the novel RNAs detected in these libraries are nearly identical showing that these RNAs are not uniquely detected on the basis of length (data not shown). Rather, the basis of unique detection is likely due to the different library preparation strategies, in particular the inclusion of size selection and fragmentation steps. Moreover, there is an inverse relationship between the size range of RNA molecules represented in a library and its sensitivity in detecting transcripts expressed at low levels. Thus, the LIB $<200$ library is more sensitive than the other two libraries, and the LIB $<500$ library is more sensitive than the LIB $>100$ library. Although this work is centred on intergenic sRNAs, the $\mathrm{LIB}<500$ and $\mathrm{LIB}<200$ libraries can also be used to identify cis-encoded sRNAs because they are strand-specific and lack larger transcripts that could mask sRNAs.

Some different examples of sRNA detection in the three libraries are illustrated in Fig. 4. The already annotated sRNA PA 1112.1 is only detected in the LIB $>100$ library, but based on its size (300 nt) it is also expected to be detected in the LIB $<500$ library. The probable explanation for this is the different fragmentation methods used in preparation of the LIB $>100$ and $\mathrm{LIB}<500$ libraries, where transcripts sensitive to RNase III cleavage will not be detected in the latter. The pant154 transcript is only detected in the LIB<500 library (Fig. 4). It is not detected in the $L I B<200$ and $L I B>100$ libraries due to its size (234 nt) and relative low abundance relative to mRNA respectively. The pant55 transcript is only detected in the $\mathrm{LIB}<200$ library, probably due to its small size (89 nt) and low abundance. However, it should be noted that there is also a weak signal for pant55 in the LIB $<500$ library that is below the cut-off value, indicating that sRNAs with a low
A

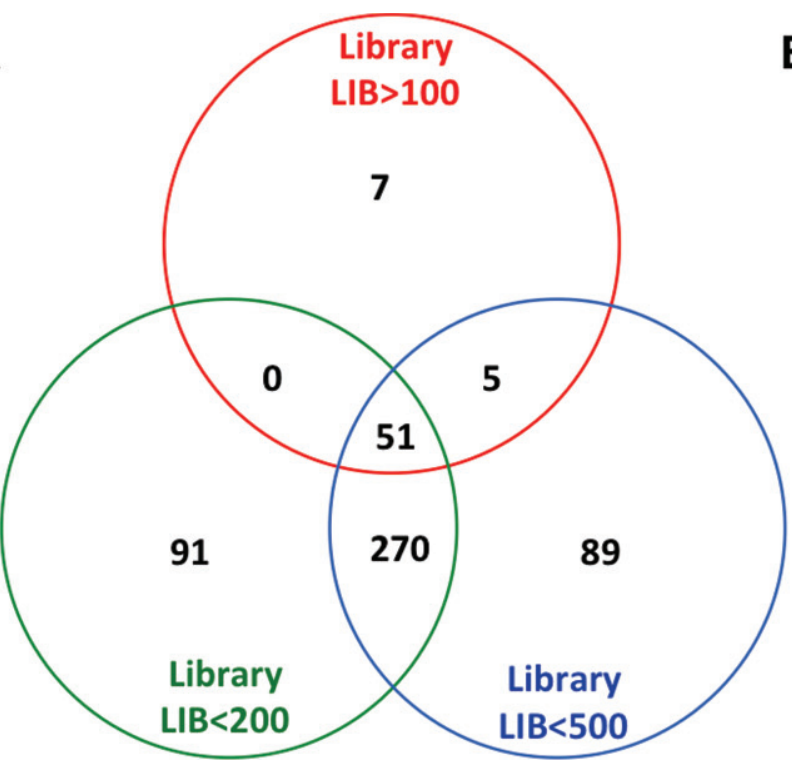

B

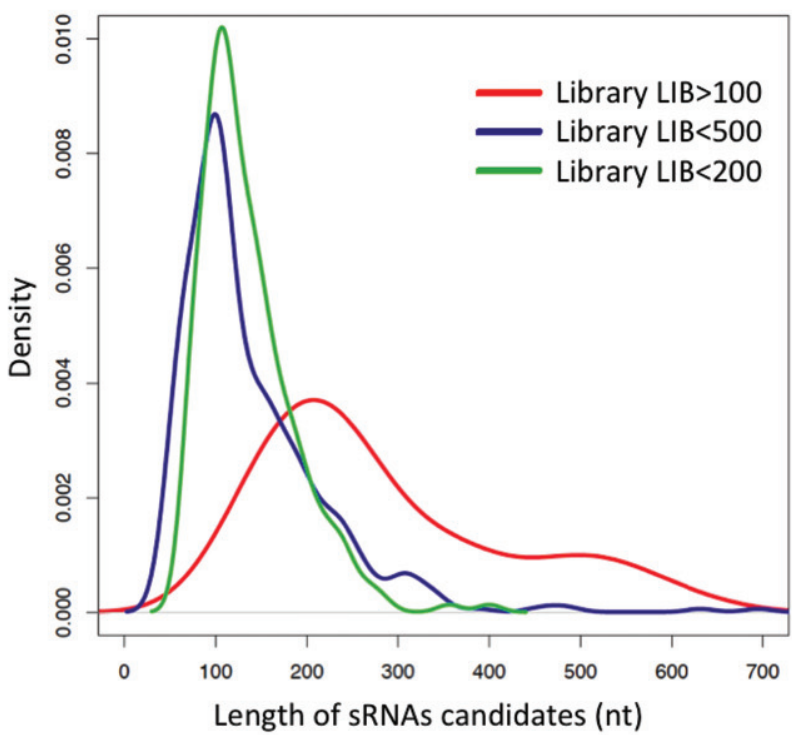

Fig. 3. A. Venn diagram illustrating the novel sRNAs detected in the three different libraries. B. Length distributions of the sRNAs detected in each library. 


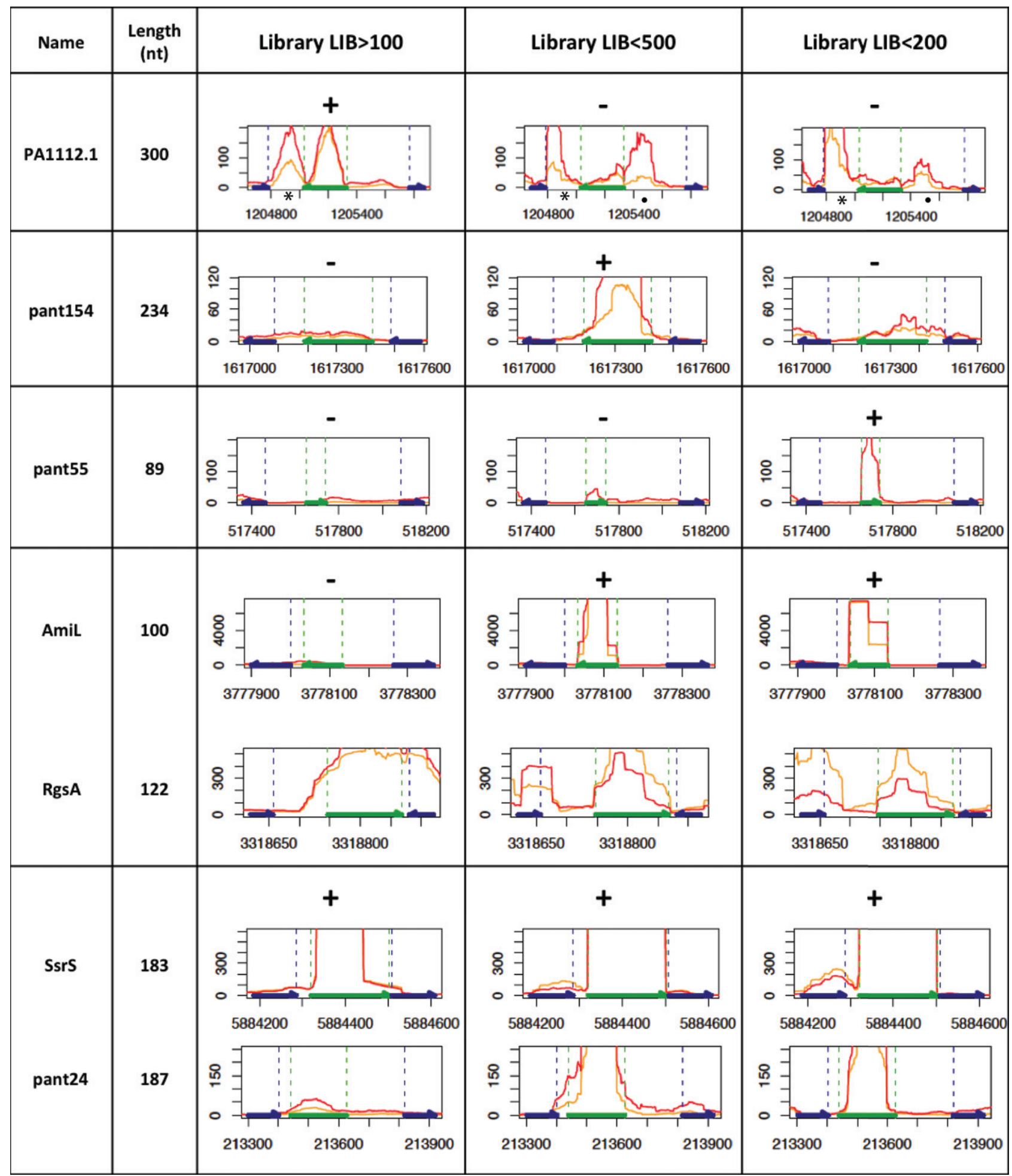

Fig. 4. Examples of sRNAs detected in the three different sequencing libraries $L I B>100, L I B<500$ and LIB $<200$. The $y$-axes of the plots denote normalized coverage at each nucleotide position. The $x$-axes denote the genomic positions according to the $P$. aeruginosa PAO1 genome coordinates (NC_002516.2). The left column of plots corresponds to the results from library LIB $>100$, the middle column to library $\mathrm{LIB}<500$ and the right column to library LIB<200. PA1112.1, AmiL, SsrS and RgsA are already annotated sRNAs in P. aeruginosa. Legend: - , not detected in the library; +, detected in the library; orange lines, exponential phase; red lines, early-stationary phase; dashed green lines, sRNA coordinates; dashed blue lines, intergenic region coordinates; blue arrows, direction of flanking genes; green arrows, direction of the SRNA (if known). The peaks next to PA1112.1 correspond to the novel sRNAs pant120 (*) and pant121 (•) detected in this study. 
relative abundance will go undetected in libraries containing more and larger transcripts. Likewise, AmiL is only identified in the $\mathrm{LIB}<200$ and $\mathrm{LIB}<500$ libraries due to its size (100 nt). The RgsA sRNA would have been misidentified as a UTR in the LIB $>100$ library, as the expression level of the SRNA is similar to the flanking gene (Fig. 4). This does not occur in the LIB $<500$ and $\mathrm{LIB}<200$ libraries because the flanking gene is not included due to the size selection steps. Two examples of transcripts detected in all three libraries are SsrS and pant24 (Fig. 4). The intensity of pant24 is lower in the LIB $>100$ library than in the $\mathrm{LIB}<500$ and $\mathrm{LIB}<200$ libraries, which illustrates the increased sensitivity of the latter two libraries.

\section{sRNA orientation and validation}

The data from the $\mathrm{LIB}<500$ and $\mathrm{LIB}<200$ libraries were used to determine the orientation of the sRNAs whose coordinates and orientation were previously defined. The annotated orientations of all these sRNAs were confirmed with two exceptions, PhrY and RgsA. In the sequencing data the orientation of the PhrY sRNA is unclear and the RgsA sRNA appears to be encoded on the minus strand, contrary to its previous annotation (Livny et al., 2006; González et al., 2008; Sonnleitner et al., 2008). RgsA was previously predicted using the computational tool RNAz (Sonnleitner et al., 2008) and detected with Northern blots (Livny et al., 2006; González et al., 2008). Here, 5'-RACE was performed to determine the coding strand of RgsA. The $5^{\prime}$ ends of RgsA could be validated on both strands, suggesting that there is another sRNA encoded just opposite of RgsA (Table S5).

The strand specificity of the $L I B<500$ and $L I B<200$ libraries was utilized to determine the orientation of the 513 novel sRNAs identified in this study. Almost all of the sRNAs (506/513) were identified in the LIB<500 and/or LIB $<200$ libraries. It was possible to determine the orientation of 388 of the 506 sRNAs. For the others, assignment of orientation was precluded by the inability to determine the accurate limits of the transcripts.

The coding strand and the $5^{\prime}$ ends of six novel sRNAs (pant44, pant66, pant217, pant381, pant441, pant503) were determined using $5^{\prime}$-RACE. These sRNAs were chosen because their direction could be predicted from the $\mathrm{LIB}<200$ and $\mathrm{LIB}<500$ libraries and the average expression levels of four of them (pant44, pant66, pant217, pant381) were close to the cut-offs used for transcript detection. In all cases the coding strand detected by RACE was the same as the one predicted by the RNA-seq data. Moreover, the genomic coordinates are identical to or fall within $12 \mathrm{nt}$ of the transcript $5^{\prime}$ end predicted by sequencing (Table S5).

The sRNAs pant43 and pant304 have similar coordinates and identical orientations to P2 and P17 sRNAs respectively. These sRNAs were predicted computationally in an earlier study, but could not be validated by Northern blotting (Livny et al., 2006). Here, pant43 (P2) was detected in the LIB $<200$ library and pant304 (P17) was detected in the LIB $<500$ and $\mathrm{LIB}<200$ libraries, indicating that the RNA-seq libraries specific for sRNA detection (libraries $L I B<500$ and $L I B<200$ ) are more sensitive than Northern blots.

\section{Growth phase-dependent expression of SRNAs}

A Student's $t$-test was performed on the average expression of the transcripts to determine those with differential expression between the two conditions tested. Of the 513 novel transcripts, 178 are differentially expressed between the conditions tested (Table S4). Around $80 \%$ of these were significantly more expressed in earlystationary relative to exponential phase. Out of the 44 previously identified sRNAs, three (1059, P27 and PA5316.1) were found to be differentially expressed between the conditions tested (Table S3). Importantly, the three sequencing libraries were very consistent in the quantification of transcripts. Of the many sRNAs detected in more than one library type, most showed similar expression patterns in all libraries in which they were detected, or in other words, the libraries were congruent in whether the sRNAs were differentially expressed or not. This suggests that RNA-seq can be reliably used to quantify transcript abundance and concurs with other studies in which RNA-seq has been proven to be a very good method to quantify expression levels. Marioni and colleagues investigated the technical variance associated with Illumina sequencing and compared its ability to identify differentially expressed genes with Affymetrix arrays (Marioni et al., 2008). Illumina sequencing data were found to be highly reproducible, with relatively little technical variation and comparable to that from the arrays in enabling identification of differentially expressed genes (Marioni et al., 2008).

\section{Conservation and homologue identification of the novel sRNAs}

The sequence conservation of novel SRNAs in other bacteria was investigated using the BLASTN algorithm. The sequences of $12 \%(62 / 513)$ of the sRNAs are conserved in other bacteria, and $4 \%(22 / 513)$ are conserved in organisms outside the Pseudomonadaceae family (Table S6). The data show that $88 \%$ of the sRNAs are not conserved outside $P$. aeruginosa, indicating that the extent of sequence conservation between sRNAs in $P$. aeruginosa and other Pseudomonas spp. is limited. As $P$. aeruginosa is the only pseudomonad that is an opportunistic human pathogen, it is likely that some of 
the specific sRNAs play a role in pathogenesis or confer an advantage inside the host. An example of an sRNA specific to $P$. aeruginosa is $\mathrm{PrrH}$, a heme-regulated RNA encoded by the two identical sRNA genes prrF1 and prrF2. These genes have a unique tandem organization in $P$. aeruginosa but are encoded at distal loci in the genomes of all other sequenced pseudomonads (Oglesby-Sherrouse and Vasil, 2010). There are no orthologous sequences in $P$. aeruginosa to previously characterized sRNAs in enterobacteria such as E. coli and Salmonella, suggesting that the sequence conservation among these sRNAs does not extend to the pseudomonads. The results illustrate the limitations in identifying sRNAs using bioinformatic prediction methods that are often based on sequence conservation. Moreover, they are consistent with the view that organisms have evolved species-specific regulatory networks involving sRNAs, and that these are necessary for niche adaptation, including host interactions in the case of pathogens.

\section{Concluding remarks}

This study is the first to use RNA-seq to discover novel sRNAs in $P$. aeruginosa and utilized three types of sequencing libraries to maximize the number of detected sRNAs. Over 500 novel sRNA transcripts are identified, increasing the number of known sRNAs in $P$. aeruginosa by a factor of 12 and revealing a large set of potential regulatory molecules in an already highly regulated species. Two libraries that do not include larger transcripts $(\mathrm{LIB}<500$ and $\mathrm{LIB}<200)$ are clearly superior in detecting sRNAs, whereas the LIB $>100$ library contains information on the full transcriptome. Although RNA-seq enables the identification of novel transcripts, it is not well suited for accurately defining transcript length. As RNA-seq allows for detection of transcripts expressed at low levels, the sensitivity of existing validation methods is therefore a limitation for further characterization of these transcripts. Roughly one-third of the novel transcripts are differentially expressed between exponential and early-stationary growth phases, underscoring that RNA-seq is a sensitive method to monitor changes in gene expression. The limited extent of sequence conservation among pseudomonads highlights the challenges of sRNA bioinformatic prediction and emphasizes the importance of sRNAs at the species level in monitoring changes in environmental conditions. The approach described here can be used to characterize the sRNAome of any bacterium under highly diverse growth and stress conditions. In conclusion, the multitude of sRNAs in $P$. aeruginosa suggests the presence of a vast and complex regulatory network that will be highly important for our understanding of an organism with such a versatile life style that can successfully move from the environment into the human body as a pathogen.

\section{Experimental procedures}

\section{RNA isolation}

Single colonies of $P$. aeruginosa strain PAO1 were grown overnight in Luria-Bertani (LB) medium at $37^{\circ} \mathrm{C}$. The cultures were diluted to a starting $\mathrm{OD}_{600}$ of 0.01 in $50 \mathrm{ml}$ of LB media and grown at $37^{\circ} \mathrm{C}$ in separate $250 \mathrm{ml}$ baffled Erlenmeyer flasks with shaking at 240 r.p.m. Cells were harvested from cultures grown to an $\mathrm{OD}_{600}$ of 0.6 (exponential phase) or 3.0 (early-stationary phase). Harvested cells were mixed immediately with 0.2 volumes of STOP solution (95\% ethanol, $5 \%$ phenol) and pelleted by centrifugation. Total RNA was extracted with Trizol (Invitrogen). Removal of DNA was carried out by treatment with DNase I (Fermentas) in combination with the RNase inhibitor RiboLock (Fermentas). The integrity of total RNA, the presence of 5S rRNA and TRNAs, and DNA contamination were assessed with an Agilent 2100 Bioanalyzer (Agilent Technologies).

\section{Removal of 23S, 165 and $5 S$ rRNAs}

The 23S, $16 \mathrm{~S}$ and $5 \mathrm{~S}$ rRNAs were removed by subtractive hybridization using the MICROBExpress kit (Ambion) with modifications. Capture oligonucleotides complementary to the rRNAs were designed specifically for $P$. aeruginosa (Table S2). For preparation of library LIB $>100$ (described below), $5 \mu \mathrm{M}$ of each capture oligonucleotide was used, for a total capture oligonucleotide concentration of $25 \mu \mathrm{M}$. Compared with the standard protocol, $25 \%$ more capture oligonucleotides and magnetic beads were used. For preparation of libraries $\mathrm{LIB}<500$ and $\mathrm{LIB}<200$ (described below), $5 \mu \mathrm{M}$ of the $5 \mathrm{~S}$ rRNA capture oligonucleotide and $50 \%$ less magnetic beads were used relative to the standard protocol. Removal of rRNAs was confirmed with an Agilent 2100 Bioanalyzer (Agilent Technologies) (Fig. S1).

\section{Library preparation and RNA sequencing}

The sequencing libraries $L I B>100, L I B<500$ and $L I B<200$ were constructed using three different protocols (Fig. 1, Table 1). Each library type was prepared with RNA isolated from cells grown in triplicate for each condition (exponential and early-stationary phase). After each step the samples were validated using an Agilent 2100 Bioanalyzer (Agilent Technologies), and the final concentration was measured using a Qubit 2.0 Fluorometer (Invitrogen). The libraries were sequenced using the Illumina HiSeq2000 platform with a paired-end protocol and read lengths of $100 \mathrm{nt}$.

LIB $>100$ library. This type of library contains transcripts longer than $100 \mathrm{nt}$ and was prepared using the TruSeq RNA Sample Preparation kit (Illumina). Briefly, the rRNA-depleted RNA is fragmented using divalent cations under elevated temperature. The cleaved RNA fragments are copied into 
cDNA using reverse transcriptase and random primers, followed by second-strand cDNA synthesis using DNA polymerase I and RNase $\mathrm{H}$. After this step, transcripts shorter than $100 \mathrm{nt}$ are not retained due to the purification performed with the Agencourt AMPure XP beads (Beckman Coulter Genomics). The cDNA fragments then go through an end repair process, 3 '-addition of single ' $A$ ' bases and adapter ligation. This is followed by product purification and PCR amplification to generate the final cDNA library.

$L I B<500$ library. This type of library contains transcripts shorter than $500 \mathrm{nt}$. RNA size selection was performed by running total RNA on $10 \%$ polyacrylamide gels containing $10 \mathrm{M}$ urea. Gel slices corresponding to RNAs up to $500 \mathrm{nt}$ were excised, followed by elution of RNA in $0.4 \mathrm{M} \mathrm{NaCl}$ and precipitation with ethanol. The 5S rRNA was depleted as previously described, followed by treatment with Tobacco Acid Pyrophosphatase (Epicentre Technologies) at $37^{\circ} \mathrm{C}$ for $90 \mathrm{~min}$. Tobacco Acid Pyrophosphatase (TAP) is used to convert 5'-triphosphate RNA into 5'-monophosphate RNA which is important for correct adapter ligation. This was followed by treatment with RNase III (Ambion) for 10 min at $37^{\circ} \mathrm{C}$ to fragment the RNA. RNase III fragments RNA into smaller pieces containing a $5^{\prime}$-phosphoryl group and a $3^{\prime}$-hydroxyl group, which is important for specific adapter ligation in the next step. Sequential ligation of RNA $3^{\prime}$ and $5^{\prime}$ adapters was performed using the adapters and enzymes from the TruSeq Small RNA Sample Preparation kit (Illumina). Next, reverse transcription followed by PCR amplification was performed to form cDNA constructs based on the RNA fragments ligated with $3^{\prime}$ and $5^{\prime}$ adapters, selectively enriching fragments with adapter molecules on both ends. The reverse transcription and subsequent PCR amplification were performed using the enzymes and reagents from the TruSeq Small RNA Sample Preparation kit (Illumina). Agencourt AMPure XP beads (Beckman Coulter Genomics) were used for the post-PCR clean-up. In this and the $L I B<200$ libraries, the fragments corresponding to transcripts shorter than $100 \mathrm{nt}$ are retained due to ligated RNA adapters that increase the length of the fragments by 125 nt.

$L I B<200$ library. This type of library contains transcripts shorter than $200 \mathrm{nt}$. Size selection of RNAs up to $200 \mathrm{nt}$ from total RNA was carried out with the mirVana miRNA Isolation Kit (Ambion), followed by depletion of 5S rRNA as previously described. The TAP treatment, RNA adapter ligation, reverse transcription and PCR amplification and clean-up steps were performed as described for library $\mathrm{LIB}<500$.

\section{Read mapping}

Reads were mapped onto the P. aeruginosa PAO1 genome (RefSeq Accession No. NC_002516.2) using the Bowtie short read aligner (Langmead et al., 2009). For the LIB $<500$ and $\mathrm{LIB}<200$ libraries, the adapters had to be trimmed in the reads with inserts shorter than $100 \mathrm{nt}$. Reads with only one alignment reported were retained. Read alignments from Bowtie were handled using SAMtools (Li et al., 2009). Read alignments onto the reference genome were visualized using Tablet 1.11.08.10 (Milne et al., 2010).

\section{Transcript quantification}

In order to obtain normalized expression intensities of the read coverage depth at each position in the genome, the number of reads in each replicate was normalized according to the total number of reads in the library, and expression intensities from replicate samples were averaged. The average expression of each already annotated sRNA transcript was calculated by dividing the normalized coverage depth of the transcript by the length of the transcript.

\section{Identification of intergenic SRNAs}

Already annotated sRNAs were identified by visual inspection of the read coverage of the reference genome at the relevant loci. A custom-made script was designed to detect novel transcripts in intergenic regions. According to this, a transcript was detected if the coverage depth at each base was higher than a certain cut-off. The cut-off was set for each library based on the average expression intensities of the 44 previously validated sRNAs in $P$. aeruginosa in each library type (Table S7). In addition, the average expression intensities of the detected transcript had to be twice the previously mentioned cut-off. This ensures detection of abrupt increases in read coverage depths. To define the length of the transcripts more accurately, the lowest chosen cut-off (the one for library LIB $>100$ ) was applied to the peaks previously found in libraries $L I B<500$ and $L I B<200$. To prevent misclassification of UTRs as ncRNAs, the script only detects transcripts that begin and end within an intergenic region. Transcripts of at least $100 \mathrm{nt}(\mathrm{LIB}>100)$ or $70 \mathrm{nt}(\mathrm{LIB}<500$, LIB $<200)$ were considered further. The resulting transcripts from automatic classification were re-evaluated by visual inspection using Tablet 1.11.08.10 (Milne et al., 2010).

\section{Differential expression of intergenic sRNAs}

The average expression of each SRNA was calculated by dividing the normalized read coverage depth by the length of the transcript. A two-sample Student's $t$-test was performed on the average expression of the sRNAs to determine those with differential expression between the two conditions tested $(P$-value $<0.05$ and fold change $>2)$. The BenjaminiHochberg multiple testing correction was applied (Benjamini, 1995). The triplicates of the conditions were not averaged for this analysis. The expression of a sRNA was considered significantly different, if the sRNA was differentially expressed in all the libraries in which it was detected.

\section{Homologue identification}

The novel sRNAs were searched against the Rfam database to look for homologies to ncRNA entries. Putative homologues of each novel transcriptional unit were predicted via BLASTN comparison of each sequence to all sequenced bacterial genomes $\left(E=10^{-6}\right.$, word $\left.=11\right)$. Only hits with nucleotide identity higher than $60 \%$ combined with coverage between query and subject sequence higher than $80 \%$ were considered to be conserved. 


\section{Validation of coding strand and $5^{\prime}$ ends of SRNAs}

We applied a RACE procedure to determine the $5^{\prime}$ ends of a selection of the novel sRNAs. The protocol used is based on the method of Gerhart and colleagues with modifications (Gerhart et al., 2005). In brief, DNase-treated total RNA (described above) was incubated with Tobacco Acid Pyrophosphatase (Epicentre Technologies) at $37^{\circ} \mathrm{C}$ for $60 \mathrm{~min}$. A short RNA adapter was ligated to the $5^{\prime}$ ends using T4 RNA ligase (New England Biolabs). The $5^{\prime}$ adapter-ligated RNA was reverse-transcribed using a primer complementary to the sRNA (GSP1) and the Thermoscript RT-PCR system (Invitrogen). Primers were removed using the NucleoSpin Gel and PCR Clean-up kit (Macherey-Nagel). The resulting cDNA was used as the template in PCR reactions using strand-specific primers to the sRNA (GSP2) along with an adapter-specific primer. Negative controls were performed using the adapterligated RNA as template. The oligonucleotides used for RACE are listed in Table S2. PCR clean-up was carried out using the NucleoSpin Gel and PCR Clean-up kit (Macherey-Nagel). The PCR products were resolved using an Agilent 2100 Bioanalyzer High Sensitivity DNA assay (Agilent Technologies) to determine their lengths. Products were sequenced with the primer used in PCR (GSP2) and with the adapter-specific primer by LGC Genomics GmbH (Germany).

\section{Acknowledgements}

Björn Renberg of the Royal Institute of Technology (KTH) and the Science for Life Laboratory in Stockholm are gratefully acknowledged for helpful discussions and sequencing of two sets of libraries. Anna Koza is thanked for assistance with sRNA validation. Laurent Gautier and Khoa Nguyen Do of the DTU Multi-Assay Core are thanked for their help and use of their facilities in connection with library preparation. This work was supported by the Novo Nordisk Foundation, Lundbeck Foundation and Danish National Research Agency.

\section{References}

Albrecht, M., Sharma, C.M., Reinhardt, R., Vogel, J., and Rudel, T. (2010) Deep sequencing-based discovery of the Chlamydia trachomatis transcriptome. Nucleic Acids Res 38: 868-877.

Bastet, L., Dubé, A., Massé, E., and Lafontaine, D.A. (2011) New insights into riboswitch regulation mechanisms. Mol Microbiol 80: 1148-1154.

Benjamini, Y. (1995) Controlling the false discovery rate: a practical and powerful approach to multiple testing. $J$ Roy Stat Soc B 57: 289-300.

Bradley, E.S., Bodi, K., Ismail, A.M., and Camilli, A. (2011) A genome-wide approach to discovery of small RNAs involved in regulation of virulence in Vibrio cholerae. PLOS Pathog 7: e1002126.

Croucher, N.J., and Thomson, N.R. (2010) Studying bacterial transcriptomes using RNA-seq. Curr Opin Microbiol 13: 619-624.

Gerhart, E., Wagner, H., and Vogel, J. (2005) Approaches to identify novel non-messenger RNAs in bacteria and to investigate their biological functions: functional analysis of identified non-mRNAs. In Handbook of RNA Biochemistry. Hartmann, R.K., Bindereif, A., Schön, A., and Westhof, E. (eds). Weinheim: Wiley-VCH Verlag GmbH, pp. 614-642.

González, N., Heeb, S., Valverde, C., Kay, E., Reimmann, C., Junier, T., and Haas, D. (2008) Genome-wide search reveals a novel GacA-regulated small RNA in Pseudomonas species. BMC Genomics 9: 167.

Gottesman, S., and Storz, G. (2011) Bacterial small RNA regulators: versatile roles and rapidly evolving variations. Cold Spring Harb Perspect Biol 3: a00379.

He, S., Wurtzel, O., Singh, K., Froula, J.L., Yilmaz, S., Tringe, S.G., et al. (2010) Validation of two ribosomal RNA removal methods for microbial metatranscriptomics. Nat Methods 7: 807-812.

Irnov, I., Sharma, C.M., Vogel, J., and Winkler, W.C. (2010) Identification of regulatory RNAs in Bacillus subtilis. Nucleic Acids Res 38: 6637-6651.

Karpinets, T., Greenwood, D., Sams, C., and Ammons, J. (2006) RNA:protein ratio of the unicellular organism as a characteristic of phosphorous and nitrogen stoichiometry and of the cellular requirement of ribosomes for protein synthesis. BMC Biol 4: 30.

Koo, J.T., Alleyne, T.M., Schiano, C.A., Jafari, N., and Lathem, W.W. (2011) Global discovery of small RNAs in Yersinia pseudotuberculosis identifies Yersinia-specific small, noncoding RNAs required for virulence. Proc Natl Acad Sci USA 108: E709-E717.

Langmead, B., Trapnell, C., Pop, M., and Salzberg, S.L. (2009) Ultrafast and memory-efficient alignment of short DNA sequences to the human genome. Genome Biol 10: R25.

Li, H., Handsaker, B., Wysoker, A., Fennell, T., Ruan, J., Homer, N., et al. (2009) The sequence alignment/map format and SAMtools. Bioinformatics 25: 2078-2079.

Liu, J.M., Livny, J., Lawrence, M.S., Kimball, M.D., Waldor, M.K., and Camilli, A. (2009) Experimental discovery of sRNAs in Vibrio cholerae by direct cloning, 5S/tRNA depletion and parallel sequencing. Nucleic Acids Res 37: e46.

Livny, J., Brencic, A., Lory, S., and Waldor, M.K. (2006) Identification of 17 Pseudomonas aeruginosa sRNAs and prediction of SRNA-encoding genes in 10 diverse pathogens using the bioinformatic tool sRNAPredict2. Nucleic Acids Res 34: 3484.

Loh, E., Dussurget, O., Gripenland, J., Vaitkevicius, K., Tiensuu, T., Mandin, P., et al. (2009) A trans-acting riboswitch controls expression of the virulence regulator PrfA in Listeria monocytogenes. Cell 139: 770-779.

Marioni, J.C., Mason, C.E., Mane, S.M., Stephens, M., and Gilad, Y. (2008) RNA-seq: an assessment of technical reproducibility and comparison with gene expression arrays. Genome Res 18: 1509-1517.

Milne, I., Bayer, M., Cardle, L., Shaw, P., Stephen, G., Wright, F., and Marshall, D. (2010) Tablet - next generation sequence assembly visualization. Bioinformatics 26: 401402.

Mitschke, J., Georg, J., Scholz, I., Sharma, C.M., Dienst, D., Bantscheff, J., et al. (2011) An experimentally anchored map of transcriptional start sites in the model cyanobacterium Synechocystis sp. PCC6803. Proc Natl Acad Sci USA 108: 2124-2129. 
Mraheil, M.A., Billion, A., Mohamed, W., Mukherjee, K., Kuenne, C., Pischimarov, J., et al. (2011) The intracellular sRNA transcriptome of Listeria monocytogenes during growth in macrophages. Nucleic Acids Res 39: 4235-4248.

Oglesby-Sherrouse, A.G., and Vasil, M.L. (2010) Characterization of a heme-regulated non-coding RNA encoded by the prrF locus of Pseudomonas aeruginosa. PLoS ONE 5: e9930.

Oliver, H.F., Orsi, R.H., Ponnala, L., Keich, U., Wang, W., Sun, Q., et al. (2009) Deep RNA sequencing of L. monocytogenes reveals overlapping and extensive stationary phase and sigma B-dependent transcriptomes, including multiple highly transcribed noncoding RNAs. BMC Genom ics 10: 641.

Papenfort, K., and Vogel, J. (2010) Regulatory RNA in bacterial pathogens. Cell Host Microbe 8: 116-127.

Perkins, T.T., Kingsley, R.A., Fookes, M.C., Gardner, P.P., James, K.D., Yu, L., et al. (2009) A strand-specific RNASeq analysis of the transcriptome of the typhoid bacillus Salmonella typhi. PLoS Genet 5: e1000569.

Repoila, F., and Darfeuille, F. (2009) Small regulatory noncoding RNAs in bacteria: physiology and mechanistic aspects. Biol Cell 101: 117-131.

Rudinger-Thirion, J., Lescure, A., Paulus, C., and Frugier, M. (2011) Misfolded human tRNA isodecoder binds and neutralizes a 3' UTR-embedded Alu element. Proc Natl Acad Sci USA 108: 794-802.

Sharma, C.M., Hoffmann, S., Darfeuille, F., Reignier, J., Findeiss, S., Sittka, A., et al. (2010) The primary transcriptome of the major human pathogen Helicobacter pylori. Nature 464: 250-255.

Sittka, A., Lucchini, S., Papenfort, K., Sharma, C.M., Rolle, K., Binnewies, T.T., et al. (2008) Deep sequencing analysis of small noncoding RNA and mRNA targets of the global post-transcriptional regulator, Hfq. PLoS Genet 4: e1000163.

Sonnleitner, E., and Haas, D. (2011) Small RNAs as regulators of primary and secondary metabolism in Pseudomonas species. Appl Microbiol Biotechnol 91: 63-79.

Sonnleitner, E., Sorger-Domenigg, T., Madej, M.J., Findeiss, S., Hackermüller, J., Hüttenhofer, A., et al. (2008) Detection of small RNAs in Pseudomonas aeruginosa by RNomics and structure-based bioinformatic tools. Microbiology 154: 3175-3187.

Sonnleitner, E., González, N., and Haas, D. (2010) Small RNAs of Pseudomonas spp. In Pseudomonas - Molecular Microbiology, Infection and Biodiversity, Vol. 6. Ramos, J.L., and Filloux, A. (eds). Dordrecht: Springer Netherlands, pp. 3-28.

Storz, G., Vogel, J., and Wassarman, K.M. (2011) Regulation by small RNAs in bacteria: expanding frontiers. Mol Cell 43: 880-891.
Toschka, H.Y., Struck, J.C., and Erdmann, V.A. (1989) The 4.5S RNA gene from Pseudomonas aeruginosa. Nucleic Acids Res 17: 31-36.

Vockenhuber, M., Sharma, C.M., Statt, M.G., Schmidt, D., Xu, Z., Dietrich, S., et al. (2011) Deep sequencing-based identification of small non-coding RNAs in Streptomyces coelicolor. RNA Biol 8: 468-477.

Vogel, D.W., Hartmann, R.K., Struck, J.C.R., Ulbrich, N., and Erdmann, V.A. (1987) The sequence of the 6S RNA gene of Pseudomonas aeruginosa. Nucleic Acids Res 15: 4583-4591.

Waters, L.S., and Storz, G. (2009) Regulatory RNAs in bacteria. Cell 136: 615-628.

Weissenmayer, B.A., Prendergast, J.G.D., Lohan, A.J., and Loftus, B.J. (2011) Sequencing illustrates the transcriptional response of Legionella pneumophila during infection and identifies seventy novel small non-coding RNAs. PLOS ONE 6: e17570.

Wilderman, P.J., Sowa, N.A., FitzGerald, D.J., FitzGerald, P.C., Gottesman, S., Ochsner, U.A., and Vasil, M.L. (2004) Identification of tandem duplicate regulatory small RNAs in Pseudomonas aeruginosa involved in iron homeostasis. Proc Natl Acad Sci USA 101: 9792-9797.

\section{Supporting information}

Additional Supporting Information may be found in the online version of this article:

Fig. S1. Agilent Bioanalyzer analysis of total and rRNAdepleted RNA. The 23S, 16S and 5S rRNAs were removed from the total RNA (A) by subtractive hybridization as described in the Experimental procedures. Note that the peaks corresponding to 23S, 165 and $5 S$ rRNAs are not present in the rRNA-depleted sample $(B)$. The peaks marked with asterisks $\left({ }^{*}\right)$ probably correspond to tRNAs and SRNA species shorter than $120 \mathrm{nt}$.

Table S1. Sequencing results.

Table S2. Oligonucleotides used in this study.

Table S3. Annotated sRNAs in Pseudomonas aeruginosa.

Table S4. Intergenic sRNAs candidates in Pseudomonas aeruginosa.

Table S5. 5'-RACE validation of sRNA candidates.

Table S6. Novel sRNA candidates conserved in organisms outside the Pseudomonadaceae family.

Table S7. Cut-offs used for the detection of novel transcripts.

Please note: Wiley-Blackwell are not responsible for the content or functionality of any supporting materials supplied by the authors. Any queries (other than missing material) should be directed to the corresponding author for the article. 
Supplementary Table 1. Sequencing results.

\begin{tabular}{|c|c|c|c|c|c|c|c|c|}
\hline \multirow{2}{*}{ Library } & \multirow{2}{*}{ Condition } & \multirow{2}{*}{$\begin{array}{c}\text { Number } \\
\text { of } \\
\text { replicates }\end{array}$} & \multirow{2}{*}{$\begin{array}{c}\text { Average } \\
\text { total } \\
\text { number of } \\
\text { reads }\end{array}$} & \multirow{2}{*}{$\begin{array}{l}\text { Average } \\
\text { number of } \\
\text { mapped } \\
\text { reads }\end{array}$} & \multicolumn{4}{|c|}{ Average \% of read coverage corresponding to } \\
\hline & & & & & 235 rRNA & 16S rRNA & 5S rRNA & tRNAs \\
\hline $\mathrm{LIB}>100$ & $\begin{array}{c}\text { Exponential } \\
\text { Early-stationary }\end{array}$ & $\begin{array}{l}3 \\
3\end{array}$ & $\begin{array}{l}16961351 \\
24030975\end{array}$ & $\begin{array}{l}14676650 \\
21001129\end{array}$ & $\begin{array}{l}12.60 \% \\
15.60 \%\end{array}$ & $\begin{array}{l}6.74 \% \\
7.88 \%\end{array}$ & $\begin{array}{l}0.07 \% \\
0.01 \%\end{array}$ & $\begin{array}{l}2.53 \% \\
1.15 \%\end{array}$ \\
\hline$L I B<500$ & $\begin{array}{c}\text { Exponential } \\
\text { Early-stationary }\end{array}$ & $\begin{array}{l}3 \\
3\end{array}$ & $\begin{array}{l}16577877 \\
14758047\end{array}$ & $\begin{array}{l}13119470 \\
10822645\end{array}$ & $\begin{array}{l}3.50 \% \\
1.79 \%\end{array}$ & $\begin{array}{l}1.62 \% \\
1.29 \%\end{array}$ & $\begin{array}{l}0.16 \% \\
0.19 \%\end{array}$ & $\begin{array}{l}3.69 \% \\
3.28 \%\end{array}$ \\
\hline$L I B<200$ & $\begin{array}{c}\text { Exponential } \\
\text { Early-stationary }\end{array}$ & $\begin{array}{l}3 \\
3\end{array}$ & $\begin{array}{l}12822325 \\
15070347\end{array}$ & $\begin{array}{l}7564110 \\
6755123\end{array}$ & $\begin{array}{l}5.18 \% \\
3.91 \%\end{array}$ & $\begin{array}{l}3.01 \% \\
2.62 \%\end{array}$ & $\begin{array}{l}0.25 \% \\
0.21 \%\end{array}$ & $\begin{array}{l}3.80 \% \\
1.89 \%\end{array}$ \\
\hline & & Average & 16703487 & 12323187 & $7.10 \%$ & $3.86 \%$ & $0.15 \%$ & $2.72 \%$ \\
\hline
\end{tabular}


Supplementary Table 2. Oligonucleotides used in this study.

\begin{tabular}{|c|c|c|}
\hline Name & Sequence $\left(5^{\prime}->3^{\prime}\right)$ & Use \\
\hline 23S-1954 & AAAAAAAAAAAAAAAAAAACTTACCCGACAAGGAATTTCGC & Removal of $23 \mathrm{~S}$ rRNA \\
\hline $23 S-2511$ & AAAAAAAAAAAAAAAAAAGAGCCGACATCGAGGTGCCAAAC & Removal of $23 S$ rRNA \\
\hline $16 S-807$ & AAAAAAAAAAAAAAAAAATGGACTACCAGGGTATCTAATCC & Removal of $16 \mathrm{~S}$ rRNA \\
\hline $16 S-1114$ & AAAAAAAAAAAAAAAAAAGGGTTGCGCTCGTTACGGGACTT & Removal of $16 \mathrm{~S}$ rRNA \\
\hline $5 S$ & AAAAAAAAAAAAAAAAAAGCGTTTCACTTCTGAGTTCGGCA & Removal of 5 S rRNA \\
\hline RNA adapter & AUAUGCGCGAAUUCCUGUAGAACGAACACUAGAAGAAA & RNA ligation in 5'-RACE \\
\hline Adapter-specific primer & GCGCGAATTCCTGTAGA & PCR in 5'-RACE \\
\hline GSP1 pant44 & TCAGGAAGCGTTCTTGTTGG & RT in 5'-RACE \\
\hline GSP2 pant44 & AGCGTTCTTGTTGGATTTCTAGC & PCR in 5'-RACE \\
\hline GSP1 pant66 & GCGAGAATCCCCCAGACT & RT in 5'-RACE \\
\hline GSP2 pant66 & GAATCCCCCAGACTCCGT & PCR in 5'-RACE \\
\hline GSP1 pant 217 & GTACGGCAACCCCTGCAT & RT in 5'-RACE \\
\hline GSP2 pant217 & GCAACCCCTGCATCGACCG & PCR in 5'-RACE \\
\hline GSP1 pant381 & AGGAGACAGGTTGGGA & RT in 5'-RACE \\
\hline GSP2 pant381 & GACAGGTTGGGAGGGAGTT & PCR in 5'-RACE \\
\hline GSP1 pant441 & GCGACTCCCCAAGCATAGCCG & RT in 5'-RACE \\
\hline GSP2 pant441 & CCAAGCATAGCCGGCGGGAC & PCR in 5'-RACE \\
\hline GSP1 pant503 & CTGGCACTACGACGAATGG & RT in 5'-RACE \\
\hline GSP2 pant503 & CACTACGACGAATGGCCAAC & PCR in 5'-RACE \\
\hline GSP1 RgsA (forward) & ATCCGGGTCAAGACCAT & RT in 5'-RACE \\
\hline GSP2 RgsA (forward) & GTCAAGACCATTAGGAG & PCR in 5'-RACE \\
\hline GSP1 RgsA (reverse) & AGTACCCAGCCAGTGAAG & RT in 5'-RACE \\
\hline GSP2 RgsA (reverse) & CAGCCAGTGAAGGTAC & PCR in 5'-RACE \\
\hline
\end{tabular}




\begin{tabular}{|c|c|c|c|c|c|c|c|c|c|c|c|c|c|c|c|c|}
\hline Name & Start $^{a}$ & End $^{\mathrm{a}}$ & $\begin{array}{c}\text { Intergenic } \\
\text { region } \\
\text { start }\end{array}$ & $\begin{array}{c}\text { Intergenic } \\
\text { region } \\
\text { end }\end{array}$ & Length $^{\mathrm{b}}$ & $\begin{array}{c}5^{\prime} \\
\text { flanking } \\
\text { gene }\end{array}$ & $\begin{array}{c}3 \text { ' flanking } \\
\text { gene }\end{array}$ & 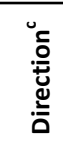 & 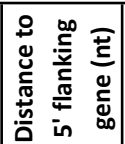 & 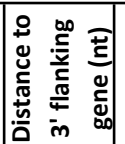 & 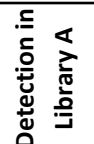 & 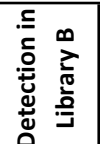 & 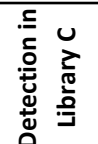 & 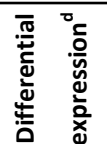 & 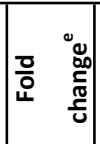 & Reference \\
\hline P1 & - & - & 334456 & 334733 & 300 & PA0296 & PA0297 & e<> & ? & $?$ & - & + & + & - & - & (Livny et al., 2006) \\
\hline $\mathrm{rsmY}$ & 586867 & 586990 & 586664 & 587016 & 124 & PA0527 & PA0528 & $<><$ & 203 & 26 & - & + & + & - & - & (Kay et al., 2006; Livny et al., 2006; Sonnleitner et al., 2008) \\
\hline phrD & 785498 & 785570 & 785174 & 785969 & 73 & PA0714 & PA0715 & $\gg$ & 324 & 399 & - & + & + & - & - & (Sonnleitner et al., 2008) \\
\hline ssrA & 901520 & 901872 & 901047 & 901933 & $353^{f}$ & PA0826 & PA0827 & $\ll<$ & 473 & 61 & + & + & + & - & - & (Sonnleitner et al., 2008; Wiilliams and Bartel 1996) \\
\hline P5 & - & - & 912780 & 913085 & 90 & PA0836 & PA0837 & $\langle>$ & $?$ & $?$ & + & + & + & - & - & (González et al., 2008; Livny et al., 2006) \\
\hline P7 & - & - & 971625 & 972166 & 140 & PA0887 & PA0888 & $\gg>$ & $?$ & $?$ & - & + & + & - & - & (Livny et al., 2006) \\
\hline P8 & - & - & 1117319 & 1118157 & 130 & PA1030 & PA1031 & $\gg>$ & $?$ & $?$ & + & + & + & - & - & (Livny et al., 2006) \\
\hline sRNA622 & - & - & 1140860 & 1141267 & 200,300 & PA1052 & PA1053 & $\gg$ & ? & ? & + & + & + & - & - & (González et al., 2008) \\
\hline PA1112.1 & 1205031 & 1205330 & 1204782 & 1205770 & 300 & PA1112 & PA1113 & $><>$ & 249 & 440 & + & - & - & - & - & (González et al., 2008) \\
\hline P9 & 1436491 & 1436618 & 1436397 & 1436663 & 128 & PA1324 & PA1325 & $\gg \gg$ & 94 & 45 & + & + & + & - & - & (Livny et al., 2006; Sonnleitner et al., 2008) \\
\hline ffs & 1668935 & 1669048 & 1668833 & 1669085 & $173(113)^{g}$ & PA1530 & PA1531 & $>><$ & 102 & 37 & - & + & + & - & - & (Toschka 1989; González et al., 2008; Sonnleitner et al., 2008) \\
\hline P11 & - & - & 1928627 & 1928893 & 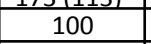 & PA1781 & PA1782 & e<< & $?$ & $?$ & - & + & + & - & - & (Livny et al., 2006; Sonnleitner et al., 2008) \\
\hline SRNA1059 & - & - & 1996807 & 1997508 & $150,200,300$ & PA1838 & PA1839 & e< & $?$ & $?$ & + & + & + & + & 9 & (González et al., 2008) \\
\hline SRNA1466 & -1 & - & 2918212 & 2918603 & 300 & PA2581 & PA2581.1 & $>?<$ & $?$ & $?$ & + & - & - & - & - & (González et al., 2008; Sonnleitner et al., 2008) \\
\hline PA2744.1 & 3106919 & 3106994 & 3106752 & 3107002 & 76 & PA2744 & PA2745 & e< & 1 & 60 & - & - & - & - & - & (Livny et al., 2006) \\
\hline SRNA1559 & - & - & 3112151 & 3112876 & 250,300 & PA2750 & PA2751 & $>?>$ & ? & $?$ & - & + & + & - & - & (González et al., 2008) \\
\hline P14 & - & - & 3206497 & 3206915 & 300 & PA2852.1 & PA2853 & $\langle>>$ & $?$ & $?$ & - & + & + & - & - & (Livny et al., 2006) \\
\hline rgsA & 3318747 & 3318868 & 3318657 & 3318881 & 122 & PA2958 & PA2959 & $>><$ & 90 & 13 & - & + & + & - & - & (Livny et al., 2006; González et al., 2008; Sonnleitner et al., 2008) \\
\hline SRNA1714 & - & - & 3360654 & 3360873 & 200 & PA3001 & PA3002 & $<?>$ & $?$ & $?$ & - & - & + & - & - & (González et al., 2008) \\
\hline P18 & - & - & 3702951 & 3703166 & 100 & PA3304 & PA3305 & e<< & $?$ & $?$ & - & - & + & - & - & (Livny et al., 2006) \\
\hline phrS & \begin{tabular}{|c|}
3705309 \\
\end{tabular} & 3705521 & 3705161 & 3705888 & 213 & PA3305 & PA3306 & e< & 148 & 367 & + & + & + & - & - & (Livny et al., 2006; González et al., 2008; Sonnleitner et al., 2008) \\
\hline amiL & 3778034 & 3778133 & 3778000 & 3778265 & 100 & PA3366 & PA3367 & $<<>$ & 34 & 132 & - & + & + & - & - & (Sonnleitner et al., 2008) \\
\hline rsmz & \begin{tabular}{|l|}
4057543 \\
\end{tabular} & 4057658 & \begin{tabular}{|l|}
4057483 \\
\end{tabular} & 4057910 & 116 & PA3621 & PA3622 & $><<$ & 60 & 252 & - & + & + & - & - & (Heurlier et al., 2004; Livny et al., 2006) \\
\hline P24 & - & - & 4444597 & 4444977 & 300 & PA3964 & PA3965 & $><>$ & $?$ & $?$ & + & + & + & - & - & (Livny et al., 2006; Sonnleitner et al., 2008) \\
\hline sRNA2315 & - & - & 4536493 & 4536919 & 180 & PA4055 & PA4056 & $<<<$ & $?$ & $?$ & + & + & + & - & - & (González et al., 2008; Sonnleitner et al., 2008) \\
\hline P26 & - & - & 4780618 & 4780838 & 250 & PA4270 & PA4271 & e< & $?$ & $?$ & - & - & - & - & - & (Livny et al., 2006) \\
\hline P27 & - & - & 4781786 & 4781985 & 90 & PA4272 & PA4273 & $<><$ & $?$ & $?$ & - & + & - & + & 0.3 & (Livny et al., 2006) \\
\hline PA4406.1 & \begin{tabular}{|l|}
4939194 \\
\end{tabular} & 4939277 & 4939188 & 4939299 & 84 & PA4406 & PA4407 & $<><$ & 6 & 22 & - & - & + & - & - & (Sonnleitner et al., 2008) \\
\hline $\mathrm{rnpB}$ & - & - & 4956029 & 4956732 & 350 & PA4421 & PA4422 & e< & $?$ & $?$ & + & + & + & - & - & (Livny et al., 2006; González et al., 2008; Sonnleitner et al., 2008) \\
\hline PA4451.1 & \begin{tabular}{|c|}
4985782 \\
\end{tabular} & 4985843 & 4985731 & 4985846 & 62 & PA4451 & PA4452 & $\ll<<$ & 51 & 3 & - & - & - & - & - & (Livny et al., 2006) \\
\hline SRNA2626 & - & - & 5196833 & 5197184 & 200 & PA4628 & PA4629 & $\gg$ & $?$ & $?$ & + & + & + & - & - & (González et al., 2008; Sonnleitner et al., 2008) \\
\hline $\mathrm{prrH}$ & 5283960 & 5284319 & 5283906 & 5284368 & 360 & PA4703 & PA4704 & $>><$ & 54 & 49 & - & + & + & - & - & (Oglesby-Sherrouse and Vasil et al., 2010) \\
\hline prrF1 & \begin{tabular}{|l|}
5283960 \\
\end{tabular} & 5284110 & 5283906 & 5284368 & 151 & PA4704 & PA4705 & $>><$ & 54 & 258 & - & + & + & - & - & (Livny et al., 2006; González et al., 2008; Sonnleitner et al., 2008; Wilderman et al., 2004) \\
\hline prrF2 & 5284172 & 5284319 & 5283906 & 5284368 & 148 & PA4704 & PA4705 & $>><$ & 266 & 49 & - & + & + & - & - & (Livny et al., 2006; Sonnleitner et al., 2008) \\
\hline $\mathrm{crcZ}$ & 5308587 & 5308993 & 5308425 & 5309326 & 407 & PA4727 & PA4728 & $\gg>$ & 162 & 333 & + & + & + & - & - & (Sonnleitner et al., 2009) \\
\hline P30 & - & - & 5308425 & 5309326 & 180 & PA4726 & PA4727 & $><>$ & $?$ & $?$ & + & + & + & - & - & (Livny et al., 2006; Sonnleitner et al., 2008) \\
\hline P32 & - & - & 5344904 & \begin{tabular}{|l|}
5345085 \\
\end{tabular} & 80 & PA4758 & PA4759 & e<< & $?$ & $?$ & - & - & - & - & - & (Livny et al., 2006; Sonnleitner et al., 2008) \\
\hline P34 & - & - & 5835071 & 5835481 & 150 & PA5181 & PA5182 & $><>$ & $?$ & $?$ & - & + & + & - & - & (Livny et al., 2006) \\
\hline PhrX & \begin{tabular}{|l|}
5836429 \\
\end{tabular} & 5836579 & 5836402 & 5836909 & 151 & PA5183 & PA5184 & $><>$ & 27 & 330 & + & + & + & - & - & (Sonnleitner et al., 2008) \\
\hline Putative spot 42 & - & - & \begin{tabular}{|l|}
6183520 \\
\end{tabular} & 6183784 & 265 & PA5492 & PA5493 & $><<$ & 0 & 0 & + & + & + & - & - & (Gottesman et al., 2006) \\
\hline
\end{tabular}


a A location is given when the $5^{\prime}$ and $3^{\prime}$ ends can be deduced with reasonable certainty from available data.

b Experimentally found values.

c The middle arrow indicates the orientation of the sRNA, while the flanking arrows indicate the orientation of the adjacent genes. Unknown orientation of sRNAs is indicated by a question mark.

d A + indicates that the sRNA is differentially expressed in the conditions tested in this work.

e The fold change is calculated as the ratio of the intensities of the sRNA between the early-stationary and exponential conditions. Thus, a fold change $>1$ means that the sRNA is more expressed in the early-stationary than the exponential phase.

$f$ Mature tmRNA according to sequence homologies (Williams and Bartel, 1996).

g The mature form was reported with a length of $113 \mathrm{nt}$ (Toschka et al., 1989).

\section{REFERENCES}

González, N., Heeb, S., Valverde, C., Kay, E., Reimmann, C., Junier, T., and Haas, D. (2008) Genome-wide search reveals a novel GacA-regulated small RNA in Pseudomonas species. BMC genomics 9: 167.

Gottesman, S., McCullen, C.A., Guillier, M., Vanderpool, C.K., Majdalani, N., Benhammou, J. et al. (2006) Small RNA regulators and the bacterial response to stress. Cold Spring Harbor symposia on quantitative biology 71: 1.

Heurlier, K., Williams, F., Heeb, S., Dormond, C., Pessi, G., Singer, D. et al. (2004) Positive control of swarming, rhamnolipid synthesis, and lipase production by the posttranscriptional RsmA/RsmZ system in Pseudomonas aeruginosa PAO1. Journal of Bacteriology 186: 2936-2945.

Kay, E., Humair, B., Dénervaud, V., Riedel, K., Spahr. S., Eberl, L. et al. (2006) Two GacA-Dependent Small RNAs Modulate the Quorum-Sensing Response in Pseudomonas aeruginosa. Journal of Bacteriology 188: 6026-6033.

Livny, J., Brencic, A., Lory, S., and Waldor, M.K. (2006) Identification of 17 Pseudomonas aeruginosa sRNAs and prediction of sRNA-encoding genes in 10 diverse pathogens using the bioinformatic tool sRNAPredict2. Nucleic Acids Research 34: 3484.

Oglesby-Sherrouse, A.G., and Vasil, M.L. (2010) Characterization of a heme-regulated non-coding RNA encoded by the prrF locus of Pseudomonas aeruginosa. PLoS ONE 5: e9930.

Sonnleitner, E., Sorger-Domenigg, T., Madej, M.J., Findeiss, S., Hackermüller, J., Hüttenhofer, A. et al. (2008) Detection of small RNAs in Pseudomonas aeruginosa by RNomics and structure-based bioinformatic tools. Microbiology 154: 3175-3187.

Sonnleitner, E., Abdou, L., and Haas, D. (2009) Small RNA as global regulator of carbon catabolite repression in Pseudomonas aeruginosa. Proceedings of the National Academy of Sciences 106: $21866-21871$.

Toschka, H.Y., Struck, J.C., and Erdmann, V.A. (1989) The 4.5S RNA gene from Pseudomonas aeruginosa. Nucleic Acids Research 17: 31-36.

Vogel, D.W., Hartmann, R.K., Struck, J.C.R., Ulbrich, N., and Erdmann, V.A. (1987) The sequence of the 6S RNA gene of Pseudomonas aeruginosa. Nucleic Acids Research 15: $4583-4591$.

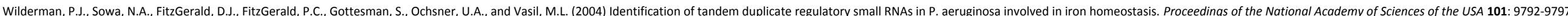
Williams, K.P., and Bartel, D.P. (1996) Phylogenetic analysis of tmRNA secondary structure. RNA 2: 1306-1310. 
Supplementary Table 4. Intergenic SRNAs candidates in Pseudomonas aeruginosa.

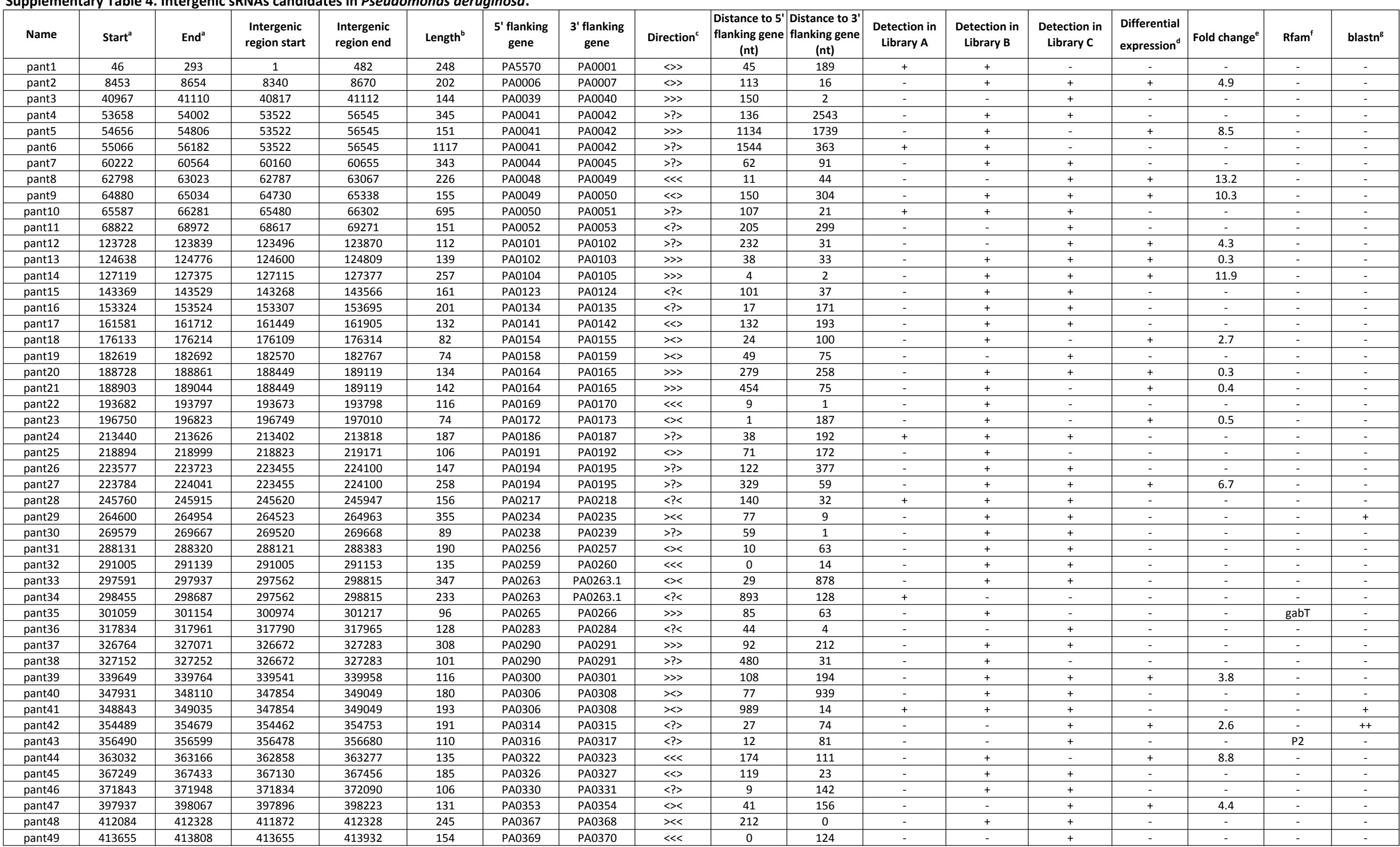




\begin{tabular}{|c|c|c|c|c|c|c|c|c|c|c|c|c|c|c|c|c|c|}
\hline pant50 & 449389 & 449483 & 449385 & 449638 & 95 & PA0407 & PA0408 & $<?>$ & 4 & 155 & - & + & - & - & - & - & - \\
\hline pant51 & 484173 & 484273 & 484116 & 484403 & 101 & PA0432 & PA0433 & $<?\rangle$ & 57 & 130 & - & - & + & - & - & AH riboswitc & - \\
\hline pant52 & 501123 & 501317 & 501121 & 501375 & 195 & PA0445 & PA0446 & $<?<$ & 2 & 58 & - & + & - & + & 2.0 & - & - \\
\hline pant53 & 507452 & 507589 & 507252 & 507630 & 138 & PA0450 & PA0451 & $\langle>\rangle$ & 200 & 41 & - & + & + & + & 3.2 & - & - \\
\hline pant54 & 514536 & 514620 & 514428 & 514774 & 85 & PA0455 & PA0456 & $\langle>\rangle$ & 108 & 154 & - & - & + & - & - & - & - \\
\hline pant55 & 517652 & 517740 & 517463 & 518082 & 89 & PA0458 & PA0459 & $\langle>\rangle$ & 189 & 342 & - & - & + & + & 246.3 & - & - \\
\hline pant56 & 521517 & 521870 & 521316 & 522464 & 354 & PA0460 & PA0462 & $><>$ & 201 & 594 & + & + & - & + & 3.1 & - & - \\
\hline pant57 & 521960 & 522172 & 521316 & 522464 & 213 & PA0460 & PA0462 & $><>$ & 644 & 292 & + & + & + & - & - & - & ++ \\
\hline pant58 & 522650 & 523205 & 522518 & 523253 & 556 & PA0461 & PA0463 & $<?>$ & 132 & 48 & + & - & - & + & 5.3 & - & + \\
\hline pant59 & 522753 & 522868 & 522518 & 523253 & 116 & PA0461 & PA0463 & $\langle>\rangle$ & 235 & 385 & - & - & + & + & 8.4 & - & ++ \\
\hline pant60 & 522900 & 523037 & 522518 & 523253 & 138 & PA0461 & PA0463 & $\langle>\rangle$ & 382 & 216 & - & + & + & + & 9.9 & - & + \\
\hline pant61 & 545931 & 546048 & 545645 & 546333 & 118 & PA0484 & PA0485 & $><<$ & 286 & 285 & - & + & - & + & 0.4 & - & - \\
\hline pant63 & 559211 & 559544 & 559079 & 559643 & 334 & PA0499 & PA0500 & $<?>$ & 132 & 99 & + & + & + & - & - & - & - \\
\hline pant64 & 600177 & 600277 & 600177 & 600425 & 101 & PA0542 & PA0543 & <<> & 0 & 148 & - & + & + & - & - & - & - \\
\hline pant65 & 627957 & 628275 & 627766 & 628334 & 319 & PA0572 & PA0573 & $<><$ & 191 & 59 & - & + & + & - & - & - & - \\
\hline pant66 & 648698 & 648847 & 648653 & 648930 & 150 & PA0588 & PA0589 & e & 45 & 83 & - & + & + & + & 7.0 & - & - \\
\hline pant67 & 674043 & 674369 & 673962 & 674418 & 327 & PA0611 & PA0612 & $\langle>\rangle$ & 81 & 49 & - & + & + & - & - & - & - \\
\hline pant68 & 698707 & 698894 & 698697 & 698931 & 188 & PA0641 & PA0642 & $\gg>$ & 10 & 37 & - & + & + & - & - & - & - \\
\hline pant69 & 703216 & 703328 & 703059 & 703476 & 113 & PA0648 & PA0649 & $\gg>$ & 157 & 148 & - & + & - & - & - & - & - \\
\hline pant70 & 706691 & 706815 & 706673 & 706943 & 125 & PA0652 & PA0653 & $\ll<$ & 18 & 128 & - & - & + & - & - & - & - \\
\hline pant71 & 707436 & 707677 & 707367 & 707685 & 242 & PA0653 & PA0654 & $\gg>$ & 69 & 8 & - & + & + & + & 0.3 & - & - \\
\hline pant72 & 727470 & 727602 & 727256 & 727607 & 133 & PA0668.5 & PA0669 & $>><$ & 214 & 5 & - & + & + & + & 0.5 & - & - \\
\hline pant73 & 773742 & 773924 & 773697 & 774415 & 183 & PA0701 & PA0702 & $>><$ & 45 & 491 & - & + & + & - & - & - & - \\
\hline pant76 & 785731 & 785832 & 785571 & 785968 & 102 & PA0714.1 & PA0715 & $><>$ & 160 & 136 & - & + & + & - & - & - & - \\
\hline pant77 & 788390 & 789051 & 788254 & 789143 & 662 & PA0716 & PA0717 & $>?>$ & 136 & 92 & - & + & + & - & - & - & + \\
\hline pant78 & 791239 & 791330 & 791235 & 791369 & 92 & PA0723 & PA0724 & $\gg>$ & 4 & 39 & - & + & - & - & - & - & - \\
\hline pant79 & 796855 & 797228 & 796777 & 797250 & 374 & PA0728 & PA0729 & $\gg>$ & 78 & 22 & - & - & + & - & - & - & - \\
\hline pant80 & 798893 & 799149 & 798828 & 799278 & 257 & PA0730 & PA0731 & $\ll<<$ & 65 & 129 & - & + & + & - & - & - & - \\
\hline pant81 & 804295 & 804574 & 804149 & 804655 & 280 & PA0736 & PA0737 & $\langle>\rangle$ & 146 & 81 & - & + & + & - & - & - & - \\
\hline pant82 & 804581 & 804652 & 804149 & 804655 & 72 & PA0736 & PA0737 & $<?>$ & 432 & 3 & - & + & + & - & - & - & - \\
\hline pant83 & 828360 & 828477 & 828345 & 828616 & 118 & PA0759 & PA0760 & $\langle>\rangle$ & 15 & 139 & - & + & + & + & 2.8 & - & - \\
\hline pant84 & 845182 & 845255 & 845180 & 845277 & 74 & $\begin{array}{l}\text { PA0777 } \\
\end{array}$ & PA0778 & e & 2 & 22 & - & - & + & - & - & - & - \\
\hline pant85 & 851613 & 851745 & 851320 & 851782 & 133 & PA0781 & PA0782 & $\langle>\rangle$ & 293 & 37 & - & - & + & + & 0.0 & - & - \\
\hline pant86 & 855071 & 855234 & 854966 & 855276 & 164 & PA0782 & PA0783 & $\gg>$ & 105 & 42 & - & + & + & - & - & - & - \\
\hline pant87 & 863428 & 863611 & 863301 & 864094 & 184 & PA0788 & PA0789 & $\langle>>$ & 127 & 483 & - & + & + & - & - & - & - \\
\hline pant88 & 863878 & 864029 & 863301 & 864094 & 152 & PA0788 & PA0789 & $\langle>\rangle$ & 577 & 65 & - & + & + & - & - & - & - \\
\hline pant89 & 883433 & 883594 & 883217 & 883776 & 162 & PA0805 & PA0806 & $<?>>$ & 216 & 182 & - & - & + & - & - & - & - \\
\hline pant90 & 884351 & 884629 & 884173 & 884798 & 279 & PA0806 & PA0807 & $>?>$ & 178 & 169 & + & - & - & - & - & - & - \\
\hline pant91 & 892821 & 892966 & 892821 & 893040 & 146 & PA0814 & PA0815 & $\ll<>$ & 0 & 74 & - & + & + & - & - & - & - \\
\hline pant92 & 896243 & 896374 & 896118 & 896415 & 132 & PA0819 & PA0820 & $\gg>$ & 125 & 41 & - & - & + & + & 6.1 & - & - \\
\hline pant93 & 913662 & 913761 & 913572 & 913776 & 100 & PA0837 & PA0838 & $\gg>$ & 90 & 15 & - & + & - & - & - & - & - \\
\hline pant94 & 916156 & 916300 & 916156 & 916345 & 145 & PA0840 & PA0841 & $><>$ & 0 & 45 & - & + & + & - & - & - & - \\
\hline pant95 & 927232 & 927551 & 927215 & 927879 & 320 & PA0847 & PA0849 & $<?>$ & 17 & 328 & - & - & + & + & 6.9 & - & ++ \\
\hline pant96 & 927603 & 927784 & 927215 & 927879 & 182 & PA0847 & PA0849 & $\langle>$ & 388 & 95 & - & + & + & - & - & - & ++ \\
\hline pant97 & 936354 & 936454 & 936295 & 936458 & 101 & PA0857 & PA0858 & $\gg \gg$ & 59 & 4 & - & + & + & - & - & - & - \\
\hline pant101 & 1006635 & 1006711 & 1006612 & 1006859 & 77 & PA0920 & PA0921 & $\ll<$ & 23 & 148 & - & + & - & + & 7.5 & - & - \\
\hline pant102 & 1038894 & 1038971 & 1038886 & 1039239 & 78 & PA0951 & PA0952 & $>><$ & 8 & 268 & - & + & - & - & - & - & - \\
\hline pant103 & 1045522 & 1045656 & 1045315 & 1045831 & 135 & PA0958 & PA0959 & <<> & 207 & 175 & - & + & + & + & 2.8 & - & - \\
\hline
\end{tabular}




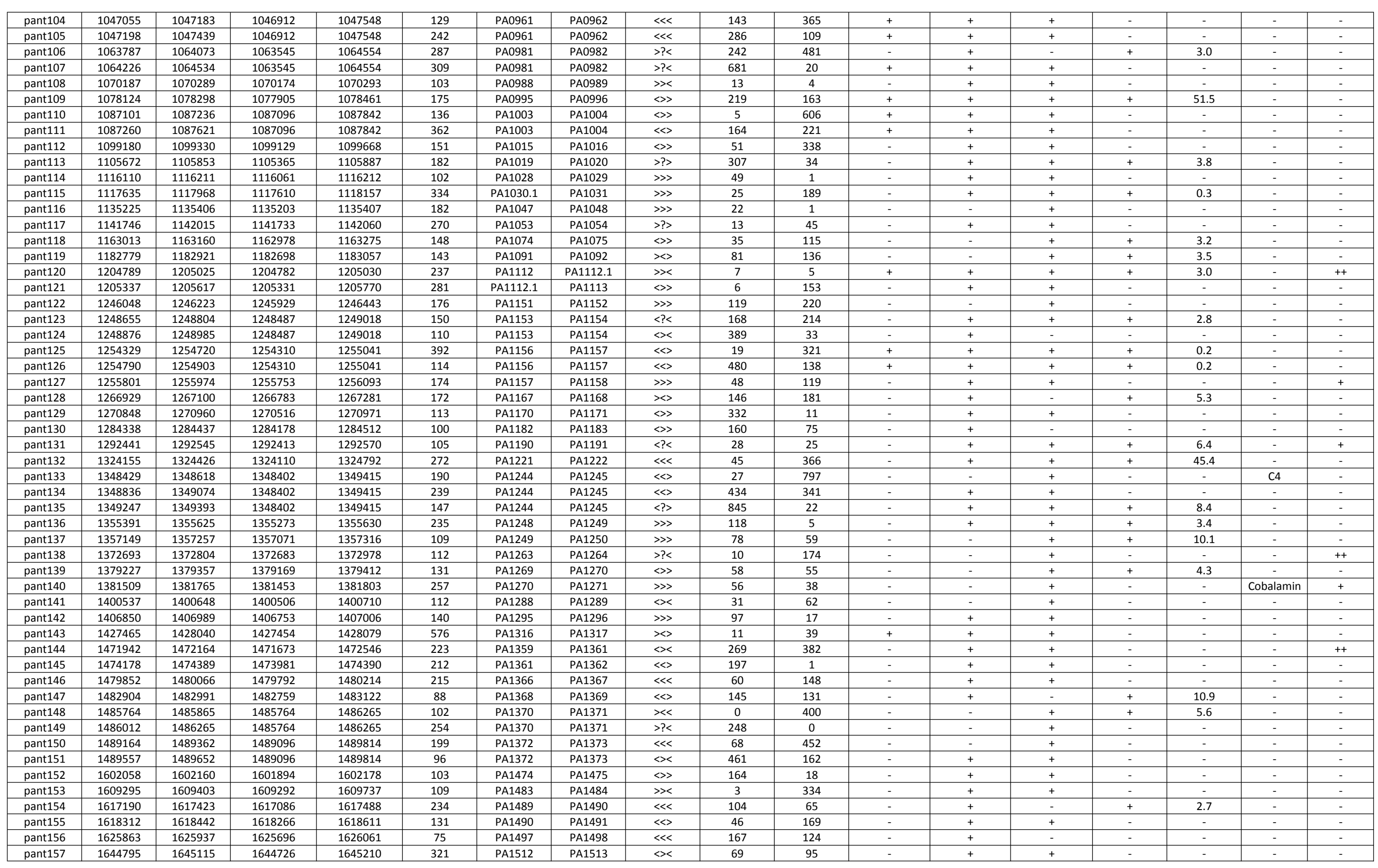




\begin{tabular}{|c|c|c|c|c|c|c|c|c|c|c|c|c|c|c|c|c|c|}
\hline pant158 & 1681845 & 1681933 & 1681806 & 1682050 & 89 & PA1544 & PA1545 & $<?>$ & 39 & 117 & - & - & + & + & 8.2 & - & - \\
\hline pant159 & 1703072 & 1703249 & 1703053 & 1703378 & 178 & PA1562 & PA1563 & $\langle ?\rangle$ & 19 & 129 & - & + & + & + & 4.0 & - & - \\
\hline pant160 & 1717940 & 1718216 & 1717895 & 1718385 & 277 & $\begin{array}{l}\text { PA1578 } \\
\end{array}$ & PA1579 & $\gg>$ & 45 & 169 & + & + & + & + & 0.2 & - & ++ \\
\hline pant161 & 1729853 & 1730100 & 1729853 & 1730180 & 248 & $\begin{array}{l}\text { PA1587 } \\
\end{array}$ & $\begin{array}{l}\text { PA1588 } \\
\end{array}$ & $\gg>$ & 0 & 80 & - & - & + & - & - & - & - \\
\hline pant162 & 1732291 & 1732390 & 1732235 & 1732544 & 100 & $\begin{array}{l}\text { PA1589 } \\
\end{array}$ & $\begin{array}{l}\text { PA1590 } \\
\end{array}$ & $>?>$ & 56 & 154 & - & + & - & - & - & - & - \\
\hline pant163 & 1758602 & 1758698 & 1758598 & 1758747 & 97 & PA1613 & PA1614 & $<?>$ & 4 & 49 & - & + & + & - & - & - & - \\
\hline pant164 & 1773494 & 1773592 & 1773441 & 1773681 & 99 & PA1629 & PA1630 & $<?>$ & 53 & 89 & - & + & - & - & - & - & - \\
\hline pant165 & 1802487 & 1802745 & 1802454 & 1803625 & 259 & PA1655 & PA1656 & $>?>$ & 33 & 880 & - & + & + & - & - & - & - \\
\hline pant166 & 1802750 & 1803294 & 1802454 & 1803625 & 545 & $\begin{array}{l}\text { PA1655 } \\
\end{array}$ & $\begin{array}{l}\text { PA1656 } \\
\end{array}$ & $\gg>$ & 296 & 331 & - & + & + & + & 8.8 & - & - \\
\hline pant167 & 1803380 & 1803604 & 1802454 & 1803625 & 225 & $\begin{array}{l}\text { PA1655 } \\
\end{array}$ & $\begin{array}{l}\text { PA1656 } \\
\end{array}$ & $\gg>$ & 926 & 21 & - & + & - & - & - & - & - \\
\hline pant168 & 1824753 & 1824900 & 1824724 & 1824968 & 148 & PA1672 & PA1673 & $<<>$ & 29 & 68 & - & - & + & - & - & - & - \\
\hline pant169 & 1882442 & 1882555 & 1882344 & 1882594 & 114 & $\begin{array}{l}\text { PA1737 } \\
\end{array}$ & $\begin{array}{l}\text { PA1738 } \\
\end{array}$ & $><<$ & 98 & 39 & - & - & + & - & - & - & - \\
\hline pant170 & 1886040 & 1886112 & 1886034 & 1886277 & 73 & $\begin{array}{l}\text { PA1741 } \\
\end{array}$ & PA1742 & $<<>$ & 6 & 165 & - & - & + & + & 4.0 & - & - \\
\hline pant171 & 1904315 & 1904419 & 1904248 & 1904478 & 105 & $\begin{array}{l}\text { PA1760 } \\
\end{array}$ & $\begin{array}{l}\text { PA1761 } \\
\end{array}$ & $\gg>$ & 67 & 59 & - & - & + & + & 8.0 & - & - \\
\hline pant172 & 1947992 & 1948157 & 1947805 & 1948501 & 166 & $\begin{array}{l}\text { PA1796.4 } \\
\end{array}$ & $\begin{array}{l}\text { PA1797 } \\
\end{array}$ & $>><$ & 187 & 344 & - & + & + & - & - & - & - \\
\hline pant173 & 1948239 & 1948395 & 1947805 & 1948501 & 157 & PA1796.4 & PA1797 & $>?<$ & 434 & 106 & - & + & - & + & 2.2 & - & - \\
\hline pant174 & 1988953 & 1989087 & 1988852 & 1989108 & 135 & PA1829 & PA1830 & $<><$ & 101 & 21 & - & + & + & - & - & - & - \\
\hline pant175 & 2005007 & 2005107 & 2004893 & 2005253 & 101 & PA1845 & PA1846 & <<> & 114 & 146 & - & + & + & + & 2.8 & - & - \\
\hline pant176 & 2012651 & 2012770 & 2012531 & 2012814 & 120 & $\begin{array}{l}\text { PA1852 } \\
\end{array}$ & $\begin{array}{l}\text { PA1853 } \\
\end{array}$ & $<?>$ & 120 & 44 & - & + & + & - & - & - & - \\
\hline pant177 & 2016813 & 2016924 & 2016582 & 2016927 & 112 & $\begin{array}{l}\text { PA1856 } \\
\end{array}$ & PA1857 & $<><$ & 231 & 3 & - & - & + & - & - & - & - \\
\hline pant178 & 2028243 & 2028416 & 2028014 & 2028453 & 174 & PA1866 & PA1867 & $\gg>$ & 229 & 37 & - & + & + & - & - & - & - \\
\hline pant179 & 2031706 & 2031839 & 2031706 & 2031987 & 134 & PA1869 & PA1870 & $\gg \gg$ & 0 & 148 & - & + & - & + & 4.2 & - & - \\
\hline pant180 & 2068748 & 2068961 & 2068729 & 2069489 & 214 & $\begin{array}{l}\text { PA1897 } \\
\end{array}$ & PA1898 & $<?>$ & 19 & 528 & - & + & - & + & 12.0 & - & - \\
\hline pant181 & 2068964 & 2069268 & 2068729 & 2069489 & 305 & $\begin{array}{l}\text { PA1897 } \\
\end{array}$ & $\begin{array}{l}\text { PA1898 } \\
\end{array}$ & $\langle>\rangle$ & 235 & 221 & - & + & + & - & - & - & - \\
\hline pant182 & 2070481 & 2070599 & 2070204 & 2070684 & 119 & $\begin{array}{l}\text { PA1898 } \\
\end{array}$ & PA1899 & $\gg>$ & 277 & 85 & - & + & + & + & 62.3 & - & - \\
\hline pant183 & 2093320 & 2093418 & 2093251 & 2093443 & 99 & PA1918 & PA1919 & $<><$ & 69 & 25 & - & + & - & - & - & - & - \\
\hline pant184 & 2104152 & 2104333 & 2104097 & 2104596 & 182 & $\begin{array}{l}\text { PA1925 } \\
\end{array}$ & PA1926 & $\gg>$ & 55 & 263 & - & + & + & - & - & - & ++ \\
\hline pant185 & 2104397 & 2104580 & 2104097 & 2104596 & 184 & $\begin{array}{l}\text { PA1925 } \\
\end{array}$ & PA1926 & $\gg>$ & 300 & 16 & - & + & + & + & 0.3 & - & ++ \\
\hline pant186 & 2118138 & 2118426 & 2118098 & 2118584 & 289 & $\begin{array}{l}\text { PA1936 } \\
\end{array}$ & $\begin{array}{l}\text { PA1937 } \\
\end{array}$ & $><>$ & 40 & 158 & - & + & + & + & 3.0 & - & - \\
\hline pant187 & 2119868 & 2120185 & 2119748 & 2120224 & 318 & $\begin{array}{l}\text { PA1938 } \\
\end{array}$ & $\begin{array}{l}\text { PA1939 } \\
\end{array}$ & $><<$ & 120 & 39 & - & + & + & + & $\begin{array}{l}2.7 \\
\end{array}$ & - & - \\
\hline pant188 & 2130677 & 2130840 & 2130636 & 2130853 & 164 & PA1945 & $\begin{array}{l}\text { PA1946 } \\
\end{array}$ & $><>$ & 41 & 13 & - & + & + & - & - & - & - \\
\hline pant189 & 2153211 & 2153381 & 2153069 & 2153593 & 171 & $\begin{array}{l}\text { PA1971 } \\
\end{array}$ & PA1972 & $\langle>\rangle$ & 142 & 212 & - & + & + & - & - & - & - \\
\hline pant190 & 2189965 & 2190071 & 2189884 & 2190083 & 107 & PA2002 & PA2003 & $>><$ & 81 & 12 & - & + & + & - & - & - & - \\
\hline pant191 & 2230425 & 2230600 & 2230184 & 2230688 & 176 & $\begin{array}{l}\text { PA2039 } \\
\end{array}$ & PA2040 & $\langle>\rangle$ & 241 & 88 & - & + & - & + & 3.2 & - & - \\
\hline pant192 & 2232100 & 2232186 & 2232066 & 2232221 & 87 & PA2040 & $\begin{array}{l}\text { PA2041 } \\
\end{array}$ & $\gg>$ & 34 & 35 & - & + & + & + & $\begin{array}{l}4.7 \\
\end{array}$ & - & - \\
\hline pant193 & 2233636 & 2233805 & 2233593 & 2234079 & 170 & PA2041 & PA2042 & $\gg \gg$ & 43 & 274 & - & + & + & - & - & - & - \\
\hline pant194 & 2282233 & 2282379 & 2281579 & 2282479 & 147 & PA2075 & PA2076 & $<?>$ & 654 & 100 & - & + & + & - & - & - & - \\
\hline pant195 & 2291596 & 2291763 & 2291590 & 2291790 & 168 & PA2082 & PA2083 & $>?>$ & 6 & 27 & - & + & - & - & - & - & - \\
\hline pant196 & 2314392 & 2314498 & 2314250 & 2314511 & 107 & $\begin{array}{l}\text { PA2102 } \\
\end{array}$ & PA2103 & $\gg>$ & 142 & 13 & - & + & - & + & 4.6 & - & - \\
\hline pant197 & 2330441 & 2330688 & 2330425 & 2330958 & 248 & $\begin{array}{l}\text { PA2118 } \\
\end{array}$ & $\begin{array}{l}\text { PA2119 } \\
\end{array}$ & $>?<$ & 16 & 270 & + & + & + & - & - & - & - \\
\hline pant198 & 2330834 & 2330934 & 2330425 & 2330958 & 101 & PA2118 & PA2119 & $>?<$ & 409 & 24 & - & - & + & + & 4.7 & - & - \\
\hline pant199 & 2341653 & 2341988 & 2341641 & 2342492 & 336 & PA2127 & PA2128 & 《<> & 12 & 504 & - & + & + & + & 3.7 & - & - \\
\hline pant200 & 2341875 & 2341978 & 2341641 & 2342492 & 104 & PA2127 & PA2128 & $\langle>\rangle$ & 234 & 514 & - & + & - & + & 3.4 & - & - \\
\hline pant201 & 2342040 & 2342162 & 2341641 & 2342492 & 123 & $\begin{array}{l}\text { PA2127 } \\
\end{array}$ & PA2128 & $<<>$ & 399 & 330 & - & + & - & - & - & - & - \\
\hline pant202 & 2396383 & 2396488 & 2396253 & 2396535 & 106 & $\begin{array}{l}\text { PA2174 } \\
\end{array}$ & PA2175 & $<><$ & 130 & 47 & - & - & + & + & 4.2 & - & - \\
\hline pant203 & 2442721 & 2443060 & 2442692 & 2443160 & 340 & PA2220 & PA2221 & $>?>$ & 29 & 100 & + & + & + & - & - & - & - \\
\hline pant204 & 2444367 & 2444624 & 2444367 & 2444885 & 258 & PA2221 & PA2222 & $><<$ & 0 & 261 & - & + & + & - & - & - & - \\
\hline pant205 & 2447361 & 2447521 & 2447326 & 2447572 & 161 & PA2224 & PA2225 & 《<< & 35 & 51 & - & + & + & + & 3.5 & - & - \\
\hline pant206 & 2450801 & 2450900 & 2450766 & 2451706 & 100 & $\begin{array}{l}\text { PA2228 } \\
\end{array}$ & PA2229 & e<> & 35 & 806 & - & + & - & - & - & - & - \\
\hline pant207 & 2451228 & 2451464 & 2450766 & 2451706 & 237 & PA2228 & PA2229 & $\langle ?\rangle$ & 462 & 242 & + & - & - & + & 2.2 & - & - \\
\hline pant 208 & 2453289 & 2453505 & 2453141 & 2453666 & 217 & PA2230 & PA2231 & $><>$ & 148 & 161 & - & + & + & - & - & - & - \\
\hline pant209 & 2493101 & 2493210 & 2493051 & 2493217 & 110 & PA2263 & PA2264 & $>?>$ & 50 & 7 & - & + & + & + & 9.3 & - & - \\
\hline pant 210 & 2521175 & 2521247 & 2521105 & 2521257 & 73 & PA2290 & PA2291 & $<?<$ & 70 & 10 & - & - & + & - & - & - & - \\
\hline pant211 & 2522623 & 2522747 & 2522617 & 2522957 & 125 & PA2291 & $\begin{array}{l}\text { PA2292 } \\
\end{array}$ & < < & 6 & 210 & - & + & + & - & - & - & - \\
\hline
\end{tabular}




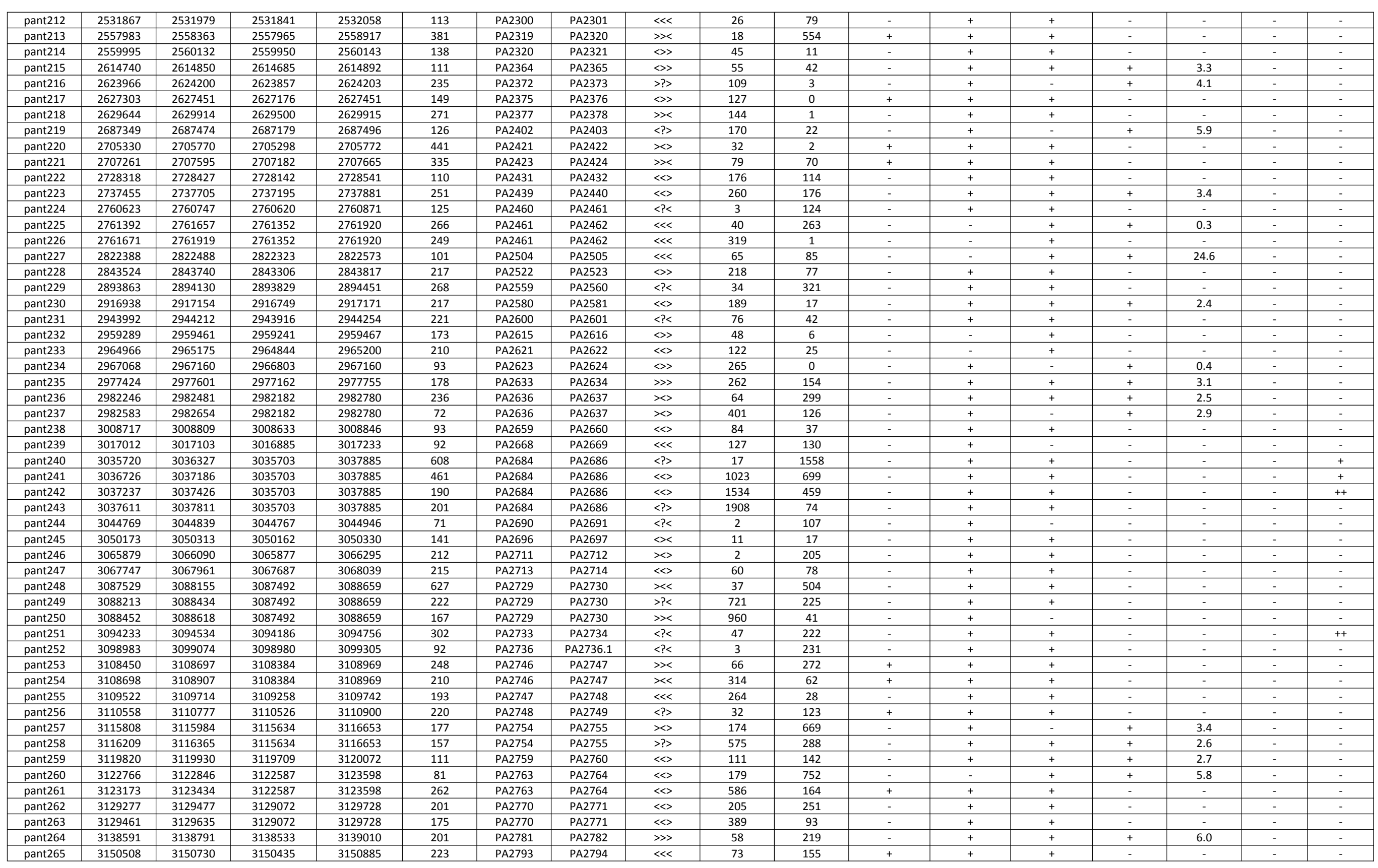




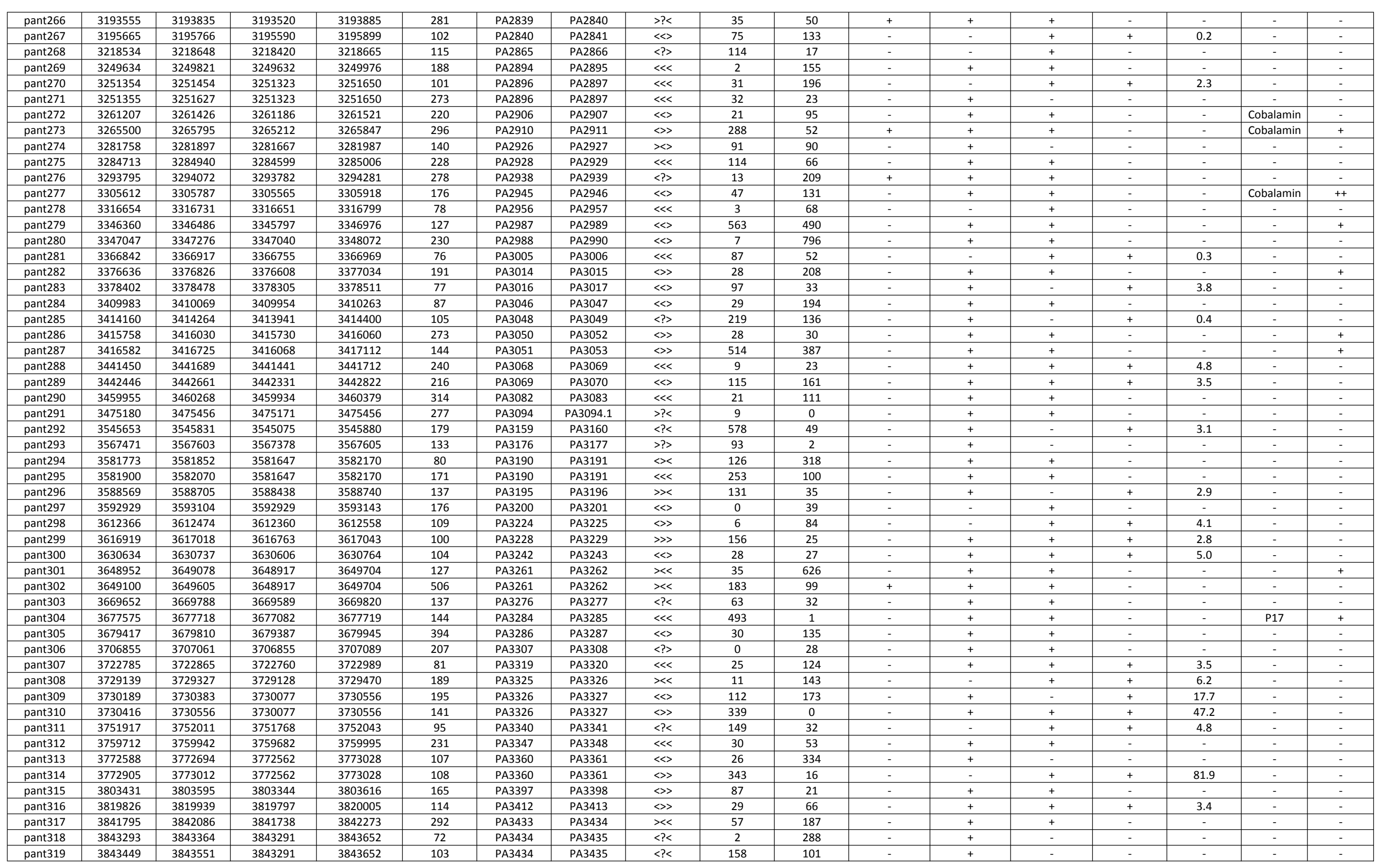




\begin{tabular}{|c|c|c|c|c|c|c|c|c|c|c|c|c|c|c|c|c|c|}
\hline pant320 & 3865152 & 3865261 & 3865127 & 3865280 & 110 & PA3457 & PA3458 & $>?<$ & 25 & 19 & - & - & + & + & 2.4 & - & - \\
\hline pant321 & 3877915 & 3878018 & 3877912 & 3878032 & 104 & PA3465 & PA3466 & $><<$ & 3 & 14 & - & - & + & - & - & - & - \\
\hline pant322 & 3885259 & 3885449 & 3885255 & 3885710 & 191 & PA3471 & PA3472 & <<> & 4 & 261 & - & + & + & - & - & - & - \\
\hline pant323 & 3885464 & 3885686 & 3885255 & 3885710 & 223 & PA3471 & PA3472 & $\langle>\rangle$ & 209 & 24 & - & - & + & - & - & - & - \\
\hline pant324 & 3893030 & 3893253 & 3893009 & 3893431 & 224 & PA3479 & PA3480 & e & 21 & 178 & - & + & + & + & 4.2 & - & + \\
\hline pant325 & 3900073 & 3900231 & 3899939 & 3900232 & 159 & PA3485 & PA3486 & $\gg>$ & 134 & 1 & - & + & + & - & - & - & - \\
\hline pant326 & 3930268 & 3930716 & 3930231 & 3930742 & 449 & PA3514 & PA3515 & $<><$ & 37 & 26 & - & + & + & - & - & - & - \\
\hline pant327 & 3936883 & 3937150 & 3936838 & 3937237 & 268 & PA3519 & PA3520 & $\ll<<$ & 45 & 87 & + & + & - & + & 6.5 & - & - \\
\hline pant328 & 3937547 & 3937816 & 3937433 & 3938019 & 270 & PA3520 & PA3521 & $<><$ & 114 & 203 & - & + & + & - & - & - & - \\
\hline pant329 & 3949697 & 3949817 & 3949594 & 3949852 & 121 & PA3529 & PA3530 & e<> & 103 & 35 & - & + & + & - & - & - & - \\
\hline pant330 & 3954610 & 3954687 & 3954609 & 3954906 & 78 & PA3534 & PA3535 & $\ll<>$ & 1 & 219 & - & - & + & + & 5.9 & - & - \\
\hline pant331 & 3957895 & 3957978 & 3957895 & 3958287 & 84 & PA3535 & PA3536 & $>><$ & 0 & 309 & - & + & - & - & - & - & - \\
\hline pant333 & 3958814 & 3959028 & 3958756 & 3959032 & 215 & PA3536 & PA3537 & e<> & 58 & 4 & + & + & + & - & - & - & - \\
\hline pant334 & 3979483 & 3979687 & 3979477 & 3979859 & 205 & PA3551 & PA3552 & $><>$ & 6 & 172 & - & + & + & - & - & - & - \\
\hline pant335 & 4009052 & 4009156 & 4009052 & 4009541 & 105 & PA3577 & PA3578 & $\ll<<$ & 0 & 385 & - & - & + & - & - & - & + \\
\hline pant336 & 4009456 & 4009526 & 4009052 & 4009541 & 71 & PA3577 & PA3578 & $<?<$ & 404 & 15 & - & + & - & - & - & - & - \\
\hline pant337 & 4012689 & 4012804 & 4012542 & 4012805 & 116 & PA3580 & PA3581 & $<?>$ & 147 & 1 & - & + & - & + & 0.1 & - & - \\
\hline pant338 & 4029599 & 4029753 & 4029541 & 4029758 & 155 & PA3594 & PA3595 & $\gg>$ & 58 & 5 & - & + & + & - & - & - & - \\
\hline pant339 & 4064994 & 4065078 & 4064988 & 4065118 & 85 & PA3629 & PA3630 & < & 6 & 40 & - & + & - & + & 3.3 & - & - \\
\hline pant340 & 4072509 & 4072650 & 4072489 & 4072658 & 142 & PA3637 & PA3638 & $\ll<$ & 20 & 8 & - & + & + & - & - & - & - \\
\hline pant341 & 4080262 & 4080358 & 4080224 & 4080439 & 97 & PA3641 & PA3642 & $<?<$ & 38 & 81 & - & + & - & + & 0.2 & - & - \\
\hline pant342 & 4092998 & 4093157 & 4092969 & 4093166 & 160 & PA3654 & PA3655 & e & 29 & 9 & - & + & + & + & 0.2 & - & - \\
\hline pant343 & 4094917 & 4095015 & 4094908 & 4095171 & 99 & PA3656 & PA3657 & $<<>$ & 9 & 156 & - & - & + & - & - & t44 & + \\
\hline pant346 & 4170519 & 4170697 & 4170484 & 4170769 & 179 & PA3724 & PA3725 & $\ll<$ & 35 & 72 & - & + & + & + & 16.3 & - & - \\
\hline pant347 & 4183467 & 4183589 & 4183229 & 4183709 & 123 & PA3732 & PA3733 & $\ll<>$ & 238 & 120 & - & + & + & - & - & - & - \\
\hline pant348 & 4185172 & 4185429 & 4184940 & 4185521 & 258 & PA3733 & PA3734 & $>>>$ & 232 & 92 & + & - & - & + & 5.5 & - & - \\
\hline pant349 & 4189585 & 4189708 & 4189548 & 4189760 & 124 & PA3736 & PA3737 & e & 37 & 52 & - & + & + & - & - & - & - \\
\hline pant350 & 4241090 & 4241338 & 4240580 & 4241341 & 249 & PA3781 & PA3782 & $>><$ & 510 & 3 & - & + & + & - & - & - & - \\
\hline pant351 & 4281929 & 4282070 & 4281752 & 4282077 & 142 & PA3824.1 & PA3825 & $>><$ & 177 & 7 & - & + & + & + & 0.3 & - & - \\
\hline pant352 & 4288718 & 4288937 & 4288607 & 4288942 & 220 & PA3830 & PA3831 & $<?>$ & 111 & 5 & - & - & + & - & - & - & - \\
\hline pant353 & 4295455 & 4296062 & 4294606 & 4297249 & 608 & PA3835 & PA3836 & $<<>$ & 849 & 1187 & + & - & - & - & - & - & - \\
\hline pant354 & 4296539 & 4296803 & 4294606 & 4297249 & 265 & PA3835 & PA3836 & <<> & 1933 & 446 & - & + & - & + & 5.3 & - & - \\
\hline pant355 & 4296877 & 4296974 & 4294606 & 4297249 & 98 & PA3835 & PA3836 & $\ll<>$ & 2271 & 275 & - & - & + & + & 9.1 & - & - \\
\hline pant356 & 4321074 & 4321255 & 4320821 & 4321433 & 182 & PA3860 & PA3861 & $\langle>\rangle$ & 253 & 178 & - & + & + & - & - & - & - \\
\hline pant357 & 4326945 & 4327123 & 4326396 & 4327696 & 179 & PA3865 & PA3866 & $<><$ & 549 & 573 & - & - & + & + & 7.8 & - & - \\
\hline pant358 & 4344851 & 4344951 & 4344836 & 4345009 & 101 & $\begin{array}{l}\text { PA3877 } \\
\end{array}$ & PA3878 & $\langle>\rangle$ & 15 & 58 & - & + & + & - & - & - & - \\
\hline pant359 & 4352499 & 4352599 & 4352495 & 4352827 & 101 & PA3886 & PA3887 & $>><$ & 4 & 228 & - & + & + & + & 5.9 & - & + \\
\hline pant360 & 4354229 & 4354375 & 4354103 & 4354543 & 147 & PA3887 & PA3888 & $\ll<>$ & 126 & 168 & - & + & + & - & - & - & - \\
\hline pant361 & 4388737 & 4388953 & 4388728 & 4389230 & 217 & PA3919 & PA3920 & $\ll<>$ & 9 & 277 & - & + & + & - & - & - & + \\
\hline pant362 & 4403499 & 4403704 & 4403427 & 4403706 & 206 & PA3927 & PA3928 & $>><$ & 72 & 2 & - & + & + & - & - & - & - \\
\hline pant363 & 4406484 & 4406652 & 4406369 & 4406805 & 169 & PA3930 & PA3931 & $\langle>\rangle$ & 115 & 153 & - & + & + & + & 7.6 & - & - \\
\hline pant364 & 4418063 & 4418200 & 4417935 & 4418302 & 138 & PA3939 & PA3940 & $\langle>\rangle$ & 128 & 102 & - & + & + & - & - & - & - \\
\hline pant365 & 4433194 & 4433358 & 4433171 & 4433410 & 165 & PA3952 & PA3953 & $\ll<>$ & 23 & 52 & - & + & + & - & - & - & - \\
\hline pant366 & 4472724 & 4472848 & 4472199 & 4473622 & 125 & PA3991 & PA3993 & $\ll<>$ & 525 & 774 & - & - & + & + & 5.2 & - & + \\
\hline pant367 & 4472877 & 4473081 & 4472199 & 4473622 & 205 & PA3991 & PA3993 & $\langle>\rangle$ & 678 & 541 & - & + & + & - & - & - & ++ \\
\hline pant371 & 4518941 & 4519197 & 4518871 & 4519274 & 257 & PA4036 & PA4037 & $><>$ & 70 & 77 & + & + & + & - & - & - & - \\
\hline pant372 & 4523842 & 4523939 & 4523754 & 4523984 & 98 & PA4040 & PA4041 & $>><$ & 88 & 45 & - & + & + & - & - & - & - \\
\hline pant373 & 4536503 & 4536632 & 4536494 & 4536920 & 130 & PA4055 & PA4056 & e & 9 & 288 & - & + & + & - & - & - & - \\
\hline
\end{tabular}




\begin{tabular}{|c|c|c|c|c|c|c|c|c|c|c|c|c|c|c|c|c|c|}
\hline pant374 & 4545655 & 4545745 & 4545306 & 4545745 & 91 & PA4067 & PA4068 & $><<$ & 349 & 0 & - & + & + & - & - & - & - \\
\hline pant375 & 4547578 & 4547720 & 4547553 & 4547820 & 143 & PA4069 & PA4070 & $\ll<$ & 25 & 100 & - & + & - & - & - & - & - \\
\hline pant376 & 4559680 & 4559844 & 4559651 & 4560294 & 165 & PA4080 & PA4081 & $\ll<$ & 29 & 450 & - & + & + & - & - & - & - \\
\hline pant377 & 4559856 & 4560204 & 4559651 & 4560294 & 349 & PA4080 & PA4081 & $<<<$ & 205 & 90 & + & + & + & - & - & - & - \\
\hline pant378 & 4592559 & 4592662 & 4592432 & 4592989 & 104 & PA4108 & $\begin{array}{l}\text { PA4109 } \\
\end{array}$ & $>><$ & 127 & 327 & - & + & + & + & 4.1 & - & - \\
\hline pant379 & 4592808 & 4592973 & 4592432 & 4592989 & 166 & PA4108 & PA4109 & $><<$ & 376 & 16 & - & + & + & + & 3.0 & - & - \\
\hline pant380 & 4601449 & 4601564 & 4601421 & 4601573 & 116 & PA4113 & PA4114 & e & 28 & 9 & - & + & + & - & - & - & - \\
\hline pant381 & 4629195 & 4629347 & 4629186 & 4629943 & 153 & PA4138 & PA4139 & <<> & 9 & 596 & - & + & + & - & - & - & - \\
\hline pant382 & 4632172 & 4632301 & 4632169 & 4632476 & 130 & PA4140 & PA4141 & $><>$ & 3 & 175 & - & + & + & + & 2.7 & - & - \\
\hline pant383 & 4639348 & 4639448 & 4639292 & 4639501 & 101 & PA4146 & PA4147 & $><<$ & 56 & 53 & - & - & + & + & 5.0 & - & - \\
\hline pant384 & 4648578 & 4648773 & 4648564 & 4648998 & 196 & PA4154 & PA4155 & $<><$ & 14 & 225 & - & + & + & - & - & - & - \\
\hline pant385 & 4670823 & 4671197 & 4670785 & 4671318 & 375 & PA4174 & PA4175 & $>?>$ & 38 & 121 & - & + & + & + & 3.9 & - & - \\
\hline pant387 & 4713137 & 4713370 & 4713100 & 4713795 & 234 & PA4209 & PA4210 & $<?>$ & 37 & 425 & - & - & + & + & 200.7 & - & + \\
\hline pant388 & 4713459 & 4713664 & 4713100 & 4713795 & 206 & PA4209 & PA4210 & $\langle>\rangle$ & 359 & 131 & - & + & + & - & - & - & + \\
\hline pant389 & 4783131 & 4783217 & 4783112 & 4783227 & 87 & PA4274 & PA4275 & $<?<$ & 19 & 10 & - & - & + & - & - & - & + \\
\hline pant390 & 4791760 & 4791860 & 4791725 & 4791950 & 101 & PA4280.2 & \begin{tabular}{|l|l} 
PA4280.3 \\
\end{tabular} & $<<<$ & 35 & 90 & - & - & + & + & 68.3 & - & ++ \\
\hline pant391 & 4813801 & 4813991 & 4812602 & 4814212 & 191 & PA4289 & PA4291 & $><>$ & 1199 & 221 & - & + & + & - & - & - & + \\
\hline pant392 & 4814535 & 4814996 & 4814215 & 4815042 & 462 & PA4290 & $\begin{array}{l}\text { PA4292 } \\
\end{array}$ & $\langle>\rangle$ & 320 & 46 & + & + & + & - & - & - & - \\
\hline pant393 & 4830663 & 4830846 & 4830555 & 4830963 & 184 & PA4305 & PA4306 & «《> & 108 & 117 & - & + & + & + & 10.5 & - & - \\
\hline pant394 & 4834913 & 4835263 & 4834865 & 4835263 & 351 & PA4308 & PA4309 & $\langle>\rangle$ & 48 & 0 & - & - & + & - & - & - & - \\
\hline pant395 & 4854991 & 4855070 & 4854979 & 4855071 & 80 & PA4326 & PA4327 & $\langle>\rangle$ & 12 & 1 & - & + & - & + & 14.8 & - & - \\
\hline pant396 & 4860508 & 4861088 & 4860256 & 4861652 & 581 & PA4331 & PA4333 & <<> & 252 & 564 & - & + & + & + & 2.6 & - & + \\
\hline pant397 & 4861124 & 4861399 & 4860256 & 4861652 & 276 & PA4331 & $\begin{array}{l}\text { PA4333 } \\
\end{array}$ & $<?>$ & 868 & 253 & + & + & + & - & - & - & - \\
\hline pant399 & 4862054 & 4862348 & 4861712 & 4863272 & 295 & PA4332 & PA4334 & $<><$ & 342 & 924 & - & + & + & + & 0.4 & - & ++ \\
\hline pant 400 & 4862626 & 4863181 & 4861712 & 4863272 & 556 & PA4332 & PA4334 & $<><$ & 914 & 91 & + & + & + & - & - & - & ++ \\
\hline pant401 & 4878593 & 4878723 & 4878588 & 4878789 & 131 & PA4349 & PA4350 & $\ll<>$ & 5 & 66 & - & + & + & + & 6.4 & - & - \\
\hline pant402 & 4888276 & 4888582 & 4888196 & 4889111 & 307 & PA4360 & PA4361 & $<<<$ & 80 & 529 & + & + & + & + & 0.4 & - & + \\
\hline pant403 & 4893521 & 4893633 & 4893351 & 4893696 & 113 & PA4365 & PA4366 & $>?>$ & 170 & 63 & - & - & + & - & - & - & - \\
\hline pant404 & 4903327 & 4903450 & 4903297 & 4903465 & 124 & PA4373 & PA4374 & $\gg>$ & 30 & 15 & - & + & - & + & 0.4 & - & - \\
\hline pant405 & 4921096 & 4921416 & 4920867 & 4921980 & 321 & PA4390 & PA4392 & e<> & 229 & 564 & - & + & + & - & - & - & + \\
\hline pant406 & 4956222 & 4956326 & 4956030 & 4956327 & 105 & PA4421 & $\begin{array}{l}\text { PA4421.1 } \\
\end{array}$ & $<<>$ & 192 & 1 & - & + & + & - & - & - & - \\
\hline pant407 & 4989152 & 4989259 & 4988892 & 4989304 & 108 & PA4456 & PA4457 & e<> & 260 & 45 & - & - & + & + & 5.7 & - & - \\
\hline pant408 & 5013486 & 5013605 & 5013432 & 5013670 & 120 & PA4481 & PA4482 & e<> & 54 & 65 & - & - & + & - & - & - & + \\
\hline pant409 & 5030276 & 5030516 & 5030249 & 5030524 & 241 & PA4494 & PA4495 & $\langle>\rangle$ & 27 & 8 & - & + & + & - & - & - & - \\
\hline pant410 & 5030390 & 5030516 & 5030249 & 5030524 & 127 & PA4494 & PA4495 & $<<>$ & 141 & 8 & - & + & + & - & - & - & - \\
\hline pant411 & 5031356 & 5031482 & 5031236 & 5031487 & 127 & PA4495 & PA4496 & $\gg>$ & 120 & 5 & - & + & - & - & - & - & - \\
\hline pant412 & 5038743 & 5038856 & 5038676 & 5038900 & 114 & PA4500 & $\begin{array}{l}\text { PA4501 } \\
\end{array}$ & $\gg>$ & 67 & 44 & - & - & + & + & 6.6 & - & - \\
\hline pant413 & 5055878 & 5056088 & 5055878 & 5056094 & 211 & PA4514 & PA4515 & $\mid \ll<>$ & 0 & 6 & - & + & - & - & - & - & - \\
\hline pant414 & 5061315 & 5061556 & 5061279 & 5061729 & 242 & PA4519 & PA4520 & $<?<$ & 36 & 173 & - & + & + & + & 0.2 & - & - \\
\hline pant415 & 5080300 & 5080649 & 5080209 & 5080756 & 350 & PA4539 & PA4540 & e<> & 91 & 107 & - & + & + & - & - & - & - \\
\hline pant416 & 5086761 & 5086889 & 5086697 & 5086924 & 129 & PA4541 & $\begin{array}{l}\text { PA4541.1 } \\
\end{array}$ & $>?<$ & 64 & 35 & - & + & - & + & 0.3 & - & - \\
\hline pant417 & 5091879 & 5091950 & 5091816 & 5091960 & 72 & PA4544 & PA4545 & $\langle>\rangle$ & 63 & 10 & - & + & - & - & - & - & - \\
\hline pant 418 & 5097463 & 5097563 & 5097463 & 5097596 & 101 & $\begin{array}{l}\text { PA4548 } \\
\end{array}$ & $\begin{array}{l}\text { PA4549 } \\
\end{array}$ & «《> & 0 & 33 & - & + & + & - & - & - & - \\
\hline pant419 & 5112382 & 5112481 & 5112380 & 5112662 & 100 & PA4562 & PA4563 & $\langle>\rangle$ & 2 & 181 & - & + & - & - & - & - & - \\
\hline pant 420 & 5118198 & 5118323 & 5118196 & 5118537 & 126 & PA4570 & PA4571 & $\gg>$ & 2 & 214 & - & + & + & - & - & - & - \\
\hline pant421 & 5141281 & 5141583 & 5141190 & 5141785 & 303 & PA4590 & PA4591 & e & 91 & 202 & - & + & + & - & - & - & - \\
\hline pant 425 & 5174710 & 5174954 & 5174653 & 5174979 & 245 & PA4616 & PA4617 & $<?>$ & 57 & 25 & + & - & - & - & - & - & - \\
\hline pant 426 & 5182285 & 5182374 & 5182269 & 5182578 & 90 & PA4621 & PA4622 & $<?>$ & 16 & 204 & - & - & + & - & - & - & - \\
\hline pant 427 & 5203330 & 5203607 & 5203243 & 5203667 & 278 & PA4634 & PA4635 & $<?>$ & 87 & 60 & + & + & + & + & 0.2 & - & - \\
\hline
\end{tabular}




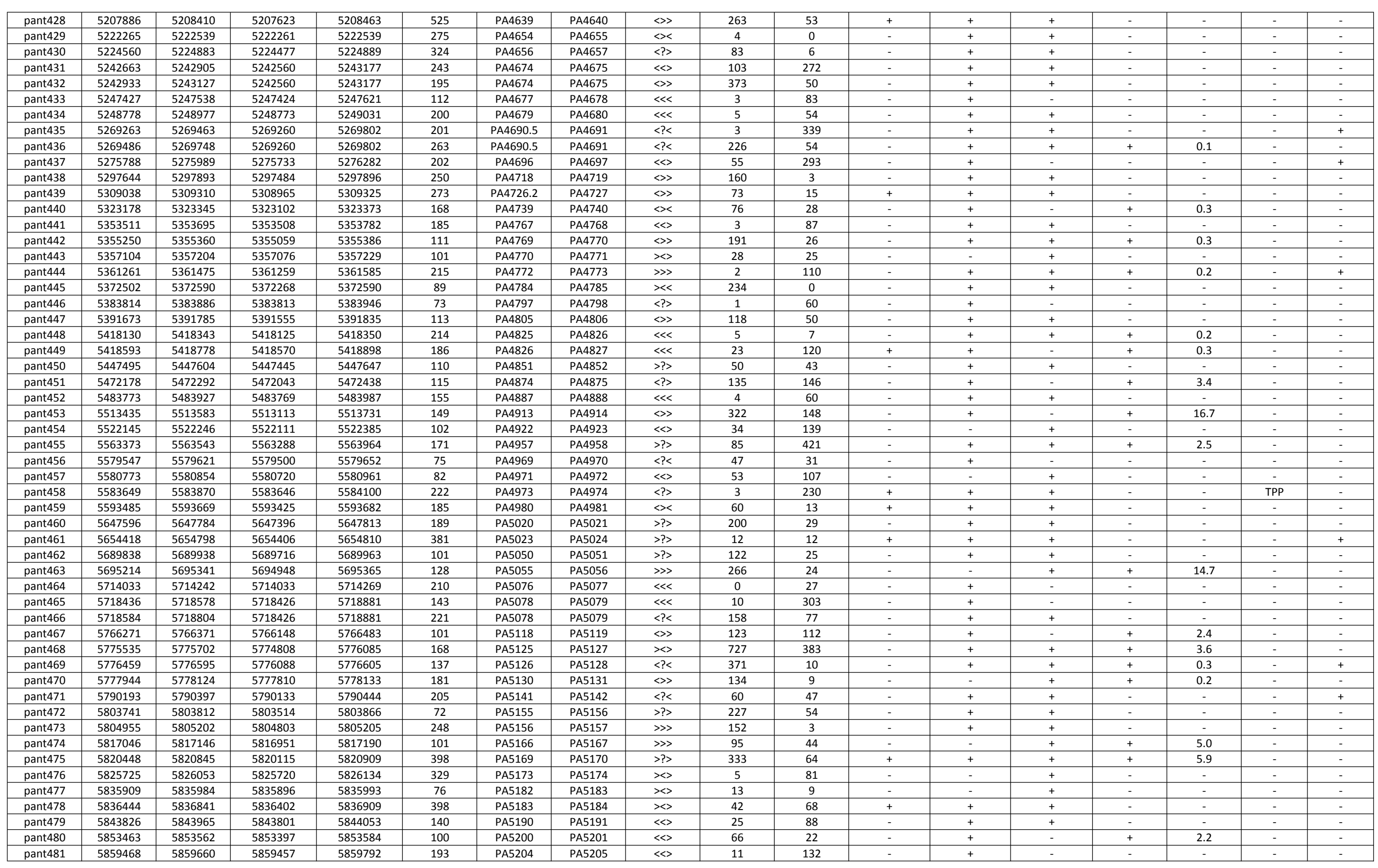




\begin{tabular}{|c|c|c|c|c|c|c|c|c|c|c|c|c|c|c|c|c|c|}
\hline pant482 & 5892668 & 5892830 & 5892661 & 5892909 & 163 & PA5234 & PA5235 & $><>$ & 7 & 79 & - & + & + & + & 0.2 & - & - \\
\hline pant483 & 5906521 & 5906609 & 5906462 & 5906625 & 89 & PA5244 & PA5245 & $><>$ & 59 & 16 & - & + & + & - & - & - & - \\
\hline pant484 & 5914527 & 5914996 & 5914522 & 5915042 & 470 & PA5252 & PA5253 & $<><$ & 5 & 46 & + & + & + & - & - & - & - \\
\hline pant485 & 5924373 & 5924582 & 5924372 & 5924595 & 210 & PA5262 & PA5263 & $\langle ?\rangle$ & 1 & 13 & - & + & + & - & - & - & - \\
\hline pant486 & 5955066 & 5955166 & 5955056 & 5955179 & 101 & PA5290 & PA5291 & $><>$ & 10 & 13 & - & + & - & + & 2.3 & - & - \\
\hline pant487 & 5973554 & 5973827 & 5973477 & 5973832 & 274 & PA5304 & PA5305 & e & 77 & 5 & + & + & + & - & - & - & - \\
\hline pant 488 & 5986290 & 5986454 & 5986171 & 5986474 & 165 & $\begin{array}{l}\text { PA5316.1 } \\
\end{array}$ & PA5317 & $><>$ & 119 & 20 & - & + & + & - & - & - & - \\
\hline pant 489 & 5991138 & 5991429 & 5991132 & 5992382 & 292 & PA5321 & PA5322 & $\gg>$ & 6 & 953 & - & + & + & - & - & - & - \\
\hline pant490 & 5991564 & 5991777 & 5991132 & 5992382 & 214 & PA5321 & PA5322 & $>?>$ & 432 & 605 & - & + & + & - & - & - & + \\
\hline pant491 & 5991800 & 5992035 & 5991132 & 5992382 & 236 & PA5321 & PA5322 & $\gg>$ & 668 & 347 & - & + & + & - & - & - & - \\
\hline pant492 & 5995818 & 5995936 & 5995812 & 5996035 & 119 & PA5324 & PA5325 & $<?>$ & 6 & 99 & - & + & + & - & - & - & - \\
\hline pant493 & 6032310 & 6032385 & 6032269 & 6032386 & 76 & PA5364 & PA5365 & $<?<$ & 41 & 1 & - & + & + & - & - & - & - \\
\hline pant495 & 6042772 & 6042872 & 6042737 & 6042962 & 101 & $\begin{array}{l}\text { PA5369.2 } \\
\end{array}$ & PA5369.3 & $<><$ & 35 & 90 & - & - & + & + & 35.1 & - & ++ \\
\hline pant496 & 6045008 & 6045246 & 6044744 & 6045309 & 239 & $\begin{array}{l}\text { PA5369.5 } \\
\end{array}$ & PA5370 & $2 \ll<$ & 264 & 63 & - & + & + & + & $\begin{array}{ll}0.1 \\
\end{array}$ & - & - \\
\hline pant497 & 6051319 & 6051484 & 6051312 & 6051643 & 166 & PA5374 & PA5375 & $\langle ?\rangle$ & 7 & 159 & - & + & - & + & 2.0 & - & - \\
\hline pant498 & 6056431 & 6056684 & 6056414 & 6056876 & 254 & PA5378 & PA5379 & $\ll<$ & 17 & 192 & - & + & + & - & - & - & - \\
\hline pant499 & 6058343 & 6058460 & 6058254 & 6058672 & 118 & PA5379 & PA5380 & $\gg \gg$ & 89 & 212 & - & + & + & - & - & - & - \\
\hline pant500 & 6086677 & 6086895 & 6086675 & 6087098 & 219 & PA5410 & PA5411 & e<> & 2 & 203 & - & + & + & + & 57.6 & - & - \\
\hline pant501 & 6125211 & 6125386 & 6125081 & 6125795 & 176 & PA5440 & PA5441 & $><<$ & 130 & 409 & - & - & + & - & - & - & ++ \\
\hline pant502 & 6125568 & 6125748 & 6125081 & 6125795 & 181 & PA5440 & PA5441 & $><<$ & 487 & 47 & - & + & - & - & - & - & + \\
\hline pant503 & 6162085 & 6162220 & 6161868 & 6162220 & 136 & PA5472 & PA5473 & $\langle>$ & 217 & 0 & - & + & + & - & - & - & - \\
\hline pant504 & 6167543 & 6167752 & 6167410 & 6167782 & 210 & PA5476 & PA5477 & $\langle>\rangle$ & 133 & 30 & - & + & + & - & - & - & - \\
\hline pant505 & 6172877 & 6172977 & 6172874 & 6173347 & 101 & PA5482 & $\begin{array}{l}\text { PA5483 } \\
\end{array}$ & $<?>$ & 3 & 370 & - & + & + & - & - & - & - \\
\hline pant508 & 6211770 & 6212005 & 6211769 & 6212146 & 236 & PA5518 & PA5519 & e & 1 & 141 & - & + & + & - & - & - & - \\
\hline pant509 & 6220755 & 6220874 & 6220740 & 6221100 & 120 & PA5528 & PA5529 & $<<>$ & 15 & 226 & - & + & + & - & - & - & - \\
\hline pant510 & 6240638 & 6240792 & 6240633 & 6240869 & 155 & PA5546 & PA5547 & $\langle ?\rangle$ & 5 & 77 & - & + & - & + & 2.9 & - & - \\
\hline pant511 & 6241760 & 6241846 & 6241494 & 6241850 & 87 & $\begin{array}{l}\text { PA5547 } \\
\end{array}$ & $\begin{array}{l}\text { PA5548 } \\
\end{array}$ & $><>$ & 266 & 4 & - & + & + & - & - & - & - \\
\hline pant512 & 6259392 & 6259552 & 6259198 & 6259670 & 161 & PA5565 & PA5566 & $<><$ & 194 & 118 & - & + & + & - & - & - & - \\
\hline pant513 & 6263613 & 6263715 & 6263565 & 6263804 & 103 & PA5568 & PA5569 & $<><$ & 48 & 89 & - & + & + & - & - & - & - \\
\hline
\end{tabular}

a The coordinates of the transcript predicted by RNA sequencing data.

b Length of the SRNA candidate predicted by RNA sequencing data.

c The middle arrow indicates the orientation of the sRNA, while the flanking arrows indicate the orientation of the adjacent genes. An unknown sRNA orientation is indicated by a question mark.

d A plus symbol (+) indicates that the sRNA is differentially expressed between the conditions tested in this work.

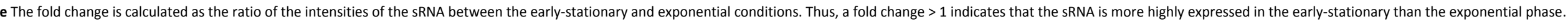

f Candidate sRNAs were queried against the Rfam database and matches to known sRNAs are indicated.

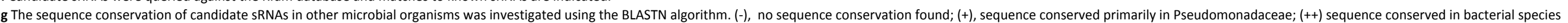
outside the Pseudomonadaceae family. 
Supplementary Table 5. 5'-RACE validation of sRNA candidates.

\begin{tabular}{|c|c|c|c|c|}
\hline Name & $\begin{array}{c}\text { Start predicted } \\
\text { by RNA } \\
\text { sequencing }^{\mathrm{a}}\end{array}$ & $\begin{array}{c}\text { Start } \\
\text { validated by } \\
5^{\prime}-\text { RACE }^{\mathrm{b}} \\
\end{array}$ & $\begin{array}{c}\text { Nt difference } \\
\text { between RNAseq } \\
\text { and } 5^{\prime}-\text { RACE }^{c}\end{array}$ & Direction $^{d}$ \\
\hline pant44 & 363166 & 363154 & 12 & $<<<$ \\
\hline pant66 & 648847 & 648847 & 0 & $<<<$ \\
\hline pant217 & 2627303 & 2627304 & 1 & $<>>$ \\
\hline RgsA (forward) & 3318747 & 3318737 & 10 & $>><$ \\
\hline RgsA (reverse) & 3318868 & 3318870 & 2 & $><<$ \\
\hline pant381 & 4629347 & 4629347 & 0 & $<<>$ \\
\hline pant441 & 5353695 & 5353695 & 0 & $<<>$ \\
\hline pant503 & 6162085 & 6162085 & 0 & $<>>$ \\
\hline
\end{tabular}

${ }^{a}$ Transcript start predicted by our script based on the RNA sequencing data.

${ }^{b}$ Experimentally found values using 5 '-RACE.

' Difference in nucleotides between the start of transcription predicted by RNA sequencing and that determined by 5 '-RACE.

${ }^{d}$ The middle arrow indicates the orientation of the SRNA, while the flanking arrows indicate the orientation of the adjacent genes. 


\begin{tabular}{|c|c|c|c|c|c|c|c|c|c|c|c|c|c|c|c|c|}
\hline Name & Start $^{a}$ & End $^{a}$ & $\begin{array}{c}\text { Intergenic } \\
\text { region } \\
\text { start }\end{array}$ & $\begin{array}{l}\text { Intergenic } \\
\text { region end }\end{array}$ & Length $^{\mathrm{b}}$ & $\begin{array}{c}5 \text { f flanking } \\
\text { gene }\end{array}$ & $\begin{array}{c}3^{\prime} \text { flanking } \\
\text { gene }\end{array}$ & Direction $^{c}$ & $\begin{array}{l}\text { Detection } \\
\text { in Library } \\
\text { A }\end{array}$ & $\begin{array}{c}\text { Detection } \\
\text { in Library } \\
\text { B }\end{array}$ & $\begin{array}{c}\text { Detection } \\
\text { in Library } \\
\quad \text { C }\end{array}$ & $\begin{array}{l}\text { Differential } \\
\text { expression }^{\mathrm{d}}\end{array}$ & $\begin{array}{c}\text { Fold } \\
\text { change }\end{array}$ & Rfam $^{t}$ & Orders $^{\mathrm{g}}$ & Classes $^{\mathrm{h}}$ \\
\hline pant42 & 354489 & 354679 & 354462 & 354753 & 191 & PA0314 & PA0315 & $\langle ?\rangle$ & - & - & + & + & 2.6 & - & Burkholderiales & Beta Proteobacteria \\
\hline pant57 & 521960 & 522172 & 521316 & 522464 & 213 & PA0460 & PA0462 & $><>$ & + & + & + & - & - & - & $\begin{array}{c}\text { Aeromonadales / Alteromonadales / Burkholderiales / unclassified Deltaproteobacteria } \\
\text { / Enterobacteriales / Oceanospirillales / Pseudomonadales / unclassified } \\
\text { Gammaproteobacteria (gamma proteobacterium HdN1) / Xanthomonadales }\end{array}$ & $\begin{array}{l}\text { Beta Proteobacteria / Delta } \\
\text { Proteobacteria / Gamma } \\
\text { Proteobacteria }\end{array}$ \\
\hline pant59 & 522753 & \begin{tabular}{|l|}
522868 \\
\end{tabular} & 522518 & 523253 & 116 & $\begin{array}{ll}\text { PA0461 } \\
\end{array}$ & PA0463 & \langle\rangle & - & - & + & + & 8.4 & - & Halomonas / Pseudomonas & Gamma Proteobacteria \\
\hline pant95 & 927232 & 927551 & 927215 & 927879 & 320 & PA0847 & PA0849 & $<?>$ & - & - & + & + & 6.9 & - & \begin{tabular}{|c|} 
Rhizobiales / Desulfovibrionales / Rhodocyclales / Gallionellales / Nitrosomonadales / \\
Neisseriales / Methylophilales / Oceanospirillales / Alteromonadales / Vibrionales / \\
Aeromonadales / Enterobacteriales / Methylococcales / Pseudomonadales \\
\end{tabular} & $\begin{array}{l}\text { Alpha Proteobacteria / Beta } \\
\text { Proteobacteria / Delta Proteobacteria } \\
\text { / Gamma Proteobacteria }\end{array}$ \\
\hline pant96 & 927603 & 927784 & 927215 & 927879 & 182 & PA0847 & PA0849 & 〈〉> & - & + & + & - & - & - & Aeromonadales / Enterobacteriales / Neisseriales / Rhodocyclales & $\begin{array}{l}\text { Beta Proteobacteria / Gamma } \\
\text { Proteobacteria }\end{array}$ \\
\hline pant120 & 1204789 & 1205025 & 1204782 & 1205030 & 237 & PA1112 & PA1112.1 & $\gg<$ & + & + & + & + & 3.0 & - & Aeromonadales / Rhodocyclales / Pseudomonadales & $\begin{array}{l}\text { Beta Proteobacteria / Gamma } \\
\text { Proteobacteria }\end{array}$ \\
\hline pant138 & 1372693 & 1372804 & 1372683 & 1372978 & 112 & PA1263 & PA1264 & $>?<$ & - & - & + & - & - & - & Aeromonadales / Burkholderiales / Xanthomonadales & $\begin{array}{l}\text { Beta Proteobacteria / Gamma } \\
\text { Proteobacteria }\end{array}$ \\
\hline pant144 & 1471942 & 1472164 & 1471673 & 1472546 & 223 & PA1359 & PA1361 & $<>$ & - & + & + & - & - & - & $\begin{array}{l}\text { Burkholderiales / Caulobacterales / Enterobacteriales / Myxococcales / } \\
\text { Oceanospirillales / Pseudomonadales / Rhizobiales / Sphingomonadales / } \\
\text { Xanthomonadales }\end{array}$ & $\begin{array}{l}\text { Alpha Proteobacteria / Beta } \\
\text { Proteobacteria / Delta Proteobacteria } \\
\text { / Gamma Proteobacteria }\end{array}$ \\
\hline pant160 & 1717940 & 1718216 & 1717895 & 1718385 & 277 & PA1578 & PA1579 & $\gg \gg$ & + & + & + & + & 0.2 & - & Burkholderiales / Pseudomonadales & $\begin{array}{l}\text { Beta Proteobacteria / Gamma } \\
\text { Proteobacteria }\end{array}$ \\
\hline pant184 & 2104152 & 2104333 & 2104097 & 2104596 & 182 & PA1925 & PA1926 & $\gg \gg$ & - & + & + & - & - & - & $\begin{array}{l}\text { Alteromonadales / Burkholderiales / Caulobacterales / Enterobacteriales / } \\
\text { Methylophilales / Myxococcales / Neisseriales / Nitrosomonadales / Oceanospirillales / } \\
\text { Pseudomonadales / Rhizobiales / Rhodocyclales / Sphingomonadales / } \\
\text { Xanthomonadales }\end{array}$ & $\begin{array}{l}\text { Alpha Proteobacteria / Beta } \\
\text { Proteobacteria / Delta Proteobacteria } \\
\text { / Gamma Proteobacteria }\end{array}$ \\
\hline pant185 & 2104397 & 2104580 & 2104097 & 2104596 & 184 & PA1925 & PA1926 & $\gg \gg$ & - & + & + & + & 0.3 & -1 & $\begin{array}{c}\text { Alteromonadales / Burkholderiales / Methylophilales / Neisseriales / Oceanospirillales / } \\
\text { Pseudomonadales / Rhodocyclales }\end{array}$ & $\begin{array}{l}\text { Beta Proteobacteria / Gamma } \\
\text { Proteobacteria }\end{array}$ \\
\hline pant242 & 3037237 & 3037426 & 3035703 & 3037885 & 190 & PA2684 & PA2686 & $\ll$ & - & + & + & - & - & - & Burkholderiales / Pseudomonas / Rhodocyclales & $\begin{array}{l}\text { Beta Proteobacteria / Gamma } \\
\text { Proteobacteria }\end{array}$ \\
\hline pant251 & 3094233 & 3094534 & 3094186 & 3094756 & 302 & PA2733 & PA2734 & $<?<$ & - & + & + & - & - & - & $\begin{array}{c}\begin{array}{c}\text { Acidithiobacillales / Desulfovibrionales / Nitrosomonas / Desulfuromonadales / } \\
\text { Chlorobiales / Pseudomonadales / unclassified Gammaproteobacteria (gamma } \\
\text { proteobacterium HdN1) / Synergistales }\end{array} \\
\end{array}$ & $\begin{array}{l}\text { Chlorobea / Synergistia / Beta } \\
\text { Proteobacteria / Delta Proteobacteria } \\
\text { / Gamma Proteobacteria }\end{array}$ \\
\hline pant277 & 3305612 & 3305787 & 3305565 & 3305918 & 176 & PA2945 & PA2946 & $\ll$ & - & + & + & - & - & obalami & Rhodobacterales / Pseudomonas / Rhizobiales & $\begin{array}{l}\text { Alpha Proteobacteria / Gamma } \\
\text { Proteobacteria }\end{array}$ \\
\hline pant366 & 4472724 & 4472848 & 4472199 & 4473622 & 125 & PA3991 & PA3993 & $\ll$ & - & - & + & + & 5.2 & - & $\begin{array}{l}\text { Burkholderiales / Caulobacterales / Pseudomonadales / Rhizobiales / Rhodobacterales } \\
\text { / Rhodospirillales / unclassified Alphaproteobacteria (Polymorphum gilvum) / } \\
\text { Xanthomonadales }\end{array}$ & $\begin{array}{l}\text { Alpha Proteobacteria / Beta } \\
\text { Proteobacteria / Gamma } \\
\text { Proteobacteria }\end{array}$ \\
\hline pant367 & 4472877 & 4473081 & 4472199 & 4473622 & 205 & PA3991 & PA3993 & 〈〉> & - & + & + & - & - & - & $\begin{array}{l}\text { Pseudomonadaceae / Burkholderiales / Rhodospirillales / unclassified } \\
\text { Alphaproteobacteria (Polymorphum gilvum) }\end{array}$ & $\begin{array}{l}\text { Alpha Proteobacteria / Beta } \\
\text { Proteobacteria / Gamma } \\
\text { Proteobacteria }\end{array}$ \\
\hline pant390 & 4791760 & 4791860 & 4791725 & 4791950 & 101 & PA4280.2 & PA4280.3 & $<><$ & - & - & + & + & 68.3 & - & \begin{tabular}{|c|} 
unclassified Bacteria (toluene-degrading bacterium UCR 026m; chlamydia-associated \\
clinical samples) / Pseudomonadales / Myxococcales
\end{tabular} & $\begin{array}{l}\text { Delta Proteobacteria / Gamma } \\
\text { Proteobacteria }\end{array}$ \\
\hline pant398 & 4861733 & 4862026 & 4861712 & 4863272 & 294 & PA4332 & PA4334 & $<?<$ & - & + & + & - & - & - & $\begin{array}{c}\begin{array}{c}\text { Alteromonadales / Burkholderiales / Acidobacteriales / Chromatiales / Gallionellales / } \\
\text { Oceanospirillales / Pseudomonadales / Rhodocyclales / Xanthomonadales }\end{array} \\
\end{array}$ & $\begin{array}{l}\text { Acidobacteria / Beta Proteobacteria / } \\
\text { Gamma Proteobacteria }\end{array}$ \\
\hline pant399 & 4862054 & 4862348 & 4861712 & 4863272 & 295 & PA4332 & PA4334 & $<><$ & - & + & + & + & 0.4 & - & \begin{tabular}{|c|}
$\begin{array}{c}\text { Aeromonadales / Burkholderiales / Chromatiales / Neisseriales / Pseudomonadales / } \\
\text { Rhizobiales / Rhodocyclales / Sphingomonadales / unclassified Betaproteobacteria } \\
\text { (Candidatus Accumulibacter) / Xanthomonadales }\end{array}$ \\
\end{tabular} & $\begin{array}{l}\text { Alpha Proteobacteria / Beta } \\
\text { Proteobacteria / Gamma } \\
\text { Proteobacteria }\end{array}$ \\
\hline pant400 & 4862626 & 4863181 & 4861712 & 4863272 & 556 & PA4332 & PA4334 & $<><$ & + & + & + & - & - & - & $\begin{array}{l}\text { Burkholderiales / Chromatiales / Neisseriales / Oceanospirillales / Pseudomonadales / } \\
\text { Rhodocyclales / Sphingomonadales / Xanthomonadales }\end{array}$ & $\begin{array}{l}\text { Alpha Proteobacteria / Beta } \\
\text { Proteobacteria / Gamma } \\
\text { Proteobacteria }\end{array}$ \\
\hline pant501 & 6125211 & 6125386 & 6125081 & 6125795 & 176 & PA5440 & PA5441 & $><<$ & - & - & + & - & - & - & Burkholderia / Aeromonadales / Pseudomonas & $\begin{array}{l}\text { Delta Proteobacteria / Gamma } \\
\text { Proteobacteria }\end{array}$ \\
\hline
\end{tabular}


a Transcript's coordinates predicted by the RNA sequencing data.

b Length of the SRNA candidate predicted by the RNA sequencing data.

c The middle arrow indicates the orientation of the SRNA, while the flanking arrows indicate the orientation of the adjacent genes. Unknown orientation of sRNAs is indicated by a question mark.

$\mathrm{d} A+$ indicates that the SRNA is differentially expressed between the conditions tested in this work.

e The fold change indicates the ratio of the intensities of the sRNA between the early-stationary and exponential conditions. Thus, a number higher than 1 indicates that the sRNA is more expressed in the early-stationary than the exponential phase.

f Candidate SRNAs was queried against the Rfam database; matches to known sRNAs are indicated.

$\mathrm{g}$ Orders of the bacteria in which the sequence of the sRNA candidate was found to be conserved. 
Supplementary Table 7. Cut-offs used for the detection of novel transcripts.

\begin{tabular}{c|c|c} 
Library & Coverage at each base & Average expression \\
\hline LIB $>\mathbf{1 0 0}$ & $>20$ & $>40$ \\
\hline LIB $<500$ & $>35$ & $>70$ \\
\hline LIB $<\mathbf{2 0 0}$ & $>50$ & $>100$
\end{tabular}


Supplementary Figure 1. Agilent Bioanalyzer analysis of total and rRNA-depleted RNA.

The 23S, 16S and 5S rRNAs were removed from the total RNA (A) by subtractive hybridization as described in the Experimental Procedures. Note that the peaks corresponding to 23S, $16 \mathrm{~S}$ and $5 \mathrm{~S}$ rRNAs are not present in the rRNA-depleted sample (B). The peaks marked with asterisks $\left({ }^{*}\right)$ probably correspond to tRNAs and sRNA species shorter than $120 \mathrm{nt}$.

A

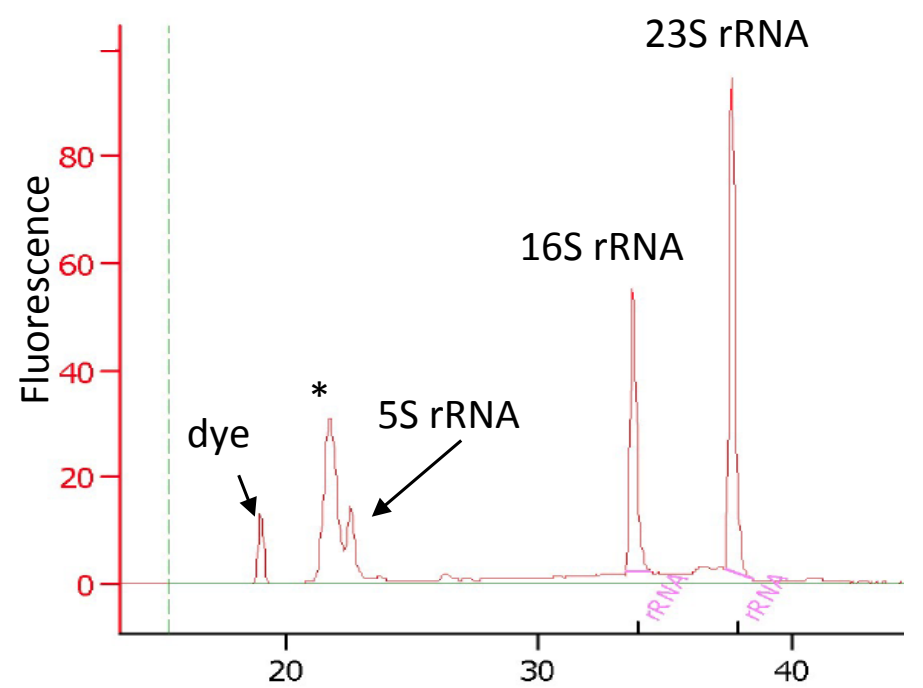

B

Time (s)
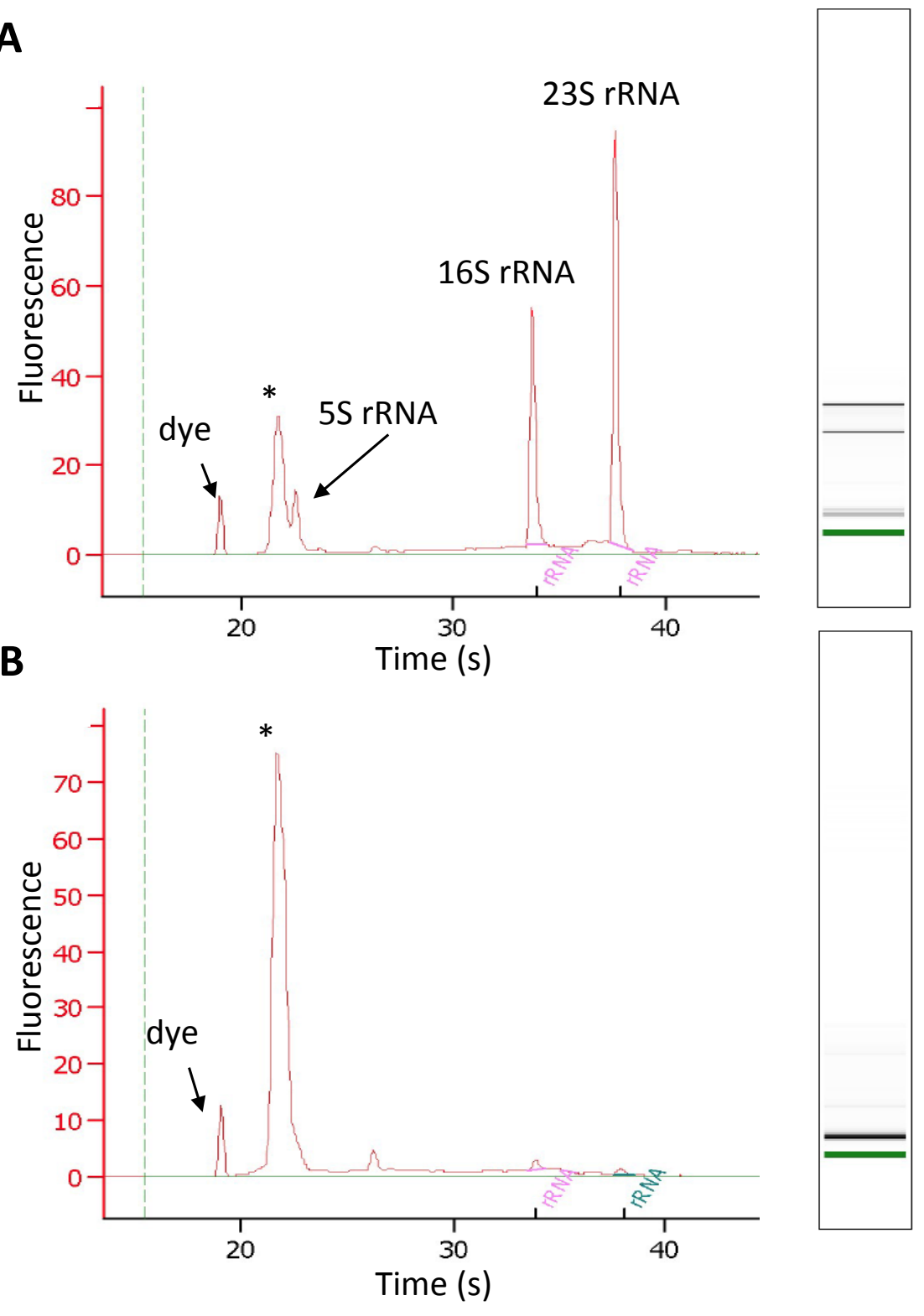


\section{Article 2}

Identification of bacterial small RNAs by RNA sequencing

Gómez-Lozano, M., Marvig, R. L., Molin, S., \& Long, K. S.

Methods in Pseudomonas aeruginosa, 2013. Accepted for publication. 


\section{Identification of bacterial small RNAs by RNA sequencing}

María Gómez-Lozano ${ }^{1,2}$, Rasmus Lykke Marvig ${ }^{1}$, Søren Molin ${ }^{1,2}$, and Katherine S. Long $^{1,2, *}$

${ }^{1}$ Department of Systems Biology, Technical University of Denmark, Lyngby, Denmark.

${ }^{2}$ Novo Nordisk Foundation Center for Biosustainability, Technical University of Denmark, Hørsholm, Denmark.

*To whom correspondence should be addressed: e-mail: kalon@biosustain.dtu.dk

\section{ABSTRACT}

Small regulatory RNAs (sRNAs) in bacteria are known to modulate gene expression and control a variety of processes including metabolic reactions, stress responses and pathogenesis in response to environmental signals. A method to identify bacterial sRNAs on a genome-wide scale based on RNA sequencing (RNA-seq) is described that involves the preparation and analysis of three different sequencing libraries. As a significant number of unique sRNAs are identified in each library, the libraries can either be used alone or in combination to increase the number of sRNAs identified. The approach may be applied to identify sRNAs in any bacterium under different growth and stress conditions.

\section{INTRODUCTION}

Small RNAs (sRNAs) in bacteria play important regulatory roles in controlling various physiological processes such as carbon metabolism, iron homeostasis, and virulence in response to environmental cues. Bacteria contain hundreds of sRNAs that exist as a heterogeneous group of transcripts with a typical size range of 70 to 500 nucleotides (nt) $(1,2)$. Many sRNAs function by affecting the expression of mRNA targets via base-pairing, while others act by binding to proteins and altering their activity. The base-pairing sRNAs fall into two broad classes: cis-encoded antisense sRNAs and trans-encoded sRNAs. The former are encoded on the DNA strand opposite the target RNA and therefore have perfect complementarity with their targets. Trans-encoded sRNAs are encoded in intergenic 
regions and often have multiple targets with which there is only limited complementarity. Despite the fact that some bacterial sRNAs have been known for some time, earlier studies to identify these RNAs have often depended on serendipity, direct detection due to high abundance, protein copurification, and computational predictions based on sequence conservation (3). Recent efforts to identify sRNAs on a genome-wide scale have been based mainly on the extremely sensitive, probe-independent RNA sequencing approach (RNA-seq) that has revolutionized the field and led to the discovery of hundreds of novel sRNAs in diverse bacteria $(4,5)$.

We have recently developed a robust RNA-seq method and used it to identify over 500 novel sRNAs in $P$. aeruginosa (6). The approach is based on three different sequencing libraries prepared from different RNA populations that can either be used alone or in combination to increase the number of identified sRNAs. In order to enrich the RNA samples for sRNA detection, ribosomal RNAs (23S, 16S and 5S rRNAs) are depleted from the total RNA. One of the libraries $(L I B>100)$ is prepared using a standard RNA-seq protocol for full transcriptomes and contains information on all mRNAs transcribed by the bacteria. The other two libraries $(\mathrm{LIB}<500$ and $\mathrm{LIB}<200)$ are prepared from size-selected RNA containing transcripts shorter than 500 and $200 \mathrm{nt}$, respectively. A significant number of unique sRNAs are detected in each library, suggesting that the set of identified RNAs obtained depends strongly on the specific library preparation strategy used (6). The detailed experimental procedures to prepare the three sequencing libraries are described in the first sections of the chapter.

Using RNA-seq allows counting the number of reads that align to specific parts of a genome, producing results similar to those of gene expression microarrays. While the end results are similar, the informatic challenges of analyzing RNA-seq data are fundamentally different than those of analyzing microarrays. Although there are several ways in which RNA-seq data can be analyzed, our analysis pipeline to find novel $P$. aeruginosa intergenic and antisense sRNAs is detailed in the latter sections of this chapter.

\section{MATERIALS (see Note 1)}

\subsection{General materials and equipment}

1. Disposable, nuclease-free pipette tips with filter, $1.5-\mathrm{mL}$ microcentrifuge tubes, $15-$ $\mathrm{mL}$ conical tubes. 
2. RNase-ZAP (Ambion) to remove ribonuclease (RNase) contamination from glass and plastic (see Note 1).

3. Glycogen $(5 \mathrm{mg} / \mathrm{mL})$ (Ambion).

4. Nuclease-free water (not DEPC-treated water).

5. TE buffer (10 mM Tris-HCl, pH 7, 1 mM EDTA).

6. $100 \%$ and $70 \%$ Ethanol.

7. Phase-Lock Gel tubes, Heavy, $2 \mathrm{~mL}$ (5 PRIME).

8. $3 \mathrm{M}$ Sodium acetate ( $\mathrm{NaOAc}$ ), $\mathrm{pH} 5.5$ (Ambion).

9. $\mathrm{PCl}$ (Phenol:Chloroform:Isoamyl Alcohol) solution (25:24:1, v/v).

10. RiboLock RNase inhibitor (40 U/ $\mu \mathrm{L}$ ) (Thermo Scientific).

11. Microcentrifuges (room temperature and $\left.4^{\circ} \mathrm{C}\right)$, centrifuge $\left(4^{\circ} \mathrm{C}\right)$.

12. Vortexer.

13. Heat block.

14. Bioanalyzer (Agilent).

15. RNA 6000 Nano Kit (Agilent).

16. Qubit $\AA$ Fluorometer (Invitrogen).

17. Qubit $\circledast$ dsDNA HS or BR Assay Kit.

18. Qubit@ RNA Assay Kit.

19. Low-volume spectrophotometer, for example the Nanodrop (Thermo Fisher Scientific).

\subsection{Preparation of total RNA}

1. Isopropanol.

2. Trizol (Invitrogen).

3. Chloroform.

4. Phenol.

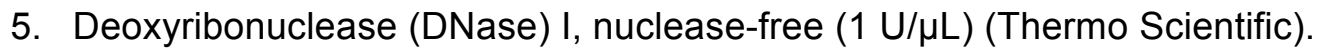

\subsection{Depletion of ribosomal RNAs (rRNAs)}

1. MICROBExpress ${ }^{\mathrm{TM}}$ Bacterial mRNA Enrichment Kit (Ambion).

2. DynaMag-2 Magnet (Invitrogen).

3. HPLC-purified $5 S$ oligo: 5'-AAAAAAAAAAAAAAAAAAGCGTTTCACTTCTGAGTTCGGCA-3'

\subsection{Size selection of transcripts shorter than $\mathbf{5 0 0} \mathrm{nt}$ (for LIB $<500$ library)}


1. Mini-PROTEAN Electrophoresis System for vertical gel electrophoresis (Bio-Rad).

2. $10 \%$ Mini-PROTEAN TBE-Urea Gel (Bio-Rad, cat no. 456-6033). This is a precast $10 \%$ polyacrylamide gel (10-well, $30 \mu \mathrm{L}$ well capacity) for use with the MiniPROTEAN system (see Note 2).

3. Gel Loading Buffer II: 95\% Formamide, 18mM EDTA, 0.025\% SDS, 0.025\% Xylene Cyanol, 0.025\% Bromophenol Blue (Ambion).

4. Nuclease-free, sterile 10X TBE solution: $890 \mathrm{mM}$ Tris base, $890 \mathrm{mM}$ boric acid, 20 $\mathrm{mM}$ EDTA, pH 8.0. From this stock prepare 1xTBE solution.

5. $0.4 \mathrm{M}$ sodium chloride $(\mathrm{NaCl})$ solution.

6. Low range ssRNA ladder (New England Biolabs).

7. $5 \mu \mathrm{m}$ filter tube (IST Engineering).

8. Gel Breaker tube (IST Engineering).

9. Sterile scalpel blade.

10. SYBR Gold Nucleic Acid Gel Stain (Invitrogen).

11. Tube shaker or rotator.

12. Safe Imager 2.0 Blue Light Transilluminator (Invitrogen) or similar

\subsection{Library-specific RNA preparation steps}

1. mirVana ${ }^{\mathrm{TM}}$ miRNA Isolation Kit (Ambion) (for LIB $<200$ library).

2. Tobacco Acid Pyrophosphatase (Epicentre) (for LIB $<500$ and $L I B<200$ libraries).

3. RNase III (Invitrogen) (for LIB $<500$ library).

\subsection{Library preparation}

\subsubsection{Library preparation (all libraries)}

1. Magnetic Stand-96 (Ambion).

2. 96-well thermal cycler.

3. 10- $\mu \mathrm{L}, 200-\mu \mathrm{L}$, and $1000-\mu \mathrm{L}$ multichannel pipettes.

4. Agencourt AMPure XP $60 \mathrm{~mL}$ kit (Beckman Coulter Genomics).

5. 96-well 250- $\mu \mathrm{L}$ PCR plates and caps for PCR strips compatible with the plates.

6. 8-well PCR strip tubes and caps.

7. SuperScript II Reverse Transcriptase (Invitrogen).

8. $10 \mathrm{mM}$ Tris- $\mathrm{Cl}, \mathrm{pH} 8.5$, solution containing $0.1 \%$ Tween 20 .

9. Microplate centrifuge. 


\subsubsection{Library preparation (for LIB $>100$ library)}

1. TruSeq ${ }^{\mathrm{TM}}$ RNA Sample Preparation Kit v2 (Illumina) (see Notes 3 and 4).

2. DNA 1000 kit (Agilent).

\subsubsection{Library preparation (for LIB $<500$ and LIB $<200$ libraries)}

1. TruSeq ${ }^{\mathrm{TM}}$ Small RNA Sample Preparation Kit (Illumina) (see Notes 3 and 5).

2. T4 RNA Ligase 2, truncated (New England Biolabs).

3. High Sensitivity DNA kit (Agilent).

\subsection{List of programs used}

The programs referred to in the data analysis pipeline are listed below with name, version, and URL:

1. Flexbar v2.2, http://sourceforge.net/projects/theflexibleadap/

2. Bowtie 2, http://bowtie-bio.sourceforge.net/bowtie2/index.shtml

3. SAMtools v1.4, http://samtools.sourceforge.net/

4. Tablet v1.12.08.29, http://bioinf.scri.ac.uk/tablet/

\section{METHODS}

A general scheme of the method is illustrated in Figure 1, and the library characteristics are summarized in Table 1. The libraries prepared in this protocol are compatible with the Illumina technology (see Note 6). The sequencing libraries are called LIB $>100, L I B<500$, and $L I B<200$ to indicate the transcript sizes in nucleotides that are not excluded from each, but all transcripts in these size ranges are not necessarily detected in the corresponding library.

Table 1. Library characteristics.

\begin{tabular}{lccc} 
& Library LIB $>\mathbf{1 0 0}$ & Library LIB $<500$ & Library $<200$ \\
\cline { 2 - 4 } Length of transcripts sequenced & $>100 \mathrm{nt}$ & $<500 \mathrm{nt}$ & $<200 \mathrm{nt}$ \\
Fragmentation & Divalent cations & RNase III & No \\
Strand specificity & No & Yes & Yes
\end{tabular}


The three libraries were prepared with different RNA populations isolated from bacterial total RNA. Library LIB>100 contains information corresponding to all transcripts in the cell, with the exception of rRNAs and transcripts shorter than $100 \mathrm{nt}$. This library was prepared using a standard RNA-seq protocol and is suitable for analyzing full transcriptomes. Although many known sRNAs are roughly $100 \mathrm{nt}$ in length, transcripts shorter than $100 \mathrm{nt}$ are not represented in this library because the corresponding cDNA fragments are not retained during the protocol. Size-selected RNA shorter than 500 and $200 \mathrm{nt}$ and depleted of $5 S$ rRNA was used to prepare the $L I B<500$ and $L I B<200$ libraries, respectively. As these libraries were prepared from RNA that does not include longer transcripts, they are enriched for information on sRNAs and thus more sensitive for sRNA detection compared to the LIB>100 library that contains information on the full transcriptome (6). Fragments corresponding to transcripts shorter than $100 \mathrm{nt}$ are retained in the $\mathrm{LIB}<500$ and LIB $<200$ libraries because specific adapters are ligated to the $5^{\prime}$ - and $3^{\prime}$-ends of RNAs prior to cDNA synthesis. In addition, they are strand-specific, which means that the information about the strand from which the transcripts are transcribed is retained. Furthermore, treatment of RNA used to prepare the $L I B<500$ and $L I B<200$ libraries ensures the inclusion of primary transcripts containing a $5^{\prime}$-triphosphate (see Note 7 ).

The library preparation protocols also differ in terms of whether they include fragmentation steps. In order to be compatible with the relatively short read-lengths of the Illumina sequencing technology, long RNA molecules must be cleaved into shorter fragments. Therefore, the protocols for preparation of the LIB $>100$ and $L I B<500$ libraries include fragmentation steps using divalent cations and RNase III, respectively. Library LIB $<200$ does not have any fragmentation-associated biases because the short RNAs used to prepare the library obviate the need for a fragmentation step.

In sections 3.12 to 3.17 , we describe a high-throughput bioinformatics pipeline for the analysis of RNA-Seq. The objectives of the pipeline are to detect transcripts and to quantify their relative abundance between different samples. Our pipeline is designed for use on organisms where an annotated reference genome exists, and as input uses the qualityfiltered and de-multiplexed sequencing reads obtained as output from sequencing centers (i.e. reads that are already in or can be converted to the FASTQ-format). Specifically, the pipeline was tested on 100-bp paired-end Illumina HiSeq2000 reads obtained from cDNAlibraries prepared from cultures of Pseudomonas aeruginosa PAO1 (6). 
Cell growth and harvest (Section 3.1)

RNA extraction (Section 3.2)

Treatment with DNase I (Section 3.3)

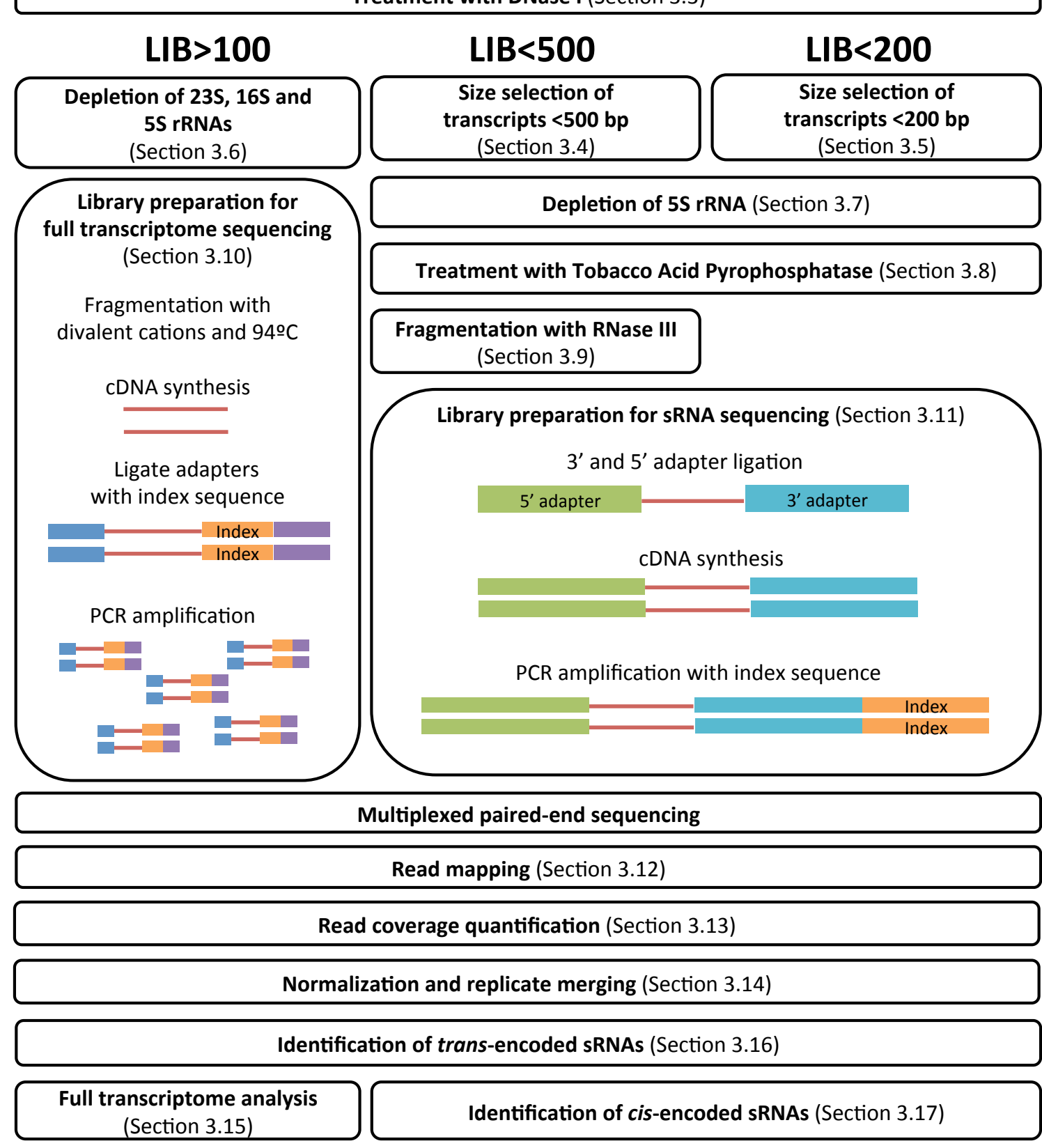

Figure 1. Library preparation scheme. Steps involved in the preparation of the different sequencing libraries $(\mathrm{LIB}>100, \mathrm{LIB}<500$ and $\mathrm{LIB}<200)$.

\subsection{Cell Growth and Harvest}

1. Prepare a $15-\mathrm{mL}$ conical tube with $2 \mathrm{~mL}$ of the STOP solution (95\% ethanol, $5 \%$ phenol). Pre-chill on ice.

2. Dilute an overnight bacterial culture in 50-100 volumes of growth medium. 
3. When the desired $O D_{600}$ is reached, transfer $10 \mathrm{~mL}$ of culture into the $15-\mathrm{mL}$ conical tube with the STOP solution.

4. Vortex thoroughly for $15 \mathrm{~s}$. Incubate at room temperature for $5 \mathrm{~min}$.

5. Pellet the bacteria by centrifugation $\left(3,500 \times \mathrm{g}, 10 \mathrm{~min}, 4^{\circ} \mathrm{C}\right)$. Remove the supernatant.

6. Dissolve the pellet in $1 \mathrm{~mL}$ Trizol by pipetting (see Notes 8 and 9). Incubate at room temperature for $5 \mathrm{~min}$.

7. Proceed to RNA extraction (section 3.2) or store at $-80^{\circ} \mathrm{C}$. The homogenized samples can be stored at $-80^{\circ} \mathrm{C}$ for at least one month.

\subsection{RNA extraction}

1. Spin down the Phase-Lock Gel (PLG) at $12,000-16,000 \times \mathrm{g}$ for $30 \mathrm{~s}$.

2. Transfer the homogenized sample to the PLG tube.

3. Add $200 \mu \mathrm{L}$ of chloroform (work inside a fume hood). Shake vigorously for $30 \mathrm{~s}$ (do not vortex).

4. Incubate at room temperature for $2 \mathrm{~min}$.

5. Centrifuge at $12,000-16,000 \times \mathrm{g}$ for $5 \mathrm{~min}$ at room temperature. The PLG will form a barrier between the aqueous and organic phases.

6. Transfer $500 \mu \mathrm{L}$ of the aqueous phase to a clean $1.5-\mathrm{mL}$ tube.

7. Add $400 \mu \mathrm{L}$ isopropanol, mix and incubate for $10 \mathrm{~min}$ at room temperature.

8. Pellet the RNA by centrifugation $\left(14,500 \times \mathrm{g}, 10 \mathrm{~min}, 4^{\circ} \mathrm{C}\right)$. Remove the supernatant.

9. Wash the RNA pellet by adding $500 \mu \mathrm{L}$ ice-cold $75 \%$ ethanol and vortex briefly.

10. Pellet the RNA by centrifugation $\left(14,500 \times \mathrm{g}, 5 \mathrm{~min}, 4^{\circ} \mathrm{C}\right)$. Remove the supernatant (see Note 10).

11. Repeat the last two steps for a total of two washes with ethanol. It is important to remove the ethanol completely at the end of the second wash.

12. Air-dry the pellet at room temperature for 5 min by leaving the tube lid open.

13. Dissolve the RNA pellet in $100 \mu \mathrm{L}$ of nuclease-free water.

14. Incubate at $65^{\circ} \mathrm{C}$ with shaking for $5 \mathrm{~min}$.

15. Proceed to DNase I treatment (section 3.3) immediately or store at $-80^{\circ} \mathrm{C}$.

\subsection{Treatment with DNase I}

1. Add to RNA sample $(100 \mu \mathrm{L})$ :

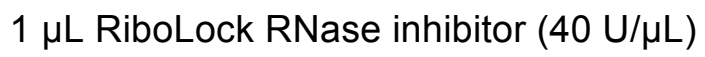

$40 \mu \mathrm{L}$ 10X DNase I reaction buffer with $\mathrm{MgCl}_{2}$

$219 \mu \mathrm{L}$ nuclease-free water 
$40 \mu \mathrm{L}$ DNase I $1 \mathrm{U} / \mu \mathrm{L}$

$400 \mu \mathrm{L}$ total volume

2. Mix by gently pipetting the entire volume ten times.

3. Incubate at $37^{\circ} \mathrm{C}$ for $30 \mathrm{~min}$.

4. Spin down the Phase-Lock Gel (PLG) at 12,000-16,000 $\mathrm{xg}$ for $30 \mathrm{~s}$.

5. Transfer the reaction mixture to the PLG tube.

6. Add $400 \mu \mathrm{L} \mathrm{PCl}$ solution.

7. Shake vigorously for $30 \mathrm{~s}$ (do not vortex).

8. Centrifuge at $12,000-16,000 \times \mathrm{g}$ for $5 \mathrm{~min}$ at room temperature.

9. Transfer the aqueous phase to a clean $1.5-\mathrm{mL}$ tube (volume should be approximately $400 \mu \mathrm{L})$.

10. Precipitate the RNA by adding 0.02 volume glycogen $(5 \mathrm{mg} / \mathrm{mL}), 0.1$ volume $3 \mathrm{M}$ $\mathrm{NaOAc} \mathrm{pH} 5.5$, and 2.5 volumes of $100 \%$ ethanol (ice-cold). Precipitate at $-20^{\circ} \mathrm{C}$ for at least one hour. At this point, the RNA can be stored at $-20^{\circ} \mathrm{C}$ or $-80^{\circ} \mathrm{C}$ (see Note 10 ). Pellet the RNA by centrifugation $\left(14,500 \times \mathrm{g}, 30 \mathrm{~min}, 4^{\circ} \mathrm{C}\right)$ and remove the supernatant. Recover the RNA as described in steps $9-12$ of section 3.2.

11. Resuspend in $50 \mu \mathrm{L}$ TE buffer.

12. Check the concentration and purity of the RNA sample using a low volume spectrophotometer (see Note 11). Check the quality of the RNA with a RNA 6000 Nano chip on the Bioanalyzer (see Note 12). The RNA profile should appear similar to that in Figure $2 \mathrm{~A}$. Proceed to the next step immediately (see Figure 1 ) or store at $-80^{\circ} \mathrm{C}$.

\subsection{Size selection of transcripts shorter than $500 \mathrm{nt}$ (LIB $<500$ library)}

Denaturing polyacrylamide-urea gels are used in order to size-select transcripts shorter than $500 \mathrm{nt}$ (see Note 2).

1. Prior to sample loading the gels are pre-run in $1 \mathrm{X}$ TBE at $300 \mathrm{~V}$ for 30 minutes.

2. Combine on ice total RNA (up to $150 \mu \mathrm{g}$ ) in a maximum volume of $30 \mu \mathrm{L}$ with one volume of Gel Loading Buffer II. Each sample is loaded onto two lanes of the gel.

3. For each lane containing the marker, combine on ice:

$6 \mu \mathrm{L}$ of Low Range ssRNA Ladder $(3 \mu \mathrm{g})$

$4 \mu \mathrm{L}$ nuclease-free water

$10 \mu \mathrm{L}$ Gel Loading Buffer II

$20 \mu \mathrm{L}$ total volume

4. Incubate the RNA and marker at $65^{\circ} \mathrm{C}$ for 5 minutes just prior to loading them onto the gel. 
5. Clean the wells of the gel with a syringe containing $1 X$ TBE buffer.

6. For each RNA sample load equal volumes into two adjacent wells on the gel. Leave an empty lane next to the RNA ladder and also between different samples.

7. Run the gel at $200 \mathrm{~V}$ for 35 minutes.

8. Stain the gel by soaking it in $50 \mathrm{~mL} 1 \mathrm{X}$ TBE with $5 \mu \mathrm{L}$ of SYBR Gold Nucleic Acid Gel Stain at room temperature for $30 \mathrm{~min}$. Use a nuclease-free container that is protected from light.

9. Place the 0.5-mL Gel Breaker tube into a 2-mL microcentrifuge tube.

10. Visualize the RNA and cut out the gel containing RNA between 50 and 500 nt by comparison with the bands of the RNA ladder.

11. Place the gel pieces corresponding to the same sample into the $0.5-\mathrm{mL}$ Gel Breaker tube.

12. Centrifuge the stacked tubes $(20,000 \times \mathrm{g}, 2 \mathrm{~min}$, room temperature) to move the gel through the holes and into the 2-mL tube. Ensure that all of the gel has moved into the bottom tube.

13. Add $400 \mu \mathrm{L} 0.4 \mathrm{M} \mathrm{NaCl}$ solution to the gel debris.

14. Elute the RNA by rotating or shaking the tube overnight at room temperature.

15. Transfer the eluate and the gel debris to the top of a $5-\mu \mathrm{m}$ filter tube.

16. Centrifuge the filter at $600 \mathrm{xg}$ for $10 \mathrm{~s}$. Discard the filter and retain the eluate which contains the RNA.

17. Precipitate the RNA by following step 10 under section 3.3 Treatment with DNase I.

18. Resuspend in $20 \mu \mathrm{L}$ TE buffer.

19. Quantitate the yield of the rRNA-depleted RNA using the Qubit@ RNA Assay Kit on the Qubit $\AA$ Fluorometer (Invitrogen), or a low-volume spectrophotometer (see Note 11). Check the quality of the RNA with a RNA 6000 Nano chip on the Bioanalyzer (see Note 12). The profile of the RNA obtained should be similar to that depicted in Figure $2 \mathrm{C}$.

20. Proceed to the $5 S$ rRNA depletion (section 3.7) immediately or store at $-80^{\circ} \mathrm{C}$.

\subsection{Size selection of transcripts shorter than $200 \mathrm{nt}(\mathrm{LIB}<200$ library)}

The mirVana ${ }^{\mathrm{TM}}$ miRNA Isolation Kit.from Ambion (Part Number $1560 \mathrm{M}$ Rev. C January 2011 / http://tools.invitrogen.com/content/sfs/manuals/fm_1560.pdf) can be used to select for sRNAs shorter than $200 \mathrm{nt}$ (see Note 13).

1. Follow the protocol described in section IV. Additional Procedures. A. Isolation of Small RNAs from Total RNA Samples of the kit manual to obtain a $100 \mu \mathrm{L}$ solution containing the $s R N A s \leq 200 \mathrm{nt}$.

2. Precipitate the RNA by following step 10 from section 3.3 Treatment with DNase I. 
3. Resuspend the RNA in $20 \mu \mathrm{L}$ TE buffer.

4. Quantitate the yield of the rRNA-depleted RNA using the Qubit $\circledast$ RNA Assay Kit on the Qubit ${ }^{\circ}$ Fluorometer (Invitrogen), or a low-volume spectrophotometer (see Note 11). Check the quality of the RNA with a RNA 6000 Nano chip on the Bioanalyzer (see Note 12). The profile of the RNA obtained should be similar to that depicted in Figure 2C.

5. Proceed to the $5 S$ rRNA depletion (section 3.7 ) immediately or store at $-80^{\circ} \mathrm{C}$.

\subsection{Depletion of 23S, $16 S$ and 5S rRNAs (LIB>100 library)}

After obtaining total RNA, the next step is to deplete abundant rRNAs from the sample. Bacterial total RNA consists of approximately $86 \%$ rRNA (7). Removal of rRNA significantly increases the fraction of mRNAs and sRNAs in the sample, allowing higher sequencing coverage and more sensitive detection of novel transcripts. Although the MICROBExpress ${ }^{\mathrm{TM}}$ Bacterial mRNA Enrichment Kit from Ambion is used here (Part $\begin{array}{llllll}\text { Number } & 1905 \mathrm{M} & \text { Rev. } & \text { C } & \end{array}$ http://tools.invitrogen.com/content/sfs/manuals/fm_1905.pdf), there are other commercially available kits to deplete rRNA (see Note 14). The MICROBExpress ${ }^{\mathrm{TM}}$ Kit is designed to enrich bacterial mRNA (including sRNAs) from purified total RNA by removing the $16 \mathrm{~S}$ and $23 S$ rRNAs via a subtractive hybridization approach.

The MICROBExpress ${ }^{\mathrm{TM}}$ Kit is followed with the following two modifications: an additional oligo is employed to remove $5 S$ rRNA and $25 \%$ more magnetic beads are used. The modifications needed to remove the 23S, $16 \mathrm{~S}$ and $5 \mathrm{~S}$ rRNAs in a single step are described below.

1. Using the concentration obtained by the spectrophotometer, calculate the volume of sample that contains 2-10 $\mathrm{gg}$ of RNA (see Note 15). The recommended maximum amount of RNA per reaction is $10 \mu \mathrm{g}$ and the recommended maximum volume is 15 $\mu \mathrm{L}$. If the recommended maximum amount of total bacterial RNA is exceeded, then rRNA removal will be incomplete.

2. Follow the protocol detailed in Section B Anneal RNA and Capture Oligonucleotide Mix of the kit manual.

3. After step B.2, add $1 \mu \mathrm{L}$ of the HPLC-purified $5 \mathrm{~S}$ oligo $(20 \mu \mathrm{M})$. Continue the protocol from step B.3.

4. In step C.1, remove $62.5 \mu \mathrm{L}$ of Oligo MagBeads for each RNA sample, corresponding to $25 \%$ more beads per sample. The reason for this is that adding the HPLC-purified $5 S$ oligo results in a $25 \%$ increase in capture oligos. We have successfully processed 
Oligo MagBeads for up to 10 samples $(625 \mu \mathrm{L})$ in a single $1.5-\mathrm{mL}$ tube. Continue the protocol from step C.2.

5. In step D.2, add $62.5 \mu \mathrm{L}$ of the prepared Oligo MagBeads to the RNA/Capture Oligo Mix and incubate at $37^{\circ} \mathrm{C}$ for $15 \mathrm{~min}$. Continue the protocol from step D.3.

6. In step E.2, resuspend the RNA pellet in $25 \mu \mathrm{L}$ of nuclease-free water. Do not resuspend in TE buffer. Continue the protocol from step E.3 (but do not perform step E.4, as this removes sRNAs).

7. Quantitate the yield of the rRNA-depleted RNA using the Qubit@ RNA Assay Kit on the Qubit@ Fluorometer (Invitrogen). Check the quality of the RNA with a RNA 6000 Nano chip on the Bioanalyzer. The profile of the RNA obtained should be similar to that depicted in Figure 2D.

8. Proceed to the LIB $>100$ library preparation immediately (section 3.10) or store at $80^{\circ} \mathrm{C}$.

\subsection{Depletion of 5S rRNA after size selection (LIB $<500$ and LIB $<200$ libraries)}

Although the $23 S$ and $16 S$ rRNAs are depleted from the samples after the size selection step, a significant fraction of the sample now consists of $5 S$ rRNA. In order to deplete $5 S$ rRNA, the MICROBExpress ${ }^{\mathrm{TM}} \quad$ Kit manual (Part Number 1905M Rev. C January 2011 / http://tools.invitrogen.com/content/sfs/manuals/fm_1905.pdf) is followed with the modification that the HPLC-purified $5 S$ oligo is added as the only Capture Oligo as described below.

1. Using the concentration obtained by the spectrophotometer, calculate the volume of sample that contains 2-10 $\mu \mathrm{g}$ of RNA (see Note 15). The recommended maximum amount of RNA per reaction is $10 \mu \mathrm{g}$ and the recommended maximum volume is $15 \mu \mathrm{L}$. If the recommended maximum amount of total bacterial RNA is exceeded, then rRNA removal will be incomplete.

2. Follow the protocol detailed in Section B Anneal RNA and Capture Oligonucleotide Mix of the kit manual. In step B.2, add $4 \mu \mathrm{L}$ of the HPLC-purified $5 S$ oligo (20 $\mu \mathrm{M})$, but do not add $4 \mu \mathrm{l}$ of Capture Oligo Mix. Continue the protocol from step B.3. Do not add the Capture Oligo Mix included in the kit, as this contains oligos complementary to $23 \mathrm{~S}$ and $16 \mathrm{~S}$ rRNAs.

3. In step E.2, resuspend the RNA pellet in $25 \mu \mathrm{L}$ of nuclease-free water. Do not resuspend in TE buffer. Continue the protocol from step E.3 (but do not perform step E.4, as this removes sRNAs). 
4. Quantitate the yield of the rRNA-depleted RNA using the Qubit@ RNA Assay Kit on the Qubit@ Fluorometer (Invitrogen). Check the quality of the RNA with a RNA 6000 Nano chip on the Bioanalyzer. The profile of the RNA obtained should be similar to that depicted in Figure 2D.

5. Proceed to the Tobacco Acid Pyrophosphatase treatment (section 3.8) immediately or store at $-80^{\circ} \mathrm{C}$.
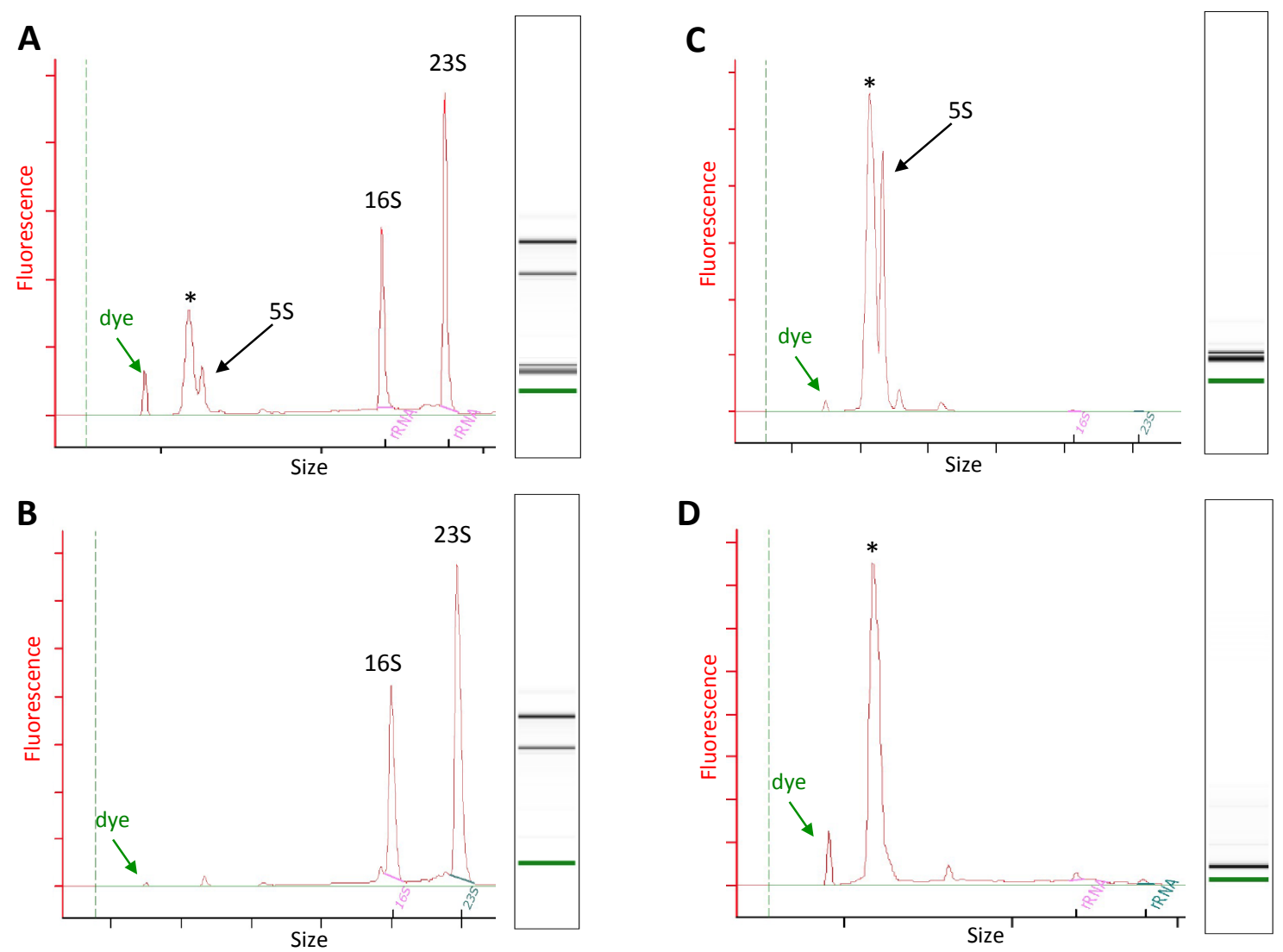

Figure 2. Typical size profiles of RNA samples. All profiles correspond to RNA extracted from $P$. aeruginosa PAO1 cells analyzed with the RNA 6000 Nano chip on the Bioanalyzer (Agilent). A. Total RNA extracted with Trizol and treated with DNase I. B. Total RNA extracted with the NucleoSpin RNA II kit (Macherey Nagel) and treated with DNase I. C. Size-selected RNA ( $<500 \mathrm{nt})$ purified on a denaturing polyacrylamide-urea gel. D. An rRNA-depleted sample. The 23S (2891 nt), 16S (1536 nt) and $5 \mathrm{~S}(120 \mathrm{nt}) \mathrm{rRNAs}$ were removed from the total RNA by subtractive hybridization as described in the Materials and Methods sections. The peaks marked with asterisks $\left(^{*}\right)$ correspond to tRNAs and sRNA species shorter than $120 \mathrm{nt}$.

\subsection{Treatment with Tobacco Acid Pyrophosphatase (LIB $<500$ and LIB $<200$ libraries)}

After size-selection of RNA (used to prepare $L I B<500$ or LIB $<200$ libraries), the RNA is treated with Tobacco Acid Pyrophosphatase (TAP). TAP is used to convert 5'-triphosphate RNA into 5'-monophosphate RNA. This step is necessary to ensure that primary transcripts (containing a 5'-triphosphate) are ligated to adapters during the library preparation. 
1. Assemble the reaction in a PCR tube on ice in the order given:

$17 \mu \mathrm{L}$ Size-selected RNA (up to $10 \mu \mathrm{g}$ ) diluted in nuclease-free water

$2 \mu \mathrm{L}$ 10X TAP Reaction Buffer

$1 \mu \mathrm{L}$ TAP $(10 \mathrm{U} / \mu \mathrm{L})$

$20 \mu \mathrm{L}$ total volume

2. Pipet up and down a few times to mix. Incubate at $37^{\circ} \mathrm{C}$ for one hour.

3. Spin down the Phase-Lock Gel (PLG) at $12,000-16,000 \times \mathrm{g}$ for $30 \mathrm{~s}$.

4. Transfer the sample to the PLG tube.

5. Add $130 \mu \mathrm{L}$ nuclease-free water.

6. Add $150 \mu \mathrm{L} \mathrm{PCl} \mathrm{solution.}$

7. Shake vigorously for $30 \mathrm{~s}$ (do not vortex).

8. Centrifuge at $12,000-16,000 \times g$ at room temperature for $5 \mathrm{~min}$.

9. Transfer the aqueous phase to a clean $1.5-\mathrm{mL}$ tube (the volume should be approximately $150 \mu \mathrm{L}$ ).

10. Precipitate the RNA by following step 10 from section 3.3 Treatment with DNase I.

11. Resuspend in $15 \mu \mathrm{L}$ nuclease-free water.

12. Quantitate the yield of the RNA using the Qubit $\circledast$ RNA Assay Kit on the Qubit $\circledast$ Fluorometer (Invitrogen). Check the quality of the RNA with a RNA 6000 Nano chip on the Bioanalyzer. The profile of the RNA obtained should be similar to that depicted in Figure 2D.

13. Proceed to the next step immediately (see Figure 1 ) or store at $-80^{\circ} \mathrm{C}$.

\subsection{Fragmentation with RNase III (LIB $<500$ library)}

During preparation of the LIB $<500$ library, the size-selected RNA needs to be fragmented after the TAP treatment. The fragmentation is performed with RNase III, which cleaves long double-stranded RNA (dsRNA) into shorter dsRNAs containing 5'-PO ${ }_{4}$, and 3'-OH termini, and a 3' dinucleotide overhang. The fragmentation procedure should produce a distribution of RNA fragment sizes from $35 \mathrm{nt}$ to several hundred nucleotides, where the average size is 100-200 nt.

1. Assemble the reaction in a microcentrifuge tube on ice in the order given:

$32 \mu \mathrm{L}$ RNA (2 $\mu \mathrm{g}$, from step 13, section 3.8) diluted in nuclease-free water

$4 \mu \mathrm{L}$ 10X RNase III Buffer

$4 \mu \mathrm{L}$ RNase III

$40 \mu \mathrm{L}$ total volume

2. Pipet up and down a few times to mix. Incubate at $37^{\circ} \mathrm{C}$ for $10 \mathrm{~min}$. 
3. Immediately after the incubation, add $110 \mu \mathrm{L}$ of nuclease-free water and place the fragmented RNA on ice.

4. Spin down the Phase-Lock Gel (PLG) at 12,000-16,000 x g for $30 \mathrm{~s}$.

5. Transfer the sample to a PLG tube.

6. Add $150 \mu \mathrm{L} \mathrm{PCl}$ solution.

7. Shake vigorously for $30 \mathrm{~s}$ (do not vortex).

8. Centrifuge at $12,000-16,000 \times \mathrm{g}$ for $5 \mathrm{~min}$ at room temperature.

9. Transfer the aqueous phase to a clean 1.5-mL tube (the volume should be approximately $150 \mu \mathrm{L}$ ).

10. Precipitate the RNA by following step 10 from section 3.3 Treatment with DNase I.

11. Resuspend in $15 \mu \mathrm{L}$ nuclease-free water.

12. Quantitate the yield of the fragmented RNA using the Qubit@ RNA Assay Kit on the Qubit $\circledast$ Fluorometer (Invitrogen). Check the quality of the RNA with a RNA 6000 Nano chip on the Bioanalyzer. The profile of the RNA obtained should be similar to that depicted in Figure 2D. Proceed to the LIB $<500$ library preparation (section 3.11) immediately, or store at $-80^{\circ} \mathrm{C}$.

\subsection{Library Preparation for full transcriptome sequencing (LIB $<100$ library)}

The LIB $>100$ library has been prepared with the Illumina TruSeq ${ }^{\mathrm{TM}}$ RNA Sample Preparation Kit v2 (Part Number 15026495 Rev. D September 2012 / http://support.illumina.com/documents/Mylllumina/b386d5c9-c919-48db-bdc1-

8a687ba2a101/TruSeq_RNA_SamplePrep_v2_Guide_15026495_D.pdf) (see Notes 3 and 4) with some modifications that are explained below. Read the Best Practices section of the manual carefully. We perform the Low Sample (LS) protocol. If only 2-4 samples are to be pooled, read the Pooling Guidelines section of the manual.

1. Start the protocol with 100-400 ng of rRNA-depleted RNA, diluted in a maximum volume of $5 \mu \mathrm{L}$ nuclease-free water (see Note 15).

2. Add $13 \mu \mathrm{L}$ Elute, Prime, Fragment Mix to the sample.

3. Continue the protocol from step Incubate RFP (included in section Purify and Fragment $R N A$ ). Perform all the steps included in sections Incubate RFP, Synthesize First Strand cDNA, Synthesize Second Strand cDNA, Perform End Repair, Adenylate 3' Ends, Ligate Adapters and Enrich DNA Fragments (see Note 16). At this point the amplified libraries are in a $30 \mu \mathrm{L}$ volume.

4. Quantify the libraries using the Qubit $\AA$ dsDNA HS or BR Assay Kit on the Qubit $\AA$ Fluorometer (Invitrogen) (see Note 17). 
5. Check the size and purity of the sample by running a DNA 1000 chip on the Bioanalyzer. The final product should be a broad band with an average size of approximately 260 bp (see Figure $3 \mathrm{~A}$ ).

6. Adjust the concentration of the libraries to $10 \mathrm{nM}$ using a $10 \mathrm{mM}$ Tris- $\mathrm{Cl}$ ( $\mathrm{pH}$ 8.5) solution containing $0.1 \%$ Tween 20 .

7. Combine $10 \mu \mathrm{L}$ of each normalized sample library to be pooled in a $1.5-\mathrm{mL}$ microcentrifuge tube (see Note 3). Each library in the pooled mixture must have a different index or barcode.

8. Send an aliquot of the pooled libraries to be sequenced (see Note 6) or store at $-20^{\circ} \mathrm{C}$. It is recommended that the libraries are shipped on dry ice.

\subsection{Library Preparation for sRNA sequencing (LIB $<500$ and LIB $<200$ libraries)}

The LIB $<500$ and LIB $<200$ libraries are prepared with the Illumina TruSeq ${ }^{\mathrm{TM}}$ Small RNA Sample Preparation Kit (Part Number 15004197 Rev. D May 2012 / http://support.illumina.com/documents/Mylllumina/b76a55b0-4ac7-4ee7-aa230e993cf7f467/TruSeq_SmallRNA_SamplePrep_Guide_15004197_D.pdf) (see Notes 3 and 5) with some modifications that are explained below. Read the Best Practices section from the manual carefully. If more than 8 samples are to be prepared, then we recommend using 250- $\mu \mathrm{L}$ PCR plates and caps for PCR strips that are compatible with the plates to perform the protocol.

1. Start the protocol at the section Ligate 3' and 5' Adapters with 100-400 ng of sizeselected RNA, diluted in a maximum volume of $5 \mu \mathrm{L}$ nuclease-free water (see Note 15).

2. Perform all steps from sections Ligate 3' and 5' Adapters and Reverse Transcribe and Amplify. At this point the amplified libraries are in a $50 \mu \mathrm{L}$ volume.

3. Allow the AMPure XP Beads to come to room temperature prior to use. Vortex the beads until they are well dispersed, and then add $50 \mu \mathrm{L}$ of the mixed AMPure XP Beads to each PCR amplified library. Gently pipette the entire volume up and down ten times to mix thoroughly.

4. Incubate the PCR tubes or plate at room temperature for $15 \mathrm{~min}$.

5. Place the PCR tubes or plate on the magnetic stand at room temperature for $5 \mathrm{~min}$ or until the liquid appears clear.

6. Remove and discard $95 \mu \mathrm{L}$ of the supernatant from each PCR tube or plate well.

7. With the PCR tubes or plate remaining on the magnetic stand, add $200 \mu \mathrm{L}$ of freshly prepared $80 \% \mathrm{EtOH}$ to each tube or well without disturbing the beads. 
8. Incubate at room temperature for $30 \mathrm{~s}$, then remove and discard all of the supernatant from each tube or well.

9. Repeat the last two steps once for a total of two $80 \% \mathrm{EtOH}$ washes.

10. While keeping the PCR tubes or plate on the magnetic stand, let the samples air dry at room temperature for $15 \mathrm{~min}$ and then remove the tubes or plate from the magnetic stand.

11. Resuspend the dried pellet with $22.5 \mu \mathrm{L}$ TE buffer. Gently pipette the entire volume up and down ten times to mix thoroughly.

12. Incubate at room temperature for $2 \mathrm{~min}$.

13. Place the PCR tubes or plate on the magnetic stand at room temperature for $5 \mathrm{~min}$ or until the liquid appears clear.

14. Transfer $20 \mu \mathrm{L}$ of the clear supernatant to a clean PCR tube or plate well.

15. Quantify the libraries using the Qubit $\circledast$ dsDNA HS BR Assay Kit on the Qubit $\circledast$ Fluorometer (Invitrogen) (see Note 17).

16. Check the size and purity of the sample by running a High Sensitivity DNA chip on the Bioanalyzer. The final product should be a broad band with an average size of approximately of $200 \mathrm{bp}$ (see Figure 3B).

17. Adjust the concentration of the libraries to $10 \mathrm{nM}$ using a $10 \mathrm{mM}$ Tris- $\mathrm{Cl} \quad(\mathrm{pH} 8.5)$ solution containing $0.1 \%$ Tween 20 .

18. Combine $10 \mu \mathrm{L}$ of each normalized sample library to be pooled in a $1.5-\mathrm{mL}$ microcentrifuge tube (see Note 3). Each library in the pooled mixture must have a different index or barcode.

19. Send an aliquot of the pooled libraries to be sequenced (see Notes 5 and 6 ) or store at $-20^{\circ} \mathrm{C}$. It is recommended that the libraries are shipped on dry ice.

A

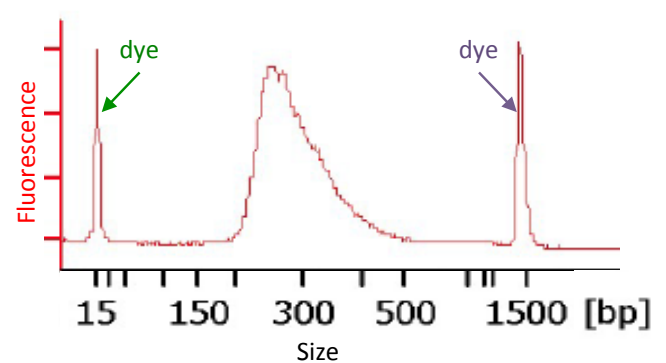

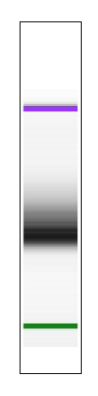

B

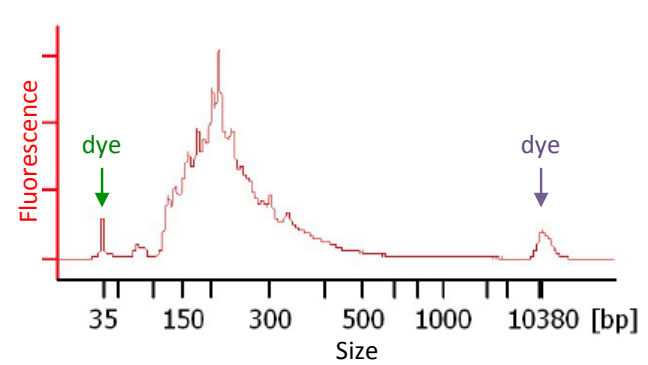

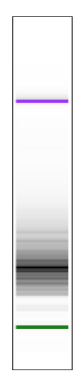

Figure 3. Typical size profiles of amplified libraries. A. The LIB $>100$ library analyzed with a DNA 1000 chip on the Bioanalyzer (Agilent). B. The LIB $<500$ library analyzed with a High Sensitivity DNA chip on the Bioanalyzer (Agilent). Libraries prepared using the LIB $<200$ protocol will have a very similar profile. 


\subsection{Read mapping}

The first step of the data analysis pipeline is to map the reads against the reference genome. Note that cDNA libraries sequenced using a paired-end protocol will yield two FASTQ files per library, one containing the forward reads, and the other the reverse reads. In the LIB $<500$ and LIB $<200$ libraries, information corresponding to short transcripts $(<100$ nucleotides) is retained in the library construction. If the native read lengths are longer than the shortest cDNA fragments, then the read sequence will run through the cDNA fragment and extend into the adapter sequence. The 3'-end adapter sequences should therefore be trimmed away before mapping. There are several tools to trim reads, including the Flexbar tool that allows for flexible barcode detection and adapter removal. We map the adaptertrimmed reads onto the reference genome using Bowtie 2, which is a fast and memoryefficient tool for aligning short sequence reads onto reference genomes. The output of Bowtie 2 is the alignment of all the reads onto the reference genome in the generic Sequence Alignment/Map (SAM) format. The SAM format is a tab-delimited text format containing generic alignment information. For faster processing the SAM format can be converted into the equivalent binary format BAM.

\subsection{Read coverage quantification}

In order to calculate the transcription level across the genome at a single base resolution, the number of aligned reads for each position in the genome is counted. Thus, the global alignment stored in the SAM format needs to be converted into a list of the genomic positions together with the number of covering bases.

We use SAMtools for manipulating alignments in the SAM format. The SAM-formatted alignments are then converted into the BAM format, which is sorted to create a pileup file. Pileup format is a text-based format for summarizing the base calls of aligned reads at each covered position in the reference sequence. In the pileup file the information about the genomic location (chromosome and position) and the count of covering reads is stored in columns one, two and eight, respectively. Note that the pileup format only contains information about genomic positions that are covered by reads. It is therefore recommended to amend the pileup file to include uncovered positions designating the number of covering reads to be 0 . If there is only one chromosome, the information about coverage depth along the genome can be stored in two columns, with the genomic position specified in the first column, and the number of covering reads given in the second column. This type of file will now be referred to as the coverage file. 


\subsection{Normalization and replicate merging}

After determining the read coverage across the genome, the read counts in the coverage file are then normalized according to the total number of reads in the cDNA library. This is done in order to compare the level of transcription across different libraries. After normalization the normalized coverage files from replicate samples are merged by calculating the average read count at each position.

\subsection{Full transcriptome analysis (library LIB>100)}

If the library LIB $>100$ protocol has been followed, it is now possible to calculate the transcription levels of all already-annotated genes.

1. Using your normalized coverage files (not merged), calculate the average expression of each gene by dividing the normalized read coverage depth (the sum of coverage at each base of the gene) by the length of the transcript. It is necessary to have an annotation file containing all the annotated genes of your organism, their coordinates and length.

2. Analyze differential gene expression between the different samples, using ANOVA for example.

\subsection{Identification of trans-encoded sRNAs (all libraries)}

Most sRNAs characterized to date regulate gene expression by base pairing with mRNAs. These sRNAs fall into two broad classes: those encoded in cis on the DNA strand opposite the target RNA that share extended regions of perfect complementarity (cis-encoded antisense sRNAs), and those encoded in intergenic regions that share limited complementarity with their targets (trans-encoded sRNAs). In this section, we explain how to identify trans-encoded sRNAs. Although this type of analysis can be performed using all three types of libraries described here, a larger number of sRNAs will be detected in the $\mathrm{LIB}<500$ and $\mathrm{LIB}<200$ libraries because they are prepared from RNA that is size-selected and enriched for sRNAs (6). For the purpose of our analysis we define trans-encoded sRNAs as transcripts encoded entirely in the intergenic regions. Nonetheless, some transencoded sRNAs might extend into their neighboring genes. Also, some of the identified sRNAs might represent 5'-UTRs truncated before the start codon of their respective genes. In order to detect trans-encoded sRNAs in a high-throughput manner, we have employed an automated algorithm that detects transcripts starting and ending in intergenic regions. 
The algorithm detects the sudden increases in read coverage depths in the intergenic regions by the following criteria: (a) A transcript is detected if the coverage depth increases above a cut-off that is set to discriminate noise caused by sequenced mRNA. Our cut-off was set based on the average expression intensities of forty-four previously validated sRNAs in $P$. aeruginosa (6). (b) The average transcriptional level (calculated as the normalized read coverage depth divided by the length of the transcript) of the detected transcript must be twice the previously defined cut-off to be considered further as an sRNA candidate. The two cut-off values are necessary and used together to identify sRNAs in that the second cut-off (b) ensures detection of very abrupt increases in read coverage depths whereas the first cut-off (a) enables the length of the transcripts to be defined more accurately.

After detecting transcripts, their transcriptional levels can be compared between samples as described in the previous section. The detected trans-encoded sRNAs can be visualized using a global alignment viewer such as Tablet (8) that may be helpful in more accurately defining the lengths of the sRNAs. Tablet visualizes the alignment using the sorted BAM format described in section 3.13. Tablet also requires an indexed BAM formatted alignment to be indexed. Indexing enables a more rapid alignment retrieval, and can be performed with SAMtools.

\subsection{Identification of cis-encoded sRNAs (LIB $<500$ and LIB $<200$ libraries)}

The next objective is detection of cis-encoded sRNAs. As these sRNAs are transcribed from the DNA strand opposite the target RNA, they can only be directly identified in strandspecific libraries like LIB $<500$ or LIB $<200$. The cis-encoded sRNAs are detected using an algorithm similar to the one used for detection of trans-encoded sRNAs. As the cis-encoded sRNAs are transcribed opposite to their respective genes, the analysis shoud be constrained to reads being in the opposite direction to the genes onto which they align. Information on the direction of the aligned reads is contained in the second column of the SAM format. A number of different flags are used to describe the orientation of the single read and its corresponding mate, and flags "99", "147", "83" and "163" designate the read and its mate to be properly aligned within a distance as defined by the insert size. Read pairs with flags 99 or 147 originate from transcripts encoded on the plus strand, while read pairs with flags 163 or 83 originate from transcripts encoded on the minus strand. This allows us to only extract reads that map to a known gene, but have the opposite direction of the gene. The reads that originate from a gene encoded on the plus strand will have the flags 99 or 147 . Thus, the reads that map to this gene and have the flags 163 or 83 need to 
be extracted. The procedure is likewise for genes encoded on the minus strand, where the reads with flags 99 or 147 need to be extracted.

The extracted reads are placed into SAM formatted files that are processed into new pileup format files which can then be normalized and merged as previously described in sections 3.13 and 3.14. The algorithm described in section 3.16 is used in order to detect transcripts with sudden increases in read coverage depths. The difference in this case is that only transcripts that overlap genes are evaluated. The ends of mRNA molecules that do not encode proteins are termed untranslated regions (UTRs). These regions can contain regulatory elements for controlling gene expression and extend into the neighboring genes. $\mathrm{Be}$ aware of the fact that some cis-encoded sRNAs detected in your libraries might be UTRs from neighboring genes. Calculations of transcriptional levels, comparisons between samples, and visualization of cis-encoded sRNAs can be performed as previously described in sections 3.13 to 3.16 .

\section{NOTES}

1. RNA is highly susceptible to degradation by ribonucleases. These enzymes are present on skin, laboratory equipment, and in dust. They are very stable and difficult to inactivate. For these reasons, it is important to follow best laboratory practices while preparing and handling RNA samples. Wear gloves and use sterile technique at all times. Reserve a set of pipettes for RNA work. Use sterile RNase-free filter pipette tips to prevent cross-contamination. Use RNase-free disposable plasticware. All reagents and solutions should be sterile and RNase-free where possible. Use RNase decontamination solution (such as RNase-ZAP) to decontaminate work surfaces and equipment prior to starting this protocol.

2. Although we have used precast gels to size-select transcripts shorter than $500 \mathrm{nt}, 1$ $\mathrm{mm}$ thick, $10 \%$ polyacrylamide TBE-Urea minigels can also be prepared. For each gel, mix $1 \mathrm{~mL}$ 10X TBE with $3.33 \mathrm{~mL}$ acrylamide: bis-acrylamide (37.5:1), $2.14 \mathrm{~mL}$ water, $4.2 \mathrm{~g}$ urea, $330 \mathrm{~mL} 1.6 \%$ ammonium persulfate, and $5 \mathrm{~mL}$ tetramethylethylenediamine (TEMED). The glass plates, combs, and chambers used should be compatible with the Mini-PROTEAN or other suitable electrophoresis system.

3. It is highly recommended to work with at least two biological replicates of every sample to be sequenced. This will enable a better comparison of the transcript expression levels between different samples. Thus, if there are twelve samples or conditions, and there are two replicates per sample, then there are twenty-four libraries to be sequenced. If multiplexed sequencing (sequencing different samples in the same lane) 
is to be performed, then each library needs to be prepared using a different index or barcode. This will allow the different libraries to be pooled together and sequenced in one lane. Therefore, the number of indexes or barcodes needed is the same as the total number of libraries to be sequenced in the same lane. We have successfully sequenced up to twenty-four different RNA libraries in the same lane.

4. There are two different versions of the TruSeq ${ }^{\mathrm{TM}}$ RNA Sample Prep Kit v2 (Illumina), where each contains twelve different indexes or barcodes (twenty-four unique indexes or barcodes in total).

5. There are four different versions of the TruSeq ${ }^{\mathrm{TM}}$ Small RNA Sample Preparation Kit (Illumina), where each contains twelve different indexes or barcodes (forty-eight unique indexes or barcodes in total). This kit is designed for sequencing of eukaryotic microRNAs (miRNAs), which are around $22 \mathrm{nt}$ in length. The libraries obtained following the kit manual will contain DNA fragments of around $150 \mathrm{bp}$, including the adapters. We describe modifications that allow using the TruSeq ${ }^{\mathrm{TM}}$ Small RNA Sample Preparation Kit for preparing libraries that enable sequencing of bacterial small RNAs, which normally range between 70 and $500 \mathrm{nt}$ in length. The libraries prepared following our protocol will contain fragments that range from 100 to $400 \mathrm{bp}$, including the adapters. Make sure to inform your sequencing provider about these modifications.

6. The libraries described here were sequenced using the Illumina HiSeq2000 platform with a paired-end protocol and read lengths of $100 \mathrm{nt}$. On average, 16.7 million sequence reads were generated from each library, and of these 12.3 million were of sufficient quality to be mapped onto our reference genome (6). However, as sequencing technologies are rapidly evolving, sequencing using the latest available technology as well as the longest possible read length is recommended.

7. The RNA used to prepare the $L I B<500$ and $L I B<200$ libraries was treated with Tobacco Acid Pyrophosphatase (TAP) to ensure the inclusion of primary transcripts containing a $5^{\prime}$-triphosphate. Although primary and processed transcripts are not distinguishable in these libraries, it is possible to modify the approach with additional libraries to obtain this information. One approach is to discriminate primary from processed 5 ' ends by preparing two libraries from the same RNA sample. One library is prepared with untreated RNA and the other library is enriched for primary transcripts by treatment with Terminator 5'-Phosphate-Dependent Exonuclease (Epicentre), which degrades RNA with 5'-monophosphate but not 5'-triphosphate ends (9).

8. There are a number of protocols and kits for RNA isolation, but many of them do not quantitatively retain the smaller RNAs that are of interest here. This is the case for most of the kits that use spin columns. We use Trizol (Invitrogen) to isolate RNA because it is a quick method that allows retention of all RNA species. The protocol 
described here can also be used to extract RNA from mucoid cells. If another method is used to extract RNA, it is important to ensure that small RNA species are retained by checking the sample with a Bioanalyzer. The RNA profile obtained after extraction with Trizol is shown in Figure 2A, and that obtained with a spin column kit (in this example the NucleoSpin RNA II kit from Macherey Nagel) is shown in Figure 2B.

9. One milliliter of Trizol is sufficient to extract RNA from $10 \mathrm{~mL}$ of $P$. aeruginosa culture harvested at $\mathrm{OD}_{600}$ of 0.5 to 3 , where the typical yields of total RNA obtained are 40 to $150 \mu \mathrm{g}$. For other growth/harvest conditions or for bacteria other than P. aeruginosa, optimization of the RNA extraction method may be necessary.

10. The RNA can be stored as pellets in $75 \%$ ethanol at $-20^{\circ} \mathrm{C}$ or $-80^{\circ} \mathrm{C}$ for at least one year, or at $4^{\circ} \mathrm{C}$ for at least one week. RNA storage in ethanol is highly recommended for long-term storage (weeks or months).

11. It is important that both the $A_{260} / A_{280}$ and the $A_{260} / A_{230}$ ratios of RNA solutions are close to 2.0. RNA has its absorbance maximum at $260 \mathrm{~nm}$ and this absorbance is not dependent on the $\mathrm{pH}$ of the solution. However, the absorbance of some contaminants (like proteins) is $\mathrm{pH}$-dependent. This means that although the $\mathrm{A}_{260}$ reading of the RNA solution will remain the same at different $\mathrm{pH}$ values, the $\mathrm{A}_{280}$ reading will differ in a $\mathrm{pH}$ dependent manner. Adjusting the $\mathrm{pH}$ of the RNA solution from approximately 5.5 to a slightly alkaline $\mathrm{pH}$ of 7.5-8.5 significantly increases $\mathrm{RNA} \mathrm{A}_{260} / \mathrm{A}_{280}$ ratios from approximately 1.5 to $2.0(10)$. This should be taken into account when measuring the absorbance ratio of RNA dissolved in nuclease-free water. When isolating low amounts of RNA the $A_{260} / A_{230}$ ratio tends to be lower. This indicates contamination of the RNA solution with chaotropic salts, phenol or protein.

12. The Bioanalyzer (Agilent) is a microfluidics-based platform for sizing, quantification and quality control of DNA, RNA, proteins and cells. Here it is used for checking the quality of RNA, and the size of DNA libraries. We recommend quantifying RNA and DNA using other technologies such as a low-volume spectrophotometer or Qubit@ Fluorometer (Invitrogen). The Bioanalyzer allows for rapid analysis of RNA and DNA samples (3040 minutes) with minimal sample consumption $(1 \mu \mathrm{L})$. The higher sensitivity afforded by the Bioanalyzer is the main advantage over gel analysis, where larger sample amounts are required.

13. Denaturing polyacrylamide-urea gels can also be used to size-select RNAs shorter than 200 nt (see Note 2). However, we find it easier and faster to use the mirVana ${ }^{\mathrm{TM}}$ miRNA Isolation Kit for this purpose.

14. The MICROBExpress ${ }^{\mathrm{TM}}$ Bacterial mRNA Enrichment Kit (Ambion) has been used because it employs subtractive hybridization to specifically deplete rRNAs from total RNA. In our libraries, the average percentage of read coverage corresponding to 23S, 
16S and $5 \mathrm{~S}$ rRNAs was $7.1 \%, 3.8 \%$, and $0.15 \%$, respectively (6). For bacteria other than $P$. aeruginosa and $E$. coli the oligos used to deplete rRNAs may need to be redesigned. There are also other commercially available kits to deplete rRNA. One of them uses exonuclease to preferentially degrade processed RNAs with $5^{\prime}$ monophosphate ends (mRNA-ONLY Prokaryotic mRNA Isolation kit, from Epicentre). Exonuclease degrades all processed RNAs and, although the majority of the processed RNAs are believed to be rRNAs and tRNAs, there may be other transcripts including sRNAs that are also processed. He et al (2010) compared the performance of the MICROBExpress ${ }^{\mathrm{TM}}$ and mRNA-ONLY kits and found that only the former based on subtractive hybridization adequately preserved relative transcript abundance for quantitative analyses, whereas the latter based on exonuclease treatment greatly compromised mRNA abundance fidelity (11). Another commercially available kit based on subtractive hybridization contains capture oligonucleotides to remove $23 \mathrm{~S}, 16 \mathrm{~S}$ and $5 S$ rRNAs (Ribo-Zero rRNA Removal Kit, Epicentre).

15. Concentration of RNA samples can be achieved via an ethanol precipitation. Follow step 10 from section 3.3 Treatment with DNase I and resuspend in the appropriate volume of TE buffer or nuclease-free water.

16. Illumina recommends using Microseal 'B' adhesive seals (BioRad) to seal the PCR plates. However, we find that sealing the PCR plates using caps for compatible PCR strips is easier and safer.

17. In our experience the Qubit $\AA$ Flurometer (Invitrogen) is a fast and easy alternative for library quantification relative to qPCR, which is recommended by Illumina.

\section{ACKNOWLEDGEMENTS}

This work was supported by the Novo Nordisk Foundation, Lundbeck Foundation and the Danish National Research Foundation.

\section{REFERENCES}

1. Waters LS, Storz G. Regulatory RNAs in bacteria. Cell. 2009 Feb 20;136(4):615-28.

2. Gottesman S, Storz G. Bacterial small RNA regulators: versatile roles and rapidly evolving variations. Cold Spring Harb Perspect Biol. 2011 Dec;3(12):a00379.

3. Vogel J, Sharma CM. How to find small non-coding RNAs in bacteria. Biol. Chem. 2005 Dec;386(12):1219-38.

4. Sharma C, Vogel J. Experimental approaches for the discovery and characterization of regulatory small RNA. Current Opinion in Microbiology. 2009;12(5):536-46.

5. Storz G, Vogel J, Wassarman KM. Regulation by small RNAs in bacteria: expanding frontiers. Molecular Cell. 2011 Sep 16;43(6):880-91.

6. Gómez-Lozano M, Marvig RL, Molin S, Long KS. Genome-wide identification of 
novel small RNAs in Pseudomonas aeruginosa. Environmental Microbiology. 2012 Aug;14(8):2006-16.

7. Karpinets TV, Greenwood DJ, Sams CE, Ammons JT. RNA:protein ratio of the unicellular organism as a characteristic of phosphorous and nitrogen stoichiometry and of the cellular requirement of ribosomes for protein synthesis. BMC Biol. 2006;4:30.

8. Milne I, Bayer M, Cardle L, Shaw P, Stephen G, Wright F, et al. Tablet--next generation sequence assembly visualization. Bioinformatics. 2010 Feb 1;26(3):4012.

9. Sharma CM, Hoffmann S, Darfeuille F, Reignier J, Findeiss S, Sittka A, et al. The primary transcriptome of the major human pathogen Helicobacter pylori. Nature. 2010 Mar 11;464(7286):250-5.

10. Wilfinger $\mathrm{W}$, Mackey $\mathrm{K}$, Chomczynski $\mathrm{P}$. Effect of $\mathrm{pH}$ and ionic strength on the spectrophotometric assessment of nucleic acid purity. BioTechniques. Eaton; 1997;22(3):474-81.

11. He S, Wurtzel O, Singh K, Froula JL, Yilmaz S, Tringe SG, et al. Validation of two ribosomal RNA removal methods for microbial metatranscriptomics. Nat Meth. 2010 Oct;7(10):807-12. 



\section{Article 3}

Antisense small RNAs respond to osmotic, oxidative and antibiotic stress in Pseudomonas aeruginosa

Gómez-Lozano, M., Marvig, R. L., Tulstrup, M. V. L., Tribelli, P., \& Molin, S. Manuscript in preparation, 2013. 


\title{
Antisense small RNAs respond to osmotic, oxidative and antibiotic stress in Pseudomonas aeruginosa
}

\author{
María Gómez-Lozano ${ }^{1,2}$, Rasmus L. Marvig ${ }^{1}$, Monica V. L. Tulstrup ${ }^{2}$, Paula Tribelli ${ }^{3}$, \\ and Søren Molin*1,2 \\ ${ }_{2}^{1}$ Department of Systems Biology, Technical University of Denmark, Lyngby, Denmark. \\ ${ }_{3}^{2}$ Novo Nordisk Foundation Center for Biosustainability, Technical University of Denmark, Hørsholm, Denmark. \\ Dpto. de Química Biológica, Facultad de Ciencias Exactas y Naturales, Universidad de Buenos \\ Aires. IQUIBICEN-CONICET, Buenos Aires, Argentina.
}

*To whom correspondence should be addressed (e-mail: sm@bio.dtu.dk).

\begin{abstract}
The use of RNA-Seq technologies is revealing that bacterial RNA molecules are more than mRNAs, rRNAs or tRNAs. During the last years bacterial transcriptomes have been shown to contain intergenic RNAs, antisense RNAs, and untranslated regions, all capable of performing diverse regulatory functions. In this study we identified 249 antisense RNAs (asRNAs) in the opportunistic pathogen Pseudomonas aeruginosa. A considerable number of asRNAs were transcribed opposite to genes encoding membrane proteins and genes involved in the transport of small molecules, cell wall, lipopolysaccharide (LPS), and capsule biosynthesis. A substantial number of asRNAs significantly changed their expression under osmotic, oxidative and antibiotic stress, suggesting that asRNAs play a regulatory role during these conditions. In addition we have validated the existence of two antisense RNAs, opposite to the $d n a A$ and ponA genes, which encode the chromosomal replication initiator protein $\mathrm{DnaA}$ and the penicillin-binding protein $1 \mathrm{~A}$, respectively.
\end{abstract}

\section{INTRODUCTION}

During the last years an increasing number of bacterial transcriptomes have been examined with tiling arrays and RNA sequencing (RNASeq) technologies, revealing that a significant number of protein-coding genes are also transcribed from the reverse complementary strand in a wide range of bacterial species (1-8). In general, overlapping transcription results in the generation of an antisense RNA (asRNA) whose size usually varies between various tens to hundreds of nucleotides (nt). The regulatory role of asRNAs was first reported more than 30 years ago in Escherichia coli, when the plasmidand transposon-encoded asRNAs RNAI and CopA were found to negatively regulate plasmid copy number $(9,10)$. However, until very recently, bacterial asRNAs were infrequently detected and therefore considered to be rare. By 
2007 , only about thirty bacterial asRNAs had been identified (reviewed in (11)). The number of reported asRNAs has lately exploded due to the use of tiling array and especially RNA sequencing (RNA-Seq) to study microbial transcriptomes. While the number of asRNAs detected in bacterial transcriptomes is rapidly growing, characterization of the physiological function of individual asRNAs is growing much slower. AsRNAs are known to affect the expression of the target gene by different mechanisms (reviewed in (12)). These include: (i) transcription interference, in which transcription from one promoter is suppressed by a second promoter located in the opposite strand, (ii) transcription attenuation, in which base pairing of the asRNA to the target mRNA causes premature transcription termination, (iii) changes in the target RNA stability, where the asRNA either promotes or blocks degradation or cleavage of the mRNA by ribonucleases, (iv) asRNAs can directly block ribosome binding, and (v) might indirectly impact ribosome binding (either positively or negatively) by affecting the target RNA structure. In addition, regulating the expression of the opposite gene is not the only function of certain asRNAs. Some asRNAs encode small proteins (13), and some have the potential to act on multiple targets in trans (1418).

In this work, we used RNA sequencing to identify asRNAs in the human pathogen Pseudomonas aeruginosa. $P$. aeruginosa can cause severe infections, particularly in immuno-compromised and cystic fibrosis (CF) patients. Recently two independent studies identified antisense transcription in $P$. aeruginosa. One of the studies investigated strains PAO1 and PA14 at early stationary phase and found 60 asRNAs (19). Interestingly, a number of these asRNAs were strain-specific or showed strain-specific expression (19). The other study identified 384 antisense transcriptional start sites, but not full length asRNAs, in $P$. aeruginosa PA14 grown at $28^{\circ} \mathrm{C}$ and at $37^{\circ} \mathrm{C}(20)$. However, it is evident that, due to their regulatory functions, the expression of asRNAs occurs mostly in a transient manner and is dependent on specific environmental cues. Therefore, we have aimed to identify asRNAs in $P$. aeruginosa PAO1 grown in a range of 13 different conditions to ensure a comprehensive characterization of the $P$. aeruginosa asRNA-ome. The conditions studied include exponential and early-stationary phase, osmotic, oxidative and antibiotic stress. Exponentially growing cultures of $P$. aeruginosa PAO1 were exposed to sodium chloride $(\mathrm{NaCl})$ and hydrogen peroxide $\left(\mathrm{H}_{2} \mathrm{O}_{2}\right)$ during osmotic and oxidative stress conditions, respectively. The antibiotics used were four different $ß$ lactams, tobramycin, azithromycin, ciprofloxacin, colistin and tetracycline.

Recently, we showed that library preparation for RNA-Seq plays a fundamental role when aiming at identifying novel transcripts. Using three RNASeq library protocols with different SRNA abundance, we identified over 500 novel intergenic sRNAs in $P$. aeruginosa PAO1 $(21,22)$. Although the use of three different libraries increased the number of novel transcripts identified, there were significant differences in the subset of transcripts detected 
in each library (21). Libraries that were prepared with a size-selected fraction of RNA were more sensitive in the detection of intergenic sRNAs. In this study we identified 249 asRNAs using strand-specific libraries that contain transcripts shorter than $500 \mathrm{nt}$.

\section{MATERIALS AND METHODS}

\section{Primers and adapters}

Supplementary Table 1 lists all primers and adapters used in this study.

\section{Plasmid construction}

The plasmids used in this study are listed in Table 1. Plasmids for L-arabinose-inducible expression of asRNAs were constructed by amplification of plasmid pBAD33 (23) with primers F1-Sacl and R1 producing a PCR product of $1250 \mathrm{bp}$ (F1-Sacl introduces a Sacl restriction site). For amplification of the asRNA insert, genomic DNA from strain PAO1 was amplified with primers F2 and R2-Xhol (F2 starts with the sRNA +1 site and R2-Xhol introduces an Xhol restriction site). The 5 'ends of primers F2 and R1 are complementary to each other. PCR synthesis by overlap extension (PCR-SOE) was carried out by combining the 2 previously amplified products and running PCR for 10 cycles, after which primers F1-Sacl and R2-Xhol are added and the reaction continues for another 30 cycles. The obtained product was digested with Sacl and Xhol and cloned into the MCS of plasmid miniCTX2 (24).

\section{Bacterial strains}

The bacterial strains used in this study are listed in Table 1. The Pseudomonas aeruginosa PAO1 strain was used as wild-type strain. The E. coli CC118גpir strain was used as cloning host (25). Strains pBADasdnaA, pBAD-asponA and $\mathrm{pBAD}$-control were created by integration of plasmids pBAD-asdnaA, pBAD-asponA and pBAD-control, respectively, at the attB site of strain PAO1, followed by Flp-mediated excision of the plasmid backbone, as described in (24). The first nucleotide of the transcribed products is the +1 of the sRNAs. This is an important consideration when cloning noncoding RNAs under the control of heterologous promoters, since altering the natural RNA start site may have unintended consequences for its function. The attB region was sequenced using primers $P_{\text {ser-up }}$ and $P_{\text {ser-down to }}$ make sure that the integration was successful and the plasmid backbone excised.

Table 1. Strains and plasmids used in this study.

\begin{tabular}{|c|c|c|}
\hline Strain or plasmid & Relevant markers/genotype & Source or reference \\
\hline \multicolumn{3}{|l|}{ Strains } \\
\hline P. aeruginosa $\mathrm{PAO1}$ & Wild type & Laboratory strain \\
\hline P. aeruginosa pBAD-asdnaA & pBAD-asdnaA fragment integrated at the attP site & This study \\
\hline P. aeruginosa $\mathrm{pBAD}$-asponA & pBAD-asponA fragment integrated at the attP site & This study \\
\hline P. aeruginosa pBAD-control & pBAD-control fragment integrated at the attP site & This study \\
\hline E. coli CC118גpir & araD139 $\Delta$ (ara leu)7697 $\Delta$ lacX74 phoA20 galE galK thi rpsE rpoB argE(Am) recA1 $\lambda$ pir lysogen & Herrero et al (1990) \\
\hline \multicolumn{3}{|l|}{ Plasmids } \\
\hline $\operatorname{mini}-\mathrm{CTX} 2$ & TcR; self-proficient integration vector with tet, $\Omega$-FRT-attP- MCS, ori, int, oriT and lacl & Hoang et al (2000) \\
\hline pBAD33 & CmR, pBAD expression plasmid with pBR322 & Guzman et al (1995) \\
\hline pBAD-asdnaA & TcR; AsdnaA expression plasmid, asdnaA is controlled by the plasmid-borne PBAD promoter & This study \\
\hline pBAD-asponA & TcR; AsponA expression plasmid, asponA is controlled by the plasmid-borne PBAD promoter & This study \\
\hline pBAD-control & TcR; pBAD control plasmid, expresses $322 \mathrm{nt}$ nonsense RNA followed by a terminator & This study \\
\hline pFLP2 & AmpR, source of Flp recombinase & Hoang et al (1998) \\
\hline
\end{tabular}

\section{Growth conditions}

Growth in Luria-Bertani (LB) broth $\left(250 \mathrm{rpm}, 37^{\circ} \mathrm{C}\right)$ or on LB plates at $37^{\circ} \mathrm{C}$ was used throughout this study. Stress exposure experiments. Overnight cultures of Pseudomonas aeruginosa PAO1 were diluted to a starting $\mathrm{OD}_{600}$ of 0.01 and grown to an $\mathrm{OD}_{600}$ of 0.5 , at which an antibiotic, $0.5 \mathrm{M} \mathrm{NaCl}$ or $1 \mathrm{mM}$ hydrogen peroxide was added. The final concentrations of antibiotics are shown in Table 2. Concentrated stock solutions of $\mathrm{H}_{2} \mathrm{O}_{2}$ and all antibiotics were prepared fresh daily. Cells were harvested 1 hour after the addition of antibiotics, $\mathrm{NaCl}$ and $\mathrm{H}_{2} \mathrm{O}_{2}$. Earlystationary phase cells were harvested from cultures grown to an $\mathrm{OD}_{600}$ of 3 . RNA was extracted and used to make RNA-Seq libraries $L I B>100$ and $L I B<500$. Experiments were performed in duplicates.

Pulse-expression experiments. Overnight cultures of strains $\mathrm{pBAD}$-asdna $A$ and $\mathrm{pBAD}$-asponA were diluted to a starting $\mathrm{OD}_{600}$ of 0.01 and grown to an $\mathrm{OD}_{600}$ of 0.5 , at which sRNA expression was induced with $1 \%$ L-arabinose. Cells were harvested after $30 \mathrm{~min}$ of the 
induction. RNA was extracted and used to make RNA-Seq libraries LIB $>100$, which contain the full transcriptome. Two sets of negative-control conditions were used for comparison. In one, the control strain pBAD-control was induced with arabinose; in the second, cells containing the pBADasdna $A$ and pBAD-asponA constructs were grown without arabinose induction. Experiments were performed in duplicates. The samples were analyzed by RNA-seq using a strand-specific library that contains transcripts longer than $100 \mathrm{nt}$. These libraries were prepared using the ScriptSeq v2 RNASeq Library Preparation Kit (Epicentre) following the manufacturer's instructions. Briefly, rRNA-depleted RNA was fragmented and reverse transcribed using random primers containing a 5'-tagging sequence. The 5'-tagged cDNA was then tagged at its 3' end by the terminal-tagging reaction to yield di-tagged, single-stranded cDNA. Following purification, the ditagged cDNA was amplified by PCR, which completes the addition of the Illumina adaptor sequences, amplifies the library for subsequent cluster generation and adds a barcode. The amplified RNA-seq library was purified with the Agencourt AMPure XP beads (Beckman Coulter Genomics).

\section{MIC value calculation}

MIC values of $P$. aeruginosa PAO1 were assessed using both the broth microdilution procedure and Etest strips.

Broth Microdilution. LB medium was added to all wells of a 96-well microtiter plate loaded with serially diluted antibiotics. Each well was inoculated with $P$. aeruginosa PAO1 at a final concentration of $5 \times 10^{5}$ $\mathrm{cfu} / \mathrm{ml}$. The plates were incubated for 24 hours $(250$ $\mathrm{rpm}, 37^{\circ} \mathrm{C}$ ). Following incubation, the optical density of all wells was measured and the lowest concentration showing complete inhibition of growth was recorded as the MIC for that antibiotic. The experiments were performed in triplicates. Concentrated stock solutions of all antibiotics were prepared fresh daily.

E-Test. E-test (bioMérieux AB BIODISK) strips were used according to the manufacturer's instructions. LB plates were inoculated equal amount of $P$. aeruginosa PAO1 cells. After drying, the E-test strips were placed on the top of the plates. The MIC values were read after $16 \mathrm{~h}$ of incubation at $37^{\circ} \mathrm{C}$. The experiments were performed in triplicates.

\section{RNA isolation}

Harvested cells were mixed immediately with 0.2 volumes of STOP solution ( $95 \%$ ethanol, $5 \%$ phenol) and pelleted by centrifugation. Total RNA was extracted with Trizol (Invitrogen). Removal of DNA was carried out by treatment with DNase I (Fermentas) in combination with the RNase inhibitor RiboLock (Fermentas). The integrity of total RNA and
DNA contamination were assessed with an Agilent 2100 Bioanalyzer (Agilent Technologies).

\section{Removal of 23S, $16 S$ and $5 S$ rRNAs}

The 23S, $16 \mathrm{~S}$ and $5 \mathrm{~S}$ rRNAs were removed by subtractive hybridization using the MICROBExpress kit (Ambion) with modifications as previously described (21) (22). Capture oligonucleotides complementary to the rRNAs of $P$.aeruginosa PAO1 were used (Supplementary Table S1). For preparation of library LIB $>100$ (described below), 5 $\mu \mathrm{M}$ of each capture oligonucleotide was used, for a total capture oligonucleotide concentration of $25 \mu \mathrm{M}$. Compared with the standard protocol, 25\% more capture oligonucleotides and magnetic beads were used. For preparation of libraries LIB $<500$ (described below), $5 \mu \mathrm{M}$ of the $5 \mathrm{~S}$ rRNA capture oligonucleotide and $50 \%$ less magnetic beads were used relative to the standard protocol. Removal of rRNAs was confirmed with an Agilent 2100 Bioanalyzer (Agilent Technologies).

\section{Library preparation and RNA sequencing}

Two different sequencing libraries (LIB>100 and $\mathrm{LIB}<500$ ) were constructed as previously described $(21,22)$. Each library type was prepared with RNA isolated from cells grown in duplicate for each condition studied. After each step the samples were validated using an Agilent 2100 Bioanalyzer (Agilent Technologies), and the final concentration was measured using a Qubit 2.0 Fluorometer (Invitrogen). The libraries were sequenced using the Illumina HiSeq2000 platform with a paired-end protocol and read lengths of $100 \mathrm{nt}$.

$L I B>100$ library. This type of library contains transcripts longer than $100 \mathrm{nt}$ and was prepared using the TruSeq RNA Sample Preparation kit (Illumina) as previously described $(21,22)$. Briefly, the rRNA-depleted RNA is fragmented using divalent cations under elevated temperature. The cleaved RNA fragments are copied into cDNA using reverse transcriptase and random primers, followed by second-strand cDNA synthesis using DNA polymerase I and RNase $\mathrm{H}$. After this step, transcripts shorter than $100 \mathrm{nt}$ are not retained due to the purification performed with the Agencourt AMPure XP beads (Beckman Coulter Genomics). The cDNA fragments then go through an end repair process, 3'addition of single ' $A$ ' bases and adapter ligation. This is followed by product purification and PCR amplification to generate the final cDNA library.

$L I B<500$ library. This type of library is strand-specific and contains transcripts shorter than $500 \mathrm{nt}$. RNA size selection was performed by running total RNA on $10 \%$ polyacrylamide gels containing $10 \mathrm{M}$ urea. Gel slices corresponding to RNAs up to $500 \mathrm{nt}$ were excised, followed by elution of RNA in $0.4 \mathrm{M} \mathrm{NaCl}$ and precipitation with ethanol. The $5 \mathrm{~S}$ rRNA was 
depleted as previously described, followed by treatment with Tobacco Acid Pyrophosphatase (Epicentre Technologies) at $37^{\circ} \mathrm{C}$ for $90 \mathrm{~min}$. Tobacco Acid Pyrophosphatase (TAP) is used to convert $5^{\prime}$ triphosphate RNA into 5'-monophosphate RNA, which is important for correct adapter ligation. This was followed by treatment with RNase III (Ambion) for 10 $\min$ at $37^{\circ} \mathrm{C}$ to fragment the RNA. RNase III fragments RNA into smaller pieces containing a $5^{\prime}$ phosphoryl group and a 3'-hydroxyl group, which is important for specific adapter ligation in the next step. Sequential ligation of RNA $3^{\prime}$ and $5^{\prime}$ adapters was performed using the adapters and enzymes from the TruSeq Small RNA Sample Preparation kit (Illumina). Next, reverse transcription followed by PCR amplification was performed to form cDNA constructs based on the RNA fragments ligated with 3 ' and 5'adapters, selectively enriching fragments with adapter molecules on both ends. The reverse transcription and subsequent PCR amplification were performed using the enzymes and reagents from the TruSeq Small RNA Sample Preparation kit (Illumina). Agencourt AMPure XP beads (Beckman Coulter Genomics) were used for the post-PCR clean-up. In this type of library the fragments corresponding to transcripts shorter than $100 \mathrm{nt}$ are retained due to ligated RNA adapters that increase the length of the fragments by $125 \mathrm{nt}$.

\section{Data analysis}

Our analysis pipeline is described in detail in GómezLozano et al (2013) (22). Briefly, reads were mapped onto the $P$. aeruginosa PAO1 genome using the Bowtie 2 short read aligner (26). Read alignments from Bowtie 2 were handled using SAMtools (27). In order to obtain normalized expression intensities of the read coverage depth at each position in the genome, the number of reads in each replicate was normalized according to the total number of reads in the library, and expression intensities from replicate samples were averaged. A custom-made script was designed to detect novel transcripts antisense to annotated genes. Only transcripts of at least $70 \mathrm{nt}$ were considered further. The resulting transcripts from automatic classification were re-evaluated by visual inspection. The asRNAs were categorized depending on their position with respect to the opposite gene as "start-span" (the asRNA spans over the start of the antisense gene), "internal" (the asRNA start and end within the antisense gene), or "endspan" (the asRNA spans over the end of the gene). A two-sample Student's $t$-test was performed on the average expression of the transcripts to determine those with differential expression between the conditions tested ( $P$-value $<0.05$ and fold change $>2$ ).

\section{Rapid Amplification of cDNA Ends (RACE)}

Schematic representations of the $5^{\prime}$ and $3^{\prime}$ RACE protocols can be seen in Supplementary Figures 1 and 2. Supplementary Table 1 lists primers and adapters used.

5' RACE. $2 \mu \mathrm{g}$ rRNA-depleted RNA was incubated with $10 \mathrm{U}$ of Tobacco Acid Pyrophosphatase (Epicentre Technologies) at $37^{\circ} \mathrm{C}$ for $1 \mathrm{~h}$ to convert RNA 5' triphosphates in 5' monophosphates. The same amount of control RNA was incubated under the same conditions in the absence of the enzyme. Reactions were stopped by phenol-chloroform extraction, followed by etanol-sodium acetate precipitation. Precipitated RNAs were redissolved in water, mixed with 500 pmol of $5^{\prime}$ RNA adapter, heatdenatured at $95^{\circ} \mathrm{C}$ for $5 \mathrm{~min}$, then quick-chilled on ice. A short RNA adapter was ligated was ligated with 50 $\mathrm{U}$ of T4 RNA ligase (Thermo Scientific) at $37^{\circ} \mathrm{C}$ for 1 h. Reactions were stopped by phenol-chloroform extraction, followed by ethanol-sodium acetate precipitation. Precipitated RNAs were re-dissolved in $20 \mu \mathrm{l}$ water. Then $10 \mu \mathrm{l}$ of $5^{\prime}$ adapter-ligated RNA was reverse-transcribed using 2 pmol of primer complementary to the SRNA (5'-GSP1) and the Thermoscript RT-PCR system (Invitrogen) according to the manufacturer's instructions. Reverse transcription (RT) was performed in three subsequent 20 min steps at $55^{\circ} \mathrm{C}, 60^{\circ} \mathrm{C}$, and $65^{\circ} \mathrm{C}$, followed by treatment with RNase $\mathrm{H}$. Primers were removed using the NucleoSpin Gel and PCR Clean-up kit (Macherey-Nagel). The products of RT were amplified using $10 \mathrm{pmol}$ of another primer complementary to the sRNA (5'-GSP2) and 10 pmol the 5' adapterspecific primer, together with the Maxima Hot Start PCR Master Mix (Thermo Scientific) according to the manufacturer's instructions. Negative controls were performed using the $5^{\prime}$ adapter-ligated RNA as template. The PCR products were resolved and purified using E-Gel SizeSelect 2\% Agarose gels (Invitrogen). Products were sequenced with 5'-GSP2 and $5^{\prime}$ adapter-specific primers by LGC Genomics $\mathrm{GmbH}$ (Germany).

3' RACE. $2 \mu \mathrm{g}$ rRNA-depleted RNA was dephosphorylated with calf intestinal alkaline phosphatase (New England Biolabs) at $37^{\circ} \mathrm{C}$ for $1 \mathrm{~h}$. Reactions were stopped by phenol-chloroform extraction, followed by etanol-sodium acetate precipitation. Ligation was done as above with a $3^{\prime}$ RNA adapter with a 3'-inverted deoxythymidine (3'idT). RT was carried out as described, but with 10 pmol of a single primer complementary to the 3' RNA adapter. PCR amplification, band purification and sequence analysis was done as described above. All enzymatic treatments of RNA were performed in the presence of 20 units of RiboLock RNase Inhibitor (Thermo Scientific). 


\section{RESULTS AND DISCUSSION}

\section{Identification of antisense sRNAs.}

Recently, we identified over 500 novel intergenic sRNAs (21) using three different RNA-Seq library preparations (22). Although the use of three different libraries increased the number of novel transcripts identified, there were significant differences in the subset of transcripts detected in each library, underscoring the importance of library preparation strategy and relative sRNA abundance for successful sRNA detection (21). In this study we identified 249 asRNAs using the library type LIB $<500$ under different stress conditions, including stationary phase, osmotic, oxidative and antibiotic stress. Libraries prepared using the LIB $<500$ protocol are strandspecific and contain transcripts shorter than 500 nt $(21,22)$. Exponentially growing cultures of $P$. aeruginosa PAO1 were exposed to sodium chloride $(\mathrm{NaCl})$ and hydrogen peroxide $\left(\mathrm{H}_{2} \mathrm{O}_{2}\right)$ during osmotic and oxidative stress conditions, respectively. The antibiotics used were four different ß-lactams (piperacillin, ceftazidime, aztreonam, meropenem), the aminoglycoside tobramycin, the macrolide azithromycin, the fluoroquinolone ciprofloxacin, the polymyxin antibiotic colistin, and the polyketide tetracycline. All antibiotics used in this study, with the exception of tetracycline, are routinely used against $P$. aeruginosa infections (28-32). The concentrations of antibiotics, $\mathrm{NaCl}$ and $\mathrm{H}_{2} \mathrm{O}_{2}$ used in this study are shown in Table 2. The conditions were chosen due to their clinical relevance during $P$. aeruginosa infection in CF patients, in which the bacteria are exposed to high salt concentrations, reactive oxygen species (ROS) secreted by the host immune response, and aggressive antibiotic treatments. The CF lung is an osmotically stressful environment, due to the viscous, dehydrated mucus, cellular debris and electrolytes competing for a limited supply of water $(33,34)$. A variety of studies have shown that $P$. aeruginosa encounters ROS in the lungs of CF patients due to the exaggerated, sustained and extended inflammatory response, characterized by influx of neutrophils and high concentrations of interleukin-8 (35-37). In addition, $P$. aeruginosa-infected CF patients are routinely treated with several types of antibiotics, because early and aggressive antipseudomonal treatment regimens are correlated with improved lung function and survival of CF patients (38). 
Table 2. Concentration of antibiotics, $\mathrm{NaCl}$ and $\mathrm{H}_{2} \mathrm{O}_{2}$ used in the stress exposure experiments.

\begin{tabular}{lccc} 
Condition & Abbreviation & $\begin{array}{c}\mathbf{M I C} \text { value } \\
(\boldsymbol{\mu g} / \mathbf{m l})\end{array}$ & $\begin{array}{c}\text { Concentration } \\
\text { added at } \mathbf{O D}=\mathbf{0 . 5}\end{array}$ \\
\hline Control & - & - & - \\
Aztreonam & $\mathrm{AZT}$ & 4 & $3 \times \mathrm{MIC}$ \\
Ceftazidime & $\mathrm{CEF}$ & 2 & $3 \times \mathrm{MIC}$ \\
Ciprofloxacin & $\mathrm{CIP}$ & 0.125 & $3 \times \mathrm{MIC}$ \\
Meropenem & $\mathrm{MER}$ & 1 & $3 \times \mathrm{MIC}$ \\
Tetracyclin & $\mathrm{TET}$ & 8 & $3 \times \mathrm{MIC}$ \\
Tobramycin & $\mathrm{TOB}$ & 1 & $3 \times \mathrm{MIC}$ \\
Azithromycin & $\mathrm{AZI}$ & 1.5 & $10 \times \mathrm{MIC}$ \\
Colistin & $\mathrm{CO}$ & 4 & $3 \times \mathrm{MIC}$ \\
Piperacillin & $\mathrm{PP}$ & 4 & $3 \times \mathrm{MIC}$ \\
Hydrogen peroxyde & $\mathrm{H}_{2} \mathrm{O}_{2}$ & - & $1 \mathrm{mM}$ \\
Sodium chloride & $\mathrm{NaCl}$ & - & $0.5 \mathrm{M}$
\end{tabular}

The analysis of the data generated revealed the existence of 249 novel asRNAs. Supplementary Table 2 lists the coordinates of the asRNAs identified in this study, as well as the annotation of the opposite genes. Antisense transcripts can overlap with the 5' end, the 3' end, an internal part of the opposite gene, the whole gene, or even various contiguous genes that have the same direction. The asRNAs were categorized depending on their position with respect to the opposite gene as "start-span" (the asRNA spans over the start of the antisense gene), "internal" (the asRNA start and end within the antisense gene), or "end-span" (the asRNA spans over the end of the gene). Only asRNAs longer than $50 \mathrm{nt}$ were taken into consideration. The longest detected asRNA is 581-nt long. Eighteen asRNAs overlapped with two contiguous genes transcribed from the opposite strand. Alternatively, antisense transcription can also be due to the overlap between $5^{\prime}$ and $3^{\prime}$ untranslated regions of genes encoded in the opposite direction. UTRs can contain regulatory elements for controlling gene expression and extend into the neighboring genes. Some
asRNAs detected in RNA-Seq libraries might actually be UTRs from neighboring genes. To prevent the mis-annotation of UTRs as asRNAs, in this study we have not considered as asRNAs antisense transcription that finished close (less than $100 \mathrm{bp}$ ) to the start of a flanking gene having the same direction as the asRNA. We cannot rule out though that some of the novel asRNAs identified in this study might be novel coding genes encoded opposite to alreadyannotated coding regions. It is also possible that some of the asRNAs identified are the result of non-specific transcription and thus do not have physiological functions.

We next examined the distribution of antisense sRNAs and found that they appear to be homogenously distributed in the genome of $P$. aeruginosa PAO1 (Figure 1A). A recent study made by Wurtzel et al (2012) found that antisense sRNAs are more often found in some parts of the accessory genome of $P$. aeruginosa PA14 (20). Specifically, the authors identified 384 sites with overlapping transcription on the reverse strand, and found that the pathogenicity 
island PAPI-1 is enriched in these kind of sites by 5 -fold compared to the core genome (20). In this study we do not observe more concentration of antisense transcripts in the accessory than in the core genome. There are three reasons that might explain these differences between this study and the one from Wurtzel et al (2012). (i) The strain used in this study is $P$. aeruginosa PAO1, while Wurtzel et al (2012) used strain PA14 (20). Another study investigated the expression of sRNAs of strains PAO1 and PA14 at early stationary phase, and found 60 asRNAs (19). Interestingly, a number of these asRNAs were strain-specific or showed strain-specific expression (19). This also seems to be the case for intergenic sRNAs, whose sequences are sometimes not conserved between different $P$. aeruginosa strains (21). In addition, the PAPI-1 island is found in strain PA14 but not in PAO1, though it can be transferred by a type IV pilus (39). (ii) Wurtzel et al (2012) studied two conditions, growth at $28^{\circ} \mathrm{C}$ and at $37^{\circ} \mathrm{C}(20)$. In this study we sequenced samples from $P$. aeruginosa in 12 different conditions. Studying more conditions might lead to finding antisense transcription sites in more genomic locations. (iii) Due to their library preparation protocol, Wurtzel et al (2012) identified antisense transcription start sites, but the authors could not determined the length of the asRNAs (20). In this study, we identified 249 asRNAs with lengths ranging from 50 to 581 nt in length. We did not take into consideration neither asRNAs shorter than $50 \mathrm{nt}$, nor asRNAs that might be suspected to be UTRs from flanking genes. This might explain why in this study we identify considerably less asRNAs than in Wurtzel et al (2012).
A

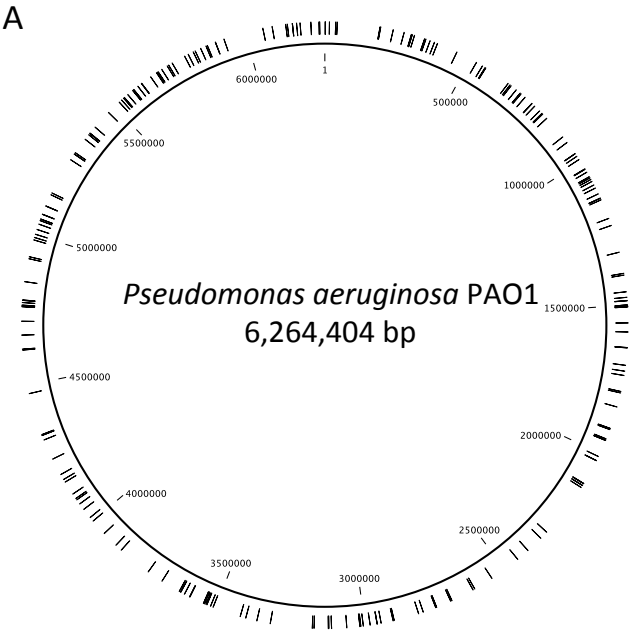

B

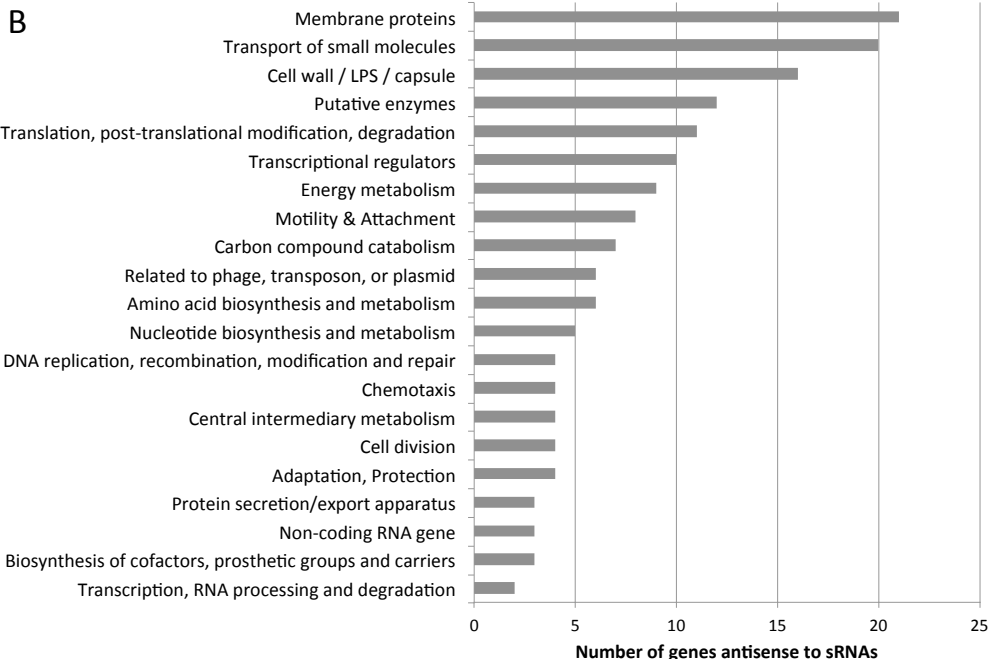

Figure 1. Distribution and targets of asRNAs. A. Distribution of asRNAs in the genome of $P$. aeruginosa PAO1. Each asRNA is marked by a black line. B. Categories of genes with asRNAs transcribed from the reverse strand. 
Intergenic and antisense sRNAs respond to stress.

Figure 1B shows the classification of genes with asRNAs transcribed from the reverse strand in our experiments. A considerable number of asRNAs are transcribed opposite to genes encoding membrane proteins, genes involved in the transport of small molecules, cell wall, lipopolysaccharide (LPS), and capsule biosynthesis. This most likely reflects the conditions used in this study: stationary phase, oxidative, osmotic and antibiotic stress. In these conditions, fast and fine-tuned regulation of the membrane proteins and transport is essential. We hypothesize that the regulatory effects of asRNAs are important in probably all cellular processes, and that the categories of genes with antisense transcription regulation mainly depend on the conditions studied.

In addition to the 249 asRNAs identified, we recently identified over 500 intergenic sRNAs in $P$. aeruginosa PAO1 (21). Figure 2 represents the number of intergenic (left) and asRNAs (right) whose expression is significantly changed during the conditions tested. A substantial number of both intergenic and asRNAs significantly change their expression, suggesting that their regulatory effects are important during antibiotic, $\mathrm{H}_{2} \mathrm{O}_{2}, \mathrm{NaCl}$ treatment, and stationary phase. About half of the asRNAs detected in this study were differentially expressed during stationary phase. Supplementary Table 3 lists the asRNAs differentially transcribed in our conditions, as well as their fold-change in expression. We anticipate that these data will be important to understand the regulation of genes that show antisense transcription on the reverse strand. However, the level of transcription alone cannot explain the mechanism of action of asRNAs, and more experiments will be needed in order to determine how asRNAs regulate the opposite genes.
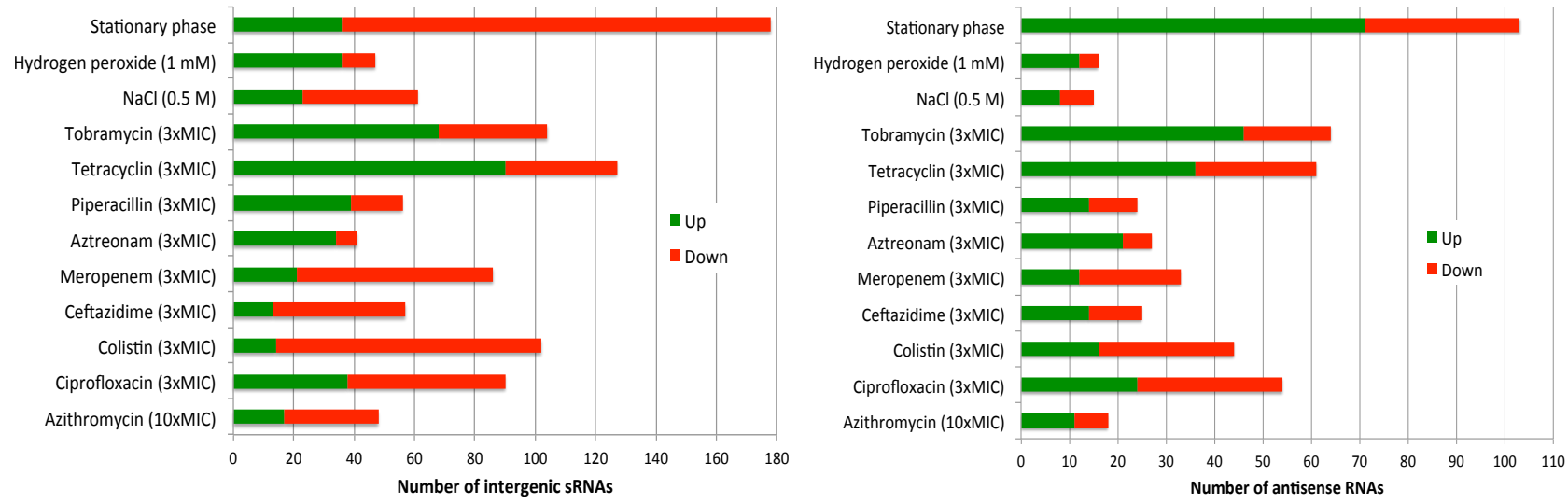

Figure 2. Differential expression of sRNAs. Number of intergenic (left) and asRNAs (right) whose expression is significantly changed during antibiotic, $\mathrm{H}_{2} \mathrm{O}_{2}$ or $\mathrm{NaCl}$ treatment. 


\section{Antisense sRNAs targeting $d n a A$ and ponA}

Two novel asRNAs were validated using 5 'and 3'-RACE. The coordinates of both asRNAs were very similar between the RNA-Seq data and the RACE experiments, with differences of up to 19 nt between the two techniques. One asRNA, called from now on AsdnaA, is transcribed from the reverse strand of the $d n a A$ gene, which encodes the chromosomal replication initiator protein DnaA (Figure 3). AsdnaA is highly expressed during stationary phase (8.7-fold) and upon ciprofloxacin (4.6-fold), aztreonam (2.9fold) and $\mathrm{H}_{2} \mathrm{O}_{2}$ (2.1-fold) exposure. The other asRNA is called AsponA and its transcription is antisense to the ponA gene, encoding the penicillin-binding protein $1 \mathrm{~A}$ (Figure 3). AsponA is upregulated upon aztreonam (2.9-fold), piperacillin (2.8-fold), and ciprofloxacin (2-fold) exposure, and downregulated during meropenem (2-fold), colistin (3-fold), tobramycin (5.4-fold), and tetracycline (5.6-fold) exposure.

To determine the effect of these two asRNAs on their opposite genes, pulse-expression experiments were carried out, in which the asRNAs are pulse-expressed with an inducible promoter and its immediate effects studied by RNA-Seq. Cells carrying the pBAD-asdnaA or the pBAD-asponA construct were grown to midlog phase in LB and treated with $1 \%$ arabinose for $30 \mathrm{~min}$. Two sets of negative-control conditions were used for comparison. In one, the control construct, pBAD-control was induced with arabinose; in the second, cells containing either the pBAD-asdnaA or pBAD-asponA construct were grown without arabinose induction. Total RNA was extracted from all cultures and processed for RNA-Seq analysis (see Materials and Methods). The gene expression profiles were compared in two ways: (i) induced pBAD-asdnaA or pBAD-asponAcontaining cells were compared to induced pBAD-control-containing cells, and (ii) uninduced pBAD-asdnaA or pBAD-asponA-containing cells were compared to induced pBAD-asdnaA or pBAD-asponA-containing cells. The results for the two types of comparisons showed consistent results, with the exception of the expected differences for arabinose-inducible genes. It is worth mentioning that while pulse-expression experiments of asRNAs can provide important insights about their role, they can also cause artifactual effects that are not observed during endogenous expression of asRNAs.

AsdnaA base is encoded opposite to the second half of gene $d n a A$ (Figure 3 ). Due to its location, we initially hypothesize that AsdnaA might (i) attenuate the transcription of $d n a A$, by prematurely terminating the transcription on the opposite strand, (ii) impact the stability of $d n a A$ by either promoting or blocking cleavage by ribonucleases, or (iii) indirectly impact (either positively or negatively) ribosome binding by affecting the target mRNA structure. When pulse-expressing AsdnaA, the transcription of AsdnaA was increased by 130 -fold after 30 min of induction. However the levels of the opposite gene dnaA were barely affected (1.4-fold more when pulse-expressing AsdnaA). This suggest that, if any, the physiological role of AsdnaA probably is to affect the level of translation of $d n a A$, but further investigations are needed to 
prove it.

AsponA spans into the intergenic region overlapping with the predicted -10 and $-35 \sigma-70$ promoter elements (Figure 3). Due to the location of AsponA, we hypothesized that it probably belongs to the class of asRNAs that prevent the transcription or translation of the opposite gene, either by transcription interference or by directly blocking ribosome binding. Wurtzel et al (2012) reported the start of antisense transcription at the same coordinates of the ponA gene (20). The conservation across strains together with the condition-dependent expression of the AsponA gives weight to the conclusion that this asRNA has a physiological role. Unfortunately, we did not observe any increase in the levels of asRNA AsponA after arabinose induction, suggesting that in the conditions tested AsponA is not stable. There are several possible reasons for this. (i) We are not over-expressing the primary transcript of AsponA, as we could not determine it by $5^{\prime}-$ RACE. In pulse-expression analysis, the first nucleotide of the transcribed product should be the +1 of the primary transcript to be pulseexpressed. This is an important consideration when cloning sRNAs under the control of heterologous promoters, since altering the natural RNA start site may have unintended consequences for its function. We were able to identify the primary transcript of AsdnaA by $5^{\prime}$ RACE. However we did not detect the primary transcript of AsponA, and this might also explain why we did not obtain stable AsponA transcription in the pulse-expression experiment. (ii) AsponA might only be stable in conditions in which is needed, such as aztreonam, piperacillin, ciprofloxacin and $\mathrm{H}_{2} \mathrm{O}_{2}$ exposure. In conditions where the expression of AsponA is deleterious it might rapidly get degraded. (iii) Some asRNAs interfere with the transcription of opposite gene. In this mechanism transcription from the antisense promoter blocks transcription from the gene promoter by preventing RNA polymerase from either binding or extending the mRNA encoded on the opposite strand. Transcription interference does not require base pairing between the asRNA and the mRNA, and it does not occur when the asRNA is provided in trans. If this is the case of AsponA, then ectopic expression of the asRNA in trans will not affect the expression of the opposite gene and it might also promote the rapid degradation of the asRNA. In conclusion, more experiments are required to conclude whether AsponA plays a physiological role in $P$. aeruginosa. 


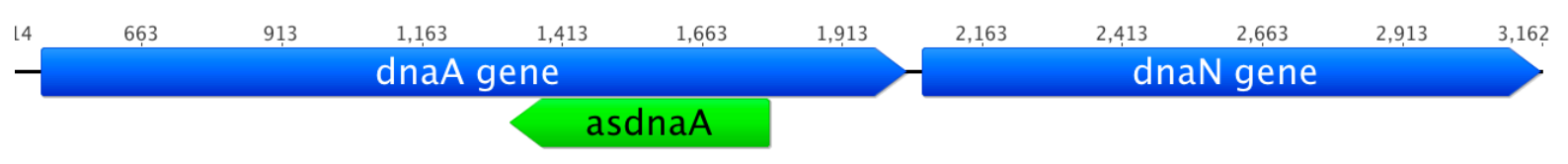

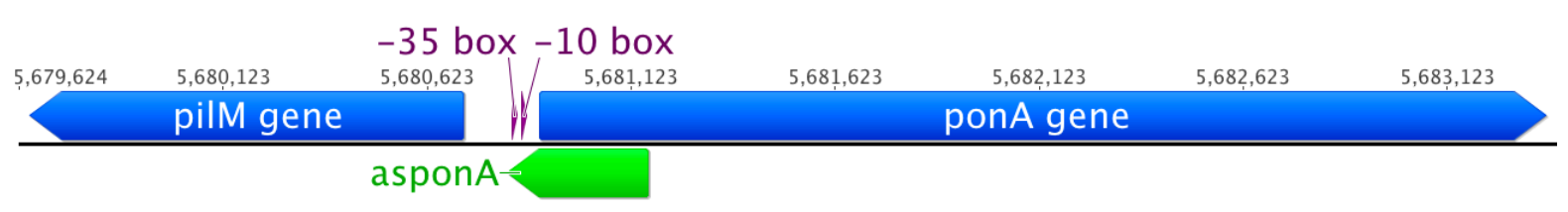

Figure 3. Antisense sRNAs AsdnaA and AsponaA. Antisense RNA AsdnaA (above) is encoded opposite of gene $d n a A$, which encodes the chromosomal replication initiator protein DnaA. Antisense RNA AsponA (below) is encoded opposite the beginning of gene ponA, encoding the penicillin-binding protein $1 \mathrm{~A}$, and spans into the intergenic region overlapping with the predicted -10 and $-35 \sigma-70$ promoter elements.

\section{CONCLUDING REMARKS}

In this work RNA-Seq was used to identify 249 asRNAs in the opportunistic pathogen $P$. aeruginosa under up to a total of 13 different conditions, including stationary phase, osmotic, oxidative and antibiotic stress. We provide the fold-change in expression of the asRNAs differentially transcribed in our conditions. A considerable number of asRNAs were transcribed opposite to genes encoding membrane proteins and genes involved in the transport of small molecules, cell wall, LPS, and capsule biosynthesis. A substantial number of asRNAs significantly changed their expression under the conditions tested, suggesting that asRNAs play a regulatory role during these conditions. Due to our library preparation protocol, only asRNAs ranging approximately from 50 to $500 \mathrm{nt}$ were detected. Thus the number of asRNAs provided in this study is most likely an underestimate. Selected asRNAs could potentially be exploited as novel drug targets, and we anticipate that the data presented here will be important to understand the regulation of genes that show antisense transcription on the reverse strand. Riboswitches have already begun to be validated as anti-bacterial drug targets. For instance, a pyrimidine compound acting as a guanine riboswitch antagonist was shown to reduce $S$. aureus infection rates in mice (40). It might be possible to exploit similar strategies to target individual sRNAs by small compounds, or target mRNAs with synthetic antisense sRNAs, in order to combat bacterial infections in a species-specific manner.

Two asRNAs have been independently validated in this study, and their roles investigated by pulse-expression experiments. High expression levels of the asRNA asdnaA, which overlaps the $d n a A$ gene, had no effect on the dnaA mRNA, and we hypothesize that either this asRNA has no physiological function or it affects the translation of the DnaA protein, by indirectly impacting (either positively or negatively) ribosome binding by affecting the target mRNA structure. The levels of the other asRNA, which 
overlaps the ponA gene, were not increased after pulse-expression. We could not detect the primary transcript of AsponA, and this might be the reason for the failure of the pulseexpression. Alternatively this asRNA might not be stable under the conditions tested, or the transcription needs to be in cis to have an effect on the ponA mRNA. In conclusion, more experiments are required to rule out whether these two asRNAs play a physiological role in $P$. aeruginosa.

There are many questions that remain to be answered regarding the physiological roles of bacterial asRNAs. With the recent advances in transcriptomics, the hundreds of asRNAs now being reported in all bacteria studied need to be further validated and functionally characterized. We anticipate that understanding the molecular mechanisms of action of individual novel RNAs will be one of the biggest challenges of current RNA research.

\section{ACKNOWLEDGEMENTS}

This work was supported by the Novo Nordisk Foundation and the Danish National Research Agency.

\section{REFERENCES}

1. Sharma CM, Hoffmann $S$, Darfeuille $F$, Reignier J, Findeiss S, Sittka A, et al. The primary transcriptome of the major human pathogen Helicobacter pylori. Nature. 2010 Mar 11;464(7286):250-5.

2. Toledo-Arana A, Dussurget $O$, Nikitas G, Sesto $N$, Guet-Revillet $H$, Balestrino $D$, et al. The Listeria transcriptional landscape from saprophytism to virulence. Nature.
2009;459(7249):950-6.

3. Filiatrault MJ, Stodghill PV, Bronstein PA, Moll $S$, Lindeberg M, Grills G, et al. Transcriptome Analysis of Pseudomonas syringae Identifies New Genes, Noncoding RNAs, and Antisense Activity. Journal of Bacteriology. 2010 May 1;192(9):2359-72.

4. Guell M, Van Noort V, Yus E, Chen W-H, Leigh-Bell J, Michalodimitrakis $\mathrm{K}$, et al. Transcriptome Complexity in a GenomeReduced Bacterium. Science. 2009 Nov 27;326(5957):1268-71.

5. Dornenburg JE, DeVita AM, Palumbo MJ, Wade JT. Widespread antisense transcription in Escherichia coli. mBio. 2010 Apr;1(1).

6. Albrecht M, Sharma CM, Reinhardt R, Vogel J, Rudel T. Deep sequencing-based discovery of the Chlamydia trachomatis transcriptome. Nucleic Acids Research. 2010 Jan;38(3):86877.

7. Lasa I, Toledo-Arana A, Dobin A, Villanueva M, de los Mozos IR, Vergara-Irigaray $M$, et al. Genome-wide antisense transcription drives mRNA processing in bacteria. Proc Natl Acad Sci USA. 2011 Dec 13;108(50):20172-7.

8. Rasmussen $S$, Nielsen HB, Jarmer $H$. The transcriptionally active regions in the genome of Bacillus subtilis. Molecular Microbiology. Wiley Online Library; 2009;73(6):1043-57.

9. Stougaard P, Molin S, Nordström K. RNAs involved in copy-number control and incompatibility of plasmid R1. Proceedings of the National Academy of Sciences. 1981 Oct;78(10):6008-12.

10. Tomizawa J, Itoh T, Selzer G, Som T. Inhibition of ColE1 RNA primer formation by a plasmidspecified small RNA. Proceedings of the National Academy of Sciences. 1981 Mar;78(3):1421-5.

11. Brantl S. Regulatory mechanisms employed by cis-encoded antisense RNAs. Current Opinion in Microbiology. 2007 Apr;10(2):102-9.

12. Thomason MK, Storz G. Bacterial Antisense RNAs: How Many Are There, and What Are They Doing? *. Annu. Rev. Genet. 2010 Dec;44(1):167-88.

13. Silby MW, Levy SB. Overlapping proteinencoding genes in Pseudomonas fluorescens Pf0-1. PLoS Genet. 2008 Jun;4(6):e1000094. 
14. Sayed N, Jousselin A, Felden B. A cisantisense RNA acts in trans in Staphylococcus aureus to control translation of a human cytolytic peptide. Nat. Struct. Mol. Biol. 2012 Jan;19(1):105-12.

15. Arnvig KB, Young DB. Identification of small RNAs in Mycobacterium tuberculosis. Molecular Microbiology. 2009 Aug;73(3):397408.

16. Mandin P, Gottesman S. Integrating anaerobic/aerobic sensing and the general stress response through the ArcZ small RNA. EMBO J. 2010 Sep 15;29(18):3094-107.

17. Papenfort K, Said N, Welsink T, Lucchini S, Hinton JCD, Vogel J. Specific and pleiotropic patterns of mRNA regulation by ArcZ, a conserved, Hfq-dependent small RNA. Molecular Microbiology. 2009 Oct;74(1):13958.

18. Mandin $\mathrm{P}$, Repoila $\mathrm{F}$, Vergassola $\mathrm{M}$, Geissmann T, Cossart P. Identification of new noncoding RNAs in Listeria monocytogenes and prediction of mRNA targets. Nucleic Acids Research. 2007;35(3):962-74.

19. Ferrara S, Brugnoli M, De Bonis A, Righetti F, Delvillani F, Dehò $G$, et al. Comparative Profiling of Pseudomonas aeruginosa Strains Reveals Differential Expression of Novel Unique and Conserved Small RNAs. PLoS ONE. 2012;7(5):e36553.

20. Wurtzel O, Yoder-Himes DR, Han K, Dandekar AA, Edelheit S, Greenberg EP, et al. The single-nucleotide resolution transcriptome of Pseudomonas aeruginosa grown in body temperature. PLoS Pathog. 2012 Sep;8(9):e1002945.

21. Gómez-Lozano M, Marvig RL, Molin S, Long KS. Genome-wide identification of novel small RNAs in Pseudomonas aeruginosa. Environmental Microbiology. 2012 Aug;14(8):2006-16.

22. Gómez-Lozano M, Marvig RL, Molin S, Long KS. Identification of bacterial small RNAs by RNA sequencing. Methods in Pseudomonas aeruginosa. In press; 2013.

23. Guzman LM, Belin D, Carson MJ, Beckwith J. Tight regulation, modulation, and high-level expression by vectors containing the arabinose PBAD promoter. Journal of Bacteriology. 1995 Jul;177(14):4121-30.
24. Hoang TT, Kutchma AJ, Becher A, Schweizer HP. Integration-Proficient Plasmids for Pseudomonas aeruginosa: Site-Specific Integration and Use for Engineering of Reporter and Expression Strains. Plasmid. 2000 Jan;43(1):59-72.

25. Herrero $M$, de Lorenzo $V$, Timmis $\mathrm{KN}$. Transposon vectors containing non-antibiotic resistance selection markers for cloning and stable chromosomal insertion of foreign genes in gram-negative bacteria. Journal of Bacteriology. Am Soc Microbiol; 1990;172(11):6557-67.

26. Langmead B, Salzberg SL. Fast gapped-read alignment with Bowtie 2. Nat Meth. 2012 Apr;9(4):357-9.

27. Li H, Handsaker B, Wysoker A, Fennell T, Ruan J, Homer N, et al. The Sequence Alignment/Map format and SAMtools. Bioinformatics. 2009 Aug 15;25(16):2078-9.

28. Saiman L, Marshall BC, Mayer-Hamblett N, Burns JL, Quittner AL, Cibene DA, et al. Azithromycin in patients with cystic fibrosis chronically infected with Pseudomonas aeruginosa: a randomized controlled trial. JAMA. 2003 Oct 1;290(13):1749-56.

29. Doring G, Conway SP, Heijerman HG, Hodson ME, Hoiby N, Smyth A, et al. Antibiotic therapy against Pseudomonas aeruginosa in cystic fibrosis: a European consensus. Eur. Respir. J. 2000. pp. 749-67.

30. Aronoff SC, Klinger JD. In vitro activities of aztreonam, piperacillin, and ticarcillin combined with amikacin against amikacin-resistant Pseudomonas aeruginosa and $P$. cepacia isolates from children with cystic fibrosis. Antimicrobial agents and chemotherapy. Am Soc Microbiol; 1984;25(2):279-80.

31. Szaff M, Hoiby N, Flensborg EW. Frequent antibiotic therapy improves survival of cystic fibrosis patients with chronic Pseudomonas aeruginosa infection. Acta Paediatr Scand. 1983 Sep;72(5):651-7.

32. Høiby N. Recent advances in the treatment of Pseudomonas aeruginosa infections in cystic fibrosis. BMC Medicine. BioMed Central Ltd; 2011 Apr 4;9(1):32.

33. Chernick WS, Barbero GJ. Composition of tracheobronchial secretions in cystic fibrosis of the pancreas and bronchiectasis. Pediatrics. 1959 Nov;24:739-45. 
34. Matthews LW, Spector S, Lemm J. Studies on pulmonary secretions. The over-all chemical composition of pulmonary secretions from patients with cystic fibrosis, bronchiectasis, and laryngectomy. The American review of Respiratory disease. 1963 Aug;88:199-204.

35. Hull J, Vervaart $P$, Grimwood K, Phelan P. Pulmonary oxidative stress response in young children with cystic fibrosis. Thorax. 1997 Jun;52(6):557-60.

36. Brown RK, Kelly FJ. Evidence for increased oxidative damage in patients with cystic fibrosis. Pediatr. Res. 1994 Oct;36(4):487-93.

37. Cantin A. Cystic fibrosis lung inflammation: early, sustained, and severe. American Journal of Respiratory and Critical Care Medicine. 1995
Apr;151(4):939-41.

38. Frederiksen B, Lanng S, Koch C, Hoiby N. Improved survival in the Danish center-treated cystic fibrosis patients: results of aggressive treatment. Pediatr. Pulmonol. 1996 Mar;21(3):153-8.

39. Carter MQ, Chen J, Lory S. The Pseudomonas aeruginosa pathogenicity island PAPI-1 is transferred via a novel type IV pilus. Journal of Bacteriology. 2010 Jul;192(13):3249-58.

40. Mulhbacher J, Brouillette E, Allard M, Fortier LC, Malouin F, Lafontaine DA. Novel riboswitch ligand analogs as selective inhibitors of Guanine-related metabolic pathways. PLoS Pathog. 2009 Dec 31;6(4):e1000865-5. 


\title{
Antisense small RNAs respond to osmotic, oxidative and antibiotic stress in Pseudomonas aeruginosa
}

\author{
María Gómez-Lozano, ${ }^{1,2}$, Rasmus L. Marvig ${ }^{1}$, Monica V. L. \\ Tulstrup $^{2}$, Paula Tribelli ${ }^{3}$, and Søren Molin ${ }^{* 1,2}$
}

\footnotetext{
${ }_{2}^{1}$ Department of Systems Biology, Technical University of Denmark, Lyngby, Denmark.

${ }^{2}$ Novo Nordisk Foundation Center for Biosustainability, Technical University of Denmark, Hørsholm, Denmark.

Dpto. de Química Biológica, Facultad de Ciencias Exactas y Naturales, Universidad de Buenos Aires. IQUIBICEN-CONICET, Buenos Aires, Argentina.
}

Supplementary material 


\section{Supplementary Table 1. Primers and adapters used in the study.}

\begin{tabular}{|c|c|c|}
\hline Primer & Sequence $\left(5^{\prime}->3^{\prime}\right)$ & Use \\
\hline 23S-1954 & AAAAAAAAAAAAAAAAAAACTTACCCGACAAGGAATTTCGC & Removal of $23 \mathrm{~S}$ rRNA (provided in the MICROBExpress kit, Ambion) \\
\hline $235-2511$ & AAAAAAAAAAAAAAAAAAGAGCCGACATCGAGGTGCCAAAC & Removal of $23 \mathrm{~S}$ rRNA (provided in the MICROBExpress kit, Ambion) \\
\hline $16 \mathrm{~S}-807$ & AAAAAAAAAAAAAAAAAATGGACTACCAGGGTATCTAATCC & Removal of 16 S rRNA (provided in the MICROBExpress kit, Ambion) \\
\hline 16S-1114 & AAAAAAAAAAAAAAAAAAGGGTTGCGCTCGTTACGGGACTT & Removal of $16 \mathrm{~S}$ rRNA (provided in the MICROBExpress kit, Ambion) \\
\hline $5 S$ & AAAAAAAAAAAAAAAAAAGCGTTTCACTTCTGAGTTCGGCA & Removal of 5 S rRNA \\
\hline F1-Sacl & GAGAGAGCTCGGCCGCTTCTAGAGTTATGA & Plasmids pBAD-asdnaA, pBAD-asponA and pBAD-control construction \\
\hline R1_asdnaA & GCACCGTCGCCGAGTACTACATGGAGAAACAGTAGAGAGT & Plasmid pBAD-asdnaA construction \\
\hline F2_asdnaA & GTAGTACTCGGCGACGGTGCGCTGGATGTTGTCGATGCTG & Plasmid pBAD-asdnaA construction \\
\hline R2-Xhol_asdnaA & ACATCTCGAGGAAGCACACCAGCTATCTCA & Plasmid pBAD-asdnaA construction \\
\hline R1_asponA & CCGCCGAGGACGACAATTTCATGGAGAAACAGTAGAGAGT & Plasmid pBAD-asponA construction \\
\hline F2_asponA & GAAATTGTCGTCCTCGGCGGACAGCAGGGCATGGATGAAG & Plasmid pBAD-asponA construction \\
\hline R2-Xhol_asponA & ACATCTCGAGTATGAGCCCTAGCACGACCA & Plasmid pBAD-asponA construction \\
\hline R1_control & ATCAGGGCGTTCTTGATAAAATGGAGAAACAGTAGAGAGT & Plasmid pBAD-control construction \\
\hline F2_control & TTTATCAAGAACGCCCTGATTCAGGACGGAGCGATAGATA & Plasmid pBAD-control construction \\
\hline R2-Xhol_control & ACATCTCGAGTGGAATAGTGATGGCCACCA & Plasmid pBAD-control construction \\
\hline Pser_up & CGAGTGGTTTAAGGCAACGGTCTTGA & Sequencing of pBAD-asdnaA, pBAD-asponA and pBAD-control \\
\hline Pser_down & AGTTCGGCCTGGTGGAGCAACTCG & Sequencing of pBAD-asdnaA, $p B A D$-asponA and pBAD-control \\
\hline 5'RNA adapter & GCUGAUGGCGAUGAAUGAACACUGCGUUUGCUGGCUUUGAUGAAA & 5'-RACE \\
\hline 5'RNA adapter-specific primer & GCTGATGGCGATGAATGAACACTG & $5^{\prime}-$ RACE \\
\hline 5'-GSP1_asdnaA & TGGAAGAGCGGCTGAAATCCC & 5'-RACE asdnaA \\
\hline 5'-GSP2_asdnaA & GCTTCGGCTGGGGCCTGAC & $5^{\prime}$-RACE asdnaA \\
\hline 5'-GSP1_asponA & AGATGCGCCGGACGCCGATC & 5'-RACE asponA \\
\hline 5'-GSP2_asponA & CTTCGCCGACATCCCGCAGGA & 5'-RACE asponA \\
\hline 3'RNA adapter E1 & UUCACUGUUCUUAGCGGCCGCAUGCUC-idT & $3^{\prime}-$ RACE \\
\hline 3'RNA adapter E1 primer & CATGCGGCCGCTAAGAACAGTGA & $3^{\prime}-$ RACE \\
\hline 3'-GSP1_asdnaA & ATCAGGATCGCCACCCGGGTTT & 3'-RACE asdnaA \\
\hline 3'-GSP2_asdnaA & TTCCGGCGGCTCGACGGCCACCGT & 3'-RACE asdnaA \\
\hline 3'-GSP1_asponA & GAAATTGTCGTCCTCGGCGGACA & 3'-RACE asponA \\
\hline 3'-GSP2_asponA & CAGGGCATGGATGAAGTCCTG & 3'-RACE asponA \\
\hline
\end{tabular}


Supplementary Table 2. Annotation of antisense sRNAs.

\begin{tabular}{|c|c|c|c|c|c|c|c|}
\hline Name & Start $^{\star}$ & End $^{*}$ & Length* & $\begin{array}{l}\text { Type of } \\
\text { SRNA** }\end{array}$ & $\begin{array}{c}\text { Antisense } \\
\text { qene }^{\star \star \star *}\end{array}$ & $\begin{array}{l}\text { Direction } \\
\text { qene }\end{array}$ & Gene \\
\hline asdna $\mathrm{A}^{\star \star \star * *}$ & 1320 & 1784 & 465 & internal & PA0001 & $>$ & $d n a A$ \\
\hline as 3 & 15121 & 15215 & 95 & end-span & PA0011 & $>$ & \\
\hline as 3 & 15121 & 15215 & 95 & start-span & PA0012 & $>$ & \\
\hline as4 & 35866 & 35974 & 109 & end-span & PA0033 & $<$ & $h p t C$ \\
\hline as5 & 40775 & 40925 & 151 & end-span & PA0039 & $>$ & \\
\hline as6 & 182516 & 182617 & 102 & end-span & PA0158 & $>$ & tric \\
\hline as7 & 184720 & 184861 & 142 & internal & PA0162 & $>$ & opdC \\
\hline as 8 & 226915 & 226976 & 62 & internal & PA0196 & $>$ & $p n t B$ \\
\hline as9 & 263722 & 263909 & 188 & internal & PA0234 & $>$ & \\
\hline as 10 & 288493 & 288639 & 147 & internal & PA0257 & $<$ & \\
\hline as 11 & 290529 & 290665 & 137 & internal & PA0259 & $<$ & \\
\hline as 12 & 291428 & 291543 & 116 & internal & PA0260 & $<$ & \\
\hline as13 & 299094 & 299181 & 88 & internal & PA0264 & $<$ & \\
\hline as 14 & 334305 & 334355 & 51 & internal & PA0296 & $<$ & spul \\
\hline $\begin{array}{l}\text { as } 15 \\
\text { a }\end{array}$ & 338651 & 338736 & 86 & internal & PA0300 & $>$ & spuD \\
\hline as 16 & 353325 & 353458 & 134 & internal & PA0313 & $<$ & \\
\hline as 17 & 368517 & 368669 & 153 & internal & PA0328 & $<$ & \\
\hline as 18 & 379215 & 379350 & 136 & internal & PA0337 & $>$ & $p t s P$ \\
\hline as19 & 448929 & 449284 & 356 & internal & PA0407 & $<$ & $\operatorname{gsh} B$ \\
\hline as20 & 521726 & 521838 & 113 & internal & PA0461 & $<$ & \\
\hline as21 & 544658 & 544778 & 121 & internal & PA0483 & $>$ & \\
\hline as22 & 554963 & 555078 & 116 & internal & PA0495 & $>$ & \\
\hline as 23 & 557312 & 557569 & 258 & end-span & PA0498 & $<$ & \\
\hline $\begin{array}{l}\text { as } 24 \\
\text { and }\end{array}$ & 646779 & 646892 & 114 & internal & PA0588 & $<$ & \\
\hline as 25 & 654775 & 654912 & 138 & internal & PA0595 & $<$ & ost $A$ \\
\hline $\begin{array}{l}\text { as } 26 \\
\text { and }\end{array}$ & 659114 & 659270 & 157 & internal & PA0599 & $<$ & \\
\hline as27 & 680736 & 680853 & 118 & internal & PA0620 & $>$ & \\
\hline as 28 & 697609 & 697703 & 95 & internal & PA0641 & $>$ & \\
\hline as29 & 701233 & 701489 & 257 & end-span & PA0645 & $>$ & \\
\hline as 29 & 701233 & 701489 & 257 & start-span & PA0646 & $>$ & \\
\hline as 30 & 718785 & 718934 & 150 & internal & PA0667 & $<$ & \\
\hline as 31 & 748895 & 749047 & 153 & internal & PA0689 & $>$ & \\
\hline as 32 & 749460 & 749562 & 103 & internal & PA0689 & $>$ & \\
\hline as 33 & 761761 & 761823 & 63 & internal & PA0690 & $>$ & \\
\hline as 34 & 784213 & 784303 & 91 & internal & PA0713 & $>$ & \\
\hline as 35 & 795503 & 795648 & 146 & internal & PA0727 & $>$ & \\
\hline as 36 & 798624 & 798854 & 231 & start-span & PA0730 & $<$ & \\
\hline as 37 & 817964 & 818095 & 132 & start-span & PA0750 & $>$ & ung \\
\hline as 38 & 898637 & 898918 & 282 & end-span & PA0823 & $<$ & \\
\hline as 38 & 898637 & 898918 & 282 & start-span & PA0822 & $<$ & \\
\hline as 39 & 921673 & 921840 & 168 & end-span & PA0845 & $<$ & \\
\hline as 40 & 967079 & 967178 & 100 & internal & PA0884 & $>$ & \\
\hline as41 & 967184 & 967283 & 100 & internal & PA0884 & $>$ & \\
\hline as 42 & 977508 & 977658 & 151 & internal & PA0894 & $<$ & \\
\hline as 43 & 990194 & 990309 & 116 & internal & PA0904 & $>$ & lys $C$ \\
\hline as 44 & 1026460 & 1026563 & 104 & internal & PA0936 & $<$ & $10 \times 02$ \\
\hline as 45 & 1027896 & 1028083 & 188 & end-span & PA0937 & $>$ & \\
\hline as 46 & 1039125 & 1039255 & 131 & end-span & PA0952 & $<$ & \\
\hline as 47 & 1056103 & 1056248 & 146 & internal & PA0972 & $>$ & tolB \\
\hline as48 & 1060351 & 1060676 & 326 & end-span & PA0977 & $<$ & \\
\hline as 49 & 1066483 & 1066610 & 128 & internal & PA0985 & $<$ & pyos5 \\
\hline as 50 & 1073865 & 1074007 & 143 & end-span & PA0992 & $>$ & cupc1 \\
\hline as50 & 1073865 & 1074007 & 143 & start-span & PA0993 & $>$ & сupC2 \\
\hline as51 & 1087094 & 1087222 & 129 & start-span & PA1003 & $<$ & $m v f R$ \\
\hline as52 & 1098349 & 1098557 & 209 & internal & PA1015 & $<$ & \\
\hline as53 & 1119615 & 1119886 & 272 & end-span & PA1032 & $<$ & quip \\
\hline as 54 & 35102 & 1135286 & 185 & end-span & PA1047 & $>$ & \\
\hline as55 & 5776 & 1135875 & 100 & internal & PA1048 & $>$ & \\
\hline as56 & 1141250 & 1141364 & 115 & start-span & PA1053 & $>$ & \\
\hline as 57 & 1207482 & 1207531 & 50 & internal & PA1113 & $>$ & \\
\hline as58 & 1232028 & 1232169 & 142 & start-span & PA1140 & $<$ & \\
\hline $\begin{array}{l}\text { as59 } \\
\text { as }\end{array}$ & 23807 & 1323918 & 112 & internal & PA1221 & $<$ & \\
\hline as60 & 1394817 & 1395002 & 186 & internal & PA1284 & $<$ & \\
\hline as61 & 1400645 & 1400720 & 76 & end-span & PA1289 & $<$ & \\
\hline as 62 & 1455941 & 1456046 & 106 & internal & PA1342 & $<$ & \\
\hline as63 & 1474290 & 1474393 & 104 & start-span & PA1362 & $>$ & \\
\hline as64 & 4863 & 1485037 & 175 & internal & PA1370 & $>$ & \\
\hline $\begin{array}{l}\text { as } 65 \\
\text { as }\end{array}$ & 85541 & 1485595 & 55 & internal & PA1370 & $>$ & \\
\hline as66 & 99584 & 1499684 & 101 & internal & PA1382 & $>$ & \\
\hline as 67 & 1499690 & 1499742 & 53 & internal & PA1382 & $>$ & \\
\hline as 68 & 1502841 & 1502987 & 147 & internal & PA1383 & $>$ & \\
\hline as69 & 1503570 & 1503696 & 127 & internal & PA1384 & $>$ & gale \\
\hline as70 & 1503843 & 1503937 & 95 & internal & PA1384 & $>$ & galE \\
\hline as71 & 1504553 & 1504676 & 124 & end-span & PA1384 & $>$ & galE \\
\hline as71 & 1504553 & 1504676 & & pan & & $>$ & \\
\hline r & 4788 & 1504927 & 140 & internal & PA1385 & $>$ & \\
\hline 73 & 107 & 15 & 10 & internal & 386 & $>$ & \\
\hline as 74 & 8500 & 1558752 & & internal & PA1430 & $>$ & lasR \\
\hline as75 & 38434 & 1588549 & 116 & internal & $\begin{array}{l}\text { PA1458 } \\
\text { P } 14\end{array}$ & $>$ & \\
\hline as76 & 9661 & (2) & 10 & & PA1510 & $<$ & \\
\hline & & & & & & $<$ & \\
\hline as77 & 640773 & 1640948 & 176 & internal & PA1510 & $<$ & \\
\hline as78 & 98424 & 16985 & 11 & interna & PA15 & $<$ & aer \\
\hline & & & & & & $>$ & \\
\hline as 80 & 1732127 & 1732265 & 139 & end-span & PA1589 & $>$ & sucD \\
\hline as81 & 1785747 & 1785881 & 135 & internal & PA1640 & $<$ & \\
\hline as 82 & 6 & 17906 & 1 & & PA16 & $<$ & \\
\hline 3 & 8134 & 1838246 & 113 & internal & PA1688 & $>$ & \\
\hline as 84 & 1911985 & 1912118 & 134 & internal & PA1767 & $<$ & \\
\hline as 85 & 1912994 & 1913099 & 106 & end-span & PA1769 & $<$ & \\
\hline
\end{tabular}




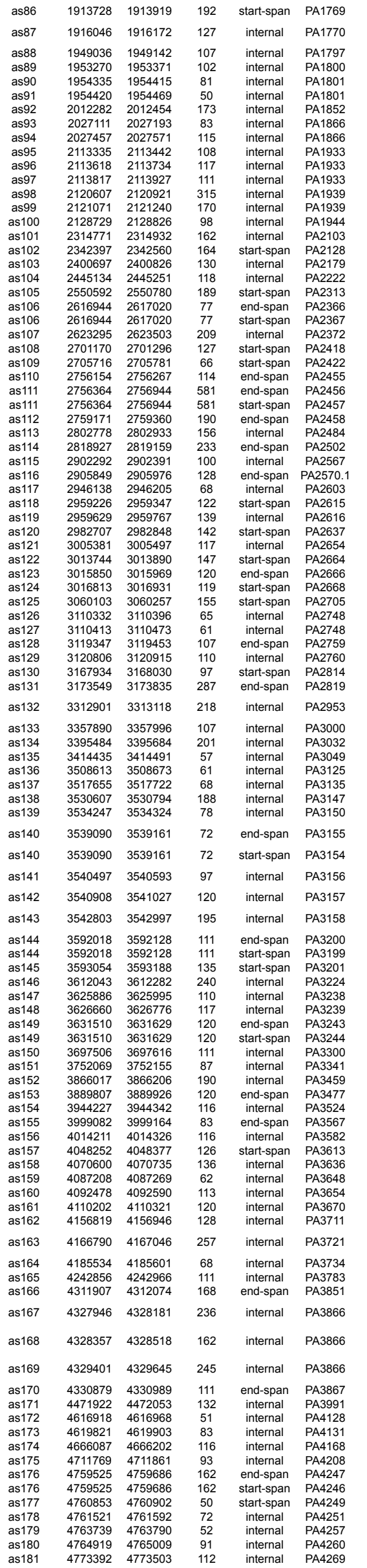

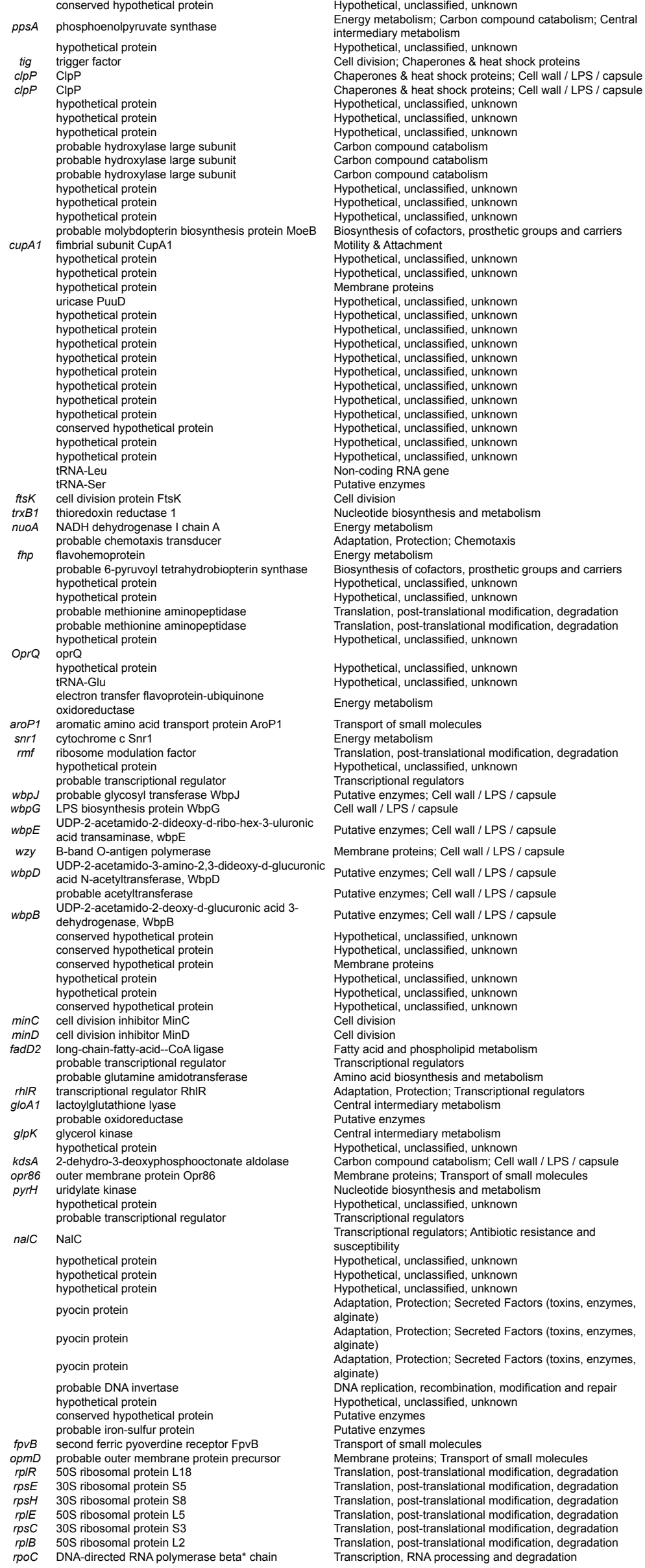




\begin{tabular}{|c|c|c|c|c|c|c|c|c|c|}
\hline as182 & 4780416 & 4780494 & 79 & internal & PA4270 & $<$ & $r p o B$ & $\mathrm{P} 26$ & Transcription, RNA processing and degradation \\
\hline as 183 & 4781848 & 4781947 & 100 & internal & PA4272.1 & $>$ & P27 & P27 & Non-coding RNA gene \\
\hline as184 & 4842427 & 4842583 & 157 & end-span & PA4313 & $>$ & & hypothetical protein & Hypothetical, unclassified, unknown \\
\hline as185 & 4919101 & 4919236 & 136 & internal & PA4389 & $>$ & & probable short-chain dehydrogenase & Putative enzymes; Amino acid biosynthesis and metabolism \\
\hline as186 & 4925623 & 4925733 & 111 & internal & PA4395 & $<$ & & conserved hypothetical protein & Hypothetical, unclassified, unknown \\
\hline as187 & 4982939 & 4983086 & 148 & internal & PA4448 & $<$ & hisD & histidinol dehydrogenase & Amino acid biosynthesis and metabolism \\
\hline as188 & 4991277 & 4991330 & 54 & internal & PA4459 & $>$ & & conserved hypothetical protein & Hypothetical, unclassified, unknown \\
\hline as 189 & 5002347 & 5002404 & 58 & internal & PA4473 & $>$ & & hypothetical protein & Hypothetical, unclassified, unknown \\
\hline as190 & 5018832 & 5019000 & 169 & internal & PA4488 & $<$ & & conserved hypothetical protein & Hypothetical, unclassified, unknown \\
\hline as191 & 5037299 & 5037430 & 132 & internal & PA4500 & $>$ & & $\begin{array}{l}\text { probable binding protein component of } \mathrm{ABC} \\
\text { transporter }\end{array}$ & Transport of small molecules \\
\hline as192 & 5049739 & 5049879 & 141 & start-span & PA4512 & $>$ & Ipx01 & lipopolysaccharide biosynthetic protein $\mathrm{LpxO} 1$ & Putative enzymes; Cell wall / LPS / capsule \\
\hline as193 & 5055080 & 5055129 & 50 & internal & PA4514 & $<$ & & probable outer membrane receptor for iron transport & Transport of small molecules \\
\hline as194 & 5055132 & 5055185 & 54 & internal & PA4514 & $<$ & & probable outer membrane receptor for iron transport & Transport of small molecules \\
\hline as195 & 5071575 & 5071963 & 389 & internal & PA4527 & $>$ & pilc & still frameshift type 4 fimbrial biogenesis protein PilC & Motility \& Attachment \\
\hline as196 & 5071970 & 5072154 & 185 & internal & PA4527 & $>$ & pilc & still frameshift type 4 fimbrial biogenesis protein PilC & Motility \& Attachment \\
\hline as197 & 5101107 & 5101200 & 94 & internal & PA4554 & $>$ & pilY1 & type 4 fimbrial biogenesis protein PilY1 & Motility \& Attachment \\
\hline as198 & 5101511 & 5101611 & 101 & internal & PA4554 & $>$ & pilY1 & $\begin{array}{l}\text { type } 4 \text { fimbrial biogenesis protein PilY1 } \\
\text { tim }\end{array}$ & Motility \& Attachment \\
\hline as199 & 5141781 & 5141969 & 189 & end-span & PA4591 & $<$ & & hypothetical protein & Hypothetical, unclassified, unknown \\
\hline as 200 & 5148538 & 5148668 & 131 & start-span & PA4595 & $<$ & & probable ATP-binding component of ABC transporter & Transport of small molecules \\
\hline as201 & 5274032 & 5274193 & 162 & internal & PA4696 & $<$ & $i l v l$ & acetolactate synthase large subunit & $\begin{array}{l}\text { Biosynthesis of cofactors, prosthetic groups and carriers; } \\
\text { Amino acid biosynthesis and metabolism }\end{array}$ \\
\hline as202 & 5296232 & 5296293 & 62 & internal & PA4717 & $>$ & & conserved hypothetical protein & $\begin{array}{l}\text { Amino acid biosynthesis and metabolism } \\
\text { Hypothetical, unclassified, unknown }\end{array}$ \\
\hline as203 & 5296311 & 5296538 & 228 & internal & PA4717 & $>$ & & conserved hypothetical protein & Hypothetical, unclassified, unknown \\
\hline as204 & 5301771 & 5301838 & 68 & internal & PA4722 & $<$ & & probable aminotransferase & 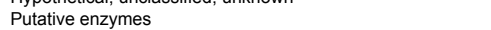 \\
\hline as205 & 5356355 & 5356495 & 141 & internal & PA4770 & $>$ & $\| d P$ & L-lactate permease & Transport of small molecules \\
\hline as206 & 5375454 & 5375529 & 76 & end-span & PA4786 & $>$ & & probable short-chain dehydrogenase & Putative enzymes \\
\hline as207 & 5380813 & 5380919 & 107 & internal & PA4793 & $>$ & & hypothetical protein & Hypothetical, unclassified, unknown \\
\hline as208 & 5382370 & 5382497 & 128 & end-span & PA4796 & $>$ & & hypothetical protein & Hypothetical, unclassified, unknown \\
\hline as209 & 5408036 & 5408137 & 102 & internal & PA4818 & $<$ & & conserved hypothetical protein & Membrane proteins \\
\hline as 210 & 5473394 & 5473504 & 111 & internal & PA4877 & $<$ & & hypothetical protein & Hypothetical, unclassified, unknown \\
\hline as 211 & 5522339 & 5522410 & 72 & start-span & PA4923 & $>$ & & conserved hypothetical protein & Hypothetical, unclassified, unknown \\
\hline as 212 & 5532791 & 5532916 & 126 & internal & PA4929 & $>$ & & hypothetical protein & Membrane proteins \\
\hline as 213 & 5541691 & 5541800 & 110 & end-span & PA4937.1 & $>$ & & tRNA-Leu & Non-coding RNA gene \\
\hline as214 & 5545002 & 5545131 & 130 & internal & PA4941 & $<$ & $h f l C$ & protease subunit HfIC & Translation, post-translational modification, degradation; Cell \\
\hline as215 & 5559871 & 5559952 & 82 & start-span & PA4954 & $<$ & motA & chemotaxis protein MotA & Adaptation, Protection; Chemotaxis \\
\hline as216 & 5580862 & 5581109 & 248 & start-span & PA4972 & $>$ & & hypothetical protein & Hypothetical, unclassified, unknown \\
\hline as217 & 5584935 & 5585163 & 229 & internal & PA4974 & $>$ & & probable outer membrane protein precursor & Protein secretion/export apparatus \\
\hline as218 & 5585580 & 5585652 & 73 & end-span & PA4975 & $<$ & & NAD $(P) H$ quinone oxidoreductase & Energy metabolism \\
\hline as219 & 5602759 & 5602870 & 112 & internal & PA4986 & $>$ & & probable oxidoreductase & $\begin{array}{l}\text { Putative enzymes } \\
\text { Pats }\end{array}$ \\
\hline as220 & 5617657 & 5617793 & 137 & internal & PA5000 & $<$ & $\operatorname{wapR}$ & alpha-1,3-rhamnosyltransferase WapR & Putative enzymes; Cell wall / LPS / capsule \\
\hline as221 & 5618584 & 5618634 & 51 & internal & PA5001 & $<$ & & hypothetical protein & Hypothetical, unclassified, unknown \\
\hline as222 & 5655041 & 5655112 & 72 & internal & PA5024 & $>$ & & conserved hypothetical protein & Hypothetical, unclassified, unknown \\
\hline as223 & 5678557 & 5678652 & 96 & internal & PA5042 & $<$ & pilO & type 4 fimbrial biogenesis protein PilO & Motility \& Attachment \\
\hline aspon $A^{* * * *}$ & 5680819 & 5681167 & 349 & start-span & PA5045 & $>$ & ponA & penicillin-binding protein $1 \mathrm{~A}$ & Cell wall / LPS / capsule \\
\hline as225 & 5684803 & 5684910 & 108 & end-span & PA5047 & $<$ & & hypothetical protein & Hypothetical, unclassified, unknown \\
\hline as226 & 5699012 & 5699062 & 51 & internal & PA5058 & $>$ & phaC2 & poly(3-hydroxyalkanoic acid) synthase 2 & Central intermediary metabolism \\
\hline as227 & 5720268 & 5720351 & 84 & start-span & PA5080 & $<$ & & prolyl aminopeptidase & Translation, post-translational modification, degradation \\
\hline as228 & 5725557 & 5725795 & 239 & internal & PA5087 & $<$ & & hypothetical protein & Hypothetical, unclassified, unknown \\
\hline as229 & 5739066 & 5739203 & 138 & internal & PA5097 & $<$ & & probable amino acid permease & Membrane proteins; Transport of small molecules \\
\hline as 230 & 5785777 & 5785905 & 129 & internal & PA5136 & $>$ & & hypothetical protein & Hypothetical, unclassified, unknown \\
\hline as231 & 5799079 & 5799208 & 130 & internal & PA5150 & $<$ & & probable short-chain dehydrogenase & $\begin{array}{l}\text { Putative enzymes } \\
\text { Pame }\end{array}$ \\
\hline as 232 & 5817430 & 5817493 & 64 & internal & PA5167 & $>$ & & probable c4-dicarboxylate-binding protein & Membrane proteins; Transport of small molecules \\
\hline as 233 & 5824524 & 5824599 & 76 & internal & PA5172 & $>$ & $\operatorname{arc} B$ & ornithine carbamoyltransferase, catabolic & Amino acid biosynthesis and metabolism \\
\hline as234 & 5844451 & 5844527 & 77 & end-span & PA5192 & $<$ & pckA & phosphoenolpyruvate carboxykinase & Carbon compound catabolism; Energy metabolism \\
\hline as 235 & 5863452 & 5863719 & 268 & start-span & PA5208 & $<$ & & conserved hypothetical protein & Hypothetical, unclassified, unknown \\
\hline as 236 & 5868209 & 5868408 & 200 & internal & PA5213 & $<$ & $g c v P 1$ & glycine cleavage system protein $\mathrm{P} 1$ & $\begin{array}{l}\text { Central intermediary metabolism; Amino acid biosynthesis } \\
\text { and metabolism }\end{array}$ \\
\hline as & 5896925 & 5897003 & 79 & internal & PA5238 & $<$ & & probable O-antigen acetylase & $\begin{array}{l}\text { Putative enzymes; Membrane proteins; Cell wall / LPS / } \\
\text { capsule }\end{array}$ \\
\hline as 238 & 5897008 & 5897057 & 50 & internal & PA5238 & $<$ & & probable O-antigen acetylase & Putative enzymes; Membrane proteins; Cell wall / LPS / \\
\hline as 239 & 5926819 & 5926963 & 145 & internal & PA5264 & $<$ & & hypothetical protein & $\begin{array}{l}\text { capsule } \\
\text { Hypothetical, unclassified, unknown; Membrane proteins }\end{array}$ \\
\hline as240 & 6059529 & 6059600 & 72 & internal & PA5380 & $>$ & $g b d R$ & GbdR & Transcriptional regulators \\
\hline as241 & 6090655 & 6090800 & 146 & start-span & PA5412 & $<$ & & hypothetical protein & Hypothetical, unclassified, unknown \\
\hline as 242 & 6135711 & 6135789 & 79 & internal & PA5446 & $>$ & & hypothetical protein & Hypothetical, unclassified, unknown \\
\hline as 243 & 6141133 & 6141239 & 107 & internal & PA5451 & $<$ & $w z m$ & membrane subunit of A-band LPS efflux transporter & Cell wall / LPS / capsule; Membrane proteins; Transport of \\
\hline as 244 & 6157855 & 6157964 & 110 & internal & PA5468 & $>$ & & probable citrate transpc & $\begin{array}{l}\text { small molecules } \\
\text { Transport of small molecules }\end{array}$ \\
\hline as 245 & 6158032 & 6158203 & 172 & end-span & PA5468 & $>$ & & probable citrate transporter & Transport of small molecules \\
\hline as245 & 6158032 & 6158203 & 172 & start-span & PA5469 & $>$ & & conserved hypothetical protein & Membrane proteins \\
\hline as 246 & 6171684 & 6171915 & 232 & start-span & PA5480 & $>$ & & hypothetical protein & Hypothetical, unclassif \\
\hline as247 & 6183216 & 6183389 & 174 & internal & PA5492 & $>$ & & conserved hypothetical protein & Hypothetical, unclassified, unknown \\
\hline as248 & 6218749 & 6219078 & 330 & end-span & PA5525 & $>$ & & probable transcriptional regulator & Transcriptional regulators \\
\hline 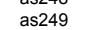 & 6245830 & 6245973 & 144 & internal & PA5551 & $<$ & & $\begin{array}{l}\text { hypothetical protein } \\
\text { hellot }\end{array}$ & Hypothetical, unclassified, unknown \\
\hline as 250 & 6247796 & 6247909 & 114 & end-span & PA5553 & $<$ & $\operatorname{atp} C$ & ATP synthase epsilon chain & Energy metabolism \\
\hline
\end{tabular}

" The antisense sRNAs were categorize depending on their position with respect to the opposite gene as "start-span" (the asRNA spans over the start of the antisense gene), "internal" (the asRNA start and end within the antisense gene), or "end"*The antisense sRNAs were categorize depending
span" (the asRNA spans over the end of the gene).

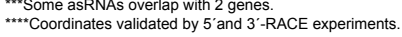


Supplementary Table 3. Antisense sRNAs differentially expressed.

\begin{tabular}{|c|c|c|c|c|c|}
\hline Name & Start* & End* & Length* & Direction asRNA & Fold change** \\
\hline \multicolumn{6}{|c|}{ asRNAs differentially expressed during AZI (10xMIC) treatment } \\
\hline as165 & 4242856 & 4242966 & 111 & $<$ & 0.12 \\
\hline as210 & 5473394 & 5473504 & 111 & $>$ & 0.21 \\
\hline as94 & 2027457 & 2027571 & 115 & $<$ & 0.26 \\
\hline as230 & 5785777 & 5785905 & 129 & $<$ & 0.32 \\
\hline as77 & 1640773 & 1640948 & 176 & $>$ & 0.38 \\
\hline as 100 & 2128729 & 2128826 & 98 & $<$ & 0.39 \\
\hline as42 & 977508 & 977658 & 151 & $>$ & 0.42 \\
\hline as 183 & 4781848 & 4781947 & 100 & $<$ & 2.55 \\
\hline as 130 & 3167934 & 3168030 & 97 & $>$ & 2.66 \\
\hline as99 & 2121071 & 2121240 & 170 & $>$ & 2.69 \\
\hline as 123 & 3015850 & 3015969 & 120 & $<$ & 2.90 \\
\hline as231 & 5799079 & 5799208 & 130 & $>$ & 2.94 \\
\hline as115 & 2902292 & 2902391 & 100 & $<$ & 3.30 \\
\hline as111 & 2756364 & 2756944 & 581 & $<$ & 3.34 \\
\hline as112 & 2759171 & 2759360 & 190 & $<$ & 3.88 \\
\hline as117 & 2946138 & 2946205 & 68 & $<$ & 4.87 \\
\hline as244 & 6157855 & 6157964 & 110 & $<$ & 11.33 \\
\hline as 184 & 4842427 & 4842583 & 157 & $<$ & 27.49 \\
\hline \multicolumn{6}{|c|}{ asRNAs differentially expressed during AZT (3xMIC) treatment } \\
\hline as6 & 182516 & 182617 & 102 & $<$ & 0.09 \\
\hline as48 & 1060351 & 1060676 & 326 & $>$ & 0.26 \\
\hline as 104 & 2445134 & 2445251 & 118 & $>$ & 0.32 \\
\hline as19 & 448929 & 449284 & 356 & $>$ & 0.33 \\
\hline as119 & 2959629 & 2959767 & 139 & $<$ & 0.36 \\
\hline as78 & 1698424 & 1698534 & 111 & $>$ & 0.41 \\
\hline as 120 & 2982707 & 2982848 & 142 & $<$ & 2.06 \\
\hline as29 & 701233 & 701489 & 257 & $<$ & 2.07 \\
\hline as 163 & 4166790 & 4167046 & 257 & $<$ & 2.20 \\
\hline as10 & 288493 & 288639 & 147 & $>$ & 2.30 \\
\hline as200 & 5148538 & 5148668 & 131 & $>$ & 2.33 \\
\hline as228 & 5725557 & 5725795 & 239 & $>$ & 2.34 \\
\hline as195 & 5071575 & 5071963 & 389 & $<$ & 2.51 \\
\hline $\operatorname{asdna}^{* * * *}$ & 1320 & 1784 & 465 & $<$ & 2.79 \\
\hline as 146 & 3612043 & 3612282 & 240 & $>$ & 2.82 \\
\hline as51 & 1087094 & 1087222 & 129 & $>$ & 2.85 \\
\hline aspon $A^{* * * *}$ & 5680819 & 5681167 & 349 & $<$ & 2.94 \\
\hline as205 & 5356355 & 5356495 & 141 & $<$ & 3.13 \\
\hline as 162 & 4156819 & 4156946 & 128 & $<$ & 3.24 \\
\hline as45 & 1027896 & 1028083 & 188 & $<$ & 3.56 \\
\hline as135 & 3414435 & 3414491 & 57 & $<$ & 4.21 \\
\hline as181 & 4773392 & 4773503 & 112 & $>$ & 5.50 \\
\hline as221 & 5618584 & 5618634 & 51 & $>$ & 6.08 \\
\hline as244 & 6157855 & 6157964 & 110 & $<$ & 6.37 \\
\hline as32 & 749460 & 749562 & 103 & $<$ & 6.84 \\
\hline as39 & 921673 & 921840 & 168 & $>$ & 20.82 \\
\hline as152 & 3866017 & 3866206 & 190 & $<$ & 21.77 \\
\hline as128 & 3119347 & 3119453 & 107 & $>$ & 22.06 \\
\hline \multicolumn{6}{|c|}{ asRNAs differentially expressed during CEF (3xMIC) treatment } \\
\hline as6 & 182516 & 182617 & 102 & $<$ & 0.08 \\
\hline as75 & 1588434 & 1588549 & 116 & $<$ & 0.09 \\
\hline
\end{tabular}




\begin{tabular}{|c|c|c|c|c|c|}
\hline as210 & 5473394 & 5473504 & 111 & $>$ & 0.12 \\
\hline as 48 & 1060351 & 1060676 & 326 & $>$ & 0.14 \\
\hline as83 & 1838134 & 1838246 & 113 & $<$ & 0.16 \\
\hline as119 & 2959629 & 2959767 & 139 & $<$ & 0.17 \\
\hline as19 & 448929 & 449284 & 356 & $>$ & 0.20 \\
\hline as43 & 990194 & 990309 & 116 & $<$ & 0.35 \\
\hline as 138 & 3530607 & 3530794 & 188 & $>$ & 0.37 \\
\hline as94 & 2027457 & 2027571 & 115 & $<$ & 0.39 \\
\hline as235 & 5863452 & 5863719 & 268 & $>$ & 0.43 \\
\hline as 146 & 3612043 & 3612282 & 240 & $>$ & 2.10 \\
\hline as29 & 701233 & 701489 & 257 & $<$ & 2.17 \\
\hline as24 & 646779 & 646892 & 114 & $>$ & 2.21 \\
\hline as200 & 5148538 & 5148668 & 131 & $>$ & 2.22 \\
\hline as 45 & 1027896 & 1028083 & 188 & $<$ & 2.32 \\
\hline as192 & 5049739 & 5049879 & 141 & $<$ & 2.45 \\
\hline as51 & 1087094 & 1087222 & 129 & $>$ & 3.15 \\
\hline as 4 & 35866 & 35974 & 109 & $>$ & 4.02 \\
\hline as16 & 353325 & 353458 & 134 & $>$ & 4.93 \\
\hline as213 & 5541691 & 5541800 & 110 & $<$ & 7.18 \\
\hline as 145 & 3593054 & 3593188 & 135 & $<$ & 7.72 \\
\hline as129 & 3120806 & 3120915 & 110 & $<$ & 12.58 \\
\hline as39 & 921673 & 921840 & 168 & $>$ & 24.03 \\
\hline as56 & 1141250 & 1141364 & 115 & $<$ & 32.30 \\
\hline \multicolumn{6}{|c|}{ asRNAs differentially expressed during CIP (3xMIC) treatment } \\
\hline as6 & 182516 & 182617 & 102 & $<$ & 0.02 \\
\hline as92 & 2012282 & 2012454 & 173 & $>$ & 0.05 \\
\hline as64 & 1484863 & 1485037 & 175 & $<$ & 0.07 \\
\hline as169 & 4329401 & 4329645 & 245 & $>$ & 0.07 \\
\hline as 104 & 2445134 & 2445251 & 118 & $>$ & 0.10 \\
\hline as 157 & 4048252 & 4048377 & 126 & $>$ & 0.11 \\
\hline as183 & 4781848 & 4781947 & 100 & $<$ & 0.11 \\
\hline as131 & 3173549 & 3173835 & 287 & $<$ & 0.13 \\
\hline as 110 & 2756154 & 2756267 & 114 & $<$ & 0.15 \\
\hline as23 & 557312 & 557569 & 258 & $>$ & 0.17 \\
\hline as111 & 2756364 & 2756944 & 581 & $<$ & 0.19 \\
\hline as231 & 5799079 & 5799208 & 130 & $>$ & 0.20 \\
\hline as29 & 701233 & 701489 & 257 & $<$ & 0.20 \\
\hline as21 & 544658 & 544778 & 121 & $<$ & 0.21 \\
\hline as77 & 1640773 & 1640948 & 176 & $>$ & 0.23 \\
\hline as 19 & 448929 & 449284 & 356 & $>$ & 0.23 \\
\hline as225 & 5684803 & 5684910 & 108 & $>$ & 0.24 \\
\hline as 165 & 4242856 & 4242966 & 111 & $<$ & 0.24 \\
\hline as31 & 748895 & 749047 & 153 & $<$ & 0.27 \\
\hline as12 & 291428 & 291543 & 116 & $>$ & 0.31 \\
\hline as 101 & 2314771 & 2314932 & 162 & $<$ & 0.34 \\
\hline as 48 & 1060351 & 1060676 & 326 & $>$ & 0.34 \\
\hline as55 & 1135776 & 1135875 & 100 & $<$ & 0.36 \\
\hline as38 & 898637 & 898918 & 282 & $>$ & 0.37 \\
\hline as 43 & 990194 & 990309 & 116 & $<$ & 0.38 \\
\hline as94 & 2027457 & 2027571 & 115 & $<$ & 0.40 \\
\hline as98 & 2120607 & 2120921 & 315 & $>$ & 0.43 \\
\hline as138 & 3530607 & 3530794 & 188 & $>$ & 0.47 \\
\hline as235 & 5863452 & 5863719 & 268 & $>$ & 0.49 \\
\hline as9 & 263722 & 263909 & 188 & $<$ & 0.49 \\
\hline as 100 & 2128729 & 2128826 & 98 & $<$ & 2.05 \\
\hline spon $A^{\star * \star *}$ & 5680819 & 5681167 & 349 & $<$ & 2.06 \\
\hline
\end{tabular}




\begin{tabular}{|c|c|c|c|c|c|}
\hline as 179 & 4763739 & 4763790 & 52 & $>$ & 2.22 \\
\hline as208 & 5382370 & 5382497 & 128 & $<$ & 2.48 \\
\hline as52 & 1098349 & 1098557 & 209 & $>$ & 2.80 \\
\hline as26 & 659114 & 659270 & 157 & $>$ & 2.84 \\
\hline as 160 & 4092478 & 4092590 & 113 & $>$ & 2.97 \\
\hline as 163 & 4166790 & 4167046 & 257 & $<$ & 3.05 \\
\hline as7 & 184720 & 184861 & 142 & $<$ & 3.26 \\
\hline as24 & 646779 & 646892 & 114 & $>$ & 3.35 \\
\hline as 45 & 1027896 & 1028083 & 188 & $<$ & 3.54 \\
\hline as181 & 4773392 & 4773503 & 112 & $>$ & 3.69 \\
\hline as32 & 749460 & 749562 & 103 & $<$ & 3.77 \\
\hline as115 & 2902292 & 2902391 & 100 & $<$ & 4.45 \\
\hline $\operatorname{asdna} A^{* * \star *}$ & 1320 & 1784 & 465 & $<$ & 4.67 \\
\hline as136 & 3508613 & 3508673 & 61 & $<$ & 6.06 \\
\hline as4 & 35866 & 35974 & 109 & $>$ & 6.41 \\
\hline as 152 & 3866017 & 3866206 & 190 & $<$ & 6.96 \\
\hline as 170 & 4330879 & 4330989 & 111 & $<$ & 10.94 \\
\hline as 16 & 353325 & 353458 & 134 & $>$ & 12.17 \\
\hline as128 & 3119347 & 3119453 & 107 & $>$ & 16.61 \\
\hline as 122 & 3013744 & 3013890 & 147 & $>$ & 22.25 \\
\hline as 129 & 3120806 & 3120915 & 110 & $<$ & 24.88 \\
\hline as213 & 5541691 & 5541800 & 110 & $<$ & 30.64 \\
\hline
\end{tabular}

asRNAs differentially expressed during CO (3xMIC) treatment

\begin{tabular}{|c|c|c|c|c|c|}
\hline as6 & 182516 & 182617 & 102 & $<$ & 0.02 \\
\hline as37 & 817964 & 818095 & 132 & $<$ & 0.10 \\
\hline as19 & 448929 & 449284 & 356 & $>$ & 0.11 \\
\hline as230 & 5785777 & 5785905 & 129 & $<$ & 0.12 \\
\hline as201 & 5274032 & 5274193 & 162 & $>$ & 0.14 \\
\hline as131 & 3173549 & 3173835 & 287 & $<$ & 0.14 \\
\hline as64 & 1484863 & 1485037 & 175 & $<$ & 0.18 \\
\hline as104 & 2445134 & 2445251 & 118 & $>$ & 0.18 \\
\hline as235 & 5863452 & 5863719 & 268 & $>$ & 0.19 \\
\hline as48 & 1060351 & 1060676 & 326 & $>$ & 0.20 \\
\hline as83 & 1838134 & 1838246 & 113 & $<$ & 0.20 \\
\hline as92 & 2012282 & 2012454 & 173 & $>$ & 0.20 \\
\hline as12 & 291428 & 291543 & 116 & $>$ & 0.21 \\
\hline as206 & 5375454 & 5375529 & 76 & $<$ & 0.30 \\
\hline as9 & 263722 & 263909 & 188 & $<$ & 0.30 \\
\hline as203 & 5296311 & 5296538 & 228 & $<$ & 0.32 \\
\hline as42 & 977508 & 977658 & 151 & $>$ & 0.32 \\
\hline aspon $A^{* * * *}$ & 5680819 & 5681167 & 349 & $<$ & 0.32 \\
\hline as225 & 5684803 & 5684910 & 108 & $>$ & 0.33 \\
\hline as112 & 2759171 & 2759360 & 190 & $<$ & 0.33 \\
\hline as11 & 290529 & 290665 & 137 & $>$ & 0.34 \\
\hline as55 & 1135776 & 1135875 & 100 & $<$ & 0.34 \\
\hline as44 & 1026460 & 1026563 & 104 & $>$ & 0.36 \\
\hline as61 & 1400645 & 1400720 & 76 & $>$ & 0.36 \\
\hline as169 & 4329401 & 4329645 & 245 & $>$ & 0.39 \\
\hline as82 & 1790530 & 1790650 & 121 & $>$ & 0.42 \\
\hline as63 & 1474290 & 1474393 & 104 & $<$ & 0.43 \\
\hline as81 & 1785747 & 1785881 & 135 & $>$ & 0.45 \\
\hline as 146 & 3612043 & 3612282 & 240 & $>$ & 2.25 \\
\hline as119 & 2959629 & 2959767 & 139 & $<$ & 2.30 \\
\hline as192 & 5049739 & 5049879 & 141 & $<$ & 2.37 \\
\hline as90 & 1954335 & 1954415 & 81 & $<$ & 2.72 \\
\hline as 120 & 2982707 & 2982848 & 142 & $<$ & 2.95 \\
\hline
\end{tabular}




\begin{tabular}{|c|c|c|c|c|c|}
\hline as78 & 1698424 & 1698534 & 111 & $>$ & 3.04 \\
\hline as16 & 353325 & 353458 & 134 & $>$ & 3.41 \\
\hline as221 & 5618584 & 5618634 & 51 & $>$ & 3.87 \\
\hline as247 & 6183216 & 6183389 & 174 & $<$ & 4.48 \\
\hline as205 & 5356355 & 5356495 & 141 & $<$ & 4.96 \\
\hline as162 & 4156819 & 4156946 & 128 & $<$ & 5.35 \\
\hline as57 & 1207482 & 1207531 & 50 & $<$ & 5.44 \\
\hline as121 & 3005381 & 3005497 & 117 & $<$ & 6.22 \\
\hline as25 & 654775 & 654912 & 138 & $>$ & 6.25 \\
\hline as 36 & 798624 & 798854 & 231 & $>$ & 6.86 \\
\hline as20 & 521726 & 521838 & 113 & $>$ & 36.01 \\
\hline
\end{tabular}

asRNAs differentially expressed during $\mathrm{H} 2 \mathrm{O} 2(1 \mathrm{mM})$ treatment

\begin{tabular}{|c|c|c|c|c|c|}
\hline as6 & 182516 & 182617 & 102 & $<$ & 0.06 \\
\hline as 48 & 1060351 & 1060676 & 326 & $>$ & 0.35 \\
\hline as 104 & 2445134 & 2445251 & 118 & $>$ & 0.45 \\
\hline as 19 & 448929 & 449284 & 356 & $>$ & 0.45 \\
\hline as 84 & 1911985 & 1912118 & 134 & $>$ & 2.05 \\
\hline $\operatorname{asdna} A^{* * * *}$ & 1320 & 1784 & 465 & $<$ & 2.11 \\
\hline as29 & 701233 & 701489 & 257 & $<$ & 2.28 \\
\hline as 146 & 3612043 & 3612282 & 240 & $>$ & 2.96 \\
\hline as 174 & 4666087 & 4666202 & 116 & $<$ & 3.31 \\
\hline as205 & 5356355 & 5356495 & 141 & $<$ & 3.89 \\
\hline as 143 & 3542803 & 3542997 & 195 & $>$ & 4.70 \\
\hline as244 & 6157855 & 6157964 & 110 & $<$ & 5.40 \\
\hline as 120 & 2982707 & 2982848 & 142 & $<$ & 5.79 \\
\hline as221 & 5618584 & 5618634 & 51 & $>$ & 6.24 \\
\hline as 145 & 3593054 & 3593188 & 135 & $<$ & 6.51 \\
\hline as20 & 521726 & 521838 & 113 & $>$ & 7.47 \\
\hline as39 & 921673 & 921840 & 168 & $>$ & 9.95 \\
\hline \multicolumn{6}{|c|}{ asRNAs differentially expressed during MP (3xMIC) treatment } \\
\hline as6 & 182516 & 182617 & 102 & $<$ & 0.05 \\
\hline as19 & 448929 & 449284 & 356 & $>$ & 0.09 \\
\hline as201 & 5274032 & 5274193 & 162 & $>$ & 0.09 \\
\hline as77 & 1640773 & 1640948 & 176 & $>$ & 0.09 \\
\hline as 104 & 2445134 & 2445251 & 118 & $>$ & 0.10 \\
\hline as235 & 5863452 & 5863719 & 268 & $>$ & 0.14 \\
\hline as 12 & 291428 & 291543 & 116 & $>$ & 0.15 \\
\hline as131 & 3173549 & 3173835 & 287 & $<$ & 0.16 \\
\hline as 48 & 1060351 & 1060676 & 326 & $>$ & 0.16 \\
\hline as55 & 1135776 & 1135875 & 100 & $<$ & 0.19 \\
\hline as230 & 5785777 & 5785905 & 129 & $<$ & 0.22 \\
\hline as 138 & 3530607 & 3530794 & 188 & $>$ & 0.26 \\
\hline as63 & 1474290 & 1474393 & 104 & $<$ & 0.27 \\
\hline as169 & 4329401 & 4329645 & 245 & $>$ & 0.27 \\
\hline as225 & 5684803 & 5684910 & 108 & $>$ & 0.31 \\
\hline as220 & 5617657 & 5617793 & 137 & $>$ & 0.33 \\
\hline as203 & 5296311 & 5296538 & 228 & $<$ & 0.41 \\
\hline as31 & 748895 & 749047 & 153 & $<$ & 0.44 \\
\hline as94 & 2027457 & 2027571 & 115 & $<$ & 0.45 \\
\hline as23 & 557312 & 557569 & 258 & $>$ & 0.45 \\
\hline aspon $A^{* * * *}$ & 5680819 & 5681167 & 349 & $<$ & 0.48 \\
\hline as81 & 1785747 & 1785881 & 135 & $>$ & 2.20 \\
\hline as 146 & 3612043 & 3612282 & 240 & $>$ & 2.62 \\
\hline as200 & 5148538 & 5148668 & 131 & $>$ & 2.82 \\
\hline as16 & 353325 & 353458 & 134 & $>$ & 3.57 \\
\hline as163 & 4166790 & 4167046 & 257 & $<$ & 3.92 \\
\hline
\end{tabular}




\begin{tabular}{|c|c|c|c|c|c|}
\hline as 248 & 6218749 & 6219078 & 330 & $<$ & 4.08 \\
\hline as29 & 701233 & 701489 & 257 & $<$ & 4.51 \\
\hline as 162 & 4156819 & 4156946 & 128 & $<$ & 5.46 \\
\hline as 130 & 3167934 & 3168030 & 97 & $>$ & 14.81 \\
\hline as62 & 1455941 & 1456046 & 106 & $>$ & 15.67 \\
\hline as213 & 5541691 & 5541800 & 110 & $<$ & 15.76 \\
\hline as236 & 5868209 & 5868408 & 200 & $>$ & 21.07 \\
\hline \multicolumn{6}{|c|}{ asRNAs differentially expressed during $\mathrm{NaCl}(0.5 \mathrm{M})$ treatment } \\
\hline as6 & 182516 & 182617 & 102 & $<$ & 0.12 \\
\hline as12 & 291428 & 291543 & 116 & $>$ & 0.16 \\
\hline as19 & 448929 & 449284 & 356 & $>$ & 0.20 \\
\hline as 48 & 1060351 & 1060676 & 326 & $>$ & 0.27 \\
\hline as55 & 1135776 & 1135875 & 100 & $<$ & 0.33 \\
\hline as235 & 5863452 & 5863719 & 268 & $>$ & 0.36 \\
\hline as74 & 1558500 & 1558752 & 253 & $<$ & 0.41 \\
\hline as 84 & 1911985 & 1912118 & 134 & $>$ & 2.55 \\
\hline as214 & 5545002 & 5545131 & 130 & $>$ & 2.71 \\
\hline as116 & 2905849 & 2905976 & 128 & $>$ & 2.78 \\
\hline as 36 & 798624 & 798854 & 231 & $>$ & 3.58 \\
\hline as236 & 5868209 & 5868408 & 200 & $>$ & 4.13 \\
\hline as204 & 5301771 & 5301838 & 68 & $>$ & 6.66 \\
\hline as 130 & 3167934 & 3168030 & 97 & $>$ & 11.83 \\
\hline as62 & 1455941 & 1456046 & 106 & $>$ & 12.37 \\
\hline \multicolumn{6}{|c|}{ asRNAs differentially expressed during PP (3xMIC) treatment } \\
\hline as6 & 182516 & 182617 & 102 & $<$ & 0.07 \\
\hline as 104 & 2445134 & 2445251 & 118 & $>$ & 0.09 \\
\hline as 48 & 1060351 & 1060676 & 326 & $>$ & 0.25 \\
\hline as94 & 2027457 & 2027571 & 115 & $<$ & 0.29 \\
\hline as19 & 448929 & 449284 & 356 & $>$ & 0.34 \\
\hline as 138 & 3530607 & 3530794 & 188 & $>$ & 0.39 \\
\hline as 43 & 990194 & 990309 & 116 & $<$ & 0.40 \\
\hline as92 & 2012282 & 2012454 & 173 & $>$ & 0.42 \\
\hline as63 & 1474290 & 1474393 & 104 & $<$ & 0.48 \\
\hline as55 & 1135776 & 1135875 & 100 & $<$ & 0.50 \\
\hline as212 & 5532791 & 5532916 & 126 & $<$ & 2.11 \\
\hline as 181 & 4773392 & 4773503 & 112 & $>$ & 2.31 \\
\hline as 44 & 1026460 & 1026563 & 104 & $>$ & 2.36 \\
\hline as 162 & 4156819 & 4156946 & 128 & $<$ & 2.47 \\
\hline as96 & 2113618 & 2113734 & 117 & $<$ & 2.71 \\
\hline as143 & 3542803 & 3542997 & 195 & $>$ & 2.79 \\
\hline aspon $A^{* * * *}$ & 5680819 & 5681167 & 349 & $<$ & 2.83 \\
\hline as 146 & 3612043 & 3612282 & 240 & $>$ & 2.95 \\
\hline as91 & 1954420 & 1954469 & 50 & $<$ & 3.14 \\
\hline as 170 & 4330879 & 4330989 & 111 & $<$ & 4.03 \\
\hline as221 & 5618584 & 5618634 & 51 & $>$ & 4.17 \\
\hline as205 & 5356355 & 5356495 & 141 & $<$ & 4.22 \\
\hline as 16 & 353325 & 353458 & 134 & $>$ & 4.25 \\
\hline as244 & 6157855 & 6157964 & 110 & $<$ & 6.49 \\
\hline as 129 & 3120806 & 3120915 & 110 & $<$ & 21.17 \\
\hline \multicolumn{6}{|c|}{ asRNAs differentially expressed during TET (3xMIC) treatment } \\
\hline as92 & 2012282 & 2012454 & 173 & $>$ & 0.02 \\
\hline as78 & 1698424 & 1698534 & 111 & $>$ & 0.04 \\
\hline as 19 & 448929 & 449284 & 356 & $>$ & 0.05 \\
\hline as 165 & 4242856 & 4242966 & 111 & $<$ & 0.07 \\
\hline as21 & 544658 & 544778 & 121 & $<$ & 0.08 \\
\hline as 12 & 291428 & 291543 & 116 & $>$ & 0.10 \\
\hline
\end{tabular}




\begin{tabular}{|c|c|c|c|c|c|}
\hline as 6 & 182516 & 182617 & 102 & $<$ & 0.13 \\
\hline as26 & 659114 & 659270 & 157 & $>$ & 0.14 \\
\hline as61 & 1400645 & 1400720 & 76 & $>$ & 0.15 \\
\hline as 217 & 5584935 & 5585163 & 229 & $<$ & 0.15 \\
\hline as94 & 2027457 & 2027571 & 115 & $<$ & 0.16 \\
\hline $\operatorname{aspon} A^{* \star \star *}$ & 5680819 & 5681167 & 349 & $<$ & 0.18 \\
\hline as31 & 748895 & 749047 & 153 & $<$ & 0.20 \\
\hline as 120 & 2982707 & 2982848 & 142 & $<$ & 0.24 \\
\hline as42 & 977508 & 977658 & 151 & $>$ & 0.25 \\
\hline as 157 & 4048252 & 4048377 & 126 & $>$ & 0.26 \\
\hline as53 & 1119615 & 1119886 & 272 & $>$ & 0.26 \\
\hline as29 & 701233 & 701489 & 257 & $<$ & 0.28 \\
\hline as9 & 263722 & 263909 & 188 & $<$ & 0.31 \\
\hline as23 & 557312 & 557569 & 258 & $>$ & 0.33 \\
\hline as192 & 5049739 & 5049879 & 141 & $<$ & 0.36 \\
\hline as 250 & 6247796 & 6247909 & 114 & $>$ & 0.40 \\
\hline as 144 & 3592018 & 3592128 & 111 & $>$ & 0.43 \\
\hline as206 & 5375454 & 5375529 & 76 & $<$ & 0.47 \\
\hline as67 & 1499690 & 1499742 & 53 & $<$ & 0.49 \\
\hline as74 & 1558500 & 1558752 & 253 & $<$ & 2.30 \\
\hline as60 & 1394817 & 1395002 & 186 & $>$ & 2.40 \\
\hline as 11 & 290529 & 290665 & 137 & $>$ & 2.43 \\
\hline as 154 & 3944227 & 3944342 & 116 & $<$ & 2.98 \\
\hline as111 & 2756364 & 2756944 & 581 & $<$ & 3.03 \\
\hline as 162 & 4156819 & 4156946 & 128 & $<$ & 3.51 \\
\hline as 104 & 2445134 & 2445251 & 118 & $>$ & 3.72 \\
\hline as163 & 4166790 & 4167046 & 257 & $<$ & 4.18 \\
\hline as239 & 5926819 & 5926963 & 145 & $>$ & 4.37 \\
\hline as 142 & 3540908 & 3541027 & 120 & $>$ & 4.83 \\
\hline as203 & 5296311 & 5296538 & 228 & $<$ & 5.44 \\
\hline as54 & 1135102 & 1135286 & 185 & $<$ & 5.69 \\
\hline as236 & 5868209 & 5868408 & 200 & $>$ & 6.63 \\
\hline as241 & 6090655 & 6090800 & 146 & $>$ & 6.76 \\
\hline as30 & 718785 & 718934 & 150 & $>$ & 6.97 \\
\hline as136 & 3508613 & 3508673 & 61 & $<$ & 7.51 \\
\hline as210 & 5473394 & 5473504 & 111 & $>$ & 7.66 \\
\hline as99 & 2121071 & 2121240 & 170 & $>$ & 7.79 \\
\hline as 107 & 2623295 & 2623503 & 209 & $<$ & 9.26 \\
\hline as25 & 654775 & 654912 & 138 & $>$ & 10.98 \\
\hline as 16 & 353325 & 353458 & 134 & $>$ & 11.47 \\
\hline as64 & 1484863 & 1485037 & 175 & $<$ & 11.74 \\
\hline as216 & 5580862 & 5581109 & 248 & $<$ & 12.15 \\
\hline as 244 & 6157855 & 6157964 & 110 & $<$ & 14.57 \\
\hline as112 & 2759171 & 2759360 & 190 & $<$ & 14.91 \\
\hline as 167 & 4327946 & 4328181 & 236 & $>$ & 16.07 \\
\hline as 88 & 1949036 & 1949142 & 107 & $>$ & 19.62 \\
\hline as117 & 2946138 & 2946205 & 68 & $<$ & 20.08 \\
\hline as 49 & 1066483 & 1066610 & 128 & $>$ & 20.16 \\
\hline as20 & 521726 & 521838 & 113 & $>$ & 21.57 \\
\hline as76 & 1639661 & 1639805 & 145 & $>$ & 24.33 \\
\hline as50 & 1073865 & 1074007 & 143 & $<$ & 25.41 \\
\hline as134 & 3395484 & 3395684 & 201 & $>$ & 26.97 \\
\hline as 47 & 1056103 & 1056248 & 146 & $<$ & 27.11 \\
\hline as115 & 2902292 & 2902391 & 100 & $<$ & 42.28 \\
\hline as247 & 6183216 & 6183389 & 174 & $<$ & 43.19 \\
\hline
\end{tabular}




\begin{tabular}{|c|c|c|c|c|c|}
\hline as92 & 2012282 & 2012454 & 173 & $>$ & 0.07 \\
\hline as165 & 4242856 & 4242966 & 111 & $<$ & 0.08 \\
\hline as42 & 977508 & 977658 & 151 & $>$ & 0.11 \\
\hline as 120 & 2982707 & 2982848 & 142 & $<$ & 0.13 \\
\hline as6 & 182516 & 182617 & 102 & $<$ & 0.14 \\
\hline as78 & 1698424 & 1698534 & 111 & $>$ & 0.16 \\
\hline as 19 & 448929 & 449284 & 356 & $>$ & 0.17 \\
\hline aspon $A^{* \star * *}$ & 5680819 & 5681167 & 349 & $<$ & 0.18 \\
\hline as119 & 2959629 & 2959767 & 139 & $<$ & 0.21 \\
\hline as74 & 1558500 & 1558752 & 253 & $<$ & 0.25 \\
\hline as 12 & 291428 & 291543 & 116 & $>$ & 0.36 \\
\hline as63 & 1474290 & 1474393 & 104 & $<$ & 0.37 \\
\hline as26 & 659114 & 659270 & 157 & $>$ & 0.40 \\
\hline as206 & 5375454 & 5375529 & 76 & $<$ & 0.40 \\
\hline as183 & 4781848 & 4781947 & 100 & $<$ & 0.41 \\
\hline as21 & 544658 & 544778 & 121 & $<$ & 0.45 \\
\hline as200 & 5148538 & 5148668 & 131 & $>$ & 0.47 \\
\hline as31 & 748895 & 749047 & 153 & $<$ & 0.48 \\
\hline as7 & 184720 & 184861 & 142 & $<$ & 2.07 \\
\hline as214 & 5545002 & 5545131 & 130 & $>$ & 2.31 \\
\hline as 77 & 1640773 & 1640948 & 176 & $>$ & 2.36 \\
\hline as195 & 5071575 & 5071963 & 389 & $<$ & 2.40 \\
\hline as 250 & 6247796 & 6247909 & 114 & $>$ & 2.43 \\
\hline as39 & 921673 & 921840 & 168 & $>$ & 2.46 \\
\hline as38 & 898637 & 898918 & 282 & $>$ & 2.53 \\
\hline as 146 & 3612043 & 3612282 & 240 & $>$ & 2.55 \\
\hline as 168 & 4328357 & 4328518 & 162 & $>$ & 2.67 \\
\hline as203 & 5296311 & 5296538 & 228 & $<$ & 2.79 \\
\hline as179 & 4763739 & 4763790 & 52 & $>$ & 2.94 \\
\hline as 176 & 4759525 & 4759686 & 162 & $>$ & 3.38 \\
\hline as233 & 5824524 & 5824599 & 76 & $<$ & 3.67 \\
\hline as107 & 2623295 & 2623503 & 209 & $<$ & 3.75 \\
\hline as182 & 4780416 & 4780494 & 79 & $>$ & 3.80 \\
\hline as247 & 6183216 & 6183389 & 174 & $<$ & 3.82 \\
\hline as 97 & 2113817 & 2113927 & 111 & $<$ & 3.94 \\
\hline as115 & 2902292 & 2902391 & 100 & $<$ & 4.15 \\
\hline as52 & 1098349 & 1098557 & 209 & $>$ & 4.22 \\
\hline as 45 & 1027896 & 1028083 & 188 & $<$ & 4.34 \\
\hline as 27 & 680736 & 680853 & 118 & $<$ & 4.41 \\
\hline as50 & 1073865 & 1074007 & 143 & $<$ & 4.57 \\
\hline as76 & 1639661 & 1639805 & 145 & $>$ & 4.60 \\
\hline as95 & 2113335 & 2113442 & 108 & $<$ & 5.62 \\
\hline as 25 & 654775 & 654912 & 138 & $>$ & 6.19 \\
\hline as138 & 3530607 & 3530794 & 188 & $>$ & 6.37 \\
\hline as64 & 1484863 & 1485037 & 175 & $<$ & 6.41 \\
\hline as99 & 2121071 & 2121240 & 170 & $>$ & 7.55 \\
\hline as110 & 2756154 & 2756267 & 114 & $<$ & 7.72 \\
\hline as62 & 1455941 & 1456046 & 106 & $>$ & 7.76 \\
\hline as 30 & 718785 & 718934 & 150 & $>$ & 8.27 \\
\hline as236 & 5868209 & 5868408 & 200 & $>$ & 9.24 \\
\hline as 130 & 3167934 & 3168030 & 97 & $>$ & 10.13 \\
\hline as 96 & 2113618 & 2113734 & 117 & $<$ & 11.00 \\
\hline as205 & 5356355 & 5356495 & 141 & $<$ & 11.76 \\
\hline as93 & 2027111 & 2027193 & 83 & $<$ & 14.45 \\
\hline as162 & 4156819 & 4156946 & 128 & $<$ & 14.83 \\
\hline as 16 & 353325 & 353458 & 134 & $>$ & 18.51 \\
\hline
\end{tabular}




\begin{tabular}{|c|c|c|c|c|c|}
\hline as71 & 1504553 & 1504676 & 124 & $<$ & 20.05 \\
\hline as 245 & 6158032 & 6158203 & 172 & $<$ & 20.79 \\
\hline as118 & 2959226 & 2959347 & 122 & $>$ & 27.44 \\
\hline as 70 & 1503843 & 1503937 & 95 & $<$ & 30.29 \\
\hline as244 & 6157855 & 6157964 & 110 & $<$ & 37.70 \\
\hline as136 & 3508613 & 3508673 & 61 & $<$ & 41.81 \\
\hline as 20 & 521726 & 521838 & 113 & $>$ & 51.70 \\
\hline as36 & 798624 & 798854 & 231 & $>$ & 104.80 \\
\hline
\end{tabular}

asRNAs differentially expressed during early stationary phase

\begin{tabular}{|c|c|c|c|c|c|}
\hline as6 & 182516 & 182617 & 102 & $<$ & 0.02 \\
\hline as231 & 5799079 & 5799208 & 130 & $>$ & 0.11 \\
\hline as78 & 1698424 & 1698534 & 111 & $>$ & 0.05 \\
\hline as201 & 5274032 & 5274193 & 162 & $>$ & 0.05 \\
\hline as75 & 1588434 & 1588549 & 116 & $<$ & 0.10 \\
\hline as 161 & 4110202 & 4110321 & 120 & $>$ & 0.11 \\
\hline as 190 & 5018832 & 5019000 & 169 & $>$ & 0.11 \\
\hline as44 & 1026460 & 1026563 & 104 & $>$ & 0.13 \\
\hline as 121 & 3005381 & 3005497 & 117 & $<$ & 0.15 \\
\hline as230 & 5785777 & 5785905 & 129 & $<$ & 0.16 \\
\hline as212 & 5532791 & 5532916 & 126 & $<$ & 0.18 \\
\hline as203 & 5296311 & 5296538 & 228 & $<$ & 0.19 \\
\hline as82 & 1790530 & 1790650 & 121 & $>$ & 0.20 \\
\hline as48 & 1060351 & 1060676 & 326 & $>$ & 0.22 \\
\hline as26 & 659114 & 659270 & 157 & $>$ & 0.24 \\
\hline as19 & 448929 & 449284 & 356 & $>$ & 0.26 \\
\hline as7 & 184720 & 184861 & 142 & $<$ & 0.27 \\
\hline as 104 & 2445134 & 2445251 & 118 & $>$ & 0.30 \\
\hline as43 & 990194 & 990309 & 116 & $<$ & 0.31 \\
\hline as 165 & 4242856 & 4242966 & 111 & $<$ & 0.32 \\
\hline as216 & 5580862 & 5581109 & 248 & $<$ & 0.32 \\
\hline as 210 & 5473394 & 5473504 & 111 & $>$ & 0.32 \\
\hline as23 & 557312 & 557569 & 258 & $>$ & 0.32 \\
\hline as74 & 1558500 & 1558752 & 253 & $<$ & 0.35 \\
\hline as81 & 1785747 & 1785881 & 135 & $>$ & 0.36 \\
\hline as21 & 544658 & 544778 & 121 & $<$ & 0.36 \\
\hline as42 & 977508 & 977658 & 151 & $>$ & 0.37 \\
\hline as 138 & 3530607 & 3530794 & 188 & $>$ & 0.44 \\
\hline as235 & 5863452 & 5863719 & 268 & $>$ & 0.47 \\
\hline as144 & 3592018 & 3592128 & 111 & $>$ & 0.48 \\
\hline as55 & 1135776 & 1135875 & 100 & $<$ & 0.49 \\
\hline as94 & 2027457 & 2027571 & 115 & $<$ & 0.49 \\
\hline as9 & 263722 & 263909 & 188 & $<$ & 0.56 \\
\hline as53 & 1119615 & 1119886 & 272 & $>$ & 0.57 \\
\hline as92 & 2012282 & 2012454 & 173 & $>$ & 0.70 \\
\hline as31 & 748895 & 749047 & 153 & $<$ & 0.90 \\
\hline as60 & 1394817 & 1395002 & 186 & $>$ & 1.51 \\
\hline as29 & 701233 & 701489 & 257 & $<$ & 1.70 \\
\hline as67 & 1499690 & 1499742 & 53 & $<$ & 1.83 \\
\hline as214 & 5545002 & 5545131 & 130 & $>$ & 1.89 \\
\hline as142 & 3540908 & 3541027 & 120 & $>$ & 2.00 \\
\hline as 143 & 3542803 & 3542997 & 195 & $>$ & 2.09 \\
\hline as200 & 5148538 & 5148668 & 131 & $>$ & 2.39 \\
\hline as111 & 2756364 & 2756944 & 581 & $<$ & 2.77 \\
\hline as38 & 898637 & 898918 & 282 & $>$ & 2.91 \\
\hline as84 & 1911985 & 1912118 & 134 & $>$ & 3.18 \\
\hline as68 & 1502841 & 1502987 & 147 & $<$ & 3.27 \\
\hline
\end{tabular}




\begin{tabular}{|c|c|c|c|c|c|}
\hline as204 & 5301771 & 5301838 & 68 & $>$ & 3.64 \\
\hline as 110 & 2756154 & 2756267 & 114 & $<$ & 3.67 \\
\hline as228 & 5725557 & 5725795 & 239 & $>$ & 3.91 \\
\hline as 168 & 4328357 & 4328518 & 162 & $>$ & 3.91 \\
\hline as 157 & 4048252 & 4048377 & 126 & $>$ & 4.10 \\
\hline as 101 & 2314771 & 2314932 & 162 & $<$ & 4.12 \\
\hline as194 & 5055132 & 5055185 & 54 & $>$ & 4.31 \\
\hline as 158 & 4070600 & 4070735 & 136 & $>$ & 4.60 \\
\hline as 169 & 4329401 & 4329645 & 245 & $>$ & 5.21 \\
\hline as112 & 2759171 & 2759360 & 190 & $<$ & 5.25 \\
\hline as197 & 5101107 & 5101200 & 94 & $<$ & 5.35 \\
\hline as249 & 6245830 & 6245973 & 144 & $>$ & 7.19 \\
\hline as99 & 2121071 & 2121240 & 170 & $>$ & 7.48 \\
\hline as 135 & 3414435 & 3414491 & 57 & $<$ & 7.76 \\
\hline as 173 & 4619821 & 4619903 & 83 & $<$ & 7.97 \\
\hline as 177 & 4760853 & 4760902 & 50 & $>$ & 8.22 \\
\hline asdna $A^{\star \star \star \star ~}$ & 1656 & 1813 & 158 & $<$ & 8.70 \\
\hline as62 & 1455941 & 1456046 & 106 & $>$ & 9.45 \\
\hline as238 & 5897008 & 5897057 & 50 & $>$ & 11.15 \\
\hline as239 & 5926819 & 5926963 & 145 & $>$ & 11.43 \\
\hline as195 & 5071575 & 5071963 & 389 & $<$ & 12.18 \\
\hline as218 & 5585580 & 5585652 & 73 & $>$ & 12.18 \\
\hline as 148 & 3626660 & 3626776 & 117 & $<$ & 12.90 \\
\hline as 147 & 3625886 & 3625995 & 110 & $<$ & 14.45 \\
\hline as221 & 5618584 & 5618634 & 51 & $>$ & 14.92 \\
\hline as 11 & 290529 & 290665 & 137 & $>$ & 15.87 \\
\hline as 182 & 4780416 & 4780494 & 79 & $>$ & 16.64 \\
\hline as 176 & 4759525 & 4759686 & 162 & $>$ & 17.15 \\
\hline as34 & 784213 & 784303 & 91 & $<$ & 18.57 \\
\hline as8 & 226915 & 226976 & 62 & $<$ & 18.59 \\
\hline as 151 & 3752069 & 3752155 & 87 & $>$ & 20.20 \\
\hline as105 & 2550592 & 2550780 & 189 & $<$ & 20.43 \\
\hline as196 & 5071970 & 5072154 & 185 & $<$ & 21.03 \\
\hline as 141 & 3540497 & 3540593 & 97 & $>$ & 21.54 \\
\hline as232 & 5817430 & 5817493 & 64 & $<$ & 22.70 \\
\hline as 133 & 3357890 & 3357996 & 107 & $>$ & 23.80 \\
\hline as186 & 4925623 & 4925733 & 111 & $>$ & 23.83 \\
\hline as114 & 2818927 & 2819159 & 233 & $>$ & 24.56 \\
\hline as 149 & 3631510 & 3631629 & 120 & $<$ & 25.52 \\
\hline as89 & 1953270 & 1953371 & 102 & $<$ & 28.32 \\
\hline as 87 & 1916046 & 1916172 & 127 & $<$ & 28.79 \\
\hline as 178 & 4761521 & 4761592 & 72 & $>$ & 29.29 \\
\hline as223 & 5678557 & 5678652 & 96 & $>$ & 30.13 \\
\hline as227 & 5720268 & 5720351 & 84 & $>$ & 33.56 \\
\hline as199 & 5141781 & 5141969 & 189 & $>$ & 34.59 \\
\hline as237 & 5896925 & 5897003 & 79 & $>$ & 39.97 \\
\hline as 145 & 3593054 & 3593188 & 135 & $<$ & 42.93 \\
\hline as242 & 6135711 & 6135789 & 79 & $<$ & 45.32 \\
\hline as109 & 2705716 & 2705781 & 66 & $<$ & 50.81 \\
\hline as 13 & 299094 & 299181 & 88 & $>$ & 57.43 \\
\hline as56 & 1141250 & 1141364 & 115 & $<$ & 66.44 \\
\hline as 137 & 3517655 & 3517722 & 68 & $>$ & 67.12 \\
\hline as229 & 5739066 & 5739203 & 138 & $>$ & 72.49 \\
\hline as 108 & 2701170 & 2701296 & 127 & $<$ & 61.53 \\
\hline as122 & 3013744 & 3013890 & 147 & $>$ & 55.57 \\
\hline as28 & 697609 & 697703 & 95 & $<$ & 77.29 \\
\hline
\end{tabular}




\begin{tabular}{|c|c|c|c|c|c|}
\hline as 164 & 4185534 & 4185601 & 68 & $<$ & 70.65 \\
\hline as3 & 15121 & 15215 & 95 & $<$ & 128.92 \\
\hline as189 & 5002347 & 5002404 & 58 & $<$ & 71.99 \\
\hline as226 & 5699012 & 5699062 & 51 & $<$ & 77.00 \\
\hline as59 & 1323807 & 1323918 & 112 & $>$ & 70.06 \\
\hline as159 & 4087208 & 4087269 & 62 & $>$ & 73.52 \\
\hline as222 & 5655041 & 5655112 & 72 & $<$ & 79.82 \\
\hline as172 & 4616918 & 4616968 & 51 & $<$ & 92.70 \\
\hline
\end{tabular}

* Coordinates and length of the sRNAs predicted by RNA-Seq data.

** The fold change is calculated as the ratio of the intensities between the treated condition and the untreated control. Thus a fold change $>1$ indicates that the sRNA is significantly more expressed in the treated condition.

${ }^{* * *}$ Coordinates validated by 5 'and 3 '-RACE experiments. 
Supplementary Figure 1. 5'RACE strategy used to identify 5'ends of primary and processed transcripts.
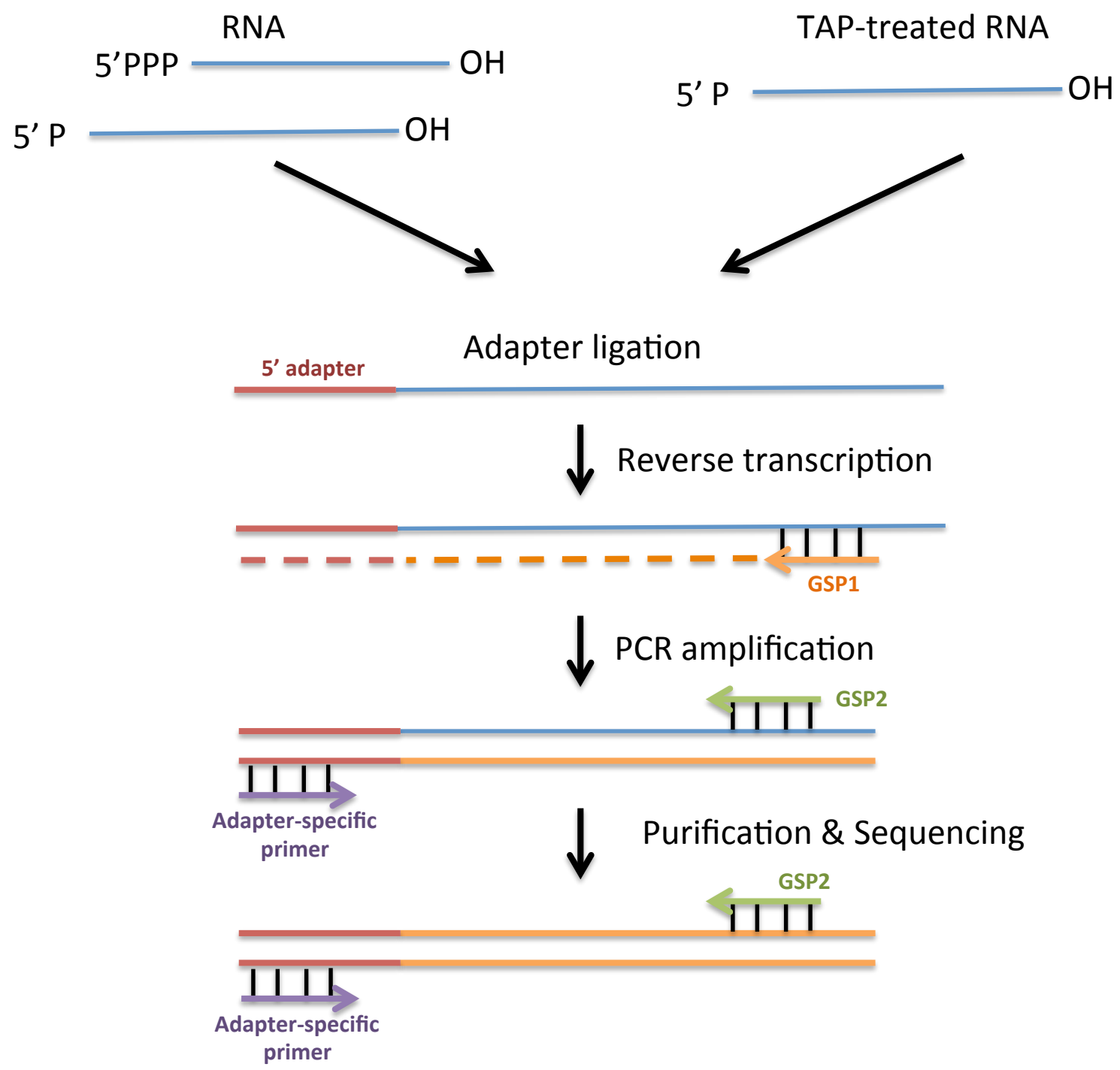
Supplementary Figure 2. 3'RACE strategy used to identify 3'ends of transcripts.

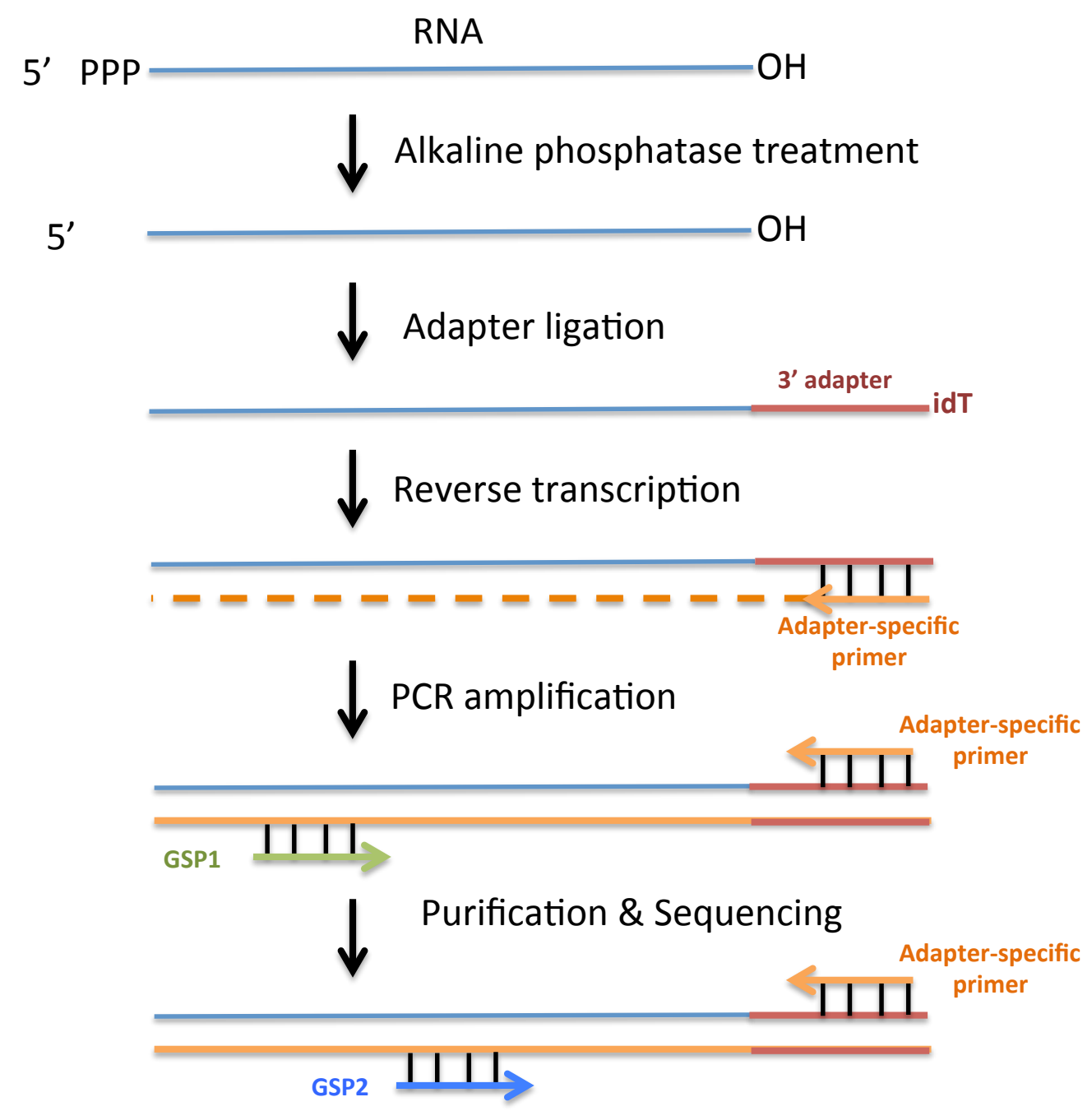




\section{Article 4}

Small RNA OsiS links oxidative stress to quorum sensing control in Pseudomonas aeruginosa

Gómez-Lozano, M. \& Molin, S.

Manuscript in preparation, 2013. 


\title{
Small RNA OsiS links oxidative stress to quorum sensing control in Pseudomonas aeruginosa
}

\author{
María Gómez-Lozano ${ }^{1,2}$ and Søren Molin ${ }^{1,2 *}$ \\ Department of Systems Biology, Technical University of Denmark, Lyngby, Denmark. \\ ${ }^{2}$ Novo Nordisk Foundation Center for Biosustainability, Technical University of Denmark, \\ Hørsholm, Denmark.
}

*To whom correspondence should be addressed (e-mail: sm@bio.dtu.dk).

\begin{abstract}
Small RNAs are known to control diverse adaptation processes, where bacterial physiology is adjusted in response to environmental cues. In this study we investigated the role of sRNA OsiS that was recently identified in genome-wide search of sRNAs in $P$. aeruginosa. OsiS is highly transcribed during oxidative stress conditions. We show that by inducing the expression of OsiS the levels of the sRNA PhrS are greatly reduced. PhrS activates the translation of PqsR under low oxygen concentrations, which in turn activates the synthesis of PQS. Thus, OsiS links the oxygen levels to the production of quorum sensing (QS) molecules. We hypothesize that the interaction is by direct base-pairing between the two sRNAs, with a predicted recognition site of OsiS at the highly conserved-region of PhrS. However, more experiments are required to know the exact nature of the interaction between these two sRNAs. OsiS is, to the best of our knowledge, the first sRNA whose main function seems to be regulating the cellular levels of another sRNA.
\end{abstract}

\section{INTRODUCTION}

The opportunistic human pathogen Pseudomonas aeruginosa can cause severe infections, particularly in immuno-compromised and cystic fibrosis (CF) patients. Despite aggressive antibiotic therapy, a high number of
CF patients suffer from chronic $P$. aeruginosa infections. The establishment of a chronic infection requires a high level of adaptation of the pathogen to the host environment $(1,2)$.

During the last decade many novel small regulatory RNAs (sRNAs) have been described 
in different bacteria, including Escherichia coli, Listeria monocytogenes, Staphylococcus aureus, Helicobacter pylori, Vibrio cholerae and Pseudomonas aeruginosa (3-8). In $P$. aeruginosa, sRNAs are known to be involved in the regulation of virulence genes (RsmY/Z), carbon catabolite repression ( $\mathrm{CrcZ})$, iron metabolism (PrrF1, PrrF2, PrrH), and quorum sensing (PhrS) (9-13). Recently, we identified more than 500 novel intergenic sRNAs (8) and more than 200 novel antisense transcripts (unpublished data) using different RNA-Seq library protocols (14). Following this study, we used RNA-Seq to study the transcriptional response of $P$. aeruginosa under different stress conditions, including osmotic, oxidative and antibiotic stress (unpublished data). In this study we show that one of the novel sRNAs (named pant67 in (8) and OsiS in this study) is highly expressed during oxidative stress, and that its role is to downregulate the sRNA PhrS.

PhrS is a 213-nt long sRNA, predicted by biocomputation $(15,16)$ and isolated by an RNomics approach (7). PhrS is highly transcribed under low oxygen conditions, and its expression requires the oxygen-responsive regulator ANR (13). PhrS activates the translation of the pqsR gene by base-pairing with a short untranslated open reading frame (uof) to which the $p q s R$ gene is translationally coupled (13). PqsR is one of the key QS regulators in $P$. aeruginosa and its synthesis induces the $\mathrm{PQS}$ synthetic operon pqsABCDE $(17,18)$. Beside its function in inter-bacterial signaling, $P Q S$ is required for full synthesis of the $P$. aeruginosa virulence factor pyocianin, which can react with molecular oxygen to generate oxidative stress (19). In addition to its function as a regulatory RNA, PhrS encodes a highly conserved 37 amino-acid peptide (7). The peptide contains a predicted transmembrane segment and sub-cellular fractionation revealed that the peptide is indeed located in the cytoplasmic membrane. Sonnleitner et al. (2011) performed a BLASTN search with the DNA sequence of PhrS to identify homologues. This analysis revealed homologues of PhrS only in 12 different isolates of $P$. aeruginosa (13). Sonnleitner et al. (2011) performed another BLAST search with the amino acid sequence of the peptide encoded by PhrS, and found homologous amino acid sequences in several Pseudomonas species as well as in $A$. vinelandii (13). This analysis identified a highly conserved region of $12 \mathrm{nt}$ downstream of the internal ORF of PhrS (13). In this study we show that the transcription of OsiS RNA is activated during oxidative stress, and that by inducing the expression of OsiS the levels of the sRNA PhrS are greatly reduced.

\section{MATERIALS AND METHODS}

\section{Primers and adapters}

Supplementary Table S1 lists all primers and adapters used in this study.

\section{Plasmid construction}

The plasmids used in this study are listed in Table 1. Plasmids for L-arabinose-inducible expression of asRNAs were constructed by amplification of plasmid pBAD33 (20) with primers F1-Sacl and R1 producing a PCR product of $1250 \mathrm{bp}$ (F1-Sacl introduces a Sacl restriction site). For amplification of the asRNA insert, genomic DNA from strain 
PAO1 was amplified with primers $\mathrm{F} 2$ and R2-Xhol (F2 starts with the sRNA +1 site and R2-Xhol introduces an Xhol restriction site). The $5^{\prime}$ ends of primers $\mathrm{F} 2$ and $\mathrm{R} 1$ are complementary to each other. PCR synthesis by overlap extension (PCRSOE) was carried out by combining the 2 previously amplified products and running PCR for 10 cycles, after which primers F1-Sacl and R2-Xhol are added and the reaction continues for another 30 cycles. The obtained product was digested with Sacl and Xhol and cloned into the MCS of plasmid mini-CTX2 (21).

\section{Bacterial strains}

The bacterial strains used in this study are listed in Table 1. The Pseudomonas aeruginosa PAO1 strain was used as wild-type strain. The E. coli CC118גpir strain was used as cloning host (22). Strains pBADosiS (Figure 2A) and pBAD-control were created by integration of plasmids pBAD-osis and pBADcontrol, respectively, at the attB site of strain PAO1, followed by Flp-mediated excision of the plasmid backbone, as described in (21). The first nucleotide of the transcribed product is the +1 of the primary OsiS. This is an important consideration when cloning noncoding RNAs under the control of heterologous promoters, since altering the natural RNA start site may have unintended consequences for its function. The attB region was sequenced using primers $P_{\text {ser-up }}$ and $P_{\text {ser-down to make sure }}$ that the integration was successful and the plasmid backbone excised.

Table 1. Strains and plasmids used in this study.

\begin{tabular}{|c|c|c|}
\hline Strain or plasmid & Relevant markers/genotype & Source or reference \\
\hline \multicolumn{3}{|l|}{ Strains } \\
\hline P. aeruginosa $\mathrm{PAO} 1$ & Wild type & Laboratory strain \\
\hline P. aeruginosa $\mathrm{pBAD}$-osis & pBAD-osiS fragment integrated at the attP site & This study \\
\hline P. aeruginosa $\mathrm{pBAD}$-control & pBAD-control fragment integrated at the attP site & This study \\
\hline E. coli CC118גpir & araD139 $\Delta$ (ara leu)7697 $\triangle$ lacX74 phoA20 galE galK thi rpsE rpoB argE $(\mathrm{Am})$ recA1 $\lambda$ pir lysogen & Herrero et al (1990) \\
\hline \multicolumn{3}{|c|}{ 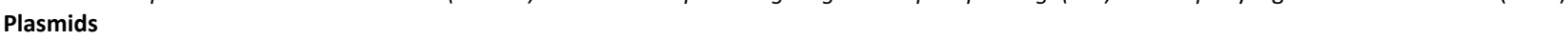 } \\
\hline $\operatorname{mini}-\mathrm{CTX} 2$ & TcR; self-proficient integration vector with tet, $\Omega$-FRT-attP- MCS, ori, int, oriT and lacl & Hoang et al (2000) \\
\hline pBAD33 & CmR, pBAD expression plasmid with pBR322 & Guzman et al (1995) \\
\hline pBAD-osis & TcR; OsiS expression plasmid, osiS is controlled by the plasmid-borne PBAD promoter & This study \\
\hline pBAD-control & TcR; pBAD control plasmid, expresses $322 \mathrm{nt}$ nonsense RNA followed by a terminator & This study \\
\hline pFLP2 & AmpR, source of Flp recombinase & Hoang et al (1998) \\
\hline
\end{tabular}

\section{Growth conditions}

Growth in Luria-Bertani (LB) broth $\left(250 \mathrm{rpm}, 37^{\circ} \mathrm{C}\right)$ or on $\mathrm{LB}$ plates at $37^{\circ} \mathrm{C}$ was used throughout this study.

Stress exposure experiments. Overnight cultures of Pseudomonas aeruginosa PAO1 were diluted to a starting $\mathrm{OD}_{600}$ of 0.01 and grown to an $\mathrm{OD}_{600}$ of 0.5 , at which 3xMIC ciprofloxacin or $1 \mathrm{mM}$ hydrogen peroxide was added. Concentrated stock solutions of $\mathrm{H}_{2} \mathrm{O}_{2}$ and ciprofloxacin were prepared fresh daily. Cells were harvested 1 hour after the addition of ciprofloxacin or hydrogen peroxide. RNA was extracted and used to make RNA-Seq libraries $\mathrm{LIB}<500$. Experiments were performed in duplicates.

Pulse-expression experiments. Overnight cultures of strains pBAD-osiS were diluted to a starting $\mathrm{OD}_{600}$ of 0.01 and grown to an $\mathrm{OD}_{600}$ of 0.5 , at which sRNA expression was induced with $1 \% \mathrm{~L}$-arabinose. Cells were harvested after $30 \mathrm{~min}$ and $45 \mathrm{~min}$ of the induction. RNA was extracted and used to make RNA-Seq libraries LIB $>100$. Two sets of negativecontrol conditions were used for comparison. In one, the control strain pBAD-control was induced with arabinose; in the second, cells containing the pBAD-
osiS construct were grown without arabinose induction. Experiments were performed in duplicates.

\section{RNA isolation}

Harvested cells were mixed immediately with 0.2 volumes of STOP solution $(95 \%$ ethanol, $5 \%$ phenol) and pelleted by centrifugation. Total RNA was extracted with Trizol (Invitrogen). Removal of DNA was carried out by treatment with DNase I (Fermentas) in combination with the RNase inhibitor RiboLock (Fermentas). The integrity of total RNA and DNA contamination were assessed with an Agilent 2100 Bioanalyzer (Agilent Technologies).

\section{Removal of 23S, $16 S$ and $5 S$ rRNAs}

The 23S, 16S and 5S rRNAs were removed by subtractive hybridization using the MICROBExpress kit (Ambion) with modifications as previously described (8) (14). Capture oligonucleotides complementary to the rRNAs of $P$.aeruginosa PAO1 were used (Supplementary Table S1). Briefly, $5 \mu \mathrm{M}$ of each capture oligonucleotide was used, for a total capture oligonucleotide concentration of $25 \mu \mathrm{M}$. 
Compared with the standard protocol, $25 \%$ more capture oligonucleotides and magnetic beads were used. Removal of rRNAs was confirmed with an Agilent 2100 Bioanalyzer (Agilent Technologies).

\section{Library preparation and RNA sequencing}

Two different sequencing libraries (LIB>100 and LIB $<500$ ) were constructed as previously described $(8,14)$. Each library type was prepared with RNA isolated from cells grown in duplicate for each condition studied. After each step the samples were validated using an Agilent 2100 Bioanalyzer (Agilent Technologies), and the final concentration was measured using a Qubit 2.0 Fluorometer (Invitrogen). The libraries were sequenced using the Illumina HiSeq2000 platform with a paired-end protocol and read lengths of $100 \mathrm{nt}$.

$L I B>100$ library. This type of library contains transcripts longer than $100 \mathrm{nt}$ and was prepared using the TruSeq RNA Sample Preparation kit (Illumina) as previously described $(8,14)$. Briefly, the rRNA-depleted RNA is fragmented using divalent cations under elevated temperature. The cleaved RNA fragments are copied into cDNA using reverse transcriptase and random primers, followed by second-strand CDNA synthesis using DNA polymerase $\mathrm{I}$ and RNase $\mathrm{H}$. After this step, transcripts shorter than $100 \mathrm{nt}$ are not retained due to the purification performed with the Agencourt AMPure XP beads (Beckman Coulter Genomics). The cDNA fragments then go through an end repair process, 3 '-addition of single ' $A$ ' bases and adapter ligation. This is followed by product purification and PCR amplification to generate the final CDNA library.

$L I B<500$ library. This type of library is strand-specific and contains transcripts shorter than $500 \mathrm{nt}$. RNA size selection was performed by running total RNA on $10 \%$ polyacrylamide gels containing $10 \mathrm{M}$ urea. Gel slices corresponding to RNAs up to 500 nt were excised, followed by elution of RNA in $0.4 \mathrm{M} \mathrm{NaCl}$ and precipitation with ethanol. The 5S rRNA was depleted as previously described, followed by treatment with Tobacco Acid Pyrophosphatase (Epicentre Technologies) at $37^{\circ} \mathrm{C}$ for $90 \mathrm{~min}$. Tobacco Acid Pyrophosphatase (TAP) is used to convert 5'-triphosphate RNA into 5'-monophosphate RNA, which is important for correct adapter ligation. This was followed by treatment with RNase III (Ambion) for $10 \mathrm{~min}$ at $37^{\circ} \mathrm{C}$ to fragment the RNA. RNase III fragments RNA into smaller pieces containing a 5'-phosphoryl group and a 3'-hydroxyl group, which is important for specific adapter ligation in the next step. Sequential ligation of RNA $3^{\prime}$ and $5^{\prime}$ adapters was performed using the adapters and enzymes from the TruSeq Small RNA Sample Preparation kit (Illumina). Next, reverse transcription followed by PCR amplification was performed to form cDNA constructs based on the
RNA fragments ligated with $3^{\prime}$ and $5^{\prime}$ adapters, selectively enriching fragments with adapter molecules on both ends. The reverse transcription and subsequent PCR amplification were performed using the enzymes and reagents from the TruSeq Small RNA Sample Preparation kit (Illumina). Agencourt AMPure XP beads (Beckman Coulter Genomics) were used for the post-PCR clean-up. In this type of library the fragments corresponding to transcripts shorter than $100 \mathrm{nt}$ are retained due to ligated RNA adapters that increase the length of the fragments by $125 \mathrm{nt}$.

\section{Data analysis}

Our analysis pipeline is described in detail in Gómez-Lozano et al (2013) (14).

Briefly, sequencing reads were mapped onto the $P$. aeruginosa PAO1 genome using the Bowtie 2 short read aligner (23). Read alignments from Bowtie 2 were handled using SAMtools (24). In order to obtain normalized expression intensities of the read coverage depth at each position in the genome, the number of reads in each replicate was normalized according to the total number of reads in the library, and expression intensities from replicate samples were averaged. A two-sample Student's $t$-test was performed on the average expression of the transcripts to determine those with differential expression between the conditions tested ( $P$-value $<0.05)$.

\section{Rapid Amplification of cDNA Ends (RACE)}

Schematic representations of the $5^{\prime}$ and $3^{\prime}$ RACE protocols can be seen in Supplementary Figures 1 and 2. Supplementary Table 1 lists primers and adapters used.

5' RACE. $2 \mu \mathrm{g}$ rRNA-depleted RNA was incubated with $10 \mathrm{U}$ of Tobacco Acid Pyrophosphatase (Epicentre Technologies) at $37^{\circ} \mathrm{C}$ for $1 \mathrm{~h}$ to convert RNA $5^{\prime}$ triphosphates in $5^{\prime}$ monophosphates. The same amount of control RNA was incubated under the same conditions in the absence of the enzyme. Reactions were stopped by phenol-chloroform extraction, followed by etanol-sodium acetate precipitation. Precipitated RNAs were redissolved in water, mixed with 500 pmol of $5^{\prime}$ RNA adapter, heat-denatured at $95^{\circ} \mathrm{C}$ for $5 \mathrm{~min}$, then quick-chilled on ice. A short RNA adapter was ligated was ligated with $50 \mathrm{U}$ of T4 RNA ligase (Thermo Scientific) at $37^{\circ} \mathrm{C}$ for $1 \mathrm{~h}$. Reactions were stopped by phenolchloroform extraction, followed by ethanol-sodium acetate precipitation. Precipitated RNAs were redissolved in $20 \mu \mathrm{l}$ water. Then $10 \mu \mathrm{l}$ of 5 'adapterligated RNA was reverse-transcribed using 2 pmol of primer complementary to the sRNA (5'-GSP1) and the Thermoscript RT-PCR system (Invitrogen) according to the manufacturer's instructions. Reverse transcription (RT) was performed in three 
subsequent $20 \mathrm{~min}$ steps at $55^{\circ} \mathrm{C}, 60^{\circ} \mathrm{C}$, and $65^{\circ} \mathrm{C}$, followed by treatment with RNase $\mathrm{H}$. Primers were removed using the NucleoSpin Gel and PCR Cleanup kit (Macherey-Nagel). The products of RT were amplified using 10 pmol of another primer complementary to the sRNA (5'-GSP2) and $10 \mathrm{pmol}$ the $5^{\prime}$ adapter-specific primer, together with the Maxima Hot Start PCR Master Mix (Thermo Scientific) according to the manufacturer's instructions. Negative controls were performed using the $5^{\prime}$ adapter-ligated RNA as template. The PCR products were resolved and purified using EGel SizeSelect 2\% Agarose gels (Invitrogen). Products were sequenced with $5^{\prime}$-GSP2 and $5^{\prime}$ adapter-specific primers by LGC Genomics $\mathrm{GmbH}$ (Germany).

3' RACE. $2 \mu \mathrm{g}$ rRNA-depleted RNA was dephosphorylated with calf intestinal alkaline phosphatase (New England Biolabs) at $37^{\circ} \mathrm{C}$ for $1 \mathrm{~h}$. Reactions were stopped by phenol-chloroform extraction, followed by etanol-sodium acetate precipitation. Ligation was done as above with a 3' RNA adapter with a $3^{\prime}$-inverted deoxythymidine (3'idT). RT was carried out as described, but with 10 pmol of a single primer complementary to the $3^{\text {' }}$ RNA adapter. PCR amplification, band purification and sequence analysis was done as described above. All enzymatic treatments of RNA were performed in the presence of 20 units of RiboLock RNase Inhibitor (Thermo Scientific).

\section{Quantitative reverse transcriptase PCR ( $q R T-P C R)$}

DNase-treated total RNA was reverse transcribed using gene-specific primers and the ThermoScript RT-PCR System (Invitrogen). Quantitative PCR was run using the Brilliant III Ultra-Fast SYBR Green qPCR Master Mix (Stratagene), the Strategene Mv3005P equipment and MxPro qPCR software. 5S rRNA gene was used as the normalizer. Three independent sets of experiments were performed. In all cases, controls lacking reverse transcriptase were included to assess DNA contamination.

\section{RESULTS}

\section{OsiS is expressed under oxidative stress} conditions.

In a recent study, we found more than 500 novel intergenic sRNAs (8) and more than 200 novel antisense transcripts (unpublished data) using different RNA-Seq library protocols (14). Following this study, we used RNA-Seq to study the transcriptional response of $P$. aeruginosa under different stress conditions, including osmotic, oxidative and antibiotic stress (unpublished data). It was discovered that one of the novel sRNAs, OsiS, is highly expressed following ciprofloxacin (CIP) and hydrogen peroxide $\left(\mathrm{H}_{2} \mathrm{O}_{2}\right)$ treatment. Ciprofloxacin is a fluoroquinolone antibiotic commonly used against $P$. aeruginosa infections. Ciprofloxacin inhibits DNA topoisomerase II and DNA topoisomerase IV activities, eventually leading to bacterial cell death. In addition, an increase of reactive oxygen species (ROS) in the bacterial cells in response to ciprofloxacin has been shown $(25,26)$. Hydrogen peroxide is a common ROS produced by the host immune system, which $P$. aeruginosa exogenously encounters during infection (27-29). In our experiments, OsiS expression was not activated during exposure to $\mathrm{NaCl}$, ß-lactams (piperacillin, ceftazidime, aztreonam, meropenem), aminoglycosides (tobramycin), macrolides (azithromycin), colistin or tetracycline. These results indicate that OsiS is activated during oxidative stress, as caused by $\mathrm{H}_{2} \mathrm{O}_{2}$ and ciprofloxacin. As seen in Figure 1B the levels of OsiS are higher after CIP exposure (fold change 99.99 \pm 36.37 ) than after $\mathrm{H}_{2} \mathrm{O}_{2}$ (fold change $9.34 \pm 0.04$ ). This is most likely due to the concentration of CIP and $\mathrm{H}_{2} \mathrm{O}_{2}$ used in the experiments, which was lethal in the case of CIP (3xMIC, 0,375 $\mu \mathrm{g} / \mathrm{ml})$ and sub-lethal in the case of $\mathrm{H}_{2} \mathrm{O}_{2}(1 \mathrm{mM})$. 


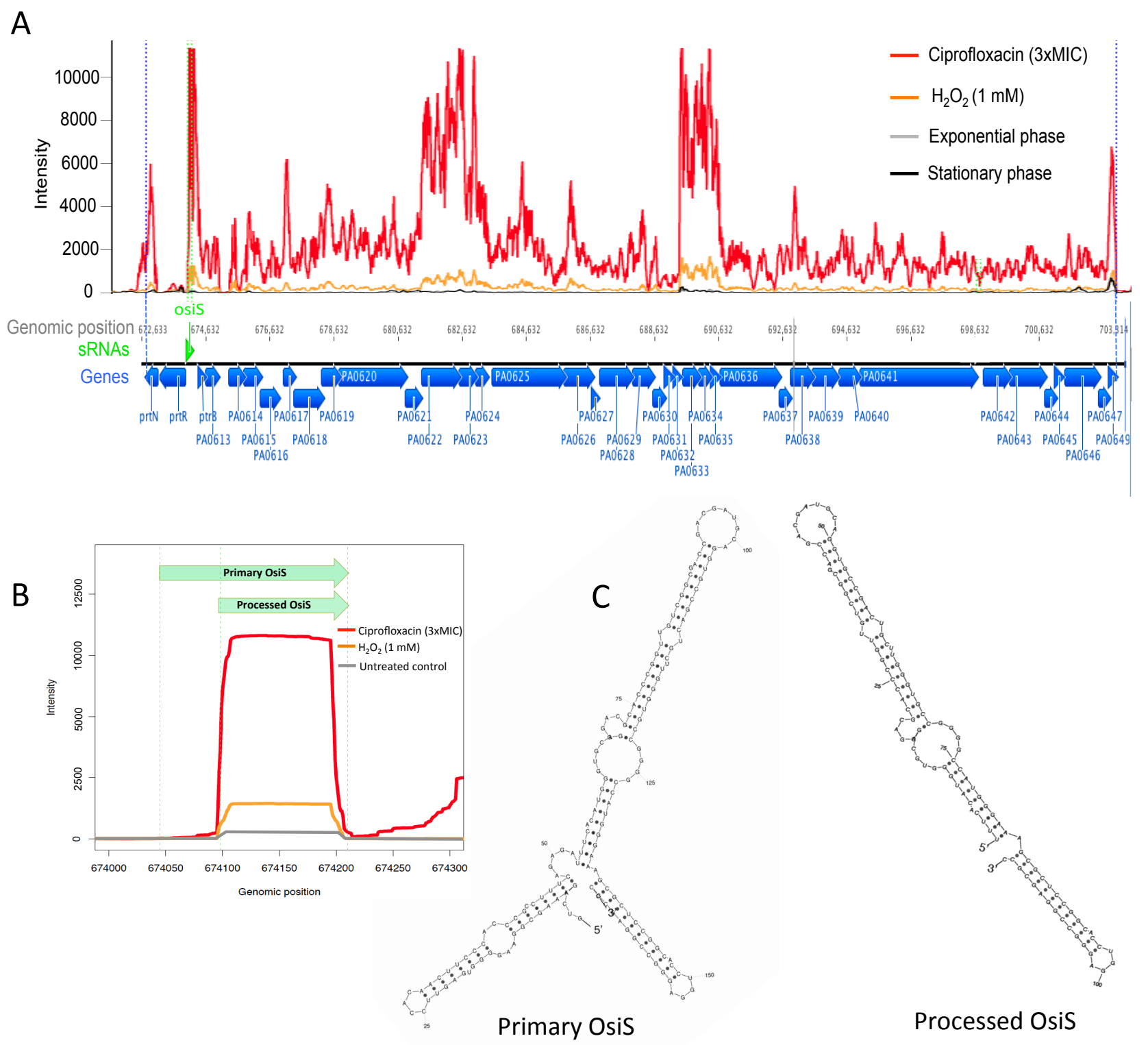

Figure 1. Changes in transcriptional response upon ciprofloxacin (3xMIC) and hydrogen peroxide (1 mM) treatment. A. The PAO1 R- and F- type pyocin loci. All the pyocin locus, with the exception of the pyocin repressor gene prtR, are upregulated upon ciprofloxacin and hydrogen peroxide treatment. The osiS gene (green arrow) is located between the genes prtR and prtB. B. Changes in expression of OsiS upon ciprofloxacin (3xMIC) and hydrogen peroxide $(1 \mathrm{mM})$ treatment. The coordinates of the primary and processed versions of OsiS (assessed by $5^{\prime}$-RACE) are marked with green arrows. C. Predicted secondary structures of OsiS (primary and processed) predicted with sfold (30).

\section{Pulse-expression of OsiS leads to down- regulation of PhrS.}

The osiS gene is located in between the genes prtR and prtB in the R- and F- type pyocin loci. The R- and F-type pyocin loci are upregulated upon $\mathrm{H}_{2} \mathrm{O}_{2}$ and CIP treatment with fold changes similar as those of OsiS (Figure 1A). Pyocins are bacteriocins produced by $P$. aeruginosa that have been shown to kill both a diversity of $P$. aeruginosa strains in addition to a number of Campylobacter species $N$. gonorrhea, $N$. 
meningiditis, $H$. ducreyi, $P$. fluorescens, P.putida and B. cepacia complex (31-36). Some $P$. aeruginosa strains do not produce both R- and F- types of pyocins, however all known strains produce at least one of the two types $(37,38)$. DNA damage, and therefore the bacterial SOS response, is believed to trigger the induction of pyocins. Some studies have shown that the R- and F- type pyocin genes are upregulated during both lethal and sublethal treatment with CIP (39) and during $\mathrm{H}_{2} \mathrm{O}_{2}$ exposure (40).

Based on the above mentioned, our initial hypothesis was that OsiS was involved in the regulation of pyocin production during oxidative stress conditions. To investigate this further, OsiS was pulse-expressed with an inducible promoter and its immediate effects studied by RNA-Seq. In these experiments OsiS expression was restricted to a construct inserted at the attB site containing osiS under the control of the heterologous $\mathrm{pBAD}$ promoter, which is only induced in the presence of arabinose (Figure 2A). Inserting the construct at a specific site of the genome has several advantages over using a plasmid-based system. Since the integration vector used in this study is equipped with FRT sites (see Materials and Methods), it allows Flp-mediated excision of the plasmid backbone. Thus, our engineered strains are devoid of any selection marker and the experiments can be done without using any selective pressure. Different copy-numbers in the strains to be compared can be an issue when working with plasmidbased system, but that represents no problem when working with chromosomal integrations. Furthermore, genomic DNA and plasmid DNA differ in their degree of supercoiling, a state of DNA that has been shown to play a major role in regulation of gene expression (41).
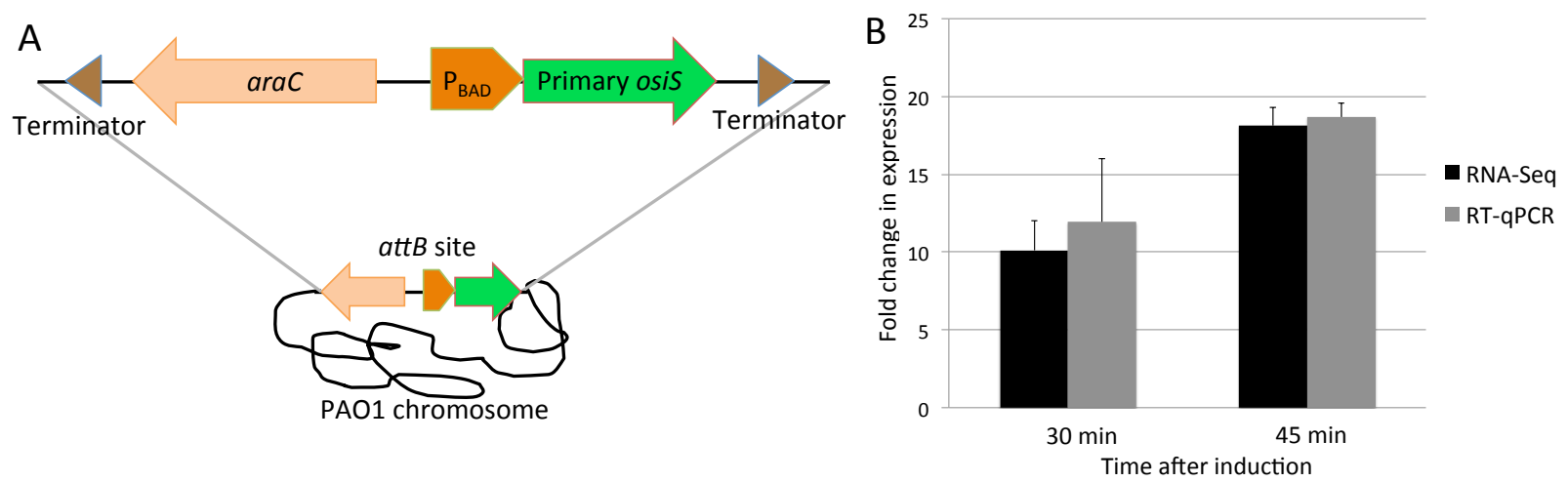

Figure 2. A. The pBAD-osiS construct inserted at the attB site of strain pBAD-osiS. The first nucleotide of the transcribed product is the +1 of the primary OsiS. B. Fold change in OsiS levels after induction with Larabinose. The levels of OsiS were measured both with RNA-Seq and RT-qPCR. 1\% L-arabinose was added to induce the expression of OsiS when $\mathrm{OD}_{600}$ reached 0.5 . The OsiS level was detected after the expression of OsiS was induced for 30 and $45 \mathrm{~min}$. Strain pBAD-control was used as the control. For the RTqPCR experiments, the expression was normalized to the level of 5S rRNA in each sample. 
In pulse-expression analysis, the first nucleotide of the transcribed product should be the +1 of the primary transcript to be pulseexpressed. This is an important consideration when cloning sRNAs under the control of heterologous promoters, since altering the natural RNA start site may have unintended consequences for its function. Thus, $5^{\prime}-$ and $3^{\prime}-$ RACE experiments were performed to accurately map the boundaries of OsiS. From the RNA-Seq data OsiS appeared as a 113-nt transcript (674,098-674,210) (Figure 1B). However, differential 5'-RACE experiments revealed that the start site of OsiS was located $53 \mathrm{bp}$ upstream. This result fitted well with the prediction of -10 and $-35 \sigma^{70}$ promoter elements (Supplementary figure S3). 3'-RACE results were consistent with RNA-Seq data. Thus, the primary transcript of OsiS is 166-nt long (674,045-674,210). The predicted structures of both primary and processed OsiS are shown in Figure 1C. The RNA-Seq data revealed that OsiS was already processed after $30 \mathrm{~min}$ of pulse-expression of the primary transcript of OsiS.

Cells carrying the pBAD-osis construct were grown to mid-log phase in LB and treated with $1 \%$ arabinose for 30 and $45 \mathrm{~min}$, respectively. Two sets of negative-control conditions were used for comparison. In one, the control construct, pBAD-control was induced with arabinose; in the second, cells containing the pBAD-osis construct were grown without arabinose induction. Total RNA was extracted from all cultures and processed for RNA-Seq analysis (see Materials and Methods). The gene expression profiles were compared in two ways: (i) induced pBAD-osiS-containing cells were compared to induced pBAD-controlcontaining cells, and (ii) uninduced pBAD-osiScontaining cells were compared to induced pBAD-osiS-containing cells. The results for the two types of comparisons showed consistent results, with the exception of the expected differences for arabinose-inducible genes. The expression levels of OsiS obtained after induction were investigated both by RT-PCR and RNA-Seq (Figure 2B), obtaining similar results. The fold change of OsiS 30 and $45 \mathrm{~min}$ after the induction were 10.2 and 18.0, respectively. These fold changes are slightly higher than those obtained upon treatment with $1 \mathrm{mM} \mathrm{H}_{2} \mathrm{O}_{2}$.

Table 2 shows the list of genes significantly upor downregulated after 30 and 45 min of pulseexpression of OsiS. The main effect after 30 min was the dramatic downregulation of PhrS levels (fold change -79.7). PhrS activates the translation of the pqsR gene. PqsR is one of the key QS regulators in $P$. aeruginosa and its synthesis induces the PQS synthetic operon pqsABCDE $(17,18)$. In fact, the pqsABCDE genes are downregulated $45 \mathrm{~min}$ after OsiS induction (fold changes between -1.6 and -2.1). Some of the genes controlled by PqsR are also downregulated upon OsiS pulse-expression, with greater effects after 45 min than after 30 min: the phenazines biosynthesis genes phzA1B1, required for pyocianin production (42), and the phnAB genes, encoding the enzymes required to convert chorismate to anthranilate, the PQS precursor (43). Some of 
the genes required for exoenzyme $S$ production are also dowregulated. Interestingly, the genes $r h / l$ and $r h / R$ are also mildly downregulated in our experiments, and it has been shown that PQS induces the transcription of genes rhll and rhIR (44). The outer membrane protein OprG was also more than 2-fold downregulated. Strikingly, only one gene, the polyhydroxyalkanoate synthesis gene phaF, increased its levels after OsiS overexpression. The levels of sRNA P5 are also reduced significantly, but unfortunately the role of this sRNA is still unknown. These results indicate that OsiS provides a link between oxygen levels and QS, by downregulating the levels of the sRNA PhrS during oxidative stress conditions.

Table 2. Transcripts up- and downregulated upon osiS overexpression.

\begin{tabular}{|c|c|c|c|c|c|}
\hline Locus ID & Gene & Description & Pathway & $\begin{array}{l}\text { Fold change } \\
\text { after } 30 \mathrm{~min}\end{array}$ & $\begin{array}{l}\text { Fold change } \\
\text { after } 45 \mathrm{~min}\end{array}$ \\
\hline \multicolumn{6}{|c|}{ Transcripts upregulated upon osiS overexpression } \\
\hline PA0611.1 & osis & Osis & Non-coding RNA gene & +10.2 & +18 \\
\hline PA5060 & phaF & polyhydroxyalkanoate synthesis protein & Central intermediary metabolism & +1.6 & +1.9 \\
\hline \multicolumn{6}{|c|}{ Transcripts downregulated upon osiS overexpression } \\
\hline PA1003 & $m v f R / p q s R$ & Transcriptional regulator MvfR & Transcriptional regulators & -1.3 & -1.4 \\
\hline PA3476 & rhll & autoinducer synthesis protein Rhll & Adaptation, Protection & -1.5 & -1.4 \\
\hline PA1713 & exsA & transcriptional regulator ExsA & Protein secretion/export apparatus; Transcriptional regulators & -1.6 & -1.5 \\
\hline PA1002 & phnB & anthranilate synthase component II & Amino acid biosynthesis and metabolism; Adaptation, Protection & -1.2 & -1.5 \\
\hline PA3477 & $r h / R$ & transcriptional regulator RhIR & Adaptation, Protection; Transcriptional regulators & -1.3 & -1.5 \\
\hline PA1001 & phnA & anthranilate synthase component I & Adaptation, Protection & -1.2 & -1.5 \\
\hline PA1712 & exs $B$ & exoenzyme $\mathrm{S}$ synthesis protein $\mathrm{B}$ & Protein secretion/export apparatus & -1.4 & -1.6 \\
\hline PA1711 & exsE & ExsE & Transcriptional regulators; Protein secretion/export apparatus & -1.6 & -1.6 \\
\hline PA1000 & pqsE & Quinolone signal response protein & Biosynthesis of cofactors, prosthetic groups and carriers & -1.2 & -1.6 \\
\hline PA0999 & $p q s D$ & 3-oxoacyl-[acyl-carrier-protein] synthase III & Biosynthesis of cofactors, prosthetic groups and carriers & -1.1 & -1.7 \\
\hline PA0998 & pqsC & $\mathrm{PqsC}$ & Biosynthesis of cofactors, prosthetic groups and carriers & -1.1 & -1.7 \\
\hline PA0996 & pqsA & probable coenzyme A ligase & Biosynthesis of cofactors, prosthetic groups and carriers & 1 & -1.7 \\
\hline PA1714 & exsD & ExsD & Transcriptional regulators; Protein secretion/export apparatus & -1.5 & -2.1 \\
\hline PA0997 & $p q s B$ & PqsB & Biosynthesis of cofactors, prosthetic groups and carriers & 1 & -2.1 \\
\hline PA1433 & - & conserved hypothetical protein & Membrane proteins & -1.2 & -2.3 \\
\hline PA4132 & - & conserved hypothetical protein & Hypothetical, unclassified, unknown & -1.8 & -2.3 \\
\hline PA4067 & oprG & Outer membrane protein OprG precursor & Membrane proteins & -2.3 & -2.3 \\
\hline PA1699 & pcr1 & Pcr1 & Hypothetical, unclassified, unknown & -1.4 & -2.4 \\
\hline PA5480 & - & hypothetical protein & Hypothetical, unclassified, unknown & -3.7 & -2.4 \\
\hline PA4134 & - & hypothetical protein & Hypothetical, unclassified, unknown & -1.7 & -2.4 \\
\hline PA4211 & phzB1 & probable phenazine biosynthesis protein & Secreted Factors (toxins, enzymes, alginate) & -1.3 & -2.5 \\
\hline PA0026 & $p / c B$ & phospholipase C, PIcB & Hypothetical, unclassified, unknown & -1.3 & -2.8 \\
\hline PA4210 & phzA1 & probable phenazine biosynthesis protein & Secreted Factors (toxins, enzymes, alginate) & -2.2 & -2.8 \\
\hline PA2759 & - & hypothetical protein & Hypothetical, unclassified, unknown & -6.3 & -3 \\
\hline PA2501 & - & hypothetical protein & Membrane proteins & -7.4 & -3.6 \\
\hline PA0836.1 & P5 & P5 & Non-coding RNA gene & -2.8 & -6.6 \\
\hline PA1673 & - & hypothetical protein & Hypothetical, unclassified, unknown & -11.4 & -11.1 \\
\hline PA0200 & - & hypothetical protein & Hypothetical, unclassified, unknown & -32.3 & -18.1 \\
\hline PA1414 & - & hypothetical protein & Hypothetical, unclassified, unknown & -22.6 & -19 \\
\hline PA3305.1 & phrs & PhrS & Non-coding RNA gene & -79.7 & -38.9 \\
\hline
\end{tabular}

OsiS conservation and interaction with PhrS

It is clear from the transcriptomic results that OsiS lowers the levels of PhrS. However, the question of how these two sRNAs interact is not answered by the RNA-Seq data. The interaction could be by direct base-pairing between the sRNAs, or OsiS could be directly affecting some other transcript or protein that regulates PhrS. Sonnleitner et al. (2011) performed a BLASTN search to identify PhrS homologues. This analysis revealed homologues of PhrS in 12 different isolates of 
$P$. aeruginosa (13). Interestingly, the same kind of analysis indicated that OsiS is conserved in the exact same 12 isolates (Figure 3 ). This indicates that OsiS and PhrS have evolved together in the same isolates.
Strain

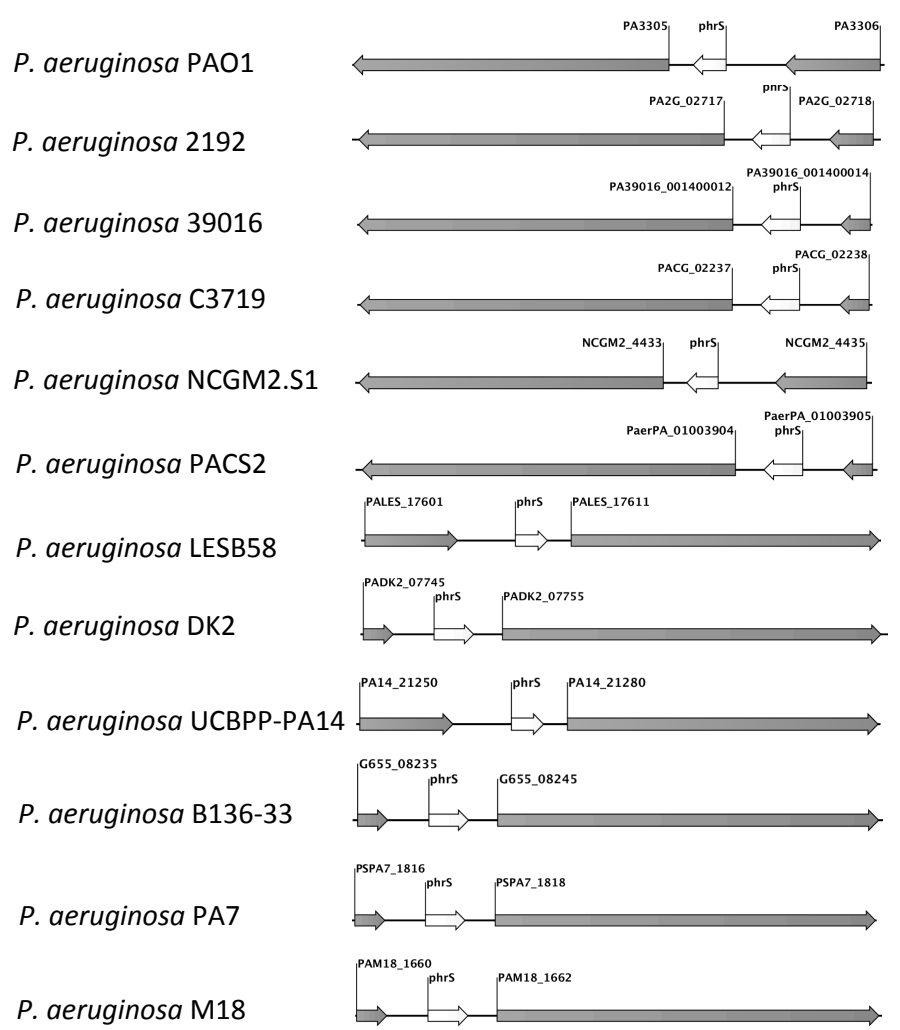

osis

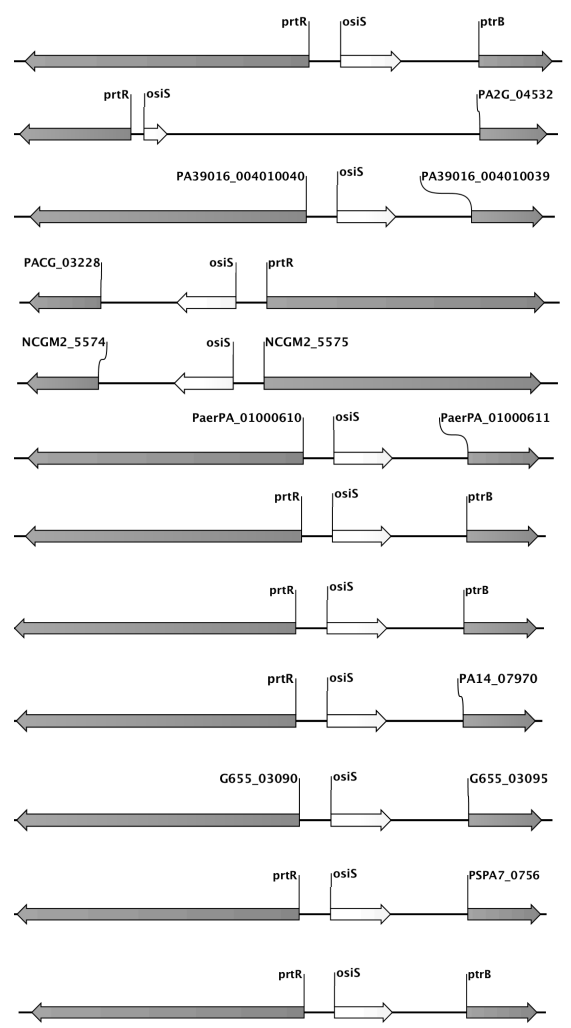

Figure 3. Genetic organization of phrS and osiS regions in all the $P$. aeruginosa strains in which these sRNAs are found. White arrows represent the sRNAs and grey ones represent flanking genes.

To identify a potential annealing site between OsiS and PhrS the IntaRNA program (45) was used. As shown in Figure 4, this analysis predicted a recognition site of OsiS upstream and at the highly conserved-region of PhrS. This highly conserved region of PhrS also base-pairs with the leader sequence of the upstream open reading frame (uof), which is co-transcribed with $p q s R$, activating the translation of PqsR (13). This suggests that the interaction between OsiS and PhrS might be by direct base-pairing. However, more experiments are required to know the exact nature of the interaction between these two sRNAs. 

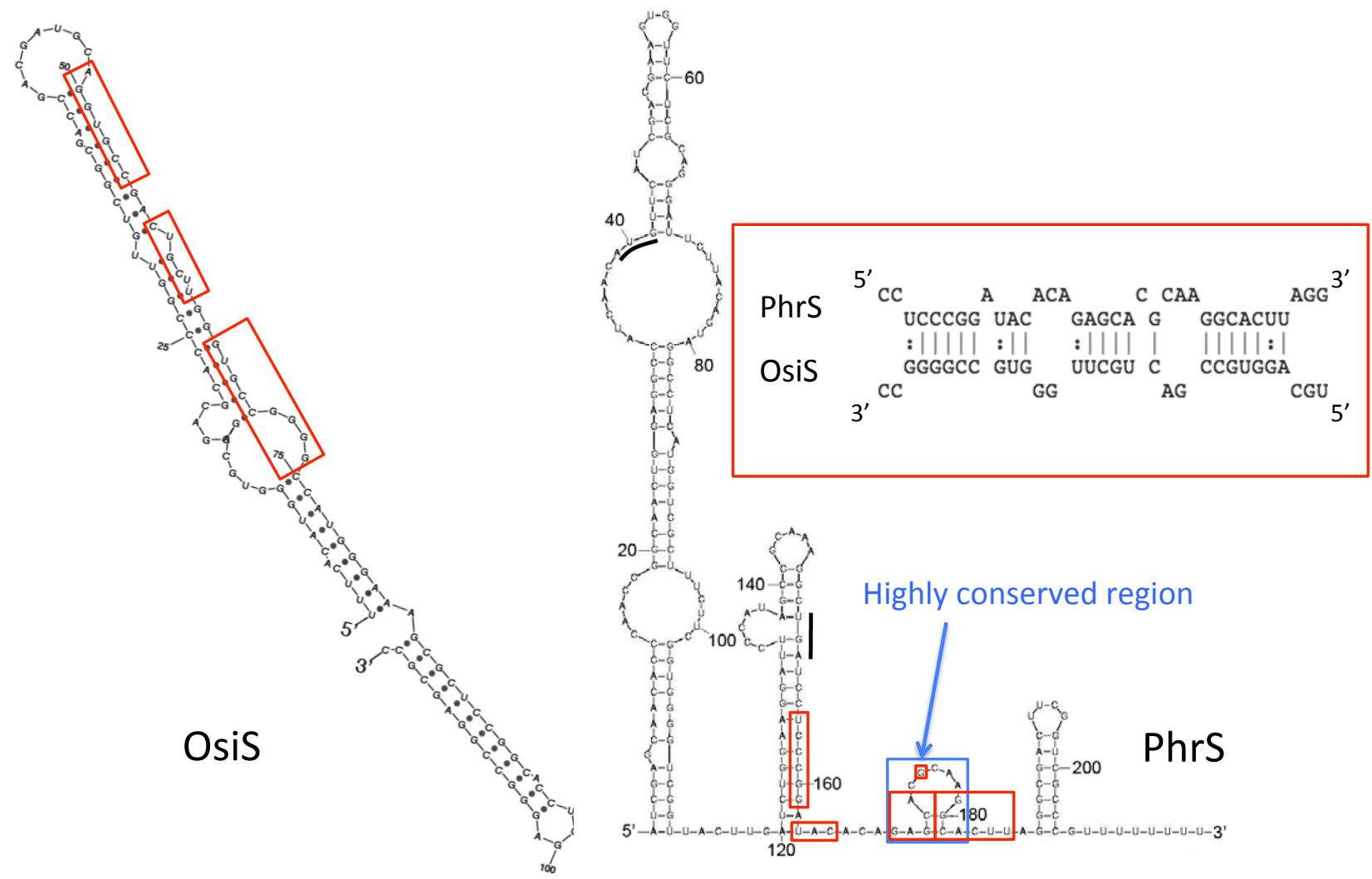

Figure 4. Predicted interaction sites between OsiS and PhrS. The secondary structures of OsiS and PhrS are shown on the left. The structure of PhrS is adapted from (13). The predicted interaction sites were predicted by the IntaRNA algorithm (45) and are boxed in red. The base-pairing interaction is depicted on the right. Part of the highly conserved region of PhrS is required for the interaction. The start and stop codons of the 37-aa peptide encoded by PhrS are underlined in black.

\section{DISCUSSION}

Under conditions that generate oxidative stress, OsiS is highly expressed. We have shown that $30 \mathrm{~min}$ of induction of the expression of OsiS produces a significant downregulation in the levels of PhrS. Also, many of the downregulated genes after $45 \mathrm{~min}$ of induction of OsiS are PqsR-dependent. These results indicate that OsiS provides a link between oxygen levels and QS, by downregulating the levels of the sRNA PhrS during oxidative stress conditions. Thus, OsiS is another sRNA that responds to oxygen levels in bacteria, such as PhrS in $P$. aeruginosa (13), RgsA in P. fluorescens (15), OxyS, FnrS and MicF in $E$. coli (46-49), and RliB in $L$. monocytogenes (50).

The osiS gene is located in the R- and F- type pyocin loci. DNA damage, and therefore the bacterial SOS response, triggers the induction of pyocins. Some studies have shown that the $\mathrm{R}$ - and F- type pyocin genes are upregulated during both lethal and sublethal treatment with CIP (39) and during $\mathrm{H}_{2} \mathrm{O}_{2}$ exposure (40). In our study the R- and F- type pyocin loci are upregulated upon $\mathrm{H}_{2} \mathrm{O}_{2}$ and CIP treatment with 
fold changes similar as those of OsiS. However, OsiS does not seem to be involved in the regulation of pyocin production. It is interesting to note that OsiS is located in a genomic region that gets transcriptionally active during the same conditions as OsiS.

Figure 5 shows our current model of the regulatory function of OsiS. During oxidative stress conditions the sRNA OsiS is transcribed at high levels. The high levels of OsiS induce the downregulation of the sRNA PhrS. In addition, the oxygen-responsive regulator ANR, which is required for PhrS transcription, is not active. On the contrary, during low oxygen conditions, OsiS is not transcribed, ANR is active and PhrS is highly transcribed $(7,13)$. PhrS activates the translation of the pqsR gene. PqsR is one of the key QS regulators in $P$. aeruginosa and its synthesis induces the PQS synthetic operon $(17,18)$. The PhrSmediated stimulation of PQS synthesis leads to an increased production of pyocianin. Pyocianin is a virulence factor that can be reduced by $\mathrm{NAD}(\mathrm{P}) \mathrm{H}$ or glutathione, and in its reduced form can react with oxygen, forming ROS (19). The ROS produced by the synthesis of pyocianin might be a signal that activates OsiS transcription and ANR inactivation, in order to regulate the levels of SRNA PhrS and in consequence the production of PQS.

We have shown that expression of OsiS results in downregulation of PhrS levels, but how do these two sRNAs interact with each other? The interaction could be by direct base-pairing, or OsiS could be directly affecting some other transcript or protein that, in turn, downregulates PhrS. The DNA sequences of OsiS and PhrS are conserved in the same strains of $P$. aeruginosa, indicating that these two sRNAs might have evolved in parallel. We have predicted a recognition site of OsiS upstream and at the highly conserved-region of PhrS. This highly conserved region of PhrS has been shown to base-pair with the leader sequence of the upstream open reading frame of $p q s R$, activating the translation of PqsR (13). Based on this, we hypothesize that OsiS and PhrS interact by direct base-pairing. However, more experiments are required to know the exact nature of the interaction between these two sRNAs. 5'-RACE analysis has shown that OsiS is found in the cell as a processed transcript, which lacks a hairpin of $53 \mathrm{nt}$ at the $5^{\prime}$ end with respect to the primary transcript of OsiS. It would also be interesting to know whether the primary or the processed version of OsiS is the one responsible for the PhrS downregulation. The oxygen-responsive regulator ANR controls the synthesis of PhrS by promoting its transcription during low-oxygen conditions, but is the transcription of PhrS also affected by OsiS in the presence of high-oxygen tension? Or does OsiS affect the stability of PhrS? Also, is the $\mathrm{Hfq}$ chaperone required for the interaction of the two sRNAs? We are currently carrying out experiments to study the steadystate levels of PhrS after OsiS induction, in the presence and absence of $\mathrm{Hfq}$. 


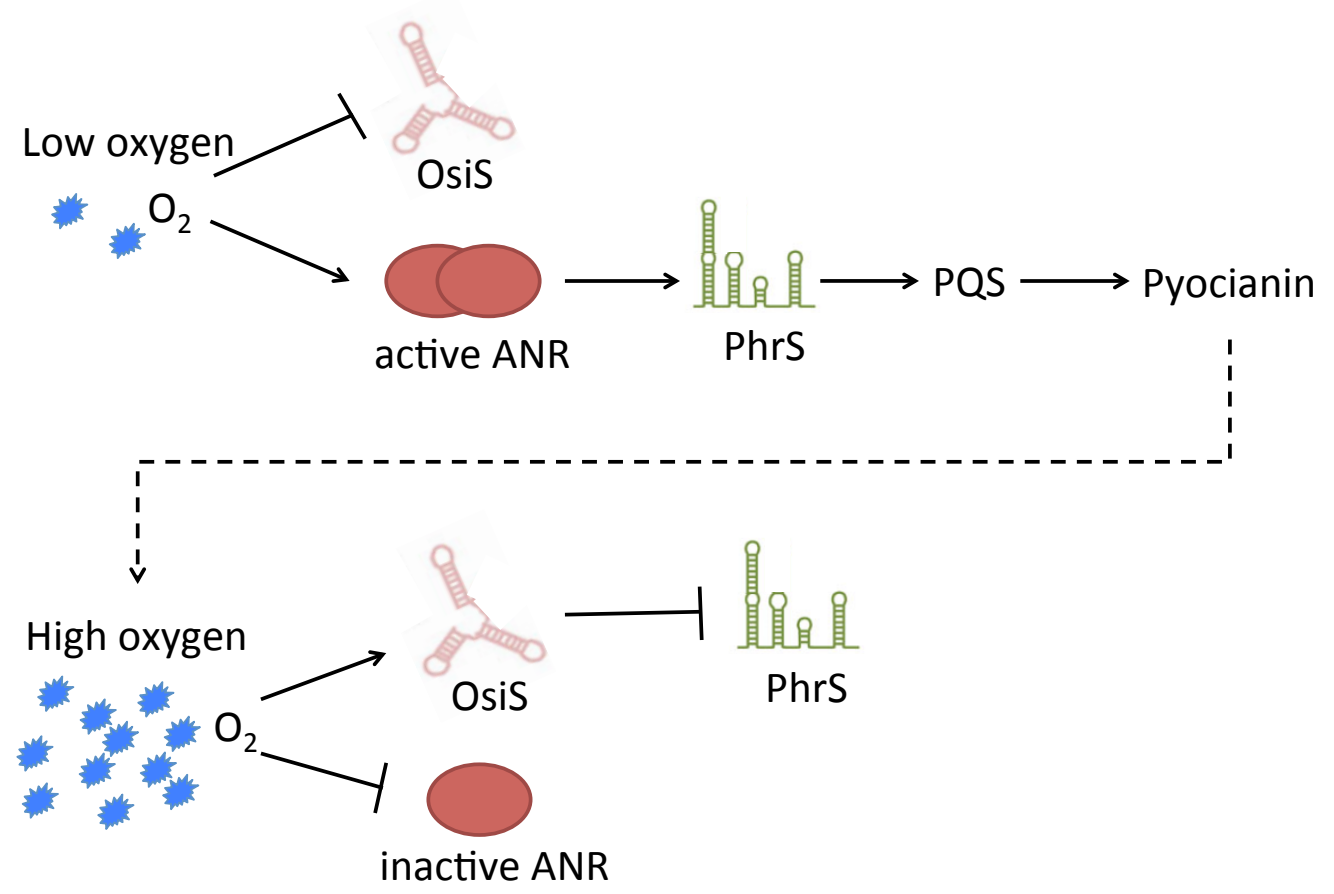

Figure 5. Current model of PhrS regulation by the sRNA OsiS. When oxygen is limited, there is no expression of OsiS and the ANR protein gets activated. The activated ANR is required for the transcription of the phrS gene, which leads to a higher production of PQS. PQS activates the production of pyocianin, which can react with molecular oxygen to generate oxidative stress. Under conditions that generate oxidative stress, OsiS is highly expressed, which produces a severe downregulation in the levels of PhrS. In addition, ANR is not active and does not promote the synthesis of PhrS.

In addition to its function as a regulatory RNA, PhrS encodes a highly conserved 37 aminoacid peptide (7). The peptide contains a predicted transmembrane segment and subcellular fractionation revealed that the peptide is indeed located in the cytoplasmic membrane (7). However, the PhrS peptide does not affect the release of $P Q S$, and it is therefore unknown whether it acts within the same regulatory circuit as the PhrS sRNA or even if it has any cellular function (13). OsiS could be downregulating PhrS in order to lower the levels of the PhrS peptide, and not only affect the PhrS base-pairing function. Moreover, OsiS could be regulating some protein or some other transcripts at the level of translation and therefore its effect could not be assessed by
RNA-Seq. Proteomic analysis are currently being carried out to address these questions.

Under hypoxic conditions, PQS production is limited. PhrS is assumed to counteract the low levels of PQS at reduced or fluctuating oxygen tensions by stimulating the expression of $p q s R$ (13). Thus, the role of SRNA OsiS is to "counteract the counteracting effect" of sRNA PhrS at high oxygen tension. Thus both OsiS and PhrS respond to oxygen levels and allow the fine-tuning of PQS synthesis. So what is the biological implication of oxygen-dependent fine-tuning of PQS? In laboratory conditions, the growth rate of mutants deficient in PhrS production is the same as the wild-type strain, though the deletion mutant produced less 
pyocianin (13). We could not produce a strain lacking the OsiS gene, however overexpression of OsiS does not affect any apparent phenotype. During infection, $P$. aeruginosa is subject to constant shifts in oxygen tension due to the human airway structure, biofilm formation, antibiotic treatment and the host immune response. $P$. aeruginosa faces oxygen limitation when growing in the lower airway mucus of CF patients (51). In addition $P$. aeruginosa can form biofilms that contain multicellular structures that show strong oxygen gradients (52-54). Some antibiotics routinely used against $P$. aeruginosa infections, like ciprofloxacin, produce an increase of ROS in the bacterial cells $(25,26)$. A variety of studies have shown that $P$. aeruginosa encounters ROS in the lungs of CF patients due to the exaggerated, sustained and extended inflammatory response, characterized by influx of neutrophils and high concentrations of interleukin-8 (27-29,55-57). We infer that $P$. aeruginosa most likely needs a tight and fine- tuned regulation of the mechanisms that allow adapting to shifts in oxygen tension, and that the sRNA OsiS is involved in this kind of regulation by responding to high oxygen tension and regulating the levels of sRNA PhrS. Thus, fine-tuning regulators as PhrS and OsiS make no extraordinary difference in controlled and steady laboratory conditions, however we hypothesized that they might be pivotal for a fast and fine-tuned regulation of the mechanisms necessary to survive during adaptation to an environment with such fluctuating levels of oxygen tension as the one inside the host.

\section{ACKNOWLEDGEMENTS}

This work was supported by the Novo Nordisk Foundation and the Danish National Research Agency. Søren D. Pedersen is gratefully thanked for assistance in the design of the cloning strategy.

\section{REFERENCES}

1. Yang L, Jelsbak L, Marvig RL, Damkiær S, Workman CT, Rau MH, et al. Evolutionary dynamics of bacteria in a human host environment. Proc Natl Acad Sci USA. 2011 May 3;108(18):7481-6.

2. Smith EE, Buckley DG, Wu Z, Saenphimmachak C, Hoffman LR, DArgenio DA, et al. Genetic adaptation by Pseudomonas aeruginosa to the airways of cystic fibrosis patients. 2006 May 19;:16.

3. Argaman L, Hershberg R, Vogel J, Bejerano $\mathrm{G}$, Wagner $\mathrm{E}$, Margalit $\mathrm{H}$, et al. Novel small RNA-encoding genes in the intergenic regions of Escherichia coli.
Current Biology. 2001;11(12):941-50.

4. Sittka A, Lucchini S, Papenfort K, Sharma CM, Rolle K, Binnewies TT, et al. Deep Sequencing Analysis of Small Noncoding RNA and mRNA Targets of the Global Post-Transcriptional Regulator, Hfq. PLoS Genet. 2008 Aug 22;4(8):e1000163.

5. Sharma CM, Hoffmann S, Darfeuille F, Reignier J, Findeiss S, Sittka A, et al. The primary transcriptome of the major human pathogen Helicobacter pylori. Nature. 2010 Mar 11;464(7286):250-5.

6. Lenz DH, Mok KC, Lilley BN, Kulkarni RV, Wingreen NS, Bassler BL. The small RNA 
chaperone $\mathrm{Hfq}$ and multiple small RNAs control quorum sensing in Vibrio harveyi and Vibrio cholerae. Cell. 2004 Jul 9;118(1):69-82.

7. Sonnleitner E, Sorger-Domenigg T, Madej MJ, Findeiss $S$, Hackermüller J, Hüttenhofer $A$, et al. Detection of small RNAs in Pseudomonas aeruginosa by RNomics and structure-based bioinformatic tools. Microbiology (Reading, Engl.). 2008 Oct;154(Pt 10):3175-87.

8. Gómez-Lozano M, Marvig RL, Molin S, Long KS. Genome-wide identification of novel small RNAs in Pseudomonas aeruginosa. Environmental Microbiology. 2012 Aug;14(8):2006-16.

9. Brencic A, McFarland KA, McManus HR. The GacS/GacA signal transduction system of Pseudomonas aeruginosaacts exclusively through its control over the transcription of the RsmY and RsmZ regulatory small RNAs. Molecular Microbiology. 2009 Aug;73(3):434-45.

10.Sonnleitner E, Abdou L, Haas D. Small RNA as global regulator of carbon catabolite repression in Pseudomonas aeruginosa. Proc Natl Acad Sci USA. 2009 Dec 22;106(51):21866-71.

11.Wilderman PJ, Sowa NA, FitzGerald DJ, FitzGerald PC, Gottesman S, Ochsner UA, et al. Identification of tandem duplicate regulatory small RNAs in Pseudomonas aeruginosa involved in iron homeostasis. Proc Natl Acad Sci USA. 2004 Jun 29;101(26):9792-7.

12. Oglesby-Sherrouse A, Vasil $M$. Characterization of a heme-regulated noncoding RNA encoded by the prrF locus of Pseudomonas aeruginosa. PLoS ONE. 2010;5(4):e9930.

13.Sonnleitner E, Gonzalez N, SorgerDomenigg $\mathrm{T}$, Heeb S, Richter AS, Backofen R, et al. The small RNA PhrS stimulates synthesis of the Pseudomonas aeruginosa quinolone signal. Molecular Microbiology. 2011 May;80(4):868-85.

14.Gómez-Lozano M, Marvig RL, Molin S, Long KS. Identification of bacterial small RNAs by RNA sequencing. Methods in Pseudomonas aeruginosa. In press; 2013 Apr pp. 1-34.
15.Gonzalez N, Heeb S, Valverde C, Kay E, Reimmann C, Junier T, et al. Genomewide search reveals a novel GacAregulated small RNA in Pseudomonas species. BMC Genomics. 2008;9:167.

16. Livny J, Brencic A, Lory S, Waldor M. Identification of 17 Pseudomonas aeruginosa sRNAs and prediction of sRNA-encoding genes in 10 diverse pathogens using the bioinformatic tool sRNAPredict2. Nucleic Acids Research. 2006;34(12):3484.

17. Gallagher LA, McKnight SL, Kuznetsova MS, Pesci EC, Manoil C. Functions required for extracellular quinolone signaling by Pseudomonas aeruginosa. Journal of Bacteriology. 2002 Dec;184(23):6472-80.

18.DArgenio DA, Calfee MW, Rainey PB, Pesci EC. Autolysis and autoaggregation in Pseudomonas aeruginosa colony morphology mutants. Journal of Bacteriology. 2002 Dec;184(23):6481-9.

19.Price-Whelan A, Dietrich LEP, Newman DK. Rethinking "secondary" metabolism: physiological roles for phenazine antibiotics. Nat Chem Biol. 2006 Feb;2(2):71-8.

20.Guzman LM, Belin D, Carson MJ, Beckwith J. Tight regulation, modulation, and high-level expression by vectors containing the arabinose PBAD promoter. Journal of Bacteriology. 1995 Jul;177(14):4121-30.

21. Hoang TT, Kutchma AJ, Becher A, Schweizer HP. Integration-Proficient Plasmids for Pseudomonas aeruginosa: Site-Specific Integration and Use for Engineering of Reporter and Expression Strains. Plasmid. 2000 Jan;43(1):59-72.

22. Herrero $\mathrm{M}$, de Lorenzo $\mathrm{V}$, Timmis $\mathrm{KN}$. Transposon vectors containing nonantibiotic resistance selection markers for cloning and stable chromosomal insertion of foreign genes in gram-negative bacteria. Journal of Bacteriology. Am Soc Microbiol; 1990;172(11):6557-67.

23.Langmead B, Salzberg SL. Fast gappedread alignment with Bowtie 2. Nat Meth. 2012 Apr;9(4):357-9.

24.Li H, Handsaker B, Wysoker A, Fennell T, 
Ruan J, Homer N, et al. The Sequence Alignment/Map format and SAMtools. Bioinformatics. 2009 Aug 15;25(16):20789.

25.Becerra MC, Albesa I. Oxidative stress induced by ciprofloxacin in Staphylococcus aureus. Biochem Biophys Res Commun. 2002 Oct 4;297(4):1003-7.

26. Goswami M, Mangoli SH, Jawali N. Involvement of reactive oxygen species in the action of ciprofloxacin against Escherichia coli. Antimicrobial agents and chemotherapy. 2006 Mar;50(3):949-54.

27. Hull J, Vervaart P, Grimwood K, Phelan P. Pulmonary oxidative stress response in young children with cystic fibrosis. Thorax. 1997 Jun;52(6):557-60.

28.Doring G, Goldstein W, Botzenhart K, Kharazmi A, Schiøtz PO, Hoiby N, et al. Elastase from polymorphonuclear leucocytes: a regulatory enzyme in immune complex disease. Clin. Exp. Immunol. 1986 Jun;64(3):597-605.

29.Brown RK, Kelly FJ. Evidence for increased oxidative damage in patients with cystic fibrosis. Pediatr. Res. 1994 Oct;36(4):487-93.

30.Ding Y, Chan CY, Lawrence CE. Sfold web server for statistical folding and rational design of nucleic acids. Nucleic Acids Research. 2004 Jul 1;32(Web Server issue):W135-41.

31.Farmer JJ, Herman LG. Epidemiological fingerprinting of Pseudomonas aeruginosa by the production of and sensitivity of pyocin and bacteriophage. Appl Microbiol. 1969 Nov;18(5):760-5.

32.Blackwell CC, Winstanley FP, Telfer Brunton WA. Sensitivity of thermophilic campylobacters to R-type pyocines of Pseudomonas aeruginosa. J. Med. Microbiol. 1982 May;15(2):247-51.

33.Morse SA, Vaughan $\mathrm{P}$, Johnson $\mathrm{D}$, Iglewski $\mathrm{BH}$. Inhibition of Neisseria gonorrhoeae by a bacteriocin from Pseudomonas aeruginosa. Antimicrobial agents and chemotherapy. 1976 Aug;10(2):354-62.

34.Campagnari AA, Karalus $R$, Apicella $M$, Melaugh W, Lesse AJ, Gibson BW. Use of pyocin to select a Haemophilus ducreyi variant defective in lipooligosaccharide biosynthesis. Infection and immunity. 1994 Jun;62(6):2379-86.

35.Jones LF, Thomas ET, Stinnett JD, Gilardi GL, Farmer JJ. Pyocin sensitivity of Pseudomonas species. Appl Microbiol. 1974 Jan;27(1):288-9.

36. Bakkal S, Robinson SM, Ordonez CL, Waltz DA, Riley MA. Role of bacteriocins in mediating interactions of bacterial isolates taken from cystic fibrosis patients. Microbiology. 2010 Jul;156(Pt 7):2058-67.

37.Ernst RK, D Argenio DA, Ichikawa JK, Bangera MG, Selgrade S, Burns JL, et al. Genome mosaicism is conserved but not unique in Pseudomonas aeruginosa isolates from the airways of young children with cystic fibrosis. Environmental Microbiology. 2003 Nov 27;5(12):1341-9.

38. Wolfgang MC, Kulasekara BR, Liang $X$, Boyd D, Wu K, Yang Q, et al. Conservation of genome content and virulence determinants among clinical and environmental isolates of Pseudomonas aeruginosa. Proceedings of the National Academy of Sciences. 2003 Jul 8;100(14):8484-9.

39.Brazas MD, Hancock REW. Ciprofloxacin induction of a susceptibility determinant in Pseudomonas aeruginosa. Antimicrobial agents and chemotherapy. 2005 Aug;49(8):3222-7.

40.Chang W, Small DA, Toghrol F, Bentley WE. Microarray analysis of Pseudomonas aeruginosa reveals induction of pyocin genes in response to hydrogen peroxide. BMC Genomics. 2005;6:115.

41.Dorman CJ. DNA supercoiling and environmental regulation of gene expression in pathogenic bacteria. Infection and immunity. 1991 Mar;59(3):745-9.

42.Mavrodi DV, Bonsall RF, Delaney SM, Soule MJ, Phillips G, Thomashow LS. Functional analysis of genes for biosynthesis of pyocyanin and phenazine1-carboxamide from Pseudomonas aeruginosa PAO1. Journal of Bacteriology. 2001 Nov;183(21):6454-65.

43.Déziel E, Lepine F, Milot $S$, He J, 
Mindrinos MN, Tompkins RG, et al. Analysis of Pseudomonas aeruginosa 4hydroxy-2-alkylquinolines (HAQs) reveals a role for 4-hydroxy-2-heptylquinoline in cell-to-cell communication. Proceedings of the National Academy of Sciences. 2004 Feb 3;101(5):1339-44.

44.McKnight SL, Iglewski BH, Pesci EC. The Pseudomonas quinolone signal regulates rhl quorum sensing in Pseudomonas aeruginosa. Journal of Bacteriology. 2000 May;182(10):2702-8.

45.Busch A, Richter AS, Backofen R. IntaRNA: efficient prediction of bacterial sRNA targets incorporating target site accessibility and seed regions. Bioinformatics. 2008 Dec 15;24(24):2849_ 56.

46.Altuvia S, Weinstein-Fischer D, Zhang A, Postow L, Storz G. A small, stable RNA induced by oxidative stress: role as a pleiotropic regulator and antimutator. Cell. 1997 Jul 11;90(1):43-53.

47.Boysen A, Møller-Jensen J, Kallipolitis B, Valentin-Hansen $P$, Overgaard $M$. Translational regulation of gene expression by an anaerobically induced small noncoding RNA in Escherichia coli. J. Biol. Chem. 2010 Apr 2;285(14):10690-702.

48. Durand S, Storz G. Reprogramming of anaerobic metabolism by the FnrS small RNA. Molecular Microbiology. Wiley Online Library; 2010;75(5):1215-31.

49.Chou JH, Greenberg JT, Demple B. Posttranscriptional repression of Escherichia coli OmpF protein in response to redox stress: positive control of the micF antisense RNA by the soxRS locus. Journal of Bacteriology. 1993 Feb;175(4):1026-31.

50.Toledo-Arana A, Dussurget O, Nikitas G, Sesto N, Guet-Revillet H, Balestrino D, et al. The Listeria transcriptional landscape from saprophytism to virulence. Nature. 2009;459(7249):950-6.
51.Worlitzsch D, Tarran R, Ulrich M, Schwab $U$, Cekici A, Meyer KC, et al. Effects of reduced mucus oxygen concentration in airway Pseudomonas infections of cystic fibrosis patients. J. Clin. Invest. 2002 Feb;109(3):317-25.

52.Xu KD, Stewart PS, Xia F, Huang CT, McFeters GA. Spatial physiological heterogeneity in Pseudomonas aeruginosa biofilm is determined by oxygen availability. Applied and environmental microbiology. 1998 Oct;64(10):4035-9.

53. Yoon SS, Hennigan RF, Hilliard GM, Ochsner UA, Parvatiyar K, Kamani MC, et al. Pseudomonas aeruginosa anaerobic respiration in biofilms: relationships to cystic fibrosis pathogenesis. Dev. Cell. 2002 Oct;3(4):593-603.

54.Yang L, Nilsson $M$, Gjermansen $M$, Givskov M, Tolker-Nielsen T. Pyoverdine and PQS mediated subpopulation interactions involved in Pseudomonas aeruginosa biofilm formation. Molecular Microbiology. 2009 Dec;74(6):1380-92.

55. Konstan MW, Hilliard KA, Norvell TM, Berger M. Bronchoalveolar lavage findings in cystic fibrosis patients with stable, clinically mild lung disease suggest ongoing infection and inflammation. American Journal of Respiratory and Critical Care Medicine. 1994 Aug;150(2):448-54.

56.Khan TZ, Wagener JS, Bost T, Martinez J, Accurso FJ, Riches DWH. Early Pulmonary Inflammation in Infants with Cystic Fibrosis. American Journal of Respiratory and Critical Care Medicine. American Lung Association; 1995 Apr;151(4):1075-82.

57.Cantin A. Cystic fibrosis lung inflammation: early, sustained, and severe. American Journal of Respiratory and Critical Care Medicine. 1995 Apr;151(4):939-41. 


\title{
Small RNA OsiS links oxidative stress to quorum sensing control in Pseudomonas aeruginosa
}

\author{
María Gómez-Lozano ${ }^{1,2}$ and Søren Molin ${ }^{1,2 *}$ \\ ${ }^{1}$ Department of Systems Biology, Technical University of Denmark, \\ Lyngby, Denmark. \\ ${ }^{2}$ Novo Nordisk Foundation Center for Biosustainability, Technical \\ University of Denmark, Hørsholm, Denmark.
}

Supplementary material 


\section{Supplementary Table S1. Primers and adapters used in the study.}

\begin{tabular}{|c|c|c|}
\hline Primer & Sequence $\left(5^{\prime}->3^{\prime}\right)$ & Use \\
\hline 23S-1954 & AAAAAAAAAAAAAAAAAAACTTACCCGACAAGGAATTTCGC & Removal of $23 \mathrm{~S}$ rRNA (provided in the MICROBExpress kit, Ambion) \\
\hline 23S-2511 & AAAAAAAAAAAAAAAAAAGAGCCGACATCGAGGTGCCAAAC & Removal of $23 S$ rRNA (provided in the MICROBExpress kit, Ambion) \\
\hline $16 S-807$ & AAAAAAAAAAAAAAAAAATGGACTACCAGGGTATCTAATCC & Removal of $16 \mathrm{~S}$ rRNA (provided in the MICROBExpress kit, Ambion) \\
\hline $16 \mathrm{~S}-1114$ & AAAAAAAAAAAAAAAAAAGGGTTGCGCTCGTTACGGGACTT & Removal of $16 \mathrm{~S}$ rRNA (provided in the MICROBExpress kit, Ambion) \\
\hline $5 S$ & AAAAAAAAAAAAAAAAAAGCGTTTCACTTCTGAGTTCGGCA & Removal of 5 S rRNA \\
\hline F1-Sacl & GAGAGAGCTCGGCCGCTTCTAGAGTTATGA & Plasmids pBAD-osiS and pBAD-control construction \\
\hline R1_osiS & CACCCCTTCCGCTTTCTGACATGGAGAAACAGTAGAGAGT & Plasmid pBAD-osiS construction \\
\hline F2_osis & GTCAGAAAGCGGAAGGGGTGAGTTCCACAACTTCCCACCC & Plasmid pBAD-osiS construction \\
\hline R2-Xhol_osiS & ACATCTCGAGTGGATGGAACATGACAGATG & Plasmid pBAD-osiS construction \\
\hline R1_control & ATCAGGGCGTTCTTGATAAAATGGAGAAACAGTAGAGAGT & Plasmid pBAD-control construction \\
\hline F2_control & TTTATCAAGAACGCCCTGATTCAGGACGGAGCGATAGATA & Plasmid pBAD-control construction \\
\hline R2-Xhol_control & ACATCTCGAGTGGAATAGTGATGGCCACCA & Plasmid pBAD-control construction \\
\hline Pser_up & CGAGTGGTTTAAGGCAACGGTCTTGA & Sequencing of $p B A D-o s i S$ and $p B A D-c o n t r o l$ \\
\hline Pser_down & AGTTCGGCCTGGTGGAGCAACTCG & Sequencing of pBAD-osiS and pBAD-control \\
\hline 5’ RNA adapter & GCUGAUGGCGAUGAAUGAACACUGCGUUUGCUGGCUUUGAUGAAA & $5^{\prime}-$ RACE \\
\hline $5^{\prime}$ adapter-specific primer & GCTGATGGCGATGAATGAACACTG & $5^{\prime}-$ RACE \\
\hline 5'-GSP1_osiS & AGGTGCCGGAGCGCTTTC & $5^{\prime}-\mathrm{RACE}$ \\
\hline 5'-GSP2_osiS & CCCGGCACCCAAGCAGTC & $5^{\prime}-$ RACE \\
\hline 3' RNA adapter E1 & UUCACUGUUCUUAGCGGCCGCAUGCUC-idT & $3^{\prime}-$ RACE \\
\hline 3' adapter E1 primer & CATGCGGCCGCTAAGAACAGTGA & 3'-RACE \\
\hline 3'-GSP1_osiS & ACATGGGTGCAGGGACGCA & $3^{\prime}-$ RACE \\
\hline 3'-GSP2_osiS & GTTGTCGGCGACCGACGATGCA & $3^{\prime}-$ RACE \\
\hline $5 S-F$ & ACGATCATAGAGCGTTGGAACCAC & RT-qPCR \\
\hline $5 S-R$ & TGACGATGACCTACTCTCACATGG & RT-qPCR \\
\hline osiS_F & AGGTGCCGGAGCGCTTTC & RT-qPCR \\
\hline osis_R & ACATGGGTGCAGGGACGCA & RT-qPCR \\
\hline
\end{tabular}



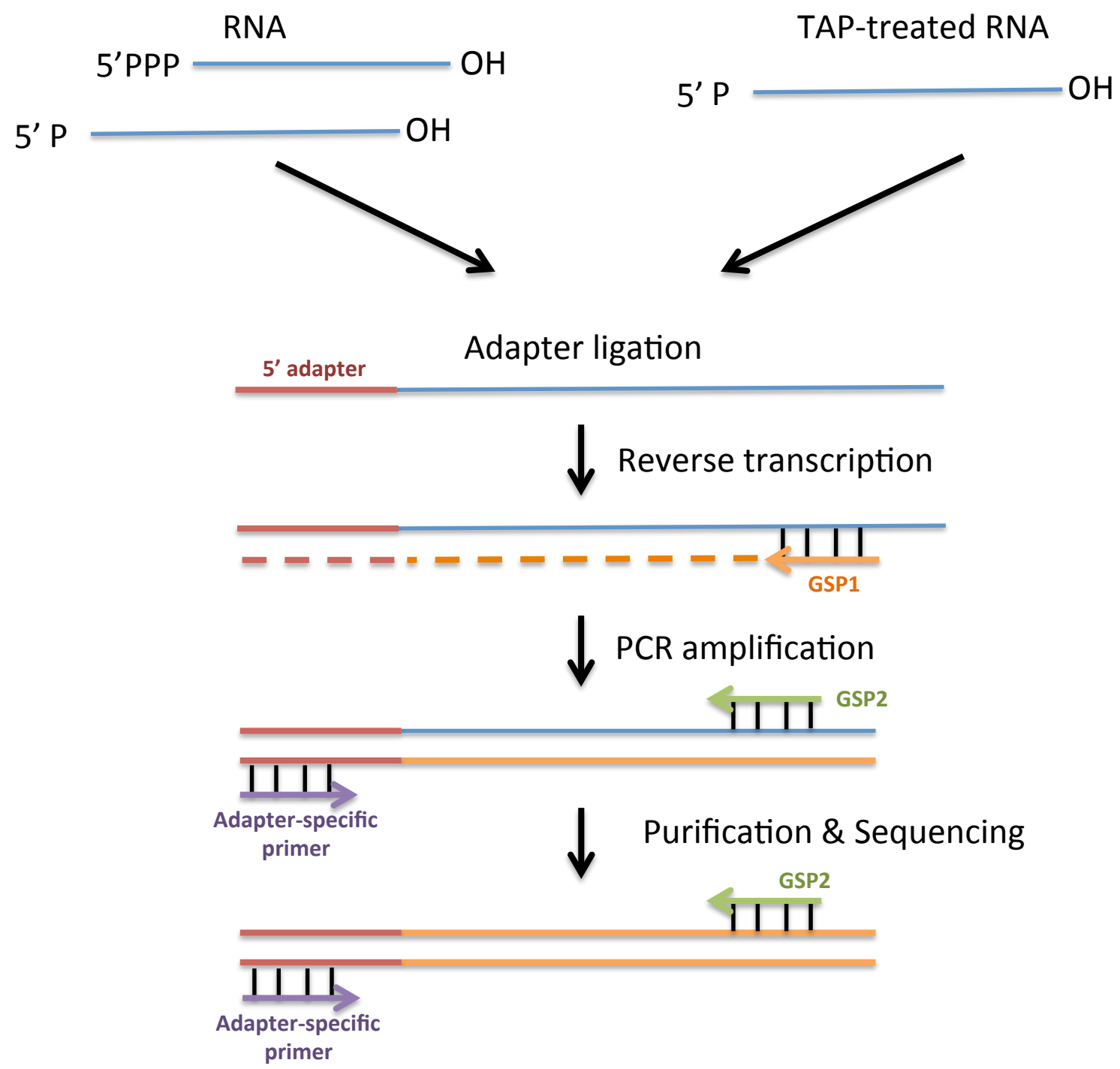

Supplementary Figure S1-A. 5'RACE strategy used to identify 5'ends of primary and processed transcripts. 


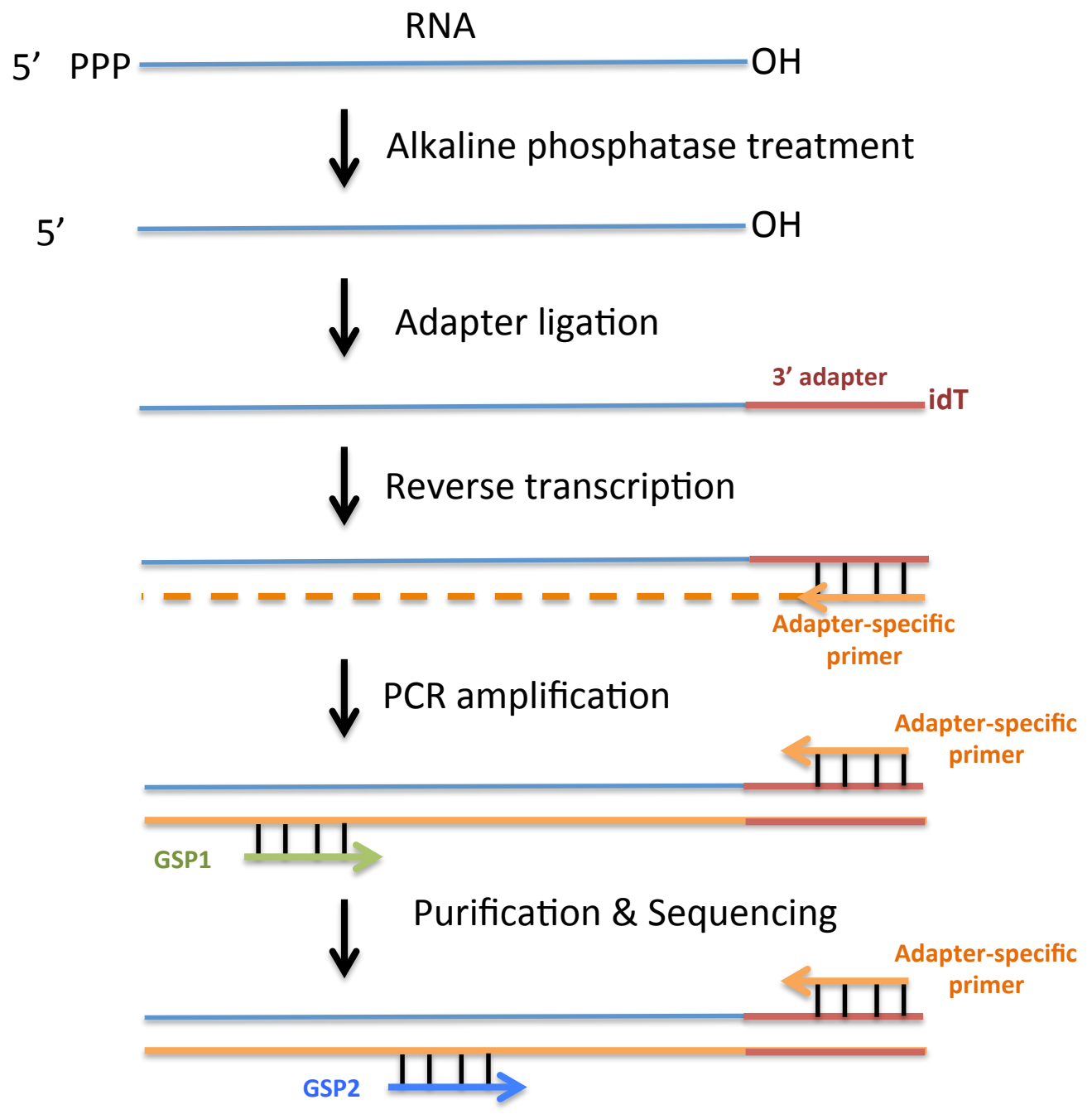

Supplementary Figure S1-B. 3'RACE strategy used to identify 3'ends of transcripts. 


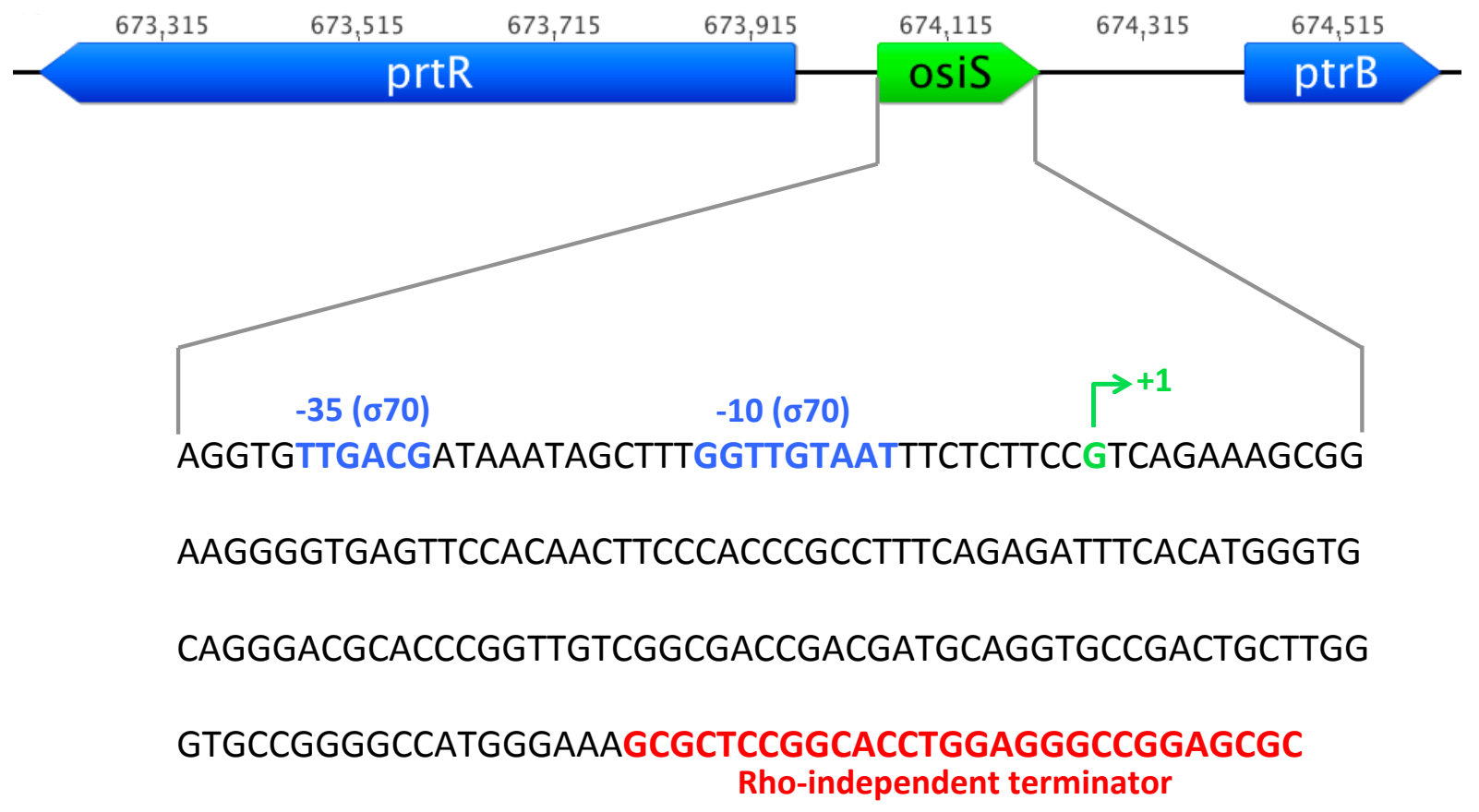

Supplementary Figure S2. Organization of the osiS region in $P$. aeruginosa PAO1. The transcription start site of the primary transcript of OsiS was assessed by $5^{\prime}$-RACE. 

(C) María Gómez-Lozano 2013

Novo Nordisk Foundation Center for Biosustainability Technical University of Denmark

Kogle Alle $62970 \mathrm{Hørsholm}$ Denmark

ISBN 978-87-91494-62-8 